

\section{Journal of Research and Innovation for Sustainable Society}

\section{Scientific Board}

President: Zaharia Marian, Professor, Honorary Member of ADER, Romania

\section{Members:}

Alexandru Cătălin, "Transilvania“" University of Brașov, Romania

Andone Diana, Politechnic University of Timișoara, Romania

Andrei Jean-Vasile, Petroleum-Gas University of Ploiesti, Romania

Babis Claudiu, Politechnic University of Bucharest, Romania

Babucea Gabriela, "Constantin Brancuşi”" University of Targu Jiu, Romania

Bălăcescu Aniela, "Constantin Brancuşi” University of Targu Jiu, Romania

Beridze Teimuraz, Ivane Javakhishvili Tbilisi State University, Georgia

Biriș Ștefan, Politechnic University of Bucharest, Romania

Boncea Amelia, "Constantin Brancuşi” University of Targu Jiu, Romania

Buciumeanu Mihaela, "Dunărea de Jos" University of Galați

Bujor Constantin, Politechnic University of Bucharest, Romania

Cananau Sorin, Politechnic University of Bucharest, Romania

Ciongaru Emilian, “Acad.Andrei Rădulescu“ Legal Research Institute of Romanian Academy

Chivu Oana Roxana, Politechnic University of Bucharest, Romania

Cîrțină Daniela, "Constantin Brancuşi” University of Targu Jiu, Romania

Cîrţină Liviu Marius, "Constantin Brancuşi” University of Targu-Jiu, Romania

Dasic Predrag, High Technical Mechanical School of Trstenik, Serbia

Dichovska Monika Angeloska, University of Sf. Kliment Ohridski Bitola, Republic of North Macedonia

Dulgheru Valeriu, Tehnical University of Moldova

Ecobici Nicolae, "Constantin Brancuşi”" University of Targu Jiu, Romania

Enăchescu Marius, Politechnic University of Bucharest, Romania

Ghimiși Ștefan, "Constantin Brancuşi” University of Targu Jiu, Romania

Gogonea Rodica-Manuela, The Bucharest University of Economic Studies, Romania

Halil İbrahim Aydın, Batman University, Turkey

Mateș Ileana Mariana, Politechnic University of Bucharest, Romania

Michalik Zbigniew, Cracow University of Economics, Poland

Moroianu Emil, Honorary Member of ADER, Romania

Negoiță Olivia Doina, Politechnic University of Bucharest, Romania

Nen Madlena, Military Technical Academy "Ferdinand I", Romania

Nica-Badea Delia, "Constantin Brancuşi” University of Targu Jiu, Romania

Okyar Mete Cüneyt, Şırnak University, Turkey

Orlov Maria, Institute of Administrative Sciences of Moldova

Petrescu Dacinia-Crina, Babeş-Bolyai University, Cluj-Napoca, Romania

Petrescu Valentin Dan, "Lucian Blaga“" University of Sibiu, Romania

Petresvka Nechkoska Renata, Ghent University, Belgium

Rădulescu Alexandru, Politechnic University of Bucharest, Romania

Renken Folker, Jade University of Applied Science, Germany

Rîpă Minodora, "Dunărea de Jos" University of Galați, Romania

Samoilescu Gheorghe, Mircea cel Bătran Naval Academy, Constanta, Romania 
Săvescu Dan, "Transilvania“" University of Brașov, Romania

Semenescu Augustin, Politechnic University of Bucharest, Romania

Strukelj Tjasa, University of Maribor, Slovenia

Timmerberg Josef, Jade University Wilhelmshaven, Germany

Trocan Laura, "Constantin Brancuşi”" University of Targu Jiu, Romania

Velev Georgi Tsonev, Technical University of Gabrovo, Bulgaria

Ziolo Magdalena, University of Szczecin, Poland

Zlateva Penka, Technical University of Varna, Bulgaria

Yaroslav Vyklyuk, Bukovinian University, Ucraina

Yordanov Krastin, Technical University of Varna, Bulgaria

\section{Editorial Board}

\section{Editor-in-chief:}

Ghimiși Ștefan, “Constantin Brancuşiı” University of Targu Jiu, Romania

\section{Members:}

Bălăcescu Aniela, "Constantin Brancuşi”" University of Targu Jiu, Romania

Cîrţînă Daniela, "Constantin Brancuşi”" University of Targu-Jiu, Romania

Cîrţînă Liviu Marius, "Constantin Brancuşi”" University of Targu-Jiu, Romania

Ecobici Nicolae, "Constantin Brancuşi”" University of Targu Jiu, Romania

Facea Adrian, "Constantin Brancuşi”" University of Targu Jiu, Romania

Zaharia Marian, Professor, Honorary Member of ADER, Romania

\section{COPYRIGHT}

All the rights are reserved for this publication, which is copyright according Romanian law of copyright. Excepting only any fair dealing for the purpose of private study, research, review, comment and criticism, no part of this publication may be reproduced, stored in a retrieval system, or transmitted in any form or by any means, mechanical, electrical, electronic, optical, photocopying, recording or otherwise, without the prior expressly permission of the copyright owners. 
Volume 2, Issue 2, 2020

ISSN: 2668-0416

Thoth Publishing House

\section{Table of Contents}

\section{Engineering Sciences}

MATHEMATICAL MODELLING OF SURFACE ROUGHNESS FOR EVALUATING THE EFFECTS OF WEDM CUTTING PARAMETERS

Sergiu Lazăr

ANALYTICAL METHOD FOR THE KINEMATICS OF THE MULTI-LINK GUIDING MECHANISMS USED FOR VEHICLE REAR AXLE SUSPENSION

Cătălin Alexandru

MEASUREMENTS OF GALVANIC SKIN RESPONSE WITH ACCELEROMETER GLOVE

Loredana Dascălu, Oana-Roxana Chivu, Claudiu Babiș, Anamaria Feier,

Alin Ion Țăpîrdea

INFLUENCE OF MACHINING PARAMETERS ON SURFACE ROUGHNESS IN WEDM CUTTING

Sergiu Lazăr

INNOVATIVE MODELS FOR SUSTAINABLE AGRICULTURE

Ştefan Ghimiși

PROFESSIONAL EXPOSURE TO NOISE IN THE AUTOMOTIVE INDUSTRY

Constanta Rinjea (Costache), Oana-Roxana Chivu, Alin Ion Țăpîrdea,

Anamaria Feier, Loredana Dascălu, Adrian Ciprian Firu, Claudiu Babiș

ENGINEERING GEOLOGICAL AND GEOTECHNICAL SITE CHARACTERIZATION FOR ECONOMIC DESIGN OF STRUCTURES AND EARTHWORK

O O Falowo, W K Olabisi

CONSIDERATIONS REGARDING THE RELATIONSHIP BETWEEN ENVIRONMENT, HEALTH AND LIFE QUALITY

Daniela Cîrţînă, Valentin Nanescu

\section{Social Sciences}

EVOLUTIONS AND STRUCTURAL CHANGES IN SECONDARY VOCATIONAL EDUCATION IN ROMANIA DURING THE LAST THREE DECADES

CONSIDERATIONS REGARDING THE EVOLUTION OF COVID-19 IN THE SOUTHMUNTENIA REGION BETWEEN JUNE 11 AND AUGUST 31, 2020 
CONSIDERATIONS ON THE POSTING OF WORKERS WITHIN THE EUROPEAN UNION

Dorina Niță

THE ECONOMY AND FOOD SECURITY IN THE ARAB WORLD IN THE MIDST OF THE CORONA CRISIS

Alexe Eva, Plesoiu Marius Daniel

ASPECTS REGARDING THE CONSEQUENCES OF CHEMICAL CONTAMINATION OF FOOD

Daniela Cîrțină, Maria Modoran

INTEGRATION OF MINORITIES IN THE EU STATES THROUGH PUBLIC POLICIES

Andrei Ghimiși

ASPECTS OF THE EVOLUTION OF SECONDARY EDUCATION DEVELOPMENT IN SOUTH MUNTENIA REGION OF ROMANIA IN THE LAST DECADES

Loredana Păunescu

POTENTIAL ASSOCIATION OF VITAMIN D IN PREVENTING COVID-19

Delia Nica-Badea, Tudor Pungan

PROFILE OF FAMILY BUSINESS IN REPUBLIC OF MOLDOVA

Liudmila Stihi

PHARMACOLOGY OF ACTIVE PRINCIPLES OF VEGETABLE ORIGIN INCLUDED IN TINCTURES

Valentin Nănescu, Daniela Cîrțînă

MINORITY GROUPS IN ROMANIA DURING THE COMMUNIST REGIME

Andrei Ghimiși 


\title{
Mathematical modelling of surface roughness for evaluating the effects of WEDM cutting parameters
}

\author{
Sergiu Lazăr ${ }^{1}$ \\ ${ }^{1}$ Faculty of Engineering, Lucian Blaga University of Sibiu, Romania \\ E-mail: sergiu.lazar@ulbsibiu.ro
}

\begin{abstract}
Wire Electrical Discharge Machining is a cutting method used for obtaining parts with complex geometries or for cutting hard metals. In machining processes, it is necessary to obtain the desired surface quality in order to produce parts providing the required functioning. The surface quality also defines some mechanical properties of the product, such as wear resistance. Being such a considerable quality, surface quality is influenced by various parameters. It will be costly and time consuming to acquire the knowledge of appropriate cutting parameters. Unconventional technologies have not been sufficiently studied so far to provide such details. So, this paper seeks to emphasize the importance of this unconventional technology and more specifically the importance of knowing the parameters of a process before planning the production of a benchmark. Cylindrical metal carbide parts with a hardness of $1620 \mathrm{HV}$ were cut during the analysis, using the minimum and maximum values of some cutting parameters. The roughness of the obtained surfaces has been measured after being cut and a comparison table that includes the parameters values set by the user and the measured roughness was drawn up. Following the regression analysis, the mathematical model that determines the value of the roughness according to the values of the parameters was established.
\end{abstract}

Keywords: WEDM, surface roughness, cutting parameters, mathematical model.

\section{Introduction}

The Electrical Discharge Machining process was discovered by two Russian scientists R. Lazarenko and I. Lazarenko in 1943 and in the beginning it was only used in the military industry. This subtractive machining process is used to machine especially very hard metals like pre-hardened steel or Titanium, but it can also be used for other materials which are electro conductive. Sometimes EDM is used to make objects like mold cavities because it is impossible to obtain a complex geometry using traditional cutting processes. [1]

It can be argued that only a mathematical model can serve to make better use of the process in a way that the tools can be used to the maximum, until they reach the required surface quality. The evolution of technology in the last two decades has put pressure on the development of unconventional technologies, especially micro technologies. Although the unconventional technologies like wire electrical discharge machining were extensively studied, no relevant aspects have been revealed regarding the cutting parameters influence on the workpiece. [2]

Regression analysis is a state-of-the-art modelling tool that is used to determine a model of the links between numerical data arrays. The term "regression" was introduced in statistics by Francis Galton. By researching hereditary problems based on their observations, he discovers, among other things, that in the realities of which it is more important than the collection. [3] 


\section{Basic information of EDM process}

The main concept behind WEDM is about the way in which an electric arc can erode the surface of a material. These electric arcs form when the voltage difference between two closely separated objects, called electrodes, becomes high enough to overcome the resistance of the gap between them. When this occurs, a current of up to 500 A flows through a microscopically small area, vaporizing the surface of the electrodes. This vaporization separates some material from the larger workpiece, leaving a pit on the surface. As numerous arcs occur, this pitting erodes the surface over a large area, shaping it in the desired manner. [4] WEDM is based on complex, discontinuous and localized erosive effects of repetitive pulsed electric discharges between the workpiece and the electrode. As mentioned earlier, only materials that have electrical conductivity can be processed. [5]

\section{Experimental procedures}

As shown in the previous study Influence of machining parameters on surface roughness in WEDM cutting, experimental trials are performed by cutting Ø18.8 tungsten carbide bars. A metallographic analysis was performed to determine the elemental structure of the material. A Leika DM6 M LIBS metallographic microscope was used and the analysis can be seen below.

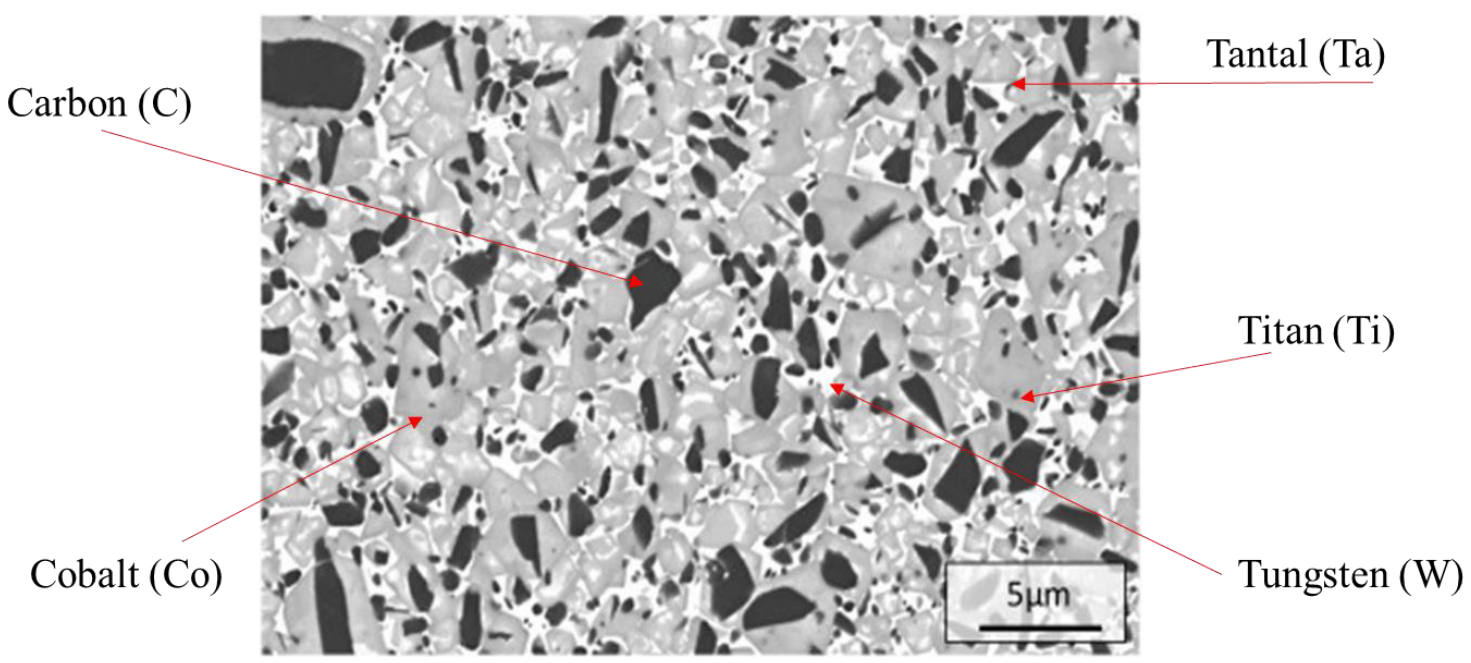

Figure 1. Metallographic analysys for carbide bar

Metal carbide contains 10\% Cobalt (Co) and the size of the Tungsten (W) grains reaches a maximum of $0.5 \mu \mathrm{m}$. There is also Carbon (C) with black, Titanium (Ti) and Tantalum (Ta). After analyzing the elemental structure, the hardness of the carbide bars was analyzed. For this, the Vickers method was used on a Struers Duramin 40 durimeter. The square-shaped frame with a square base and a diamond tip was applied for 18 seconds, according to ISO6507. The hardness of the outer cylindrical surface was measured. In Table 1. the values obtained from the hardness test analysis can be found.

Table 1. Hardness test results

\begin{tabular}{|c|c|c|c|c|c|c|c|c|c|c|}
\hline Sample nr. & $\mathbf{1}$ & $\mathbf{2}$ & $\mathbf{3}$ & $\mathbf{4}$ & $\mathbf{5}$ & $\mathbf{6}$ & $\mathbf{7}$ & $\mathbf{8}$ & $\mathbf{9}$ & $\mathbf{1 0}$ \\
\hline Hardness [HV] & 1620 & 1618 & 1618 & 1620 & 1620 & 1620 & 1619 & 1620 & 1620 & 1620 \\
\hline
\end{tabular}

Metal carbide bars were machined on the AgieCharmilles AC Progress V4. The cutting was made with CobraCut A wire of size $\varnothing 0.25 \mathrm{~mm}$, made of CuZn36 material (brass). During machining, the maximum spark size was 0.06 [mm]. The tensile strength the wire was $900 " \mathrm{~N} / \mathrm{mm} 2 "$. The main proprieties of CobraCut A can be found in Figure 2 in the below. As show in this Figure, this wire is used especially for finishing $-85 \%$ performante, with a very high cutting precision $-80 \%$. 


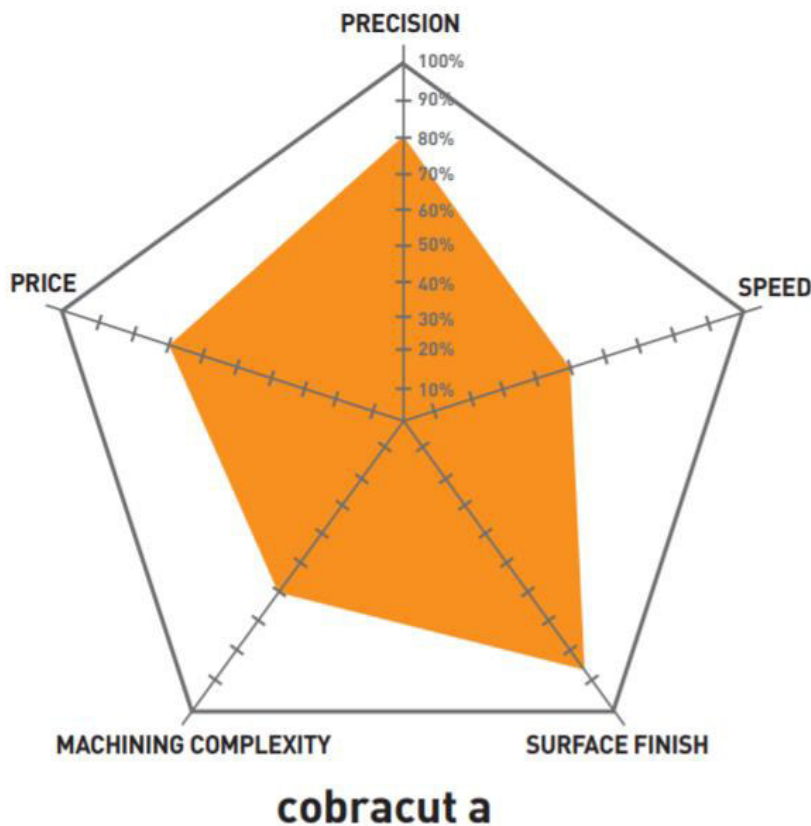

Figure 2. CobraCut A wire performance

The next step of the study was to determine the parameters that can be changed on the machine mentioned above. In the table below one can find the parameters that could be modified by the user in correlation with their minimum and maximum values.

Table 2. The minimum and maximum values of the parameters on the WEDM machine

\begin{tabular}{|c|c|c|}
\hline \multirow{2}{*}{ Parameter } & \multicolumn{2}{|c|}{ Values } \\
\cline { 2 - 3 } & min. & max. \\
\hline Wire feed rate $[\mathrm{mm} / \mathrm{min}]-\mathbf{V}_{\mathbf{a}}$ & 0,50 & 4 \\
\hline Wire rotation speed $[\mathrm{mm} / \mathrm{min}]-\mathbf{V}_{\mathbf{r}}$ & 90 & 325 \\
\hline Dielectric pressure [mmHg] $-\mathbf{P}_{\mathbf{d}}$ & 0,30 & 18 \\
\hline Wire tension [N] - $\mathbf{T}_{\mathbf{f}}$ & 10 & 40 \\
\hline Electrical current [A] $-\mathbf{I}$ & 1 & 40 \\
\hline Electrical potential [V] $-\mathbf{U}$ & 12 & 82 \\
\hline
\end{tabular}

The cutting parameters in the table above are: $\mathbf{V}_{\mathbf{a}}$ - wire feed rate, $\mathbf{V}_{\mathbf{r}}$ - wire rotation speed, $\mathbf{T}_{\mathbf{f}}$ wire tension, $\mathbf{P}_{\mathbf{d}}$ - dielectric pressure, $\mathbf{I}$ - electrical current(A) and $\mathbf{U}$ - electrical potential (V). Considering that the user can change a number of six parameters, with two values (minimum and maximum), the total number of parts that must be made to have a complete study is to be determined:

$$
2^{6}=64-\text { number of cutting parts }
$$

Thus, 64 pieces were cut to determine the mathematical model. But first, the roughness measurement plan on the workpiece surface was established. The roughness of the cut parts was measured using a Mitutoyo Surftest SJ-301 roughness meter. A linear surface was measured at midheight, more precisely at half the diameter, as it can be seen in Figure 3. 


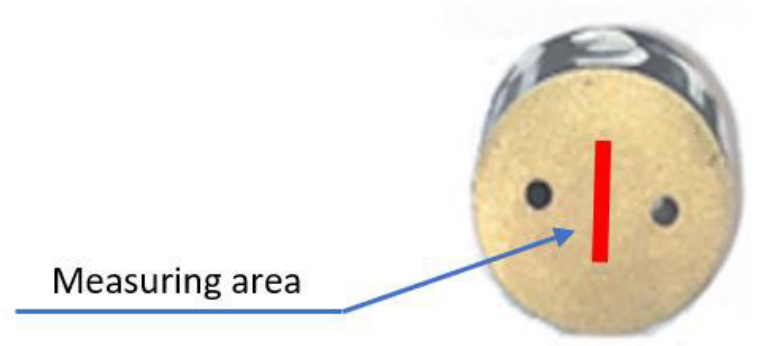

Figure 3. Roughness measuring area

Regarding the roughness measurement, the arithmetical mean deviation of the assessed profile Ra, the maximum height of the profile $\mathrm{Rz}$ and maximum peak height $\mathrm{Rp}$ were measured. [6]

Table 3. The values of the test parameters and the resulting roughness

\begin{tabular}{|c|c|c|c|c|c|c|c|}
\hline Nr. & $\begin{array}{c}\text { Wire feed } \\
\text { rate } \\
{[\mathbf{m m} / \mathbf{m i n}]}\end{array}$ & $\begin{array}{c}\text { Wire } \\
\text { rotation } \\
\text { speed } \\
{[\mathbf{m m} \text { /min] }}\end{array}$ & $\begin{array}{c}\text { Dielectric } \\
\text { pressure } \\
{[\mathbf{b a r}]}\end{array}$ & $\begin{array}{c}\text { Wire } \\
\text { tension } \\
{[\mathbf{N}]}\end{array}$ & $\begin{array}{c}\text { Electrical } \\
\text { current } \\
{[\mathbf{A}]}\end{array}$ & $\begin{array}{c}\text { Electrical } \\
\text { potential } \\
{[\mathbf{V}]}\end{array}$ & $\begin{array}{c}\mathbf{R}_{\mathbf{a}} \\
{[\boldsymbol{\mu} \mathbf{m}]}\end{array}$ \\
\hline 1 & 4 & 325 & 18 & 40 & 40 & 82 & 2,86 \\
\hline 2 & 4 & 325 & 18 & 40 & 40 & 12 & 2,88 \\
\hline 3 & 4 & 325 & 18 & 40 & 1 & 82 & 0,52 \\
\hline 4 & 4 & 325 & 18 & 10 & 40 & 82 & 2,87 \\
\hline 5 & 4 & 325 & 0,3 & 40 & 40 & 82 & 2,87 \\
\hline 6 & 4 & 90 & 18 & 40 & 40 & 82 & 2,87 \\
\hline 7 & 4 & 325 & 0,3 & 10 & 40 & 82 & 2,88 \\
\hline 8 & 4 & 325 & 18 & 10 & 1 & 82 & 0,53 \\
\hline 9 & 4 & 325 & 18 & 40 & 1 & 12 & 0,54 \\
\hline 10 & 4 & 90 & 18 & 10 & 40 & 82 & 2,87 \\
\hline 11 & 4 & 90 & 18 & 40 & 1 & 82 & 0,53 \\
\hline 12 & 4 & 90 & 18 & 40 & 40 & 12 & 2,88 \\
\hline 13 & 4 & 325 & 0,3 & 40 & 1 & 82 & 0,53 \\
\hline 14 & 4 & 90 & 0,3 & 40 & 40 & 82 & 2,87 \\
\hline 15 & 4 & 325 & 18 & 10 & 40 & 12 & 2,89 \\
\hline 16 & 4 & 90 & 0,3 & 10 & 40 & 82 & 2,88 \\
\hline 17 & 4 & 90 & 18 & 40 & 1 & 12 & 0,54 \\
\hline 18 & 4 & 90 & 0,3 & 40 & 1 & 82 & 0,53 \\
\hline 19 & 4 & 90 & 0,3 & 40 & 40 & 12 & 2,89 \\
\hline 20 & 4 & 90 & 18 & 10 & 1 & 82 & 0,53 \\
\hline 21 & 4 & 325 & 0,3 & 10 & 1 & 82 & 0,54 \\
\hline 22 & 4 & 325 & 0,3 & 10 & 40 & 12 & 2,89 \\
\hline 23 & 4 & 325 & 0,3 & 40 & 1 & 12 & 0,55 \\
\hline 24 & 4 & 325 & 18 & 10 & 1 & 12 & 0,55 \\
\hline 25 & 4 & 90 & 0,3 & 10 & 1 & 82 & 0,54 \\
\hline 26 & 4 & 325 & 0,3 & 10 & 1 & 12 & 0,55 \\
\hline
\end{tabular}




\begin{tabular}{|c|c|c|c|c|c|c|c|}
\hline Nr. & $\begin{array}{c}\text { Wire feed } \\
\text { rate } \\
{[\mathrm{mm} / \mathrm{min}]}\end{array}$ & $\begin{array}{c}\text { Wire } \\
\text { rotation } \\
\text { speed } \\
{[\mathrm{mm} / \mathrm{min}]} \\
\end{array}$ & $\begin{array}{c}\text { Dielectric } \\
\text { pressure } \\
\text { [bar] }\end{array}$ & $\begin{array}{c}\text { Wire } \\
\text { tension } \\
{[\mathbf{N}]}\end{array}$ & $\begin{array}{c}\text { Electrical } \\
\text { current } \\
{[A]}\end{array}$ & $\begin{array}{c}\text { Electrical } \\
\text { potential } \\
\text { [V] }\end{array}$ & $\begin{array}{c}\mathbf{R}_{\mathrm{a}} \\
{[\mu \mathrm{m}]}\end{array}$ \\
\hline 27 & 4 & 90 & 18 & 10 & 1 & 12 & 0,55 \\
\hline 28 & 4 & 90 & 0,3 & 40 & 1 & 12 & 0,55 \\
\hline 29 & 4 & 90 & 0,3 & 10 & 40 & 12 & 2,90 \\
\hline 30 & 4 & 90 & 0,3 & 10 & 1 & 12 & 0,56 \\
\hline 31 & 4 & 90 & 18 & 10 & 40 & 12 & 2,89 \\
\hline 32 & 4 & 325 & 0,3 & 40 & 40 & 12 & 2,89 \\
\hline 33 & 0,5 & 325 & 18 & 40 & 40 & 82 & 2,42 \\
\hline 34 & 0,5 & 325 & 18 & 40 & 40 & 12 & 2,44 \\
\hline 35 & 0,5 & 325 & 18 & 40 & 1 & 82 & 0,08 \\
\hline 36 & 0,5 & 325 & 18 & 10 & 40 & 82 & 2,43 \\
\hline 37 & 0,5 & 325 & 0,3 & 40 & 40 & 82 & 2,43 \\
\hline 38 & 0,5 & 90 & 18 & 40 & 40 & 82 & 2,43 \\
\hline 39 & 0,5 & 325 & 0,3 & 10 & 40 & 82 & 2,44 \\
\hline 40 & 0,5 & 325 & 18 & 10 & 1 & 82 & 0,09 \\
\hline 41 & 0,5 & 325 & 18 & 40 & 1 & 12 & 0,10 \\
\hline 42 & 0,5 & 90 & 18 & 10 & 40 & 82 & 2,43 \\
\hline 43 & 0,5 & 90 & 18 & 40 & 1 & 82 & 0,09 \\
\hline 44 & 0,5 & 90 & 18 & 40 & 40 & 12 & 2,44 \\
\hline 45 & 0,5 & 325 & 0,3 & 40 & 1 & 82 & 0,09 \\
\hline 46 & 0,5 & 90 & 0,3 & 40 & 40 & 82 & 2,44 \\
\hline 47 & 0,5 & 325 & 18 & 10 & 40 & 12 & 2,45 \\
\hline 48 & 0,5 & 90 & 0,3 & 10 & 40 & 82 & 2,44 \\
\hline 49 & 0,5 & 90 & 18 & 40 & 1 & 12 & 0,10 \\
\hline 50 & 0,5 & 90 & 0,3 & 40 & 1 & 82 & 0,10 \\
\hline 51 & 0,5 & 90 & 0,3 & 40 & 40 & 12 & 2,45 \\
\hline 52 & 0,5 & 90 & 18 & 10 & 1 & 82 & 0,09 \\
\hline 53 & 0,5 & 325 & 0,3 & 10 & 1 & 82 & 0,10 \\
\hline 54 & 0,5 & 325 & 0,3 & 10 & 40 & 12 & 2,45 \\
\hline 55 & 0,5 & 325 & 0,3 & 40 & 1 & 12 & 0,11 \\
\hline 56 & 0,5 & 325 & 18 & 10 & 1 & 12 & 0,11 \\
\hline 57 & 0,5 & 90 & 0,3 & 10 & 1 & 82 & 0,10 \\
\hline 58 & 0,5 & 325 & 0,3 & 10 & 1 & 12 & 0,11 \\
\hline 59 & 0,5 & 90 & 18 & 10 & 1 & 12 & 0,11 \\
\hline 60 & 0,5 & 90 & 0,3 & 40 & 1 & 12 & 0,11 \\
\hline 61 & 0,5 & 90 & 0,3 & 10 & 40 & 12 & 2,46 \\
\hline 62 & 0,5 & 90 & 0,3 & 10 & 1 & 12 & 0,12 \\
\hline 63 & 0,5 & 90 & 18 & 10 & 40 & 12 & 2,45 \\
\hline 64 & 0,5 & 325 & 0,3 & 40 & 40 & 12 & 2,45 \\
\hline
\end{tabular}


From the data in the table above some main conclusions can be drawn. First of all, we must highlight the lowest value of the roughness that was obtained $-0.08 \mu \mathrm{m}$ and the highest value $2.90 \mu \mathrm{m}$. The roughness values are low due to the machine, the wire and the dielectric on which the cutting process was made.

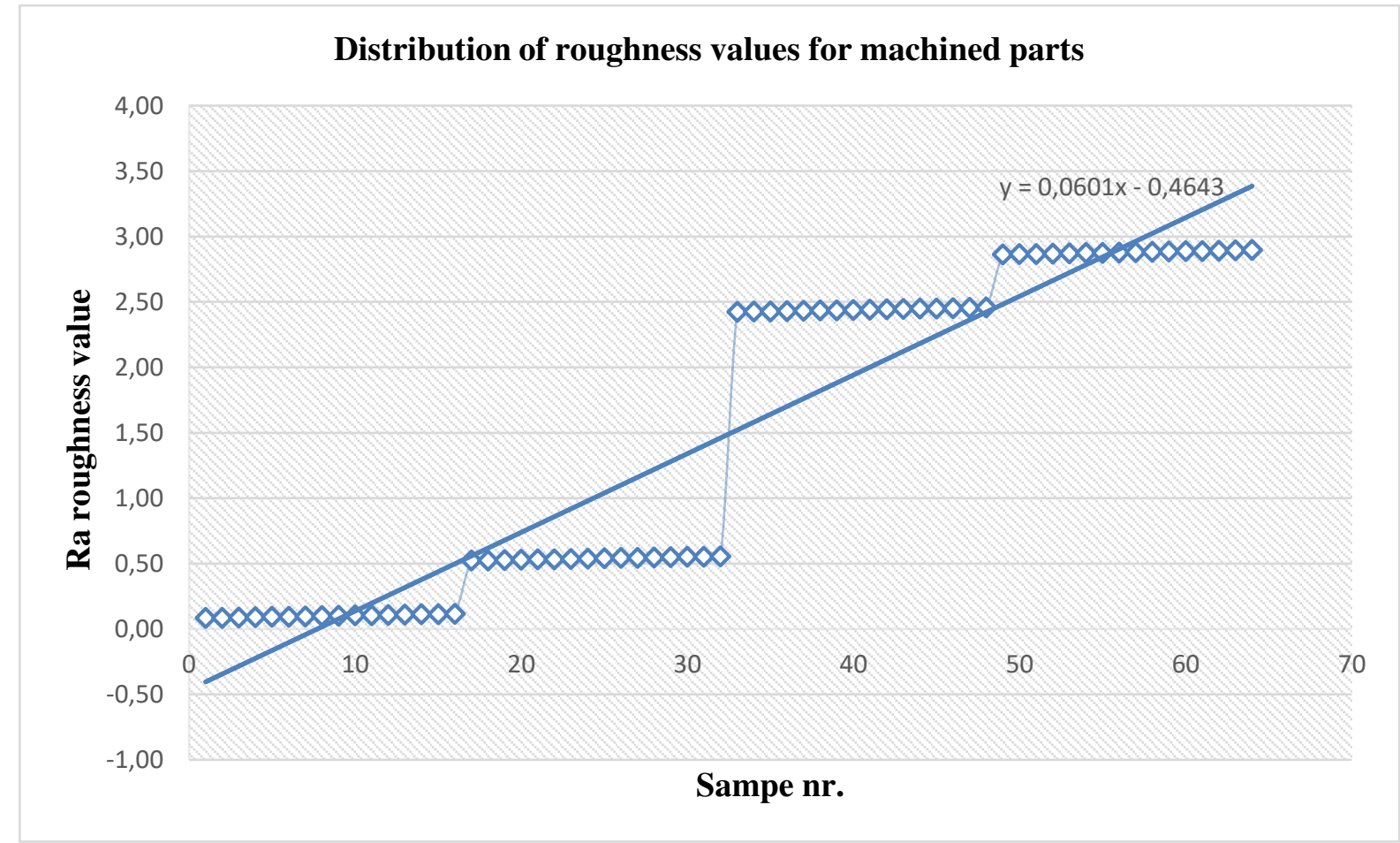

Figure 4. Distribution of roughness graph

As shown in the previous Figure, 16 roughnesses were obtained in the interval [0.08; 0.12], 16 roughnesses in the interval $[0.52 ; 0.56], 16$ roughnesses in the interval $[2.42 ; 2.46]$, and other 16 roughnesses in the interval [2.86; 2.90$]$.

This equal distribution of 4 times 16, provides truthfulness of the mathematical model of roughness. In addition, a well-simmetry distribution can be observed, in each interval of measurement of the difference between the minimum and maximum points of $0.04 \mu \mathrm{m}$ in all 4 intervals. Another symmetry highlighted in the graph Distribution of roughness values for machined parts refers to the difference between the minimum and maximum between the values of the first set of 16 roughnesses in relation to the next.

Consequently, as can be seen in the graph below, the roughness distribution does not have a linear distribution. This is due to the uneven distribution of the processing parameters, respectively to the sudden touching of the minimum and maximum points.

Reductio ad absurdum is applied to develop the mathematical model. It is understood that the functions $\mathrm{Ra}=\mathrm{f}(\mathrm{Va}, \mathrm{Vr}, \mathrm{Pd}, \mathrm{Tf}, \mathrm{I}, \mathrm{U})$ are described by subtracting the processing parameters with a given coefficient:

$$
\mathrm{Ra}=\mathrm{x} * \mathrm{Va}+\mathrm{y} * \mathrm{Vr}+\mathrm{z} * \mathrm{Pd}+\mathrm{a} * \mathrm{Tf}+\mathrm{b} * \mathrm{I}+\mathrm{c} * \mathrm{U}
$$

All the values in Table 3 are entered in an analysis program for the implementation of the regression analysis and the following information is exported: 


\begin{tabular}{lr}
\multicolumn{2}{l}{ SUMMARY OUTPUT } \\
\hline \multicolumn{2}{c}{ Regression Statistics } \\
\hline Multiple R & 1 \\
R Square & 1 \\
Adjusted R & \\
Square & 1 \\
Standard & $3,73286 \mathrm{E}-$ \\
Error & 16 \\
Observations & 64 \\
\hline
\end{tabular}

\begin{tabular}{|c|c|c|c|c|c|}
\hline & $d f$ & $S S$ & $M S$ & $F$ & $\begin{array}{c}\text { Significance } \\
F \\
\end{array}$ \\
\hline Regression & 6 & 90,70311887 & 15,11719 & $1,08 \mathrm{E}+32$ & 0 \\
\hline Residual & 57 & $7,94254 \mathrm{E}-30$ & $1,39 \mathrm{E}-31$ & & \\
\hline Total & 63 & 90,70311887 & & & \\
\hline
\end{tabular}

\begin{tabular}{lccrrrr}
\hline & $\begin{array}{c}\text { Coefficient } \\
\text { S }\end{array}$ & $\begin{array}{c}\text { Standard } \\
\text { Error }\end{array}$ & \multicolumn{1}{c}{ t Stat } & P-value & Lower 95\% & \multicolumn{1}{c}{$\begin{array}{c}\text { Upper } \\
\text { 95\% }\end{array}$} \\
\hline & & & & & & $6,59 \mathrm{E}-$ \\
Intercept & 0,000000 & $1,65148 \mathrm{E}-16$ & 1,985267 & 0,051934 & $-2,8403 \mathrm{E}-18$ & 16 \\
Va & 0,125500 & $2,66633 \mathrm{E}-17$ & $4,71 \mathrm{E}+15$ & 0 & 0,1255 & 0,1255 \\
Vr & $-0,000011$ & $3,97113 \mathrm{E}-19$ & $-2,7 \mathrm{E}+13$ & 0 & $-1,054 \mathrm{E}-05$ & $-1,1 \mathrm{E}-05$ \\
Pd & $-0,000478$ & $5,27241 \mathrm{E}-18$ & $-9,1 \mathrm{E}+13$ & 0 & $-0,0004785$ & $-0,00048$ \\
Tf & $-0,000150$ & $3,11072 \mathrm{E}-18$ & $-4,8 \mathrm{E}+13$ & 0 & $-0,00015$ & $-0,00015$ \\
I & 0,060000 & $2,39286 \mathrm{E}-18$ & $2,51 \mathrm{E}+16$ & 0 & 0,06 & 0,06 \\
$\mathrm{U}$ & $-0,000250$ & $1,33317 \mathrm{E}-18$ & $-1,9 \mathrm{E}+14$ & 0 & $-0,00025$ & $-0,00025$ \\
\hline
\end{tabular}

In conclusion, the mathematical model for the determination of roughness as a function of measurement is as follows:

$$
\begin{gathered}
\mathrm{R}_{\mathrm{a}}=0,1255 \times \mathrm{V}_{\mathrm{a}}-0,00001054 \times \mathrm{V}_{\mathrm{r}}-0,0004785 \times \mathrm{P}_{\mathrm{d}^{-}}-0,00015 \times \mathrm{T}_{\mathrm{f}}+0,06 \times \mathrm{I}-0,00025 \times \mathrm{U} \\
\mathrm{R}_{\mathrm{a}}=\frac{\mathrm{V}_{\mathrm{a}}}{8}+\frac{527 \mathrm{~V}_{\mathrm{r}}}{5 \times 10^{7}}+\frac{957 \mathrm{P}_{\mathrm{d}}}{2 \times 10^{6}}+\frac{3 \mathrm{~T}_{\mathrm{f}}}{2 \times 10^{4}}+\frac{3 \mathrm{I}}{5 \times 10}+\frac{\mathrm{U}}{4 \times 10^{3}}
\end{gathered}
$$

\section{Conclusions}

In conclusion, it can be stated that this mathematical model is accurate. The author considers it imperative that the industry prepare a library with all the information regarding the processing of materials according to hardness and electrical conductivity.

In this way, the development of mathematical models such as the one discovered in this study will help the unconventional technology industry. This is the only way that unconventional technologies will become much more powerful than they are at the moment. [7]

Using this mathematical model it will be possible to calculate the processing parameters taking into account the two essential principles: the principle of high productivity and the principle of quality. Also, it will be possible to reduce costs because the intermediate control operation of the processing surface will be necessary only rarely. 
This mathematical roughness calculation model refers only to tungsten carbide whose hardness and metallography are known. However, this mathematical model can be improved by adding correction coefficients to the formula for relative or other errors. The results of this study can also be improved.

In this case, we analyzed the surfaces of 64 machined parts with a minimum parameter and a maximum parameter. If we had analyzed with a median parameter, ie with the average value of the parameters, the results would have been closer to the truth. But in this case, we should have analyzed 729 pieces $-3^{6}=729$.

The third stage of this study will have to integrate through a software application all the values obtained and the determined mathematical mode. Then, this application will have to serve engineers, technologies and operators in order to be able to process materials better and faster.

\section{References}

[1] P. Marcel Sabin, C. Glad și P. Grigore, „Surface quality of the EDM processed materials,” în XIX IMEKO World Congress Fundamental and Applied Metrology, Lisbon, 2009.

[2] C. M. Simion, Studies and research on the surface roughness processed by EDM - PhD Thesis, București: Politehnica Publishing House, 1999.

[3] L. Z. Rumșiski, Mathematical processing of experimental data, Bucharest: Technical Publishing House, 1974.

[4] N. Hesse, „Pen State Site,” Penn State, 04 2016. [Interactiv]. Available: http://sites.psu.edu/nwhesse/wp-content/uploads/sites/37237/2016/04/Definition-EDM.pdf. [Accesat 2807 2020].

[5] C. I. Deneș, Contributions regarding WEDM porcessing - PhD Thesis, Sibiu: "Lucian Blaga" University of Sibiu, 2002.

[6] D. Dobrotă, Basics of designing cutting processes, vol. I, Craiova: Sitech Publishing House, 2007, p. 272.

[7] M. P. Jahan, Electrical Discharge Machining: Types, Technologies and Applications, New York: Nova Science Pub Inc, 2015. 


\title{
Analytical method for the kinematics of the multi-link guiding mechanisms used for vehicle rear axle suspension
}

\author{
Cătălin Alexandru' \\ ${ }^{1}$ Product Design, Mechatronics and Environment Department, Transilvania University of \\ Braşov, Romania \\ E-mail: calex@unitbv.ro
}

\begin{abstract}
The paper deals with an analytical method for the kinematic analysis of the multi-link guiding mechanisms used for the rear beam axles of motor vehicles. The method is based on the representation of spatial movement of the axle as a screw motion. The finite rotation of the axle around the screw axis is modelled by using rotational indicators and tensors. For solving the nonlinear system that describes the kinematic behaviour of the axle guiding mechanism, an algorithm based on the Newton-Kantorovich approach was developed. The numerical application was carried out by considering an axle guiding mechanism by five points - on five spheres (codified 5-SS)
\end{abstract}

\section{Introduction}

Generally, the spatial guiding of the bodies can be achieved in two ways: by guiding a characteristic point of the body and orienting it with respect to the considered point (solution that is usually used in industrial robots), or by guiding several points of the body, the latest solution being also used for guiding the rear beam axles of the motor vehicles in relative movement to the chassis. The arrangement of the guiding points on the rear axle is made taking into account the kinematic requirements (regarding the accomplishment of the necessary movements, namely the vertical displacement of the axle and its rotation around the longitudinal axis of the car), as well as the dynamic ones (taking over the contact forces from the wheels). The structural systematization of the axle guiding mechanisms according to the possible guiding cases was depicted in [3].

In addition to the necessary specified motions of the rear axle, other additional linear and angular displacements occur during the operation of the guiding mechanism, as follows: rotations of the axle around the transversal and vertical axes, displacements of the axle centre along the transversal and longitudinal axes. These movements are undesirable and they have the effect of changing the direction of travel of the car and losing stability, changes in wheelbase and wheel track (with additional wear and consumption), increased rolling resistance, and additional stresses in the suspension system. Due to these negative effects, all the additional movements must be cancelled or minimized, as far as possible. The purpose of the kinematic analysis is to establish the functions that describe the stated movements, and to calculate their variations during the operation of the axle guiding mechanism.

Considering the specific features, the kinematic analysis of the axle guiding mechanisms is based on simplified models in which the chassis is fixed connected to ground (thus being the reference part of the mechanism), and the force generating elements (such as springs, dampers, tires, bumpers, anti-roll bars) are not taken into account. The connections of the guiding links/arms to the adjacent parts (axle and chassis) are commonly modelled by spherical joints $[3,12-14,16]$. 
In the scientific literature, the kinematic analysis of the axle guiding mechanisms is achieved in two ways: by developing analytical methods, which consist of formulating and solving the equation systems that describe the kinematic behaviour [3, 5, 7, 8, 15]; by using commercial MBS (Multi-Body Systems) software solutions, which automatically formulate and solve the movement equations $[4,9,17,18]$. The use of MBS software brings important benefits for various types of applications, such as those presented in $[1,2,6,10]$, but their high cost is still a major impediment.

This paper deals with the development of a numerical method for the kinematic analysis of the axle guiding mechanisms. The method is a general one, which can be applied for all types of rear axle guiding mechanisms (at least the frequently used ones).

\section{Problem formulation}

The numerical method proposed in this work is based on the modelling of the spatial movement (position and orientation) of the rear axle as a screw movement [11], considering the rotation around the screw axis $u$ (i.e. the angle $\beta$ ) and the translation along this axis (i.e. the displacement b), as shown in Figure 1.

The axle position, with reference to the origin $\mathrm{O}$ of the global coordinate system, is determined by the position vector $r_{u}$. In order to define the axle spatial movement, the position vector, velocity and acceleration of a certain point $\mathrm{M}$ on the axle must be known. The global position of this point is defined in the following way

$$
\bar{r}_{M}=\bar{r}_{G}+\bar{q},
$$

where $\mathrm{r}_{\mathrm{G}}$ is the global position vector of a reference point $\mathrm{G}$, while $\mathrm{q}$ is the local position vector of $\mathrm{M}$ relative to $\mathrm{G}$.
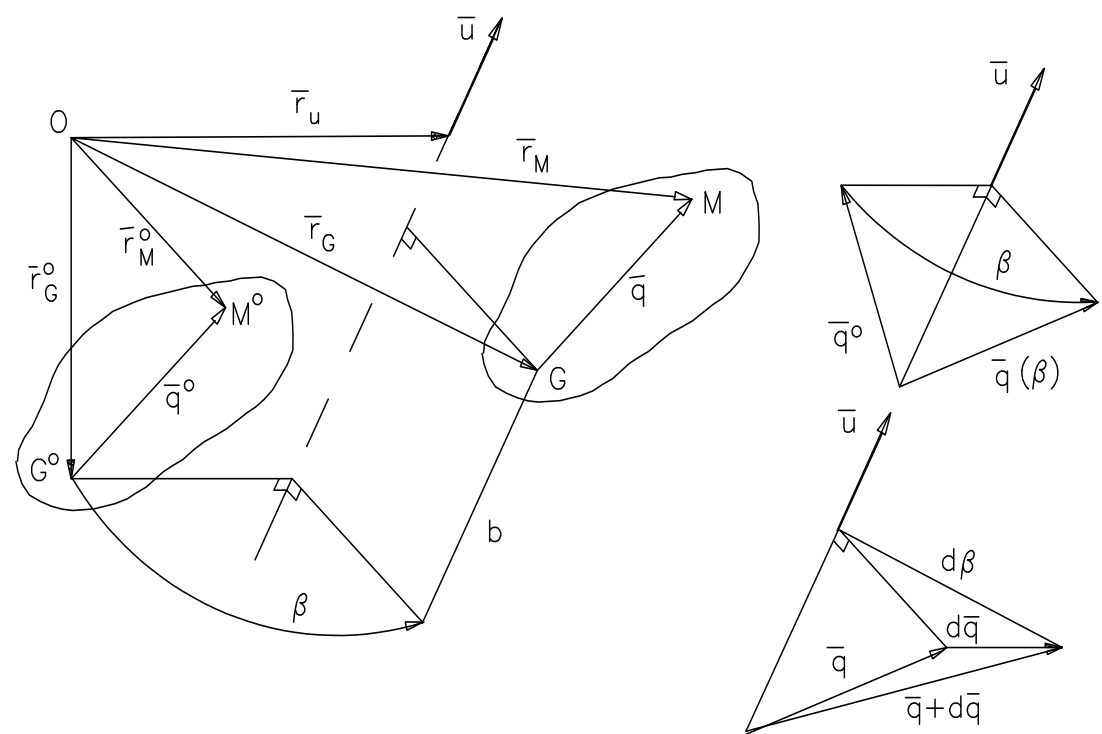

Figure 1. The modelling of the screw movement of the rear axle.

In figure 1 , the vector q defines the orientation of the rear axle, and it results by the rotation around the screw axis from the initial configuration $\mathrm{q}^{0}$, while $\mathrm{r}_{\mathrm{G}}$ is used to model the position of the axle. The scientific literature reveals several methods for modelling the orientation of the vector $\mathrm{q}$ around the screw axis u, such as Euler angles, Bryant angles, Kardan angles, director cosines, rotational indicators and tensors, and others. In what follows, the method based on rotational indicators and tensors [11] will be used. 
The rotational indicator $\beta=(\mathrm{u}, \beta)$ contains the three components of vector $\mathrm{u}$ and the corresponding revolute angle $\beta$. The finite rotation of the vector $q$ (having the initial configuration $q^{0}$ ) is obtained by integrating the differential rotation around the instant axis of angle $\mathrm{d} \beta$,

$$
\begin{gathered}
d \bar{q}=\bar{u} \cdot d \beta \times \bar{q} \rightarrow \bar{q}(\bar{\beta})=T(\bar{\beta}) \cdot \bar{q}^{-0}, \\
\mathrm{~T}(\beta)=\mathrm{I}+\sin \beta \cdot \mathrm{U}+(1-\cos \beta) \cdot \mathrm{U}^{2}, \quad U=\left[\begin{array}{ccc}
0 & -u_{z} & u_{y} \\
u_{z} & 0 & -u_{x} \\
-u_{y} & u_{x} & 0
\end{array}\right],
\end{gathered}
$$

where $T(\beta)$ is the rotational tensor that describes the finite rotation of the vector $q$ around the screw axis $q$ (of angle $\beta$ ), I - the unit tensor, and $\mathrm{U}$ - the anti-symmetric tensor.

Of the four parameters of the rotational indicator, due to the condition $|\mathrm{u}|=1$, only three are independent. The passing to three parameters is done by introducing the vector $\mathrm{w}$ of the same direction with $\mathrm{u}$,

$$
\bar{w}=\bar{u} \cdot \operatorname{tg} \frac{\beta}{2},
$$

whose components are the Rodrigues parameters of the finite rotation (the three-parametric representation of the finite rotations). The rotational tensor $\mathrm{T}(\beta)$ will be:

$$
T(\bar{\beta})=T(\bar{w})=I+2 \cdot \frac{W+W^{2}}{1+\bar{w} \cdot \bar{w}},
$$

where:

$$
W=\left[\begin{array}{ccc}
0 & -w_{z} & w_{y} \\
w_{z} & 0 & -w_{z} \\
-w_{y} & w_{x} & 0
\end{array}\right]
$$

The analytical representation of the screw movement of the point $\mathrm{M}$ is given by:

$$
\bar{r}_{M}\left(\bar{r}_{G}, \bar{w}\right)=\bar{r}_{G}+T(\bar{w}) \cdot \bar{q}^{-},
$$

where the six components of the vectors $\mathrm{w}$ and $\mathrm{r}_{\mathrm{G}}$ are independent motion parameters.

\section{Case study}

The application for this paper corresponds to an axle guiding mechanism by five points - on five spheres (5-SS), which is shown in Figure 2. The mechanism, which has a single degree of mobility, contains contains four longitudinal bars, up-down arranged relative to the axle axis in pairs of two $\left(1_{\mathrm{s}}-1_{\mathrm{d}}, 3_{\mathrm{s}}-3_{\mathrm{d}}\right)$, while the fifth bar (4), which is called Panhard bar, is transversally disposed.

The geometrical model of this guiding mechanism is defined by the following parameters: the global coordinates of the joints $\mathrm{M}_{0 \mathrm{i}}$ of the guiding bars to chassis, in the global coordinate system OXY; the local coordinates of the joints $M_{i}$ of the guiding bars to axle, in the axle reference frame $\mathrm{PX}_{\mathrm{P}} \mathrm{Y}_{\mathrm{P}} \mathrm{Z}_{\mathrm{P}}$; the static position of the axle, in OXYZ; the lengths of the guiding bars; the wheel radius and the wheel track. 


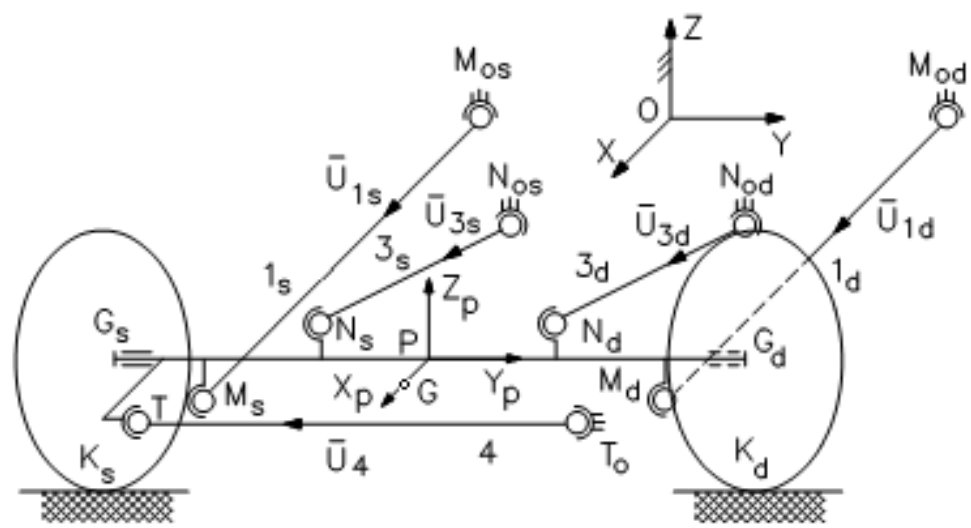

Figure 2. The axle guiding mechanism of type 5SS.

The center of the left wheel $\left(\mathrm{G}_{\mathrm{s}}\right)$ is considered as reference point (corresponding to $\mathrm{G}$ in equation (1)), from equations (7) resulting:

$$
F_{i}=\left[\bar{r}_{G s}+T(\bar{w}) \cdot\left(\bar{r}_{M i}-\bar{r}_{G s}\right)_{0}-\bar{r}_{M O i}\right]^{2}-l_{i}^{2}=0,
$$

where $\mathrm{i}=1 \ldots .5 ; \mathrm{M}_{\mathrm{i}} \in\left[\mathrm{M}_{\mathrm{s}}, \mathrm{M}_{\mathrm{d}}, \mathrm{N}_{\mathrm{s}}, \mathrm{N}_{\mathrm{d}}, \mathrm{T}\right] ; \mathrm{M}_{0 \mathrm{i}} \in\left[\mathrm{M}_{0 \mathrm{~s}}, \mathrm{M}_{0 \mathrm{~d}}, \mathrm{~N}_{0 \mathrm{~s}}, \mathrm{~N}_{0 \mathrm{~d}}, \mathrm{~T}_{0}\right]$.

The rotational tensor $\mathrm{T}(\mathrm{w})$ is defined by the following components:

$$
\begin{aligned}
& t_{11}=1-A \cdot\left(w_{y}^{2}+w_{z}^{2}\right), t_{12}=A \cdot\left(-w_{z}+w_{x} \cdot w_{y}\right), t_{13}=A \cdot\left(w_{y}+w_{x} \cdot w_{z}\right), \\
& t_{21}=A \cdot\left(w_{z}+w_{x} \cdot w_{y}\right), t_{22}=1-A \cdot\left(w_{x}^{2}+w_{z}^{2}\right), t_{23}=A \cdot\left(-w_{x}+w_{y} \cdot w_{z}\right), \\
& t_{31}=A \cdot\left(-w_{y}+w_{x} \cdot w_{z}\right), t_{32}=A \cdot\left(w_{x}+w_{y} \cdot w_{z}\right), t_{33}=1-A \cdot\left(w_{x}^{2}+w_{y}^{2}\right),
\end{aligned}
$$

where

$$
A=\frac{2}{1+\bar{w} \cdot \bar{w}}=\frac{2}{1+w_{x}^{2}+w_{y}^{2}+w_{z}^{2}} .
$$

Equation system (8) can be rewritten in the following form:

$$
\begin{aligned}
& F_{i}=\left[X_{G s}-X_{M 0 i}+t_{11}\left(X_{M i}-X_{G s}\right)_{0}+t_{12}\left(Y_{M i}-Y_{G s}\right)_{0}+t_{13}\left(Z_{M i}-Z_{G s}\right)_{0}\right]^{2}+ \\
& +\left[Y_{G s}-Y_{M 0 i}+t_{21}\left(X_{M i}-X_{G s}\right)_{0}+t_{22}\left(Y_{M i}-Y_{G s}\right)_{0}+t_{23}\left(Z_{M i}-Z_{G s}\right)_{0}\right]^{2}+ \\
& +\left[Z_{G s}-Z_{M 0 i}+t_{31}\left(X_{M i}-X_{G s}\right)_{0}+t_{32}\left(Y_{M i}-Y_{G s}\right)_{0}+t_{33}\left(Z_{M i}-Z_{G s}\right)_{0}\right]^{2}-l_{i}^{2}=0 .
\end{aligned}
$$

The vertical displacement of the left wheel centre $\left(\mathrm{Z}_{\mathrm{Gs}}\right)$ is selected as independent kinematic parameter, while the unknowns are $\mathrm{X}_{\mathrm{Gs}}, \mathrm{Y}_{\mathrm{Gs}}, \mathrm{w}_{\mathrm{x}}, \mathrm{w}_{\mathrm{y}}$, and $\mathrm{w}_{\mathrm{z}}$. In the initial position, the global coordinates of the guiding points and those of the wheel centre can be established depending on the stationary position (vehicle in rest) of the axle in the global reference frame OXYZ and the corresponding local coordinates in the axle reference frame $\mathrm{PX}_{\mathrm{P}} \mathrm{Y}_{\mathrm{P}} \mathrm{Z}_{\mathrm{P}}$, as follows:

$$
\begin{aligned}
& X_{M i}=X_{P}^{0}+X_{M i(P)}, Y_{M i}=Y_{P}^{0}+Y_{M i(P)}, Z_{M i}=Z_{P}^{0}+Z_{M i(P)}, \\
& X_{G s}=X_{P}^{0}+X_{G s(P)}, Y_{G s}=Y_{P}^{0}+Y_{G s(P)}, Z_{G s}=Z_{P}^{0}+Z_{G s(P)} .
\end{aligned}
$$


The solving the non-linear system (11) was carried out by using the Newton-Kantorovich method. The initial solution of the non-linear system corresponds to the stationary position of the vehicle, while for a current position of the guiding mechanism, the initial solution is that obtained in the previous position, and in this way the spatial positioning of the guiding mechanism (in terms of parametric vectors of the axle finite movement, namely $\mathrm{r}_{\mathrm{Gs}}$ and $\mathrm{w}$ ) can be determined for the whole vertical travel of the axle, transposed by the variation field of the independent parameter $\left(\mathrm{Z}_{\mathrm{Gs}}\right)$.

The global coordinates of the guiding points $\mathrm{M}_{\mathrm{i}}$ are then determined based on equations (7):

$$
\left[\begin{array}{c}
X_{M i} \\
Y_{M i} \\
Z_{M i}
\end{array}\right]=\left[\begin{array}{c}
X_{G s} \\
Y_{G s} \\
Z_{G s}
\end{array}\right]+T(\beta) \cdot\left[\begin{array}{c}
X_{M i}-X_{G s} \\
Y_{M i}-Y_{G s} \\
Z_{M i}-Z_{G s}
\end{array}\right]_{0}
$$

Given that

$$
u_{x}=\frac{w_{x}}{\operatorname{tg} \frac{\beta}{2}}, u_{y}=\frac{w_{y}}{\operatorname{tg} \frac{\beta}{2}}, u_{z}=\frac{w_{z}}{\operatorname{tg} \frac{\beta}{2}},
$$

there is obtained

$$
w_{x}^{2}+w_{y}^{2}+w_{z}^{2}=\left(u_{x}^{2}+u_{y}^{2}+u_{z}^{2}\right) \cdot \operatorname{tg}^{2} \frac{\beta}{2}, \beta=2 \operatorname{arctg}\left(\mathrm{w}_{\mathrm{x}}^{2}+\mathrm{w}_{\mathrm{y}}^{2}+\mathrm{w}_{\mathrm{z}}^{2}\right),
$$

where the rotational tensor $\mathrm{T}(\beta)$ has the following componenents:

$$
\begin{gathered}
t_{11}{ }^{\beta}=1-(1-\cos \beta) \cdot\left(u_{y}{ }^{2}+u_{z}{ }^{2}\right), t_{12}{ }^{b}=-u_{z} \cdot \sin \beta+(1-\cos \beta) \cdot u_{x} \cdot u_{y}, \\
t_{13}{ }^{\beta}=u_{y} \cdot \sin \beta+(1-\cos \beta) \cdot u_{x} \cdot u_{z} \\
t_{21}{ }^{\beta}=u_{z} \cdot \sin \beta+(1-\cos \beta) \cdot u_{x} \cdot u_{y}, t_{22}{ }^{\beta}=1-(1-\cos \beta) \cdot\left(u_{x}{ }^{2}+u_{z}{ }^{2}\right), \\
t_{23}{ }^{\beta}=-u_{x} \cdot \sin \beta+(1-\cos \beta) \cdot u_{y} \cdot u_{z} \\
t_{31}{ }^{\beta}=-u_{y} \cdot \sin \beta+(1-\cos \beta) \cdot u_{x} \cdot u_{z} t_{32}{ }^{\beta}=u_{x} \cdot \sin \beta+(1-\cos \beta) \cdot u_{y} \cdot u_{z}, \\
t_{33}{ }^{\beta}=1-(1-\cos \beta) \cdot\left(u_{x}{ }^{2}+u_{y}{ }^{2}\right) .
\end{gathered}
$$

For computing the coordinates for any other point of interest on axle (e.g. the axle center P), equations of form (13) can be used.

Afterwards, the kinematic functions that describe the behavior of the axle guiding mechanism can be determined, namely the linear displacements of the axle center along the longitudinal $\left(\Delta \mathrm{X}_{\mathrm{P}}\right)$, transversal $\left(\Delta \mathrm{Y}_{\mathrm{P}}\right)$ and vertical $\left(\Delta \mathrm{Z}_{\mathrm{P}}\right)$ axes (as shown in Figure 3), and respectively the rotations of the axle around the longitudinal $\left(\eta_{\mathrm{x}}\right)$, transversal $\left(\eta_{\mathrm{y}}\right)$ and vertical $\left(\eta_{\mathrm{z}}\right)$ axes (Figure 4$)$, as follows:

- displacements of the axle center:

$$
\Delta X_{P}=X_{P}-X_{P}^{0}, \Delta Y_{P}=Y_{P}-Y_{P}^{0}, \Delta Z_{P}=Z_{P}-Z_{P}^{0}
$$

- axle roll rotation:

$$
\eta_{\mathrm{X}}=\operatorname{arctg} \frac{\mathrm{Z}_{\mathrm{Gd}}-\mathrm{Z}_{\mathrm{Gs}}}{\mathrm{Y}_{\mathrm{Gd}}-\mathrm{Y}_{\mathrm{Gs}}}
$$

- axle rotation around its own axle (where $\mathrm{G}$ is a point located on the local axis $\mathrm{X}_{\mathrm{P}}$ of the axle reference frame $\mathrm{PX}_{\mathrm{P}} \mathrm{Y}_{\mathrm{P}} \mathrm{Z}_{\mathrm{P}}$ - see Figure 2): 


$$
\eta_{Y}=\operatorname{asin} \frac{\left(Z_{G}-Z_{G}^{0}\right)-\left(Z_{P}-Z_{P}^{0}\right)}{\left|X_{G(P)}\right|} ;
$$

- axle pivoting rotation:

$$
\eta_{\mathrm{Z}}=\operatorname{arctg} \frac{\mathrm{X}_{\mathrm{Gd}}-\mathrm{X}_{\mathrm{Gs}}}{\mathrm{Y}_{\mathrm{Gd}}-\mathrm{Y}_{\mathrm{Gs}}} .
$$

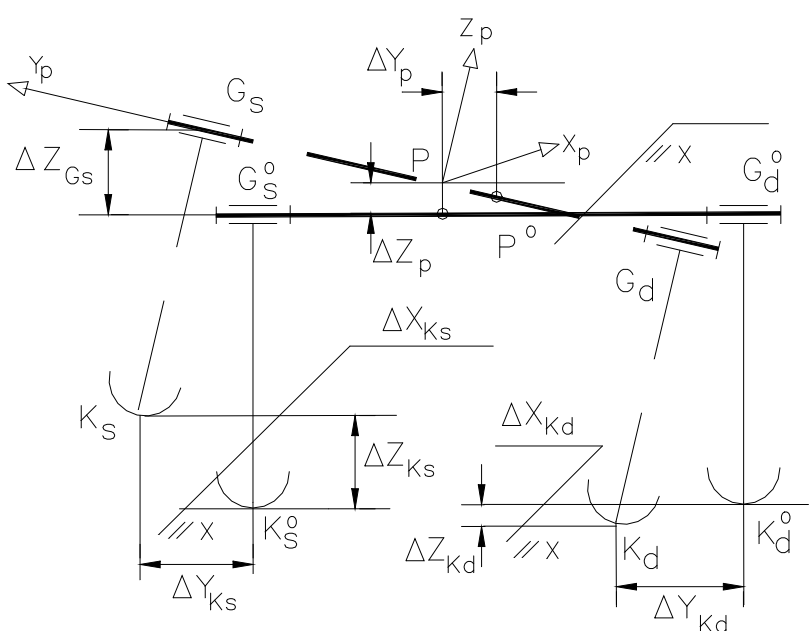

Figure 3. The linear displacements of the rear axle.

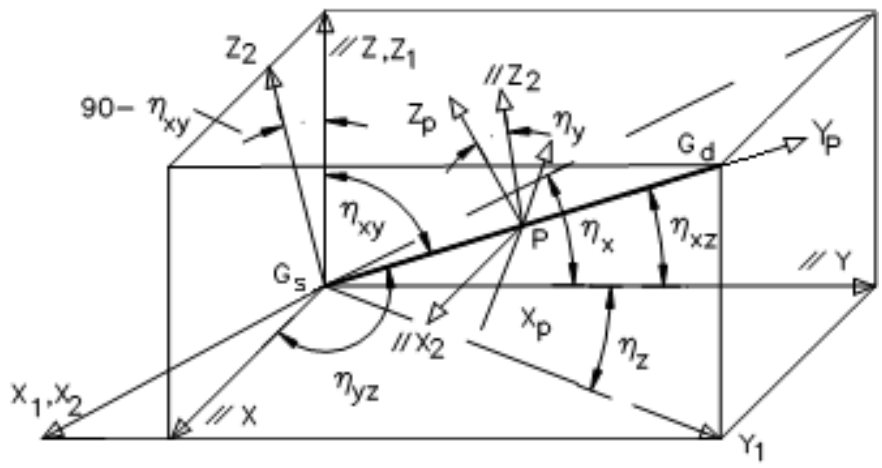

Figure 4. The orientation angles of the rear axle.

\section{Results and conclusions}

The method presented above was algorithmized and transposed on computer by using the programming software environment Borland Delphi (based on Object Pascal). The numerical simulation for this work was carried out by considering the following values of the input data for the kinematic analysis (in correlation with the notations in Figure 2):

- the global coordinates of the joints to chassis: $\mathrm{M}_{0 \mathrm{~s}}(1624.0,-457.0,79.0), \mathrm{M}_{0 \mathrm{~d}}(1624.0,457.0$, $79.0), \mathrm{N}_{0 \mathrm{~s}}(1885.0,-255.0,252.0), \mathrm{N}_{0 \mathrm{~d}}(1885.0,255.0,252.0), \mathrm{T}_{0}(2538.0,457.5,139.0)[\mathrm{mm}]$

- the global coordinates of the joints to axle: $\mathrm{M}_{\mathrm{s}(\mathrm{P})}(-58.0,-457.0,-58.0), \mathrm{M}_{\mathrm{d}(\mathrm{P})}(-58.0,457.0,-58.0)$, $\mathrm{N}_{\mathrm{s}(\mathrm{P})}(31.0,-205.0,114.0), \mathrm{N}_{\mathrm{d}(\mathrm{P})}(31.0,205.0,114.0), \mathrm{T}(101.5,-457.0,0.0)[\mathrm{mm}] ;$

- the static/initial position of the axle center: $\mathrm{P}^{0}(2400.0,0.0,145.0)[\mathrm{mm}]$;

- the lengths of the guiding bars: $1_{1 \mathrm{~s}, \mathrm{~d}}=718.04,1_{3 \mathrm{~s}, \mathrm{~d}}=548.33,1_{4}=915.25[\mathrm{~mm}]$. 
By the kinematic analysis, the results that describe the behavior of the axle guiding mechanism have been obtained. The diagrams in Figures 5 and 6 show the displacements of the axle center along the global reference frame axes, as well as the three rotations that determine the spatial orientation of the axle/guiding mechanism. The imposed variation field for the independent kinematic parameter is $\mathrm{Z}_{\mathrm{Gs}} \in[-$ $80,80] \mathrm{mm}$, thus simulating the up/down travel of the wheel/axle in a passing over bumps regime.

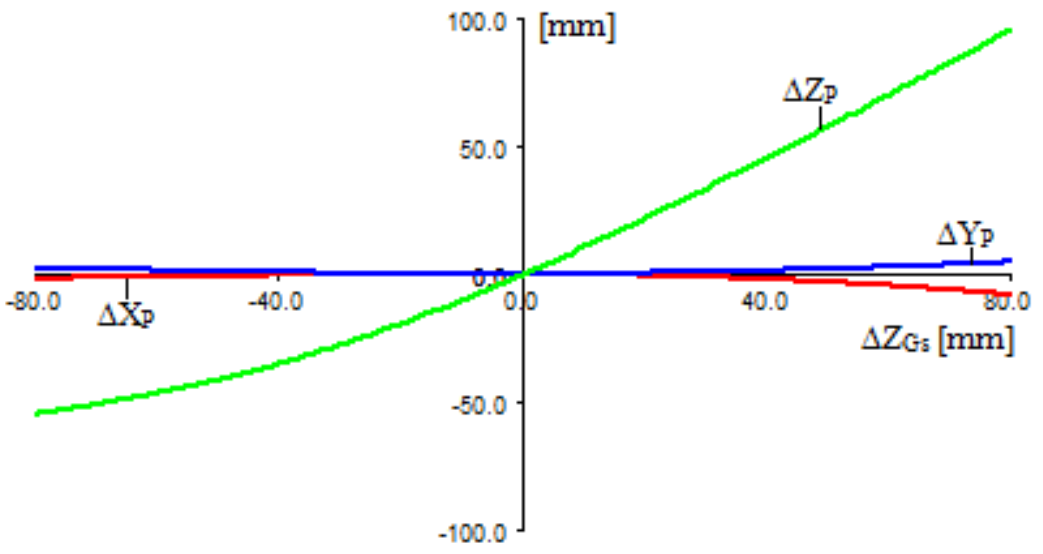

Figure 5. The linear displacements of the axle centre.

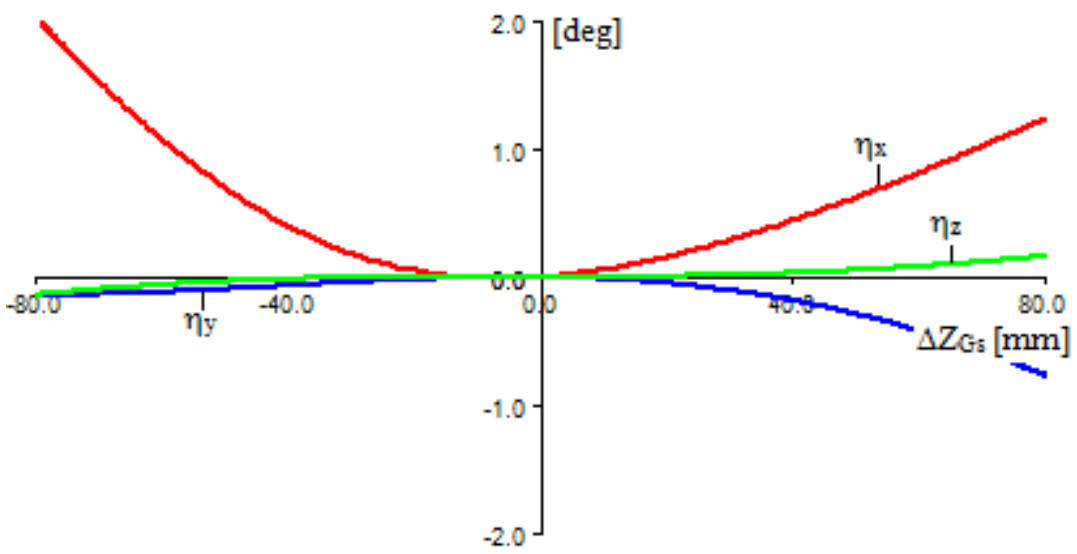

Figure 6. The orientation angles of the axle.

Based on the study presented in this paper, the following conclusions can be drawn: the proposed method uses geometric parameters of the axle guiding mechanism that can be read directly from the execution and overall drawings; by choosing as an independent parameter the vertical movement of the wheel center, there is a good correlation with the actual load on the car; the coordinates of any point on the axle are easy to calculate.

By reference to other methods from literature, the numerical algorithm proposed in this work brings several important benefits for the kinematic analysis of the axle guiding mechanisms, such as the high degree of applicability, the fast convergence of the non-linear system used to model the kinematic behavior, and the possibility to be adapted for the multi-link guiding mechanisms of the front wheels (with independent suspension).

The method here presented can be integrated / implemented in a more complex numerical algorithm for establishing the static equilibrium position of the axle suspension system (by taking into account the elastic and damping elements, as well as the system of external forces applied to the car), this being one of the directions for further research in the field. 


\section{References}

[1] Alexandru C, Comşiț M 2007 Virtual prototyping of the solar tracking systems Renewable Energy and Power Quality Journal 1(5) pp 105-110

[2] Alexandru C 2009 Software platform for analyzing and optimizing the mechanical systems Proceedings of the 10th IFToMM International Symposium on Science of Mechanisms and Machines - SYROM pp 665-677

[3] Alexandru, C 2009 The kinematic optimization of the multi-link suspension mechanism used for rear axle of the motor vehicle Proceedings of the Romanian Academy - Series A 10(3) pp 244253

[4] Alexandru C 2012 Optimal design of the mechanical systems using parametric technique \& MBS (Multi-Body Systems) software Advanced Materials Research 463-464 pp 1129-1132

[5] Alexandru C 2020 Method for the kinematic analysis of the vehicle axle guiding mechanisms. International Journal of Modeling and Optimization 10(4) pp 126-131

[6] Alexandru P, Macaveiu D, Alexandru C 2012 Design and simulation of a steering gearbox with variable transmission ratio Proceedings of the Institution of Mechanical Engineers, Part C: Journal of Mechanical Engineering Science 226(10) pp 2538-2548

[7] Attia H 2013 Kinematic analysis of the multi-link five-point suspension system in point coordinates Journal of Mechanical Science and Technology 17(8) pp 1133-1139

[8] Balike K, Rakheja S, Stiharu I 2008 Kinematic analysis and parameter sensitivity to hard points of five-link rear suspension mechanism of passenger car Proceedings of the Design Engineering Technical Conference pp 755-764

[9] Ceccarelli M 2009 Challenges for mechanism design Proceedings of the 10th IFToMM International Symposium on Science of Mechanisms and Machines - SYROM pp 1-13

[10] Enescu M, Alexandru C 2012 Modeling and simulation of a 6 DOF robot Advanced Materials Research 463-464 pp 1116-1119

[11] Hiller M, Woernle C 1985 Kinematical analysis of a five point wheel suspension ATZ 87(2) pp 59-64

[12] Knapczyk J, Maniowski M 2002 Selected effects of bushings characteristics on five-link suspension elastokinematics Mobility and Vehicle Mechanics 3(2) pp 107-121

[13] Knapczyk J, Maniowski M 2006 Elastokinematic modeling and study of five-rod suspension with subframe Mechanism and Machine Theory 41(9) pp 1031-1047

[14] Rocca E, Russo R 2002 A feasibility study on elastokinematic parameter identification for a multilink suspension Journal of Automobile Engineering 216(2) pp 153-160

[15] Simionescu P A, Beale D 2002 Synthesis and analysis of the five-link rear suspension system used in automobile Mechanism and Machine Theory 37(9) pp 815-832

[16] Tică M, Dobre G, Mateescu V 2014 Influence of compliance for an elastokinematic model of a proposed rear suspension International Journal of Automotive Technology 15(6) pp 885-891

[17] Țoțu V, Alexandru C 2013 Multi-criteria kinematic optimization of a front multi-link suspension mechanism using DOE screening and regression model Applied Mechanics and Materials 332 pp 351-356

[18] Țoțu V, Alexandru C 2014 Optimal design of the front suspension mechanism used for a race car Mechanisms and Machine Science 18 pp 243-253 


\title{
Measurements of galvanic skin response with accelerometer glove
}

\author{
Loredana Dascălu ${ }^{1}$, Oana-Roxana Chivu ${ }^{1}$, Claudiu Babiș ${ }^{1}$, Anamaria Feier ${ }^{2}$, and \\ Alin Ion Țăpîrdea ${ }^{2}$, \\ ${ }^{1}$ University Politehnica of Bucharest, Bucharest, Romania \\ ${ }^{2}$ Universitatea Politehnica Timișoara - IMF, Romania \\ E-mail: virlan_oana@yahoo.co.uk
}

\begin{abstract}
The purpose of this study is to measure the response of galvanic skin with the accelerometer glove. In this paper, we focus on detecting the level of stress using GSR sensor data and testing the possibility of using the accelerometer glove (own implementation) on a large number of people. The experimental part of this study involved interviews with 15 people. The case study was conducted using a proposed questionnaire about stress at work and, in the same time each person was connected to the glove of the accelerometer. Occupational stress is an enemy of society and, in my view, every future direction of stress identification is a good start to discovering the best way to reduce it.
\end{abstract}

Keywords: accelerometer, glove, GSR, stress, measurements.

\section{State of the art}

Reviewing the literature, we have found a lot of questionnaire about stress at work, such us: Holmes and Rahe Stress Scale Questionnaire to determine stress factors[1], Cohen Williamson Questionnaire to determine stress level[2], General Questionnaire on Working Environment and Health Status to determine the effects of stress and so on. [3]

GSR is a method of measuring the electrical conductance of the skin, because the emotion can cause more sweat. GSR device allows you to spot strong emotions by attaching electrodes to two fingers on one hand for right prediction of stress level percentage. [4]

Galvanic skin response measurement and analysis is used to measure skin resistance, skin conductance and stress level of people. With GSR device you can observe and record changes in respiratory rate, heart rate and skin resistance associated with cognitive behavior and emotion. [5]

There are several studies which propose different methods of detecting stress levels by measuring skin conductance and skin resistance. [6]

\section{Experimental}

The research was performed with accelerometer glove. The description of components are presented below.

The circuit consists of a three-stage transistor amplifier which are directly connected.

Each of the transistors being connected to the next by a conductive connection. So, this amounts to a DC voltage amplifier. The last transistor T3 has an LED diode which should detect the skin conductance. When this transistor receives a base current from its predecessor T2, it transmits it and the LED lights up. The second transistor is connected in series with T1 that supplies T2 with base current. 
This input transistor $\mathrm{T} 1$ receives a base current when the sensors are subjected to conductive overpressure. The high impedance resistance of dry skin is sufficient for this. If the fingertips are wet, the resistance descend to a few Kilo Ohms. The input potentiometer is used to adjust the sensitivity and it is turn to the left to make it insensitive and to the right for the highest sensitivity.

To activate the LED diode, the pair of transistors T2 / T3 must be between 5 and $10 \mathrm{~mA}$ as soon as the base of $\mathrm{T} 2$ receives between 5 and $10 \mu \mathrm{A}$. When the potentiometer is turned completely to the right (maximum sensitivity), a resistance of 5 to $10 \mathrm{~m} \mathrm{Ohm}$ at input and in this way $\mathrm{T} 1 \mathrm{can}$ arrived to the diode with $0.7 \mathrm{~V}$.

It is necessary to turn the potentiometer in the other direction in order to obtain an result on the resistance of the changing skin. The capacitor parallel to the base, emitter segment of T1 prevents the high impedance input parasitic signal from being absorbed. [7]

The glove detects changes in skin resistance (skin wetness) and displays the slightest changes in skin resistance on an LED diode display.

For the experimental part we take in consideration the following tools:

- The questionnaire about the stress at work

We elaborate an online survey which are presented below:

The questionaire about the stress at work

1) Did you feel stressed by the job tasks?

a) Yes; b) No

2) Interaction (physical, online) with people will make the activity worse?

a) Yes; b) No

3) Technology and changes regarding how to work will affect you?

a) Yes; b) No

4) Do you have time for your lunch break?

a) Yes; b) No

5) Usually do you make overtime work?

a) Yes; b) No

Interpretation of questionnaire:

If positive answer (yes $=1$ ) are more then 30 - considered high stress level at work.

If negative answer (no $=0$ ) are less then 30 - considered normal stress level (no affect the health).

- The accelerometer glove to detect stress under GSR sensors presented in figure 1.

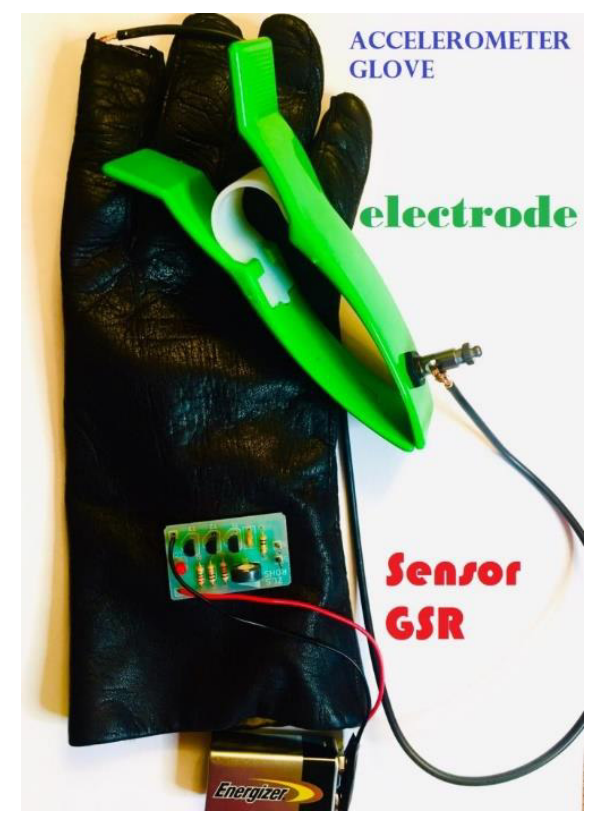

Figure 1. Accelerometer glove 


\section{Measurement results}

To analyze the results, I used GSR package software [8] presented below:

// save pin numbers to variables

int sensorPin $=\mathrm{A} 0$;

int ledPin $1=2$;

int ledPin $2=3$;

int ledPin $3=4$

int ledPin $4=5$;

void $\operatorname{setup}()\{$

// define which pins are used for input and output

pinMode(sensorPin, INPUT);

pinMode(ledPin1, OUTPUT);

pinMode(ledPin2, OUTPUT);

pinMode(ledPin3, OUTPUT);

pinMode(ledPin4, OUTPUT);

// open a serial port connection to computer

Serial.begin(9600);

void loop() \{

// read data from appropriate pin and assign value to variable

int sensorVal = analogRead(sensorPin);

// print sensor reading to the the computer via serial port

Serial.println(sensorVal);

// set all leds to off

digitalWrite(ledPin1, LOW);

digitalWrite(ledPin2, LOW);

digitalWrite(ledPin3, LOW);

digitalWrite(ledPin4, LOW);

// turn on leds based on value from sensor

if (sensorVal $>=20$ ) \{

digitalWrite(ledPin1, HIGH);

\}

if (sensorVal $>=40)\{$

digitalWrite(ledPin2, HIGH);

\}

if (

digitalWrite(ledPin3, HIGH);

\}

if (sensorVal >= 80) \{

digitalWrite(ledPin4, HIGH);

\}

// wait for 20 milliseconds before reading sensor again delay (20);

\}

The experiment involved 15 subjects from different institution of Romania.

The result obtained after answered of questionnaire and GSR measurements with accelerometer glove are related in the table 1 from bellow. 
Table 1. Results of GSR data collection

\begin{tabular}{|c|c|c|c|c|c|c|}
\hline Respondent & Q1 & Q2 & Q3 & Q4 & Q5 & GSR \\
\hline 1 & 1 & 1 & 1 & 1 & 0 & 4.13 \\
\hline 2 & 1 & 0 & 1 & 0 & 1 & 4.99 \\
\hline 3 & 1 & 1 & 1 & 0 & 1 & 3.11 \\
\hline 4 & 1 & 0 & 1 & 0 & 1 & 4.99 \\
\hline 5 & 1 & 1 & 1 & 0 & 1 & 4.56 \\
\hline 6 & 1 & 1 & 1 & 1 & 0 & 6.93 \\
\hline 7 & 1 & 1 & 1 & 0 & 1 & 3.17 \\
\hline 8 & 1 & 1 & 1 & 0 & 1 & 3.97 \\
\hline 9 & 1 & 1 & 1 & 0 & 1 & 5.27 \\
\hline 10 & 1 & 1 & 1 & 0 & 1 & 6.01 \\
\hline 11 & 1 & 0 & 1 & 0 & 1 & 5.76 \\
\hline 12 & 1 & 0 & 1 & 0 & 1 & 3.99 \\
\hline 13 & 1 & 1 & 1 & 1 & 0 & 4.03 \\
\hline 14 & 1 & 0 & 1 & 0 & 1 & 6.37 \\
\hline 15 & 1 & 0 & 1 & 1 & 0 & 6.12 \\
\hline
\end{tabular}

The questionnaire puts the brain in motion and after that, during a 5 minute screening respondents are seated with accelerometer glove in front of the monitor and we can detect changes in stress level from the GSR sensor.

The result obtained just with accelerometer glove, without survey, are related in the table 2 from bellow.

Table 2. Results of GSR without survey

\begin{tabular}{|c|c|}
\hline Respondent & GSR measurements \\
\hline 1 & 2.99 \\
\hline 2 & 3.11 \\
\hline 3 & 2.73 \\
\hline 4 & 4.32 \\
\hline 5 & 3.00 \\
\hline 6 & 5.71 \\
\hline 7 & 1.97 \\
\hline 8 & 2.87 \\
\hline 9 & 4.07 \\
\hline 10 & 4.59 \\
\hline 11 & 3.99 \\
\hline 12 & 3.61 \\
\hline 13 & 2.91 \\
\hline 14 & 5.16 \\
\hline 15 & 4.84 \\
\hline
\end{tabular}

The GSR device generates the graphics which are showing the variation of stress.

The results indicate that the stress level is high after they answer to the questionnaire. Analyzing the below figures (fig.2, fig.3, fig.4 and fig.5) we can see that the results for GSR screening are lower in case when the accelerometer glove was applied without survey than measurements GSR after they complete the survey (the brain processes the memory of different situations). 
Volume 2, Issue 2, 2020

ISSN: 2668-0416

Thoth Publishing House

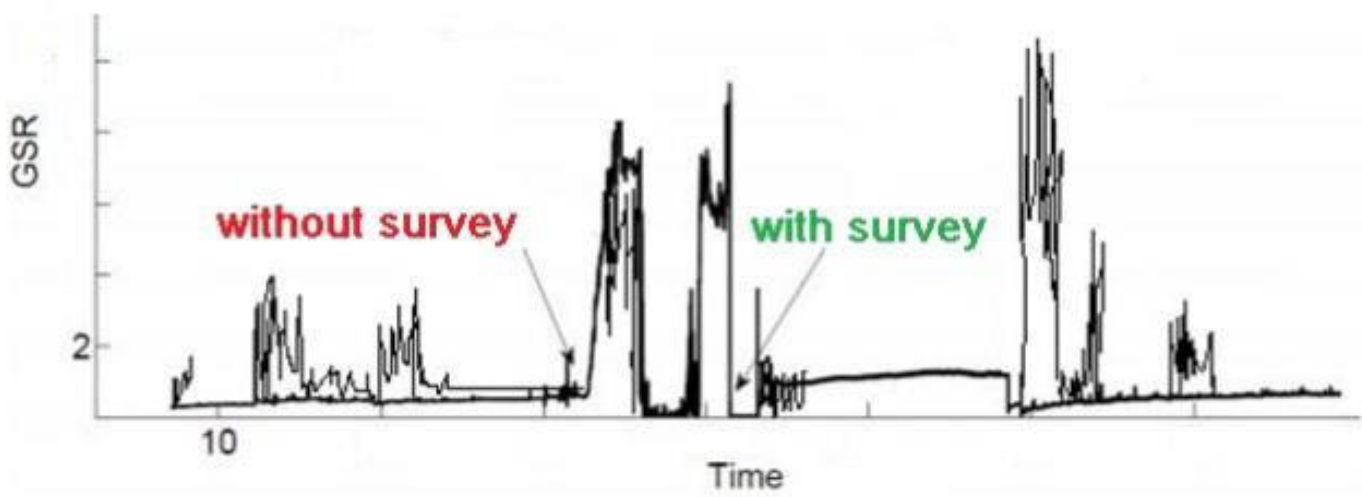

Figure 2. GSR stress level

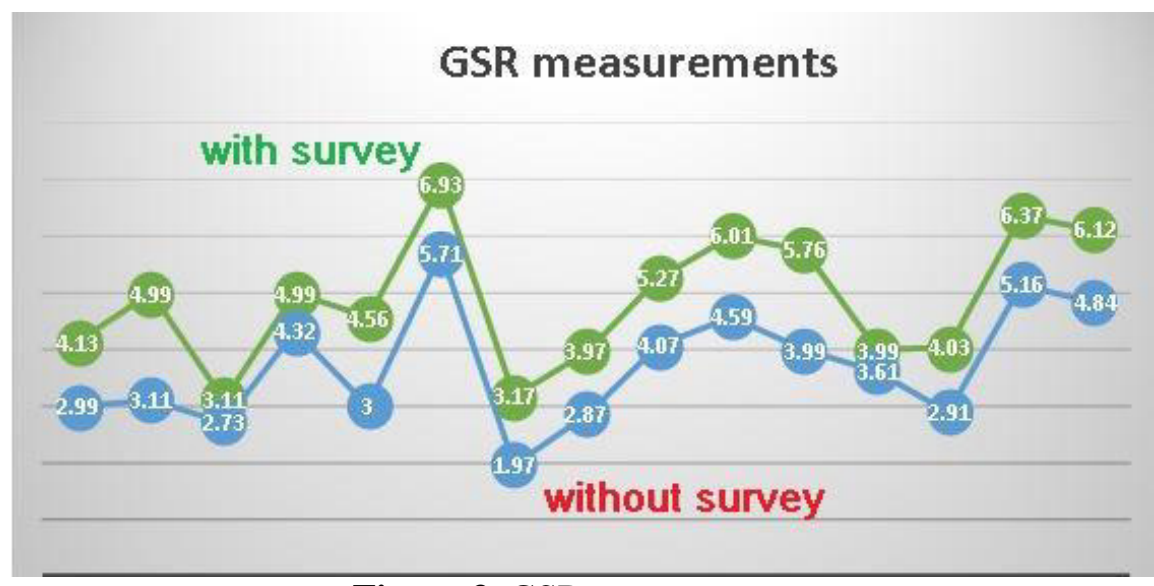

Figure 3. GSR measurements

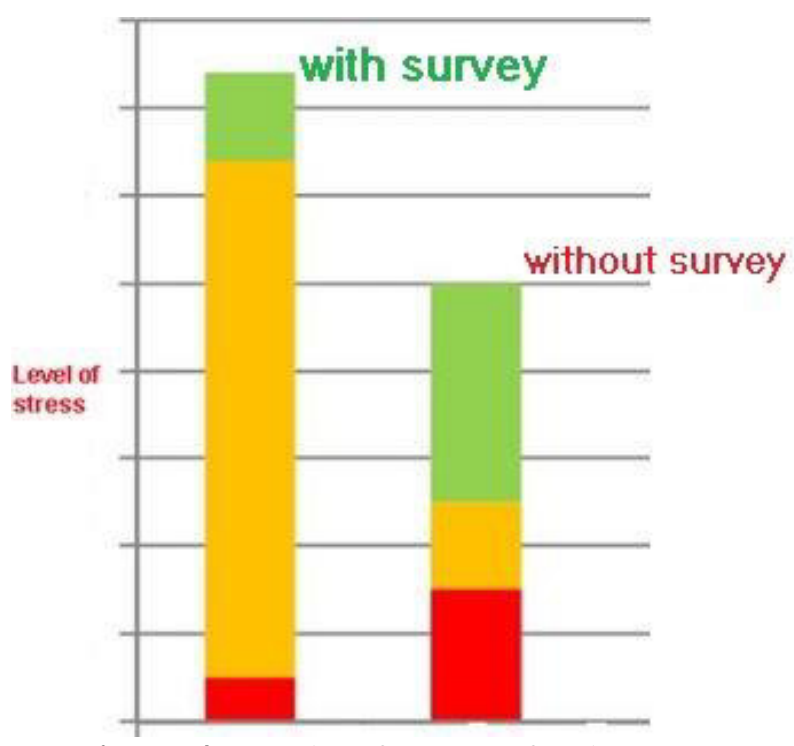

Figure 4. Results of average for the survey 


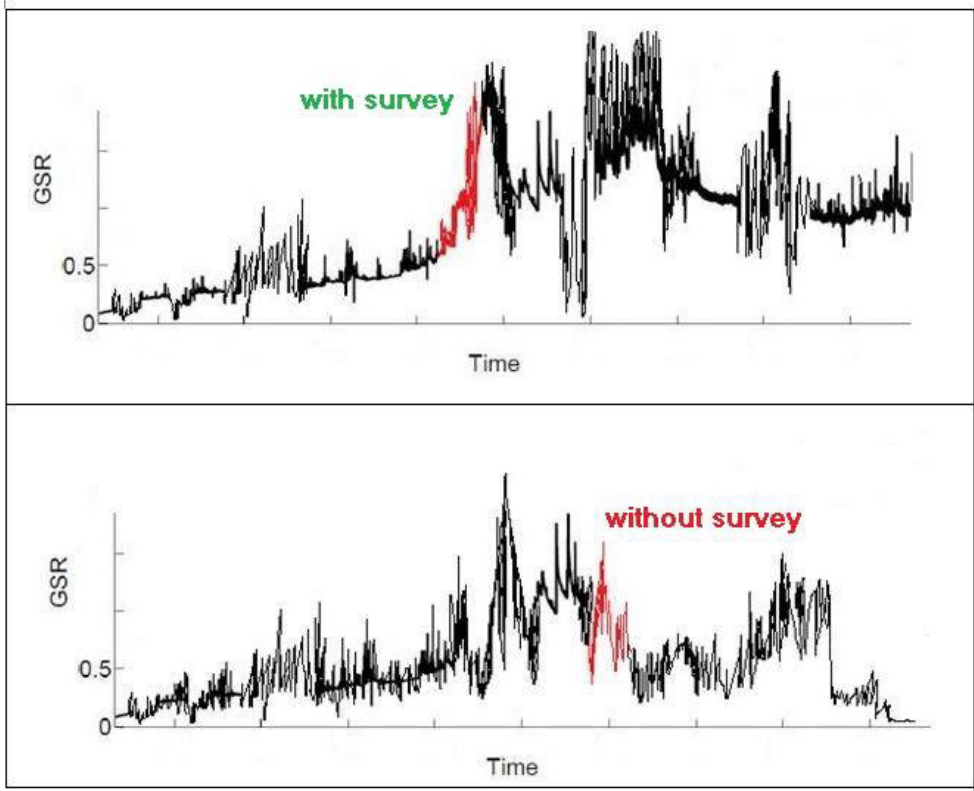

Figure 5. Results of GSR screening

\section{Conclusion}

The conclusions for the results obtained in the research are presented below:

- figure 2- GSR level showed a high variation of stress in case of respondents who complete the survey, but the GSR level for respondents without survey it is low.

- figure 3 - GSR measurements denote that the stress level is low if the respondents do not remember things from the past with the help of the questionnaire.

- figure 4 - as per average results, the questionnaire "stress at work" prove that the level of stress is very high if we make the screening after the survey.

- figure 5 - the results of GSR screening for respondents who complete the survey compared to respondents without survey are high as per red signal showed in the picture and variation of black lines.

This study is the first step in conducting scientific research with an accelerometer glove to determine the level of stress of workers from the perspective of skin galvanization.

Research in this area is extensive and future directions for this article will be to continue research based on the accelerometer glove, improve glove functions and expand the sample.

\section{References}

[1] https://www.stress.org/holmes-rahe-stress-inventory-pdf

[2] Cohen, S. and Williamson, G. Perceived Stress Scale. Newbury Park, CA: Sage, 1994.

[3] https://www.gl-assessment.co.uk/products/general-health-questionnaire-ghq/

[4] Dascălu, L., Babis, C., Chivu, O., Iacobescu, G., Dimitrescu, A., 2019, Measurements of Galvanic Skin Response on subjects affected by stress, 9 th International conference on manufacturing science and education-MSE 2019- 5-7 Iunie, Sibiu.

[5] Jayanthi, A. N., Nivedha, R., Vani, C.,2015, Galvanic Skin Response Measurement and Analysis, International Journal of Applied Engineering Research ISSN 0973-4562 Volume 10, Number 16, India.

[6] Sharma, M., Kacker, S.,Mohit, S.,2016, A brief introduction and review on Galvanic Skin Response, IJMRP, 2(6); 13-17, India.

[7] https://asset.conrad.com/media10/add/160267/c1/-/fr/000190055ML09/manual-190055-conradcomponents-assembly-kit-14-years-and-over.pdf

[8] https://gist.github.com/julioterra/123125 


\title{
Influence of machining parameters on surface roughness in WEDM cutting
}

\author{
Sergiu Lazăr ${ }^{1}$ \\ ${ }^{1}$ Faculty of Engineering, Lucian Blaga University of Sibiu, Sibiu, Romania \\ E-mail: sergiu.lazar@ulbsibiu.ro
}

\begin{abstract}
Wire Electrical Discharge Machining is a cutting method used for obtaining parts with complex geometries or for cutting hard metals. This paper seeks to emphasize the importance of this unconventional technology and more specifically the importance of knowing the parameters of a process before planning the production of a benchmark. Cylindrical metal carbide parts with a hardness of $1620 \mathrm{HV} / 92 \mathrm{HRC}$ were cut during the analysis9, using the minimum and maximum values of the cutting parameters: wire feed rate, wire rotation speed, wire tension, dielectric pressure, electrical current(A) and electrical potential (V). The roughness of the obtained surfaces has been measured after being cut and a comparison table that includes the parameters values set by the user and the measured roughness was drawn up.
\end{abstract}

Keywords: WEDM, surface roughness, cutting parameters, machining.

\section{Introduction}

Electrical Discharge Machining process was discovered by two Russian scientists R. Lazarenko and I. Lazarenko in 1943 and in the beginning, it was used only in the military industry. This subtractive machining process is used to machine especially very hard metals like pre-hardened steel or Titanium, but it can also be used for other materials which are electro conductive. Sometimes EDM is used to make objects like mold cavities because it is impossible to obtain a complex geometry using traditional cutting processes. [1]

The evolution of technology in the last two decades has put pressure on the development of unconventional technologies, especially micro technologies. Although the unconventional technologies like wire electrical discharge machining were extensively studied, no revealed aspects are known regarding the cutting parameters influence the workpiece. [2]

\section{Basic information of EDM process}

The main concept behind WEDM is about the way of an electric arc can erode the surface of a material. These electric arcs form when the voltage difference between two closely separated objects, called electrodes, becomes large enough to overcome the resistance of the gap between them. When this occurs, a current of up to 500 A flows through a microscopically small area, vaporizing the surface of the electrodes. This vaporization separates some material from the larger workpiece, leaving a pit on the surface. As numerous arcs occur, this pitting erodes the surface over a large area, shaping it in the desired manner. [3]

WEDM is based on complex, discontinuous and localized erosive effects of repetitive pulsed electric discharges between the workpiece and the electrode. As mentioned earlier, only materials that have electrical conductivity can be processed. [4] 
Volume 2, Issue 2, 2020

ISSN: 2668-0416

Thoth Publishing House

\section{Experimental procedure}

Experimental trials are performed by cutting $\varnothing 18.8 \mathrm{~mm}$ metal carbide bars. A metallographic analysis was performed to determine the elemental structure of the material, Figure 1. A Leika DM6 M LIBS metallographic microscope was used.

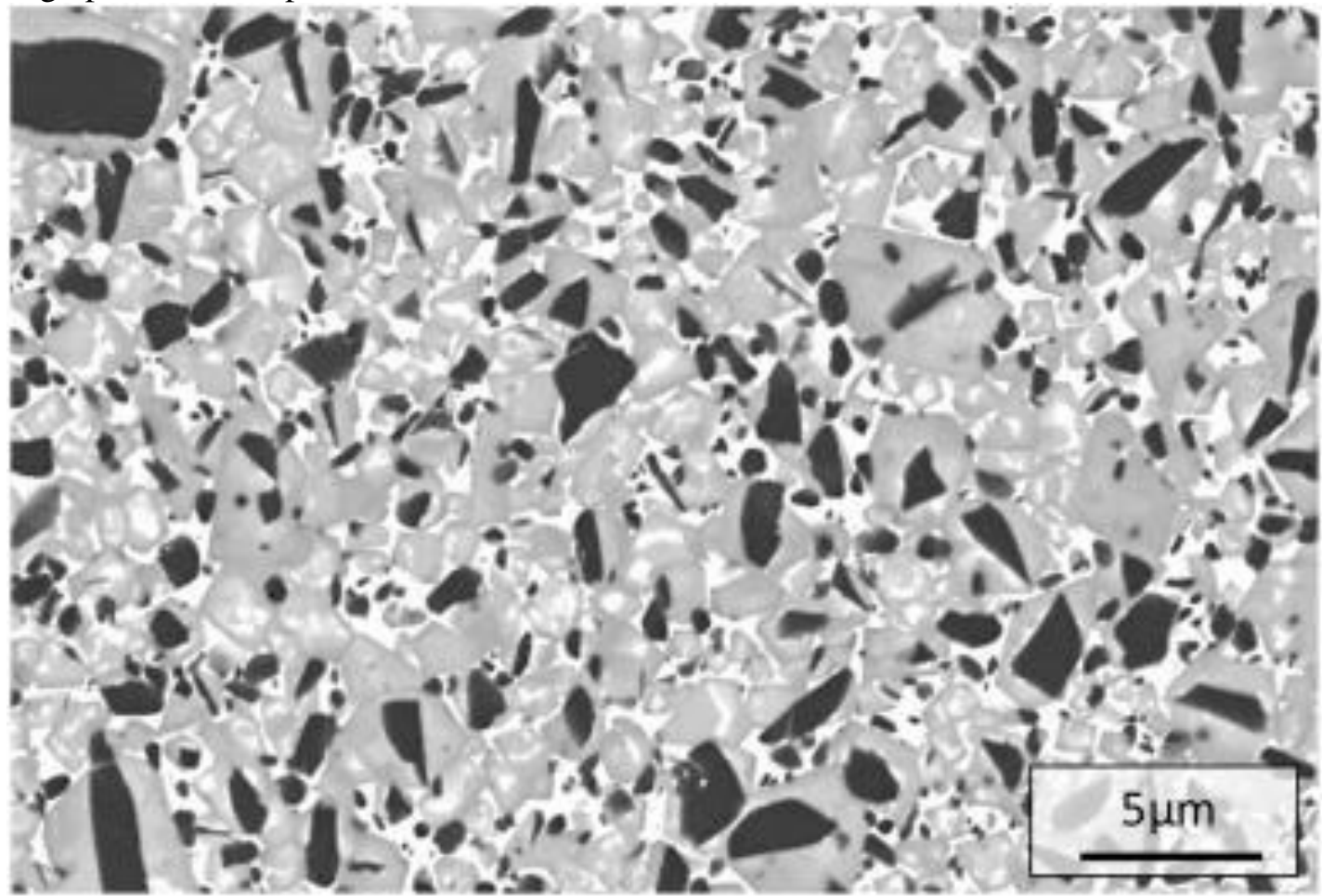

Figure 1. Metallographic analysis for carbide bar

Metal carbide contains $10 \%$ Cobalt $(\mathrm{Co})$ and the size of the Tungsten $(\mathrm{W})$ grains reaches a maximum of $0.5 \mu \mathrm{m}$. There is also Carbon (C) with black, Titanium (Ti) and Tantalum (Ta). After analysing the elemental structure, the hardness of the carbide bars was analysed. For this, the Vickers method was used on a Struers Duramin 40 durometer, Table 1. The square-shaped frame with a square base and a diamond tip was applied for 18 seconds, according to ISO6507. The hardness of the outer cylindrical surface was measured. In Table 2 . the values obtained from the hardness test analysis can be found.

Table 1. Hardness test results

\begin{tabular}{|c|c|c|c|c|c|c|c|c|c|c|}
\hline Sample nr. & $\mathbf{1}$ & $\mathbf{2}$ & $\mathbf{3}$ & $\mathbf{4}$ & $\mathbf{5}$ & $\mathbf{6}$ & $\mathbf{7}$ & $\mathbf{8}$ & $\mathbf{9}$ & $\mathbf{1 0}$ \\
\hline Hardness [HV] & 1620 & 1618 & 1618 & 1620 & 1620 & 1620 & 1619 & 1620 & 1620 & 1620 \\
\hline
\end{tabular}

Metal carbide bars will be machined on the AgieCharmilles AC Progress V4. The cutting was made with CobraCut A wire of size $\varnothing 0.25 \mathrm{~mm}$, made of CuZn36 material (brass). During machining, the maximum spark size is $0.06 \mathrm{~mm}$. The tensile strength the wire is $900 " \mathrm{~N} / \mathrm{mm} 2 "$. 
The dielectric used for WEDM is a combination of water with cationic resin SurTec476, maintained at a temperature of $18.8 \ldots 19.2^{\circ} \mathrm{C}$. The role of the dielectric is to cancel the electrical conductivity of the water, to cool the spark electrode and to wash the microparticles.

The next step of the study was to determine the parameters that can be changed on the machine mentioned above. In the table below are the parameters that could be modified by the user in correlation with their minimum and maximum values.

Table 2. The minimum and maximum values of the parameters on the WEDM machine

\begin{tabular}{|c|c|c|}
\hline \multirow{2}{*}{ Parameter } & \multicolumn{2}{|c|}{ Values } \\
\cline { 2 - 3 } & min. & max. \\
\hline Wire feed rate $[\mathrm{mm} / \mathrm{min}]-\mathbf{V}_{\mathbf{a}}$ & 0,50 & 4 \\
\hline Wire rotation speed [mm/min] $-\mathbf{V}_{\mathbf{r}}$ & 90 & 325 \\
\hline Dielectric pressure [mmHg] $-\mathbf{P}_{\mathbf{d}}$ & 0,30 & 18 \\
\hline Wire tension [N] $-\mathbf{T}_{\mathbf{f}}$ & 10 & 40 \\
\hline Electrical current [A] $\mathbf{I}$ & 1 & 40 \\
\hline Electrical potential [V] - U & 12 & 82 \\
\hline
\end{tabular}

The cutting parameters found in the table above are: $V_{a}$ - wire feed rate, $V_{r}$ - wire rotation speed, $T_{f}$ - wire tension, $\mathrm{P}_{\mathrm{d}}$ - dielectric pressure, I - electrical current(A) and $\mathrm{U}$ - electrical potential (V). Considering that the user can change a number of six parameters, with two values (minimum and maximum), it will be determined the total number of parts that must be made to have a complete study:

$$
2^{6}=64-\text { number of cutting parts }
$$

In this phase of the study, it was decided to perform 6 cuts and making only 6 workpieces to find the preliminary data for establishing a mathematical calculation model. Subsequently, to validate the mathematical model will be done another 58 workpieces with the other parameters. The main reason why we chose to cut only 6 pieces is the ease of establishing a model of influence of the parameters on the surface roughness.

The roughness of the cut parts was measured using a Mitutoyo Surftest SJ-301 roughness meter. A linear surface was measured at mid-height, more precisely at half the diameter, as can be seen in Figure 2 .

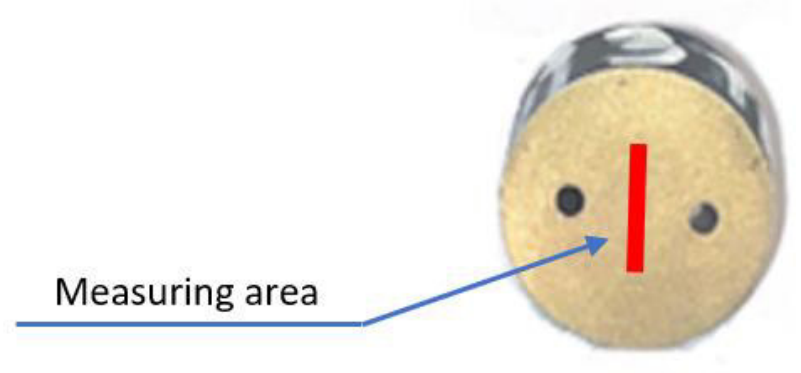

Figure 2. Roughness measuring area

Regarding the roughness measurement, the arithmetical mean deviation of the assessed profile Ra, the maximum height of the profile $\mathrm{Rz}$ and maximum peak height $\mathrm{Rp}$ were measured. [5]. The values of the test parameters and the resulting roughness is shows in Table 3. 
Table 3. The values of the test parameters and the resulting roughness

\begin{tabular}{|c|c|c|c|c|c|c|c|c|c|}
\hline $\mathbf{N r}$. & $\begin{array}{c}\text { Wire feed } \\
\text { rate } \\
{[\mathbf{m m} / \mathbf{m i n}]}\end{array}$ & $\begin{array}{c}\text { Wire } \\
\text { rotation } \\
\mathbf{s p e e d} \\
{[\mathbf{m m} / \mathbf{m i n}]}\end{array}$ & $\begin{array}{c}\text { Dielectric } \\
\mathbf{p r e s s u r e} \\
{[\mathbf{m m H g}]}\end{array}$ & $\begin{array}{c}\text { Wire } \\
\text { tension } \\
{[\mathbf{N}]}\end{array}$ & $\begin{array}{c}\text { Electrical } \\
\text { current } \\
{[\mathbf{A}]}\end{array}$ & $\begin{array}{c}\text { Electrical } \\
\mathbf{p o t e n t i a l} \\
{[\mathbf{V}]}\end{array}$ & $\begin{array}{c}\mathbf{R}_{\mathbf{a}} \\
{[\boldsymbol{\mu \mathbf { m } ]}]}\end{array}$ & $\begin{array}{c}\mathbf{R}_{\mathbf{z}} \\
{[\boldsymbol{\mu} \mathbf{m}]}\end{array}$ & $\begin{array}{c}\mathbf{R}_{\mathbf{a}} \\
{[\boldsymbol{\mu \mathbf { m } ]}]}\end{array}$ \\
\hline 1 & 0.5 & 325 & 18 & 40 & 1 & 82 & $\mathbf{0 , 0 8}$ & 0,92 & 0,12 \\
\hline 2 & 4 & 90 & 0.3 & 10 & 40 & 12 & $\mathbf{2 , 9 0}$ & 16,12 & 3,55 \\
\hline 3 & 2.8 & 310 & 16 & 35 & 14 & 80 & 1,16 & 6,88 & 1,41 \\
\hline 4 & 1 & 300 & 15 & 20 & 10 & 60 & 0,70 & 5,21 & 0,87 \\
\hline 5 & 1.5 & 305 & 13.5 & 27 & 3 & 75 & 0,33 & 2,29 & 0,42 \\
\hline 6 & 1.1 & 267 & 12 & 30 & 2.5 & 30 & 0,27 & 1,87 & 0,34 \\
\hline
\end{tabular}

The veracity of the values presented above can be extracted from the measurement reports of the Mitutoyo Surftest microscope, which can be found below, in Figure 3.

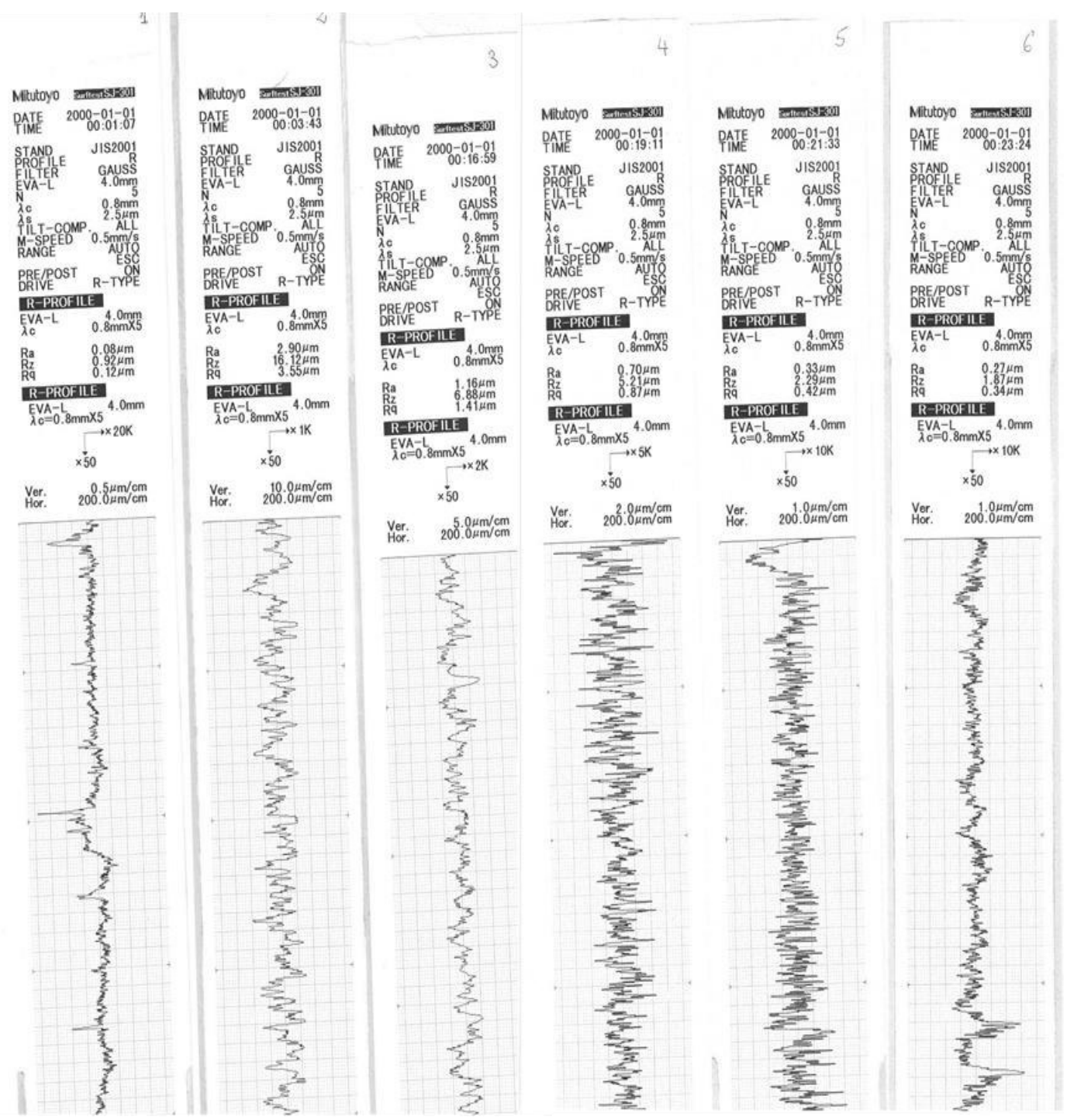

Figure 3. Roughness measurement reports 
The purpose of this study is close to fulfilment. As can be seen, the most important parameter influencing the roughness of the surface is the wire feed rate: the higher the value of the wire feed rate, the higher the surface roughness. This is justified by the fact that during cutting the surfaces are processed very little due to the high speed of movement of the wire. Consequently, the wire fails to ensure their complete finishing. [6]

The second important factor that influences the quality of surfaces is the electric current. The highest roughness Ra was obtained where the electric current has the highest value. This is explained by the fact that the size of the spark is difficult to control and erodes a larger amount of material.

The roughness decreases only when the value of the parameter $U, P_{d}$ and $T_{f}$ have high values. Of these parameters that decrease the value of roughness, the most significant seems to be the electric potential. [7]

Even if the low roughness values can only be observed with the help of special tools, in Fig. 4. a significant difference of the pieces obtained due to the pattern can be observed.
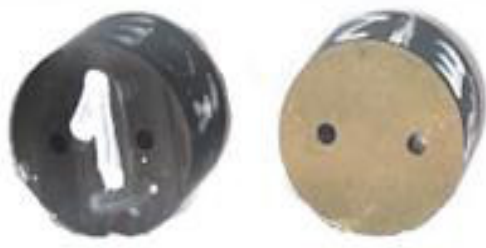
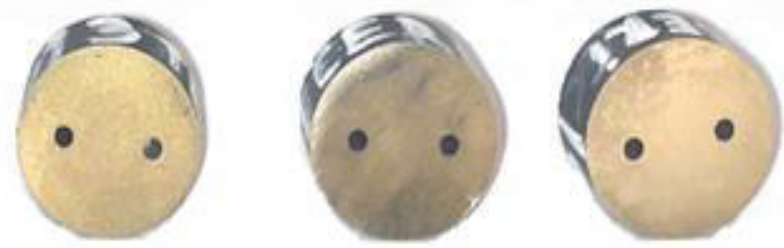

Figure 4. Parts cut by EDM

\section{Conclusions}

For the industry it would be important to prepare a library with specified parameters for machining different materials. For example, for the same kind of machining (roughing or finishing), in the tables of the machine-tools, the parameters are optimized but it is not specified the quality of the surface that can be obtained. Also, a mathematical model will improve the knowledge of the phenomena and it will open the possibilities of using the process in different applications. This is the next step of this study. [1]

Although it is very important that the productivity of this process is high, i.e. the parameter $\mathrm{V}_{\mathrm{a}}$ has maximum values during processing, it must be considered that the principle of the quality of the parts matters first.

Thus, the most important thing in WEDM machining is to establish the optimal parameters that consider productivity and quality. It is unlikely that maximum productivity and maximum quality can be achieved.

\section{Bibliography}

[1] P. Marcel Sabin, C. Glad, P. Grigore, ,Surface quality of the EDM processed materials, ” in XIX IMEKO World Congress Fundamental and Applied Metrology, Lisbon, 2009.

[2] C. M. Simion, Studies and research on the surface roughness processed by EDM - PhD Thesis, București: Politehnica Publishing House, 1999.

[3] N. Hesse, „Pen State Site,” Penn State, 04 2016. [Interactiv]. Available: http://sites.psu.edu/nwhesse/wp-content/uploads/sites/37237/2016/04/Definition-EDM.pdf.

[4] C. I. Deneș, Contributions regarding WEDM processing - PhD Thesis, Sibiu: "Lucian Blaga" University of Sibiu, 2002.

[5] D. Dobrotă, Basics of designing cutting processes, vol. I, Craiova: Sitech Publishing House, 2007, p. 272.

[6] A. Nanu și D. Nanu, Dimensional processing by EDM in magnetic field, Sibiu: Facla Publishing House, 1981.

[7] D. Nanu, Treaty of unconventional technologies. Vol.II: Processing by EDM, Sibiu: "Lucian Blaga" University of Sibiu Publishing House, 2004. 


\title{
Innovative models for sustainable agriculture
}

\author{
Stefan Ghimisi ${ }^{1}$ \\ ${ }^{1}$ Constantin Brancusi University of Targu Jiu, Romania \\ E-mail:ssghimisi@gmail.com
}

\begin{abstract}
In the full global crisis, innovation must play an active part in solving problems facing the countries of the world. Investing in research and development and production of innovations is a practical and efficient way to combat recession. The paper presents some innovation models used for the development of a sustainable agriculture, the choice of the optimal innovation model can lead to the development of society
\end{abstract}

Keywords: innovation, agriculture, sustainable

\section{Definitions and evolutions}

In 1941, English economist Schumpeter [1] proposed the first definition, in technical-economical domain, innovation, definition with general character. He says that innovation is the action whose outcome is to produce anything or to produce otherwise. As Schumpeter's definition, it is recognized that the innovation in the following activities: a new product creation introduction of new manufacturing methods; entering a new market (creating a new market); appealing to a new material; new organization of the company; create a new image of the company.

The classic definitions of "innovation" include:

- "the process of making improvements by introducing something new".

- "the act of introducing something new: something newly introduced". (The American Heritage Dictionary of the English Language)

- "the introduction of something new". (Merriam-Webster Online)

- "a new idea, method or device". (Merriam-Webster Online)

- "the successful exploitation of new ideas". (Department of Trade and Industry,UK)

- "change that creates a new dimension of performance". Peter Drucker (Hesselbein, 2002)

- "a creative idea that is realized". Frans Johansson (Harvard Business School Press, 2004)

\section{Innovation Models}

Many innovations result from seeking a new opportunity. Potential innovator must know that there are principles of innovation. These principles can be improved and allow people to innovate.

Thus:

1. Be oriented towards action, innovators always seek new ideas, new opportunities and new sources of innovation.

2. To make the product, process or service innovation, to be simple and understandable.

3. People have to easily understood how innovation function

4. To achieve product, process, service based on customer preferences.

5. To start with small-scale innovation. 
6. Need for targeted high objectives. Successful innovators should aim at trying to find a niche market for innovative product.

7. Innovators must follow the rule: attempt, test, review.

8. Learn from mistakes. Innovation does not guarantee success. Analysis of fault may give rise to another innovation.

9. Need to develop a schedule of the innovative project with periodic inspections.

10. Need to be rewarded those involved heavily in innovation activity.

\section{1 "Technology push" model}

The "Technology push" model is a linear model suggests that the innovation process starts with an idea. Sometimes the process has the idea / invention only a single man who has knowledge and skills that would transform the idea / invention into innovation. Nowadays the starting point of the innovation process is the process of research and development in the enterprise. This process includes product design and development can be put into production with minimal costs and can be done at a good price.

Thus the market is seen as a receiver of the proposed products from research and development process. Therefore an increase in research and development leads to increased innovation. In the past governments support innovation in many countries, this process was to support research and development through direct financing. A team of research and development implies that knows enough about the consumer needs to develop a new product without consumer participation.

Technology push model of innovation has not successful in all cases because sometimes the proposed innovations are not sufficiently appreciated by the customer and the product does not ensure expectations.

\section{2. "Market pull" model}

Alternatively, the "market pull "model suggests that the need for innovation comes from consumers or market segment. These needs may be perceived by entrepreneurs or producers or consumers are clearly manifested. According to this model for a subsequent successful innovation is necessary first to investigate market needs, establishing the needs of both existing products and processes and how to meet the needs of new innovative product.

Therefore this model adds "Technology push "model research phase of market needs (figure 1).

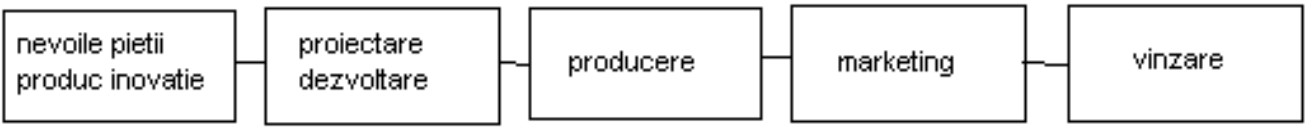

Figure 1.Market pull model

\subsection{Model of innovation chain-link}

It is a third generation model of innovation third and is proposed by SJ Kline, N. Rosenberg [2]. Following this model the innovation process is divided into five stages. In the first stage it is identified the consumers needs on a potential market. The second stage begins with an invention or / analytical project with the new product or process which as planned will meet the needs found. In the third stage takes place design and testing, and innovation process itself. In the fourth stage the project is growing and is introduced in series production. Fifth stage of innovation is to present the innovation on the market with the marketing process and distribution beginning .

Characteristic of this model is the presence of five relations of the innovation process, describing the different origins of innovation and knowledge to enter, related to the innovation process( figure 2). Main link with the index denoted by arrow $\mathrm{C}$ (Central Chain) make a process generalization which occur as a response to market needs, invention or analytical design, development and production to the marketing process.

The second link of the innovation process reflects feedback during the duration of the main link. 
The most important part of feedback, represented by F (feedback), comes from the consumer or user of the future customer of the innovation. This link reminds us that innovation is the source of consumer, or that they are consumer-oriented innovation processes. The second link shows the occurred feedback in the enterprise, noted $\mathrm{f}$ (feedback), and presents the company work to solve / skip issues that may arise at different stages of innovation, or the source innovation which is to learn from the experience (learning by doing).

The third link in the main link connecting the innovation process with knowledge. This link between innovation and fundamental research is denoted by $\mathrm{D}$ (discoveries), so for example many innovations are directly related to scientific research process appearing like enterprise and universities cooperation.

The fourth link in the process of innovation denoted by $\mathrm{K}$ (knowledge) as the first source innovation evidences the existing knowledge and in the second place the new emerging knowledge if the existing knowledge can not meet needs.

The fifth link, denoted by I (Innovation) reflects the possibilities open by the innovation for scientific progress. This means the utilization of innovations to make scientific research that will give new inventions.

\section{Chain-linked model}

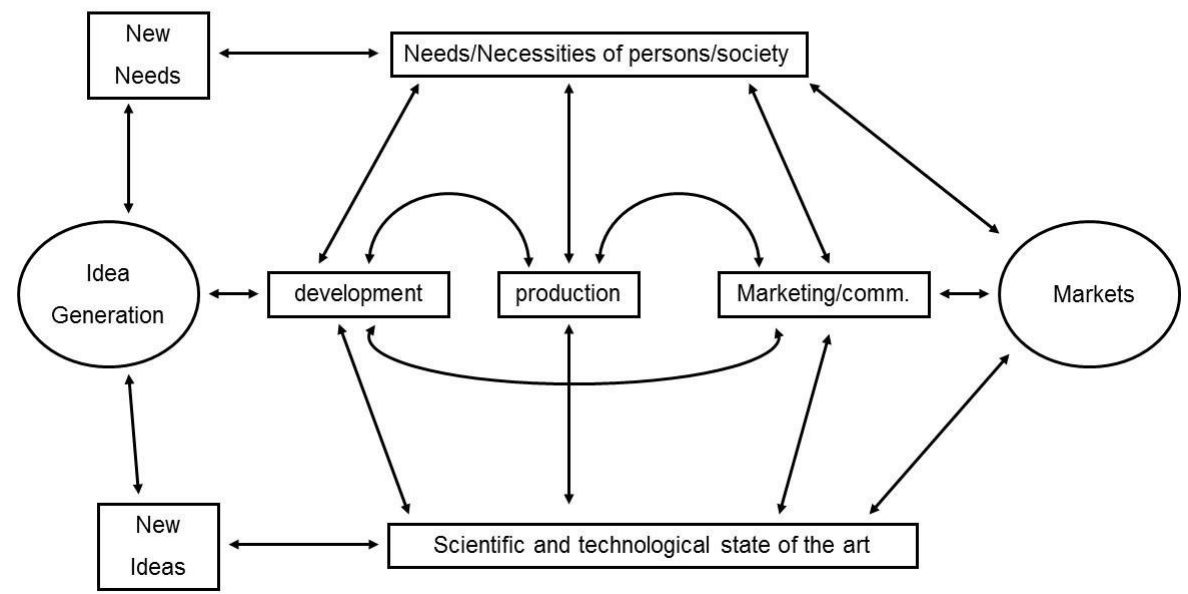

Figure 2. Model of innovation chain-

\subsection{The triple helix model}

The "triple helix" is a spiral model of innovation that captures multiple reciprocal relationships at different points in the process of knowledge capitalization. The first dimension of the triple helix model is internal transformation in each of the helices, such as the development of lateral ties among companies through strategic alliances or an assumption of an economic development mission by universities. The "triple helix" of university-agrculture-government relations is a neo-evolutionary model of innovation process is a model for analyzing innovation in the economy based on knowledge.

Definition given by Henry Etzkowitz (2002) [3] mentions that "triple helix is a spiral type innovation model which describes the mutual relations in many different points of the accumulation of knowledge process." This concept has been approached by some Romanian authors, such as Miron, D. (2008) [4] N. F.G.Filip and Vasiliu (2009) [5].VINNOVA Swedish Agency for Innovation adopted triple helix model in order to provide efficient solutions to the problems of generation, technology transfer and use of new knowledge. The triple helix denotes the university-agriculture-government relationship as one of relatively equal, yet interdependent, institutional spheres which overlap and take the role of the other. There has been a movement from separate institutional spheres, which represent, at least in ideology, the US situation. There has also been a shift from the model of the state encompassing agriculture and 
academia, in its strongest form in the former Soviet Union but versions could also be found in Latin American and European countries.

Bilateral relations between government and university, academia and agriculture and government and agriculture have expanded into triadic relationships among the spheres, especially at the regional level. Academic-agriculture-government relations are emerging from different institutional starting points in various parts of the world, but for the common purpose of stimulating knowledge-based economic development.

This is a different model of the relationship among the institutional spheres either than one in which the spheres are separate from each other and do not collaborate or one in which one sphere dominates the others. In figure 3, for example, depicts a model in which the state incorporates agriculture and the university.

The model of overlapping spheres is also different from the model of institutional spheres as separate from each other, which, at least in theory is how the US is supposed to work (figure 4).

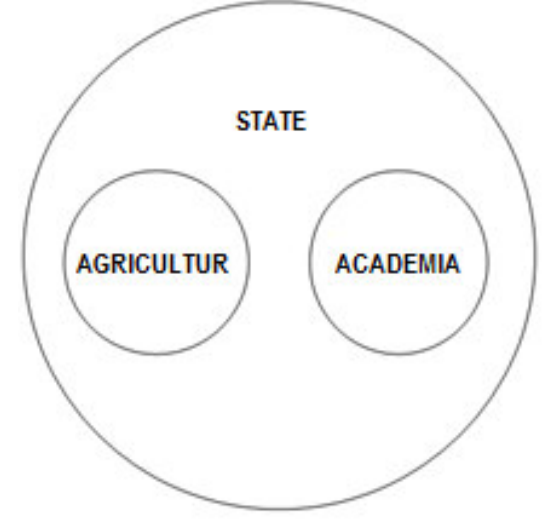

Figure 3.Relationship model

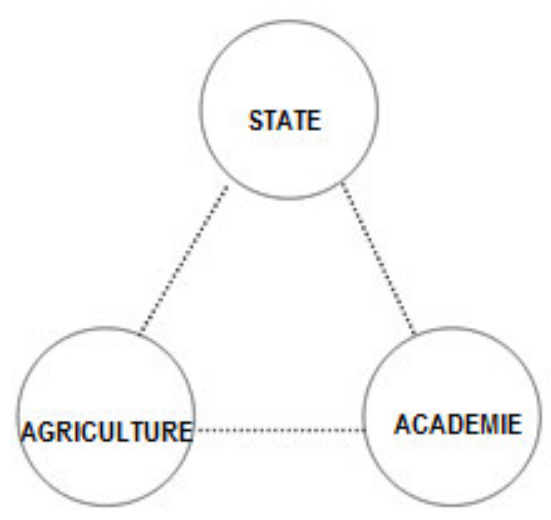

Figure 4.Relationship model.

From each of these previous models, whether it was the state dominating the other institutional spheres or the spheres separate from each other, we are moving to a model where the institutional spheres overlap and collaborate and cooperate with each other (figure 5).

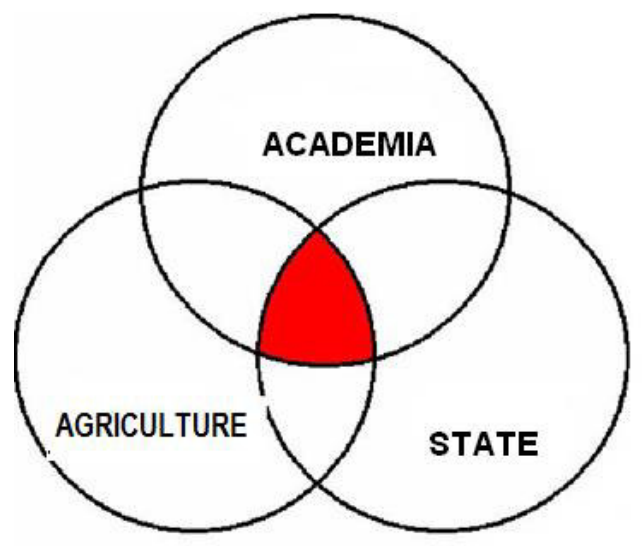

Figure 5.Relationship model

The model integrates the three "institutional spheres: research, agriculture and state. The first category is composed of researchers involved in the application of new concepts, designs and tools that they develop and universities which create educational programs focused on new vocational skills for future graduates. The second category consists of decisional factors in agriculture (entrepreneurs, investors, managers, executives). The third category consists of decisional factors in legislative and 
executive institutions of the state, which legally regulates the conditions for the functioning of agriculture, research centers and universities, public funds allocated to R \& D and education[5].

The triple helix model of innovation, with converging institutional spheres of academia, agriculture and government each taking the role of the other has been read in different ways in various parts of the world. In countries where the interface is well underway, whether occurring from the bottom up, through the interactions of individuals and organizations from different institutional spheres, or top down, encouraged by policy measures, the triple helix can be recognized as an empirical phenomenon.

There were three main forms of triple helix model. In the model "triple helix I", three spheres (university, agriculture and government) are institutionally defined. Interactions realized across the borders spheres are mediated by organizations as the agriculture liaison offices, centers of technology transfer and contract offices. In "Triple II helix ", the helix are defined as different communications systems, consisting by markets operation, technological innovation and control on the interfaces. The model "Helix Triple III" the institutional spheres (university, agriculture, government) assume each others roles, universities taking a quasi-governmental role as organizer of regional or local innovation. Triple helix model has been criticized as abstract [6].

\section{Conclusion}

In the actual situation, a solution to get out from the crisis is the state investment in researchdevelopment and stimulation of innovative work. The choosing of the appropriate model innovation can lead to the stimulation of creativity and development of innovative products and services in the economy.

A trilateral series of relationships among industries, governments and universities is emerging in regions at different stages of development and with different inherited socio-economic systems and cultural values. As regions seek to create a self-reinforcing dynamic of knowledge-based economic development, the three institutional spheres are each undergoing an internal transformation, even as new relationships are established across institutional boundaries, creating hybrid organizations such as technology centers and virtual incubators. The triple helix model and the implication of universities in innovative activity can be a solution for getting out of crisis.

In the actual situation, a solution to get out from the crisis is the state investment in researchdevelopment and stimulation of innovative work. The choosing of the appropriate model innovation can lead to the stimulation of creativity and development of innovative products and services in the economy. The triple helix model and the implication of universities in innovative activity can be a solution for getting out of crisis.

\section{References}

[1]. Schumpeter, JA 1934 The Theory of Economic Development, Cambridge, Mass.: Harvard University Press

[2]. Kline, S.J. and Rosenberg, N. 1986. "An Overview of Innovation. In: The Positive Sum Strategy: Harnessing Technology for Economic Growth. National Academy of Sciences. Washington, D.C.. http://www.nap.edu/catalog/612.html

[3]. Etzkowitz, H. 2002. The Triple Helix of University-Industry-Government Implications for Policy and Evaluation. Working Paper 2002-11, ISSN 1650-3821. http://www.sister.nu/pdf/wp_11.pdf.

[4]. Miron, D. 2008, Linking the Double Helix of Learning and to work the triple helix of universityindustry-government in the Europe of knowledge. Management \& Marketing, 3 (4), pp.3-20

[5]. Ghimisi S.,. 2015. The considerations on innovation models. Annals of Constantin Brancusi'University of Targu-Jiu. Engineering Series, (3).

[6]. Ghimisi, S., \& Nicula, D. 2019. Study to increase the quality of the scientific research process. In IOP Conference Series: Materials Science and Engineering (Vol. 564, No. 1, p. 012084). IOP Publishing. 


\title{
Professional exposure to noise in the automotive industry
}

\author{
Constanta Rinjea (Costache) ${ }^{1}$, Oana-Roxana Chivu ${ }^{1}$ Alin Ion Țăpîrdea ${ }^{2}$, \\ Anamaria Feier ${ }^{2}$, Loredana Dascălu ${ }^{1}$, Adrian Ciprian Firu ${ }^{2}$ and Claudiu Babiș ${ }^{1}$ \\ ${ }^{1}$ University Politehnica of Bucharest, Bucharest, Romania \\ ${ }^{2}$ Universitatea Politehnica Timișoara - IMF, România \\ E-mail: virlan_oana@gmail.com
}

\begin{abstract}
The automotive industry is one of the most developed industries in the world and is the engine of the economy of many states. This paper aims to present the values of the noise level to which a worker is exposed, in a factory in the automotive industry. The purpose of these measurements is to evaluate the impact of the noise produced by the activities that take place on the factory site and to verify the noise level if it falls within the limits in force at the moment. To perform the measurements, 6 areas of the factory were identified; 3 indoor areas: production area, office area and metrology laboratory area and 3 outdoor areas: smoking area, truck loading area and employee entry area.

Keywords: Noise, production, noise pollution, office, metrology laboratory.
\end{abstract}

\section{Introduction}

This industry is characterized by a high consumption of raw materials to produce cars, trucks, and buses. There are companies that have units with a complete manufacturing cycle, they are also the big car manufacturers, but there are other companies that only deal with the assembly and production of parts.[1]

Improving worker productivity, health and safety at work are major concerns of the industry.

According to [4], productivity was one of the most important factors affecting the overall performance of any organization, from small businesses to entire nations. Increased attention has been focused on the relationship between the work environment and productivity since the ' 90 .

Laboratory and field studies have shown that physical and chemical factors in the work environment could have a significant impact on human health and performance and, consequently, on productivity. Noise in the workplace has a significant relationship with worker satisfaction and performance. [5], [6], [7].

\section{The current state}

Noise pollution is a topical issue worldwide.

Following studies by the World Health Organization (WHO), it has been found that half of Europeans live their lives in a continuous noise, and more than a trinity suffer from insomnia as a result of noise pollution. Noise is a harmful factor, met frequently in several industrial activities.

Noise is a loud sound that is measured in decibels $(\mathrm{dB})$. The $\mathrm{dB}$ is used as a unit of measurement to describe the intensity of sound, and $\mathrm{dB}(\mathrm{A})$ is based on the intensity of sound and how the human ear reacts. It also has negative effects on work performance in terms of cognitive skills, memory, motor skills and perception (Sanders and McCormick, 1993). Noise affects people's nervous system and hearing, weakens employees' concentration, reduces attention and reaction skills. There is a possibility of discomfort such as fatigue, sleep disorders and headaches. The most important effect of noise is 
hearing loss. The duration of exposure to noise determines the severity of the disease, in addition to frequency, intermittent or persistent disease, age and vulnerability.[8]

\section{Monitoring the noise level in a factory from the automotive industry}

Measurements were made to determine the noise level in 6 areas located inside and outside the factory. The equipment used to perform the measurements is the iNCH Smartphone application. This is a unique application, developed by engineer Robert Bosch and is a basic tool to support noise assessments. The instrument comes with a sound level measurement module easy to use, general level mode as a function of time and data mode as a function of time. The application basically uses microphones and accelerometers built into a Smartphone.

Contain the latest calibration values for most mobile phone ranges (because every mobile phone is different in its own way). There is also a sound calibration tool included to improve the accuracy of noise measurement.[2]

The specific input of the noise analyser is sound, vibrational energy of a certain frequency and intensity.

For the human ear, the frequency of sounds heard is between 20 and 20,000 $\mathrm{Hz}$ (Hertz).

At the same time, in order to be heard, the sound must have a minimum level of intensity (minimum threshold) and not exceed a maximum intensity, over which the sound becomes harmful, and the auditory sensation is altered becoming painful (painful threshold for the ear). Noise has a complex action on the human body.

To determine the noise level in the factory, the sound measurements were performed inside the factory in 6 areas, 3 outside and 3 inside.

Table 1. Paragraph from standard SR 10009:2017[9]

\begin{tabular}{|l|c|}
\hline Street type / Space considered & $\begin{array}{c}\text { Noise level } \\
{[\mathrm{dB}]}\end{array}$ \\
\hline $\begin{array}{l}\text { Stadiums, cinemas, and open-air theaters, cultural, sports and outdoor entertainment } \\
\text { events }\end{array}$ & 90 \\
\hline Car parking & 70 \\
\hline Recreation and rest areas, medical and balneo-climatic treatment & 45 \\
\hline Markets, commercial spaces, outdoor restaurant & 65 \\
\hline Industrial units and spaces with activities assimilated to industrial activities & $\mathbf{6 5}$ \\
\hline Street of technical category IV, of local service & 60 \\
\hline Street of technical category III, collection & 65 \\
\hline Technical category II street, connecting & 70 \\
\hline
\end{tabular}

Identified noise sources:

- supply activities carried out behind the factory;

- production area noise (Figure 1).

The total noise of a supply cycle provides from 3 factors:

- noise produced by the road train engine;

- truck loading noise (Figure 5);

- noise from waste collection;

- background noise.

The background noise is represented by the road traffic from a nearby boulevard, present for the entire duration of the determinations and the noise coming from the neighbouring industrial units.

In Figures 1, 2, 3, mentioned above, it can be see the determination of the noise level in the production area, office and metrology laboratory; areas inside the factory where the values that was measure, are within the limits in force.

Tables 2, 3, 4 illustrate the average, the minimum and the maximum values from which it results that they fall within the limits. 
Also, figures 4, 5, 6 represent the areas outside the factory, the smoking area, the truck loading area and the employee entry area.

Both the values determined in the 3 figures and in tables 5,6,7 show that they have a maximum allowed value at the property limit of $65 \mathrm{~dB}$ (A) according to SR-10009-2017 and table 1.

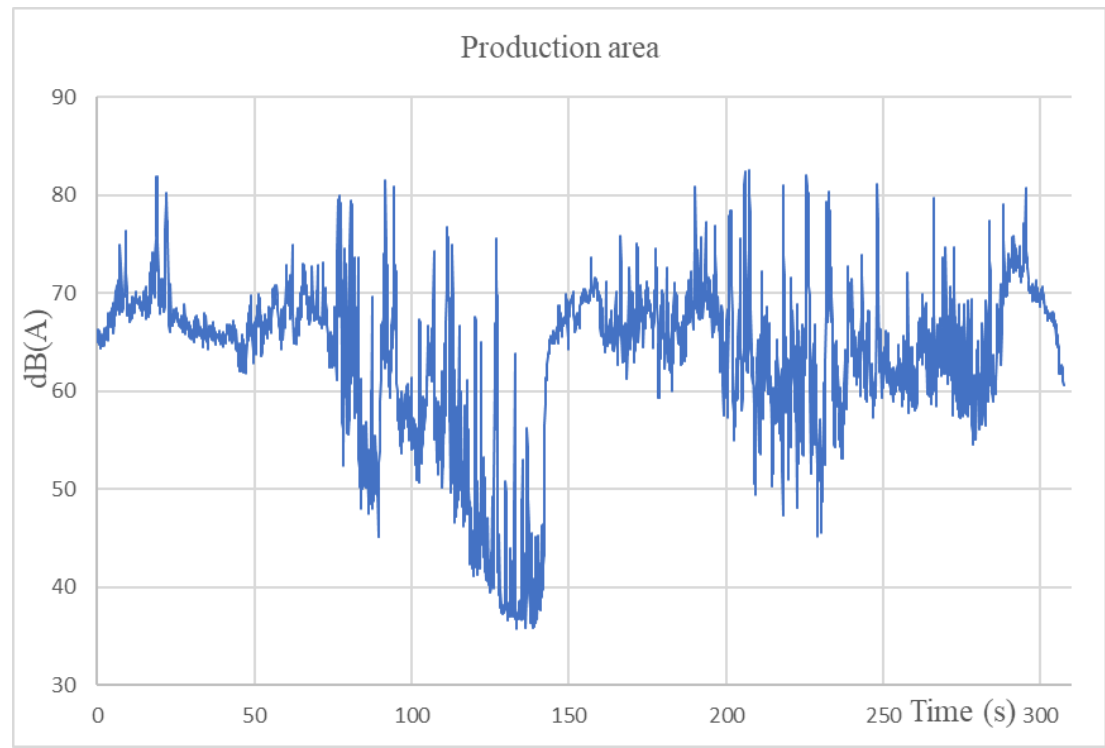

Figure 1. Determination of production noise

Table 2. Noise level in the production area

\begin{tabular}{|l|l|}
\hline Average value & $63,39 \mathrm{~dB}(\mathrm{~A})$ \\
\hline Minimum value & $35,80 \mathrm{~dB}(\mathrm{~A})$ \\
\hline Maximum value & $82,52 \mathrm{~dB}(\mathrm{~A})$ \\
\hline
\end{tabular}

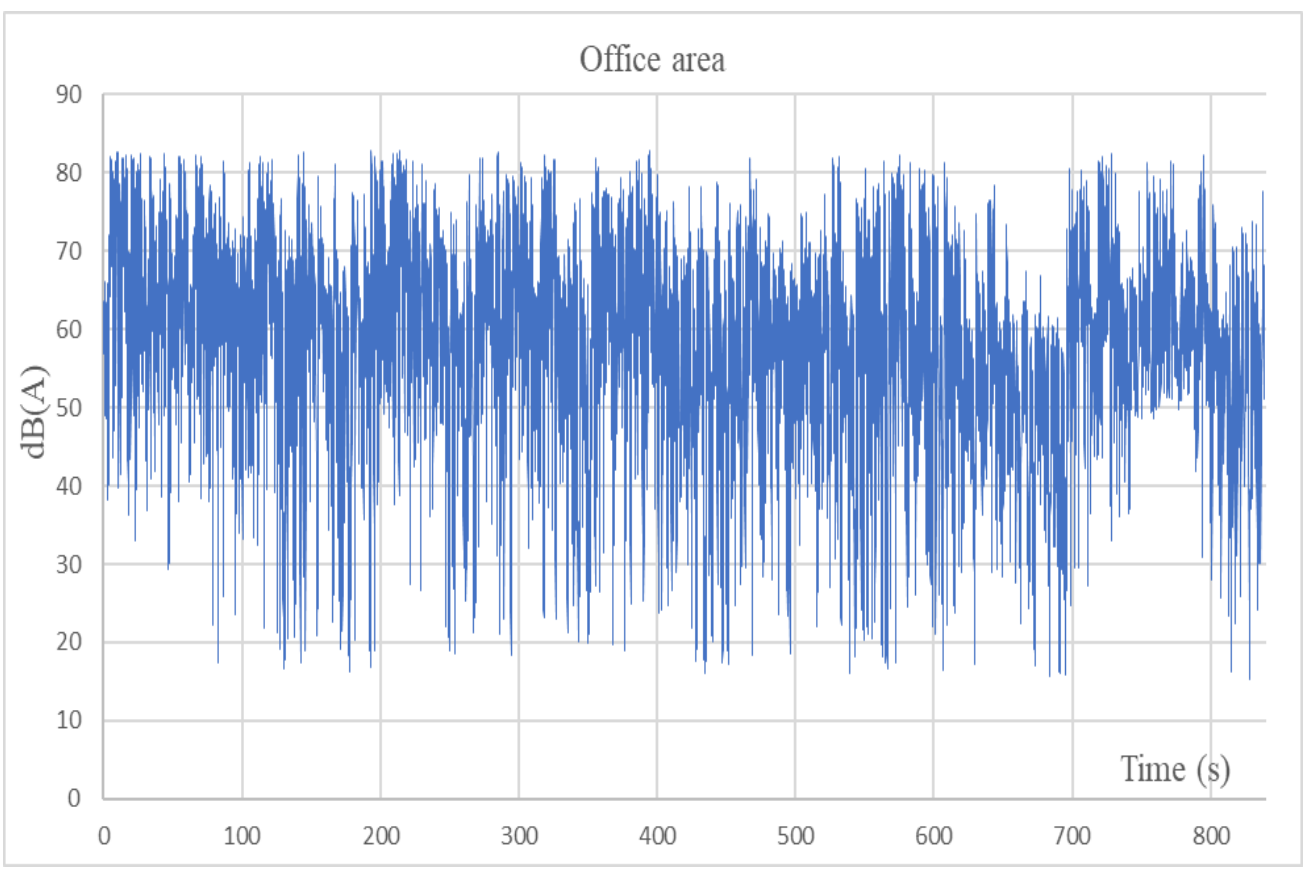

Figure 2. Determination office noise 
Table 3. Noise level in the office area

\begin{tabular}{|l|l|}
\hline Average value & $58,08 \mathrm{~dB}(\mathrm{~A})$ \\
\hline Minimum value & $15,26 \mathrm{~dB}(\mathrm{~A})$ \\
\hline Maximum value & $82,90 \mathrm{~dB}(\mathrm{~A})$ \\
\hline
\end{tabular}

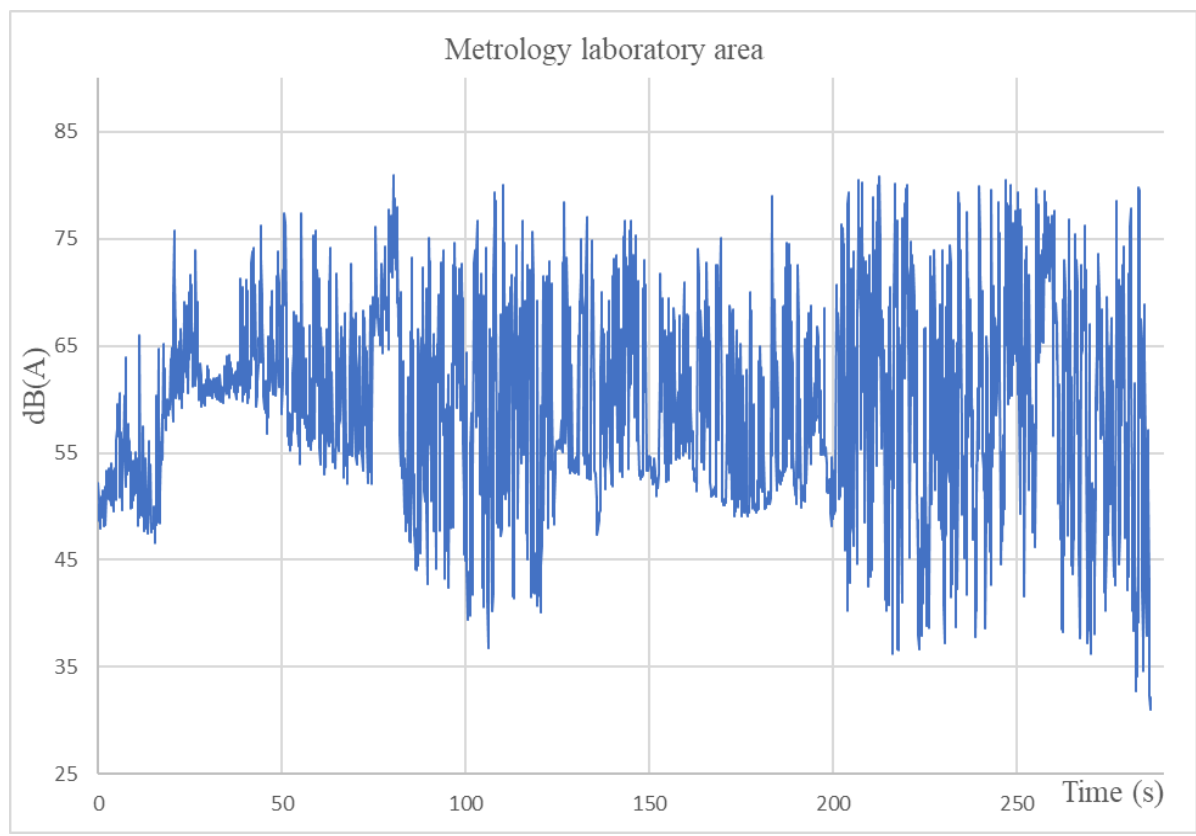

Figure 3. Noise in the metrology laboratory

Table 4. Noise level in the metrology laboratory

\begin{tabular}{|l|l|}
\hline Average value & $59,44 \mathrm{~dB}(\mathrm{~A})$ \\
\hline Minimum value & $31,00 \mathrm{~dB}(\mathrm{~A})$ \\
\hline Maximum value & $80,93 \mathrm{~dB}(\mathrm{~A})$ \\
\hline
\end{tabular}

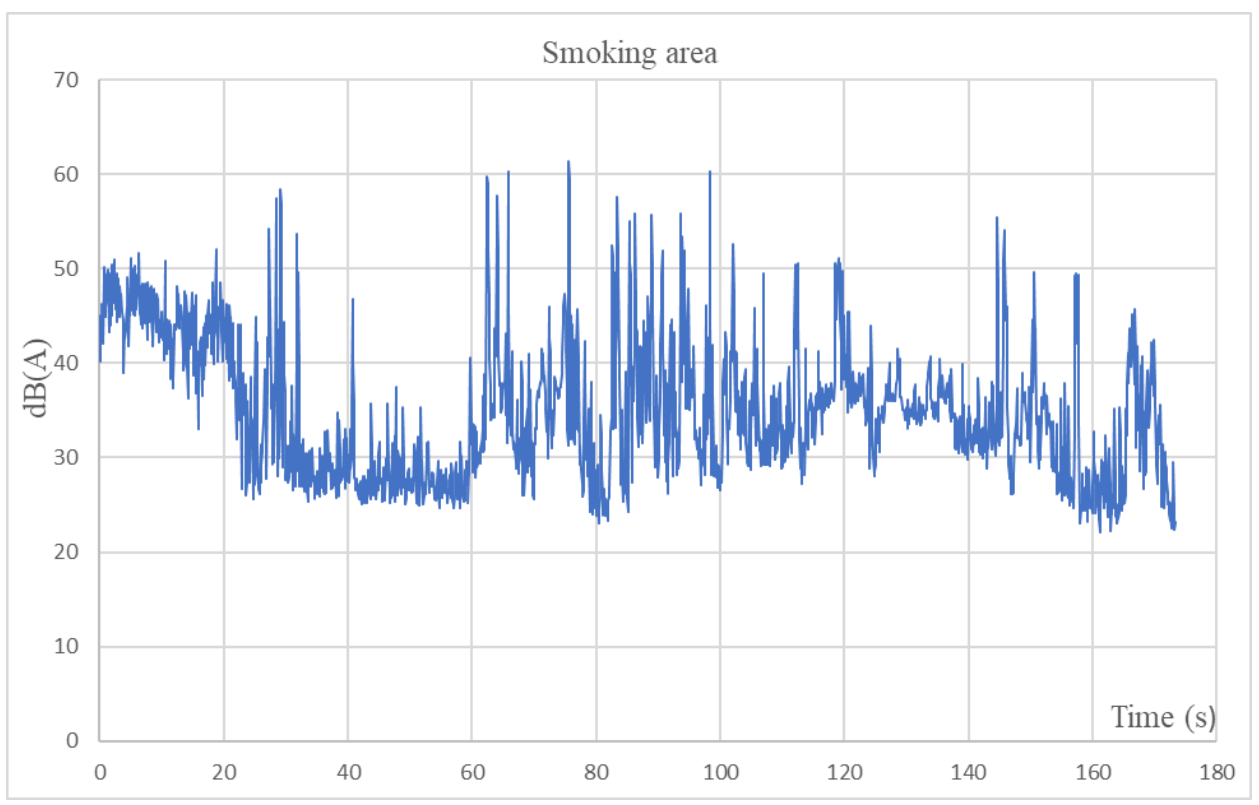

Figure 4. Noise level in the smoking area 
Table 5. Noise level in the smoking area

\begin{tabular}{|c|c|}
\hline Average value & $34,90 \mathrm{~dB}(\mathrm{~A})$ \\
\hline Minimum value & $22,11 \mathrm{~dB}(\mathrm{~A})$ \\
\hline Maximum value & $61,35 \mathrm{~dB}(\mathrm{~A})$ \\
\hline
\end{tabular}

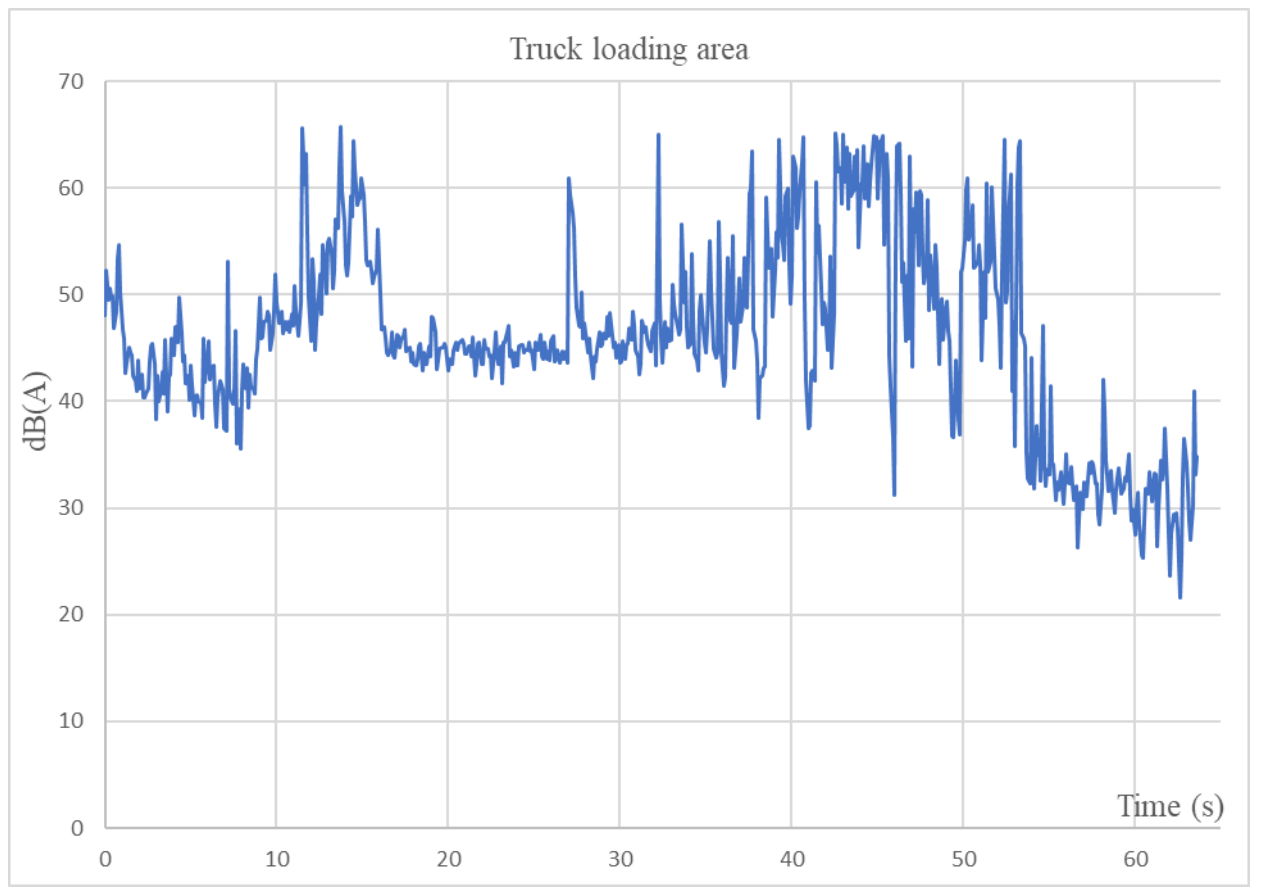

Figure 5. Determination of noise in the loading area of trucks

Table 6. Noise level in the truck loading area

\begin{tabular}{|l|l|}
\hline Average value & $46,04 \mathrm{~dB}(\mathrm{~A})$ \\
\hline Minimum value & $21,54 \mathrm{~dB}(\mathrm{~A})$ \\
\hline Maximum value & $65,78 \mathrm{~dB}(\mathrm{~A})$ \\
\hline
\end{tabular}

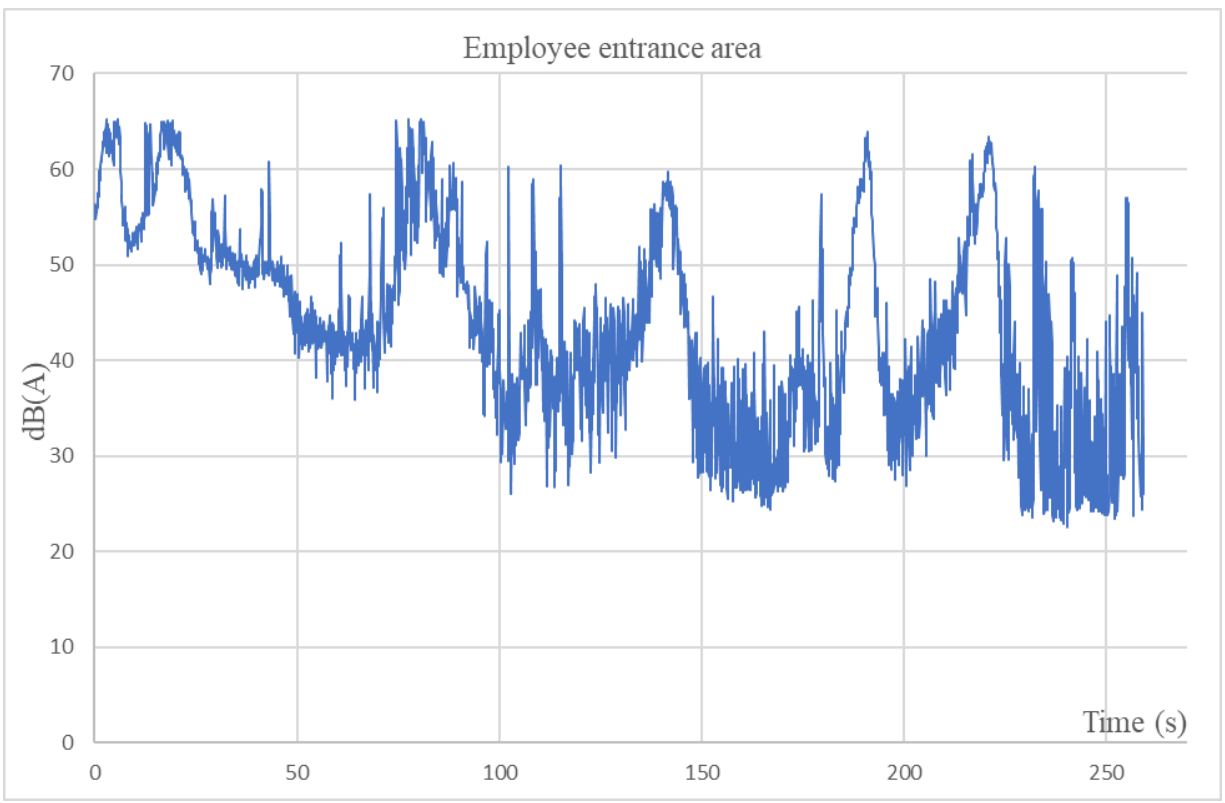

Figure 6. Determination the noise in the employee entrance area 
Table 7. Noise level in the truck loading area

\begin{tabular}{|l|c|}
\hline Average value & $43,84 \mathrm{~dB}(\mathrm{~A})$ \\
\hline Minimum value & $22,64 \mathrm{~dB}(\mathrm{~A})$ \\
\hline Maximum value & $65,23 \mathrm{~dB}(\mathrm{~A})$ \\
\hline
\end{tabular}

\section{Conclusion}

In conclusion, it can be specified that, at the factory limit, outside and inside, the noise level generated by the operation of various machinery / equipment, is manifested inside to the factory, not exceeding the limitations in force.

The measurements were performed with the noise sources on, in normal activity.

The source of noise is the supply activity that takes place using trucks. Another source of noise is represented by the production process.

The background noise is represented by the other activities in the area (cleaning, maintenance, etc.).

The measurement was performed by recording on certain time intervals and marking the events and the type of noise (source or background).

The traffic and the own activities in the area generate the increase of the noise level.

According to SR-10009-2017, industrial activities have a maximum allowed value at the property limit of $65 \mathrm{~dB}(\mathrm{~A})$.

Also, the noise level, generated by the activities inside the factory, are keep below the limits in force below $87 \mathrm{~dB}$.

Comparing the results of the measurements with the limitations presented in Table 1, it is observed that there are values that are found in all 3 areas located at the boundary of the unit, below $65 \mathrm{~dB}(\mathrm{~A})$, which is the limit for industrial premises in urban areas.

Near the noise sources, the noise level is higher and decreases with increasing distance from the noise source.

\section{References}

[1]. https://en.wikipedia.org/wiki/Automotive_industry

[2] .https://appcenter.bosch.com/applications/3c970d10-b16f-4802-ad1d-869f25df6a60

[3]. Ismail, A. R., Rani, M. R. A., Makhbul Z. K. M. and Deros, B. M., The Effect of Humidity on the Worker Productivity: A Study at Malaysia Electronics Industry

[4]. Fisk W.J. and Rosenfeld A.H. 1997 Estimates of improved productivity and health from better indoor environments. Indoor Air 7: 158-172.

[5]. Fisk, W. J. 2000 Health and Productivity Gains From Better Indoor Environments and Their Relationship with Building Energy Efficiency. Annual Review of Energy \& The Environment. 25(2): 537-566.

[6]. Marshall, L., Erica, W., Alan, A. and Sanborn, M. D. 2002 Identifying and Managing Adverse Enviromental Health Effects: 1. Taking an Exposure History Canadian Medical Association Journal. 166(8): 1049-1055.

[7]. Tarcan, E. Varol, E.S. and Ates, M. 2004 A Qualitative Study of Facilities and Their Enviromental Performance Management of Environmental Quality: An International Journal. 15(2): 154173.

[8]. Berna Haktanirlar Ulutas, Firat, N. Ozkan Osmangazi Analysis of environmental conditions in metal industry Emin Kahya*, University, Faculty of Engineering and Architecture, Dept. of Industrial Engineering, Eskisehir, Turkey

[9]. SR 10009,2017, Acoustics; Permissible noise level limits from the environment 


\title{
Engineering geological and geotechnical site characterization for economic design of structures and earthwork
}

\author{
O O Falowo ${ }^{1}$, and W K Olabisi ${ }^{2}$ \\ ${ }^{1}$ Civil Engineering Department, Rufus Giwa Polytechnic, Owo, Ondo State, Nigeria \\ ${ }^{2}$ Civil Engineering Department, Rufus Giwa Polytechnic, Owo, Ondo State, Nigeria \\ E-mail: oluwanifemi.adeboye@yahoo.com
}

\begin{abstract}
The objectives of the study is to assess the engineering competence of the subsoil and develop subsoil competence map for northern parts of Ondo State, Nigeria, using integrated remote sensing, geotechnical studies, geophysical and geological investigations, static water level measurement, and borehole logging. The generated subsoil competence map was obtained by integrating the results data of these parameters measured. Consequently, the map classified the study area into moderate competence $(60 \%)$, high competence $(35 \%)$, and very high competence $(5 \%)$. The corrosivity map of the topsoil shows predominant moderate to mildly corrosivity, prominently in Ose and Akoko areas, and constitute about $70 \%$. On the basis of design, the obtained settlement values were within the $25 \mathrm{~mm}$ commonly recommended. Subsequently, areas characterized by moderate competence material can be improved by less expensive mechanical compaction and proper use of admixtures (lime, cement, bituminous addition, sand/gravel grading) to increase bearing capacity, compaction and shear strength, which will invariably reduce compressibility, settlement and permeability. Subsequently, shallow foundation such as pad or raft foundation of reinforced concrete can be adopted in the study area
\end{abstract}

\begin{abstract}
Introduction
Site characterization usually provides subsurface information that assists civil engineers in the design of foundation of civil engineering structures. The primary purpose of all site investigations is to obtain the data needed for analysis and design [1]. Engineering structures are designed and constructed with long life expectancy [2] but most problems of structural failure are often associated with improper founding of foundations, poor quality of building materials, and inadequate knowledge of the physical parameters governing the competency of the soil supporting engineering structures [3]. Physical properties governing the stability of structures include but not limited to these: unit weights, porosity, consolidation, specific gravity, consistency limits of the soil in association in water, bearing capacity, shear strength, compaction characteristics, etc. Also these properties depend on the nature of soil or rock in terms of mineralogical contents, texture, and geologic structures. Therefore for engineering site investigation to be effective, it must employs an integrated method. Since engineering site investigation should be multidisciplinary in approach, if it is to be effective. It should involve geomorphological, geological, groundwater studies, remote sensing, geophysical investigation, geotechnical investigation/analysis, and borehole logging (to control the geophysical interpretation). Therefore many aforementioned workers failed in one or the other to use integrated approach, especially where geophysical methods were used. Many failed to constrain the interpretation of their geophysical results with borehole logging. Also, many couldn't map the water table and flow direction.
\end{abstract}


All these information gap in the previous works were considered in this study by integrating all these methods to evaluate and characterized the northern part of Ondo State into different into different engineering subsoil competence zones, for construction purposes and building development. The findings of the study would aid the structural engineer and builders in the design of appropriate structures and earthwork that command professional feat.

\subsection{Description of the Study Area}

The study area is located within the northern part of Ondo State, Nigeria (Figure 1). The selected areas include Owo, Akoko, and Ose. These areas are located within longitudes $5^{\circ} 20^{\prime} \mathrm{E}$ and $6^{\circ} 10^{\prime} \mathrm{E}$ and latitudes $6^{\circ} 30^{\prime} \mathrm{N}$ and $7^{\circ} 40^{\prime} \mathrm{N}$. The area is accessible through the Benin - Ifon highway, Abuja - Lokoja Highway and Ado-Akure Highway. The study area has a topographical elevation varying from $40-$ $750 \mathrm{~m}$ above the sea level. The northern part of the study area is a rugged terrain (i.e. hilly) especially in Akoko area [4], (Figure 2). The lowlands are widespread at Ute and Okeluse axes of the area with gentle slope, while the gradient of the northern areas are generally steep. Another aspect of the relief of the area is the prevalence of many erosion gullies along hill slopes (Figure 3). The gullies are very common and rather devastating in Owo, Ifon, Ikare, Oke Agbe and Isua.

The mean annual temperature is between $21^{\circ} \mathrm{C}$ and $33^{\circ} \mathrm{C}$ (Figure $4 \mathrm{a}$ and b) with mean temperature of $24^{\circ} \mathrm{C}$ and mean humidity of $80 \%$. The mean temperature is highest at the end of the Harmattan (averaging $28^{\circ} \mathrm{C}$ ), that is from the middle of January to the onset of the rains at the middle of March. The area is situated within the tropical rain forest region, with a climate characterized by dry and wet seasons. According to Federal Meteorological Survey [5] the annual rainfall ranges between 1000 and $1800 \mathrm{~mm}$, with a mean annual rainfall of $1500 \mathrm{~mm}$ (Figure 4c). The vegetation is the rainforest type and is composed of teak, Melina/pulp wood (Figure 1), tall crowned trees mixed with thick undergrowth and of woody savannah. The vegetation is of distinct arrangement with tall trees of about $60 \mathrm{~m}$ in height, with smaller herbaceous plants found below them.

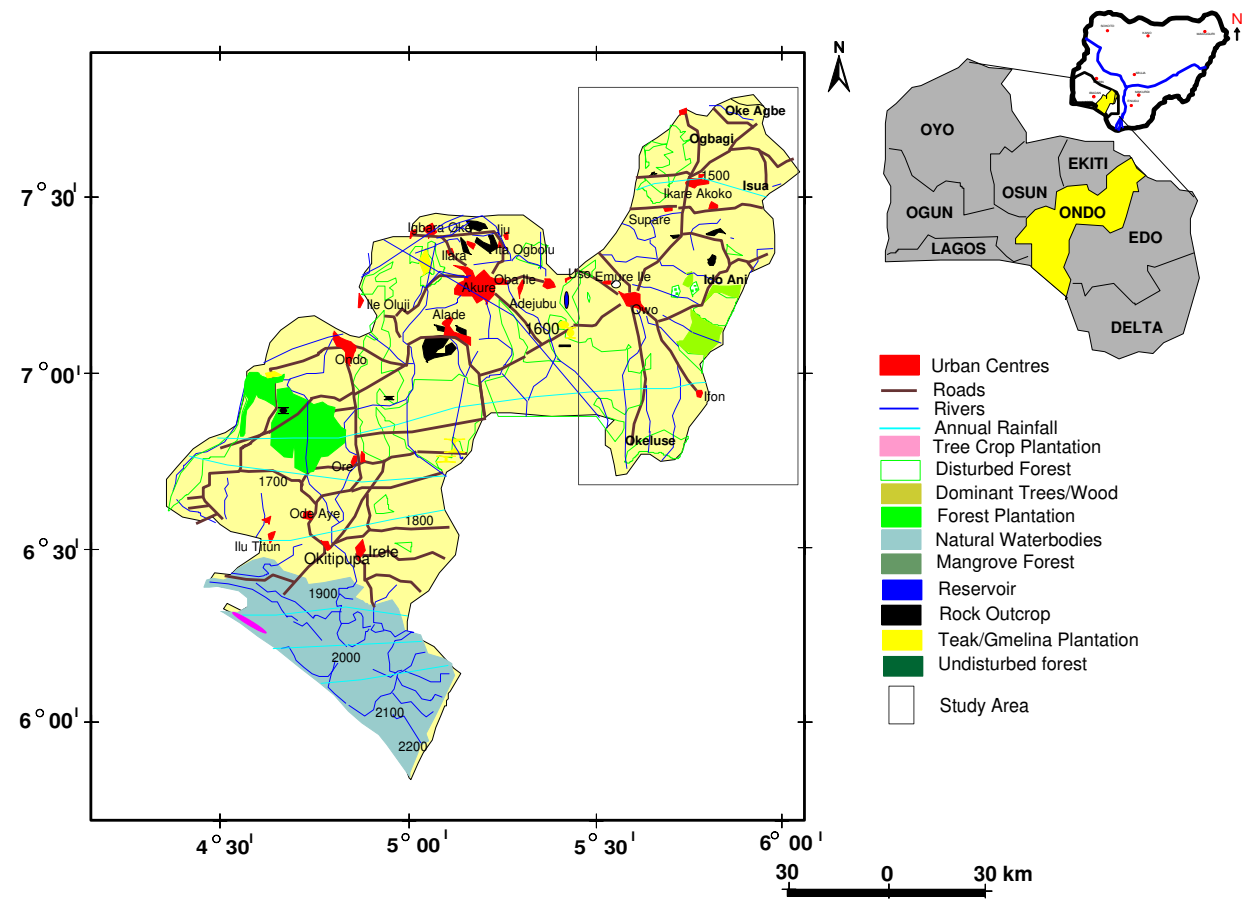

Figure 1. Land Use Map of the Study Area showing predominant Teak/Gmelina Plantation and Disturbed Forest. Inset: Location of Ondo State on Nigeria Map [9] 


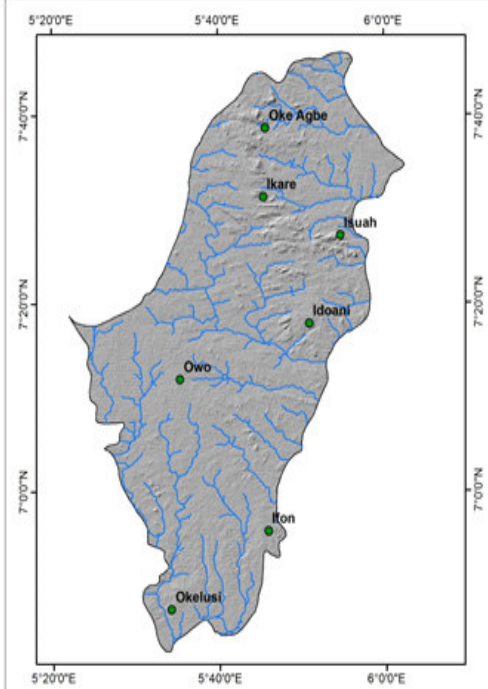

(a)
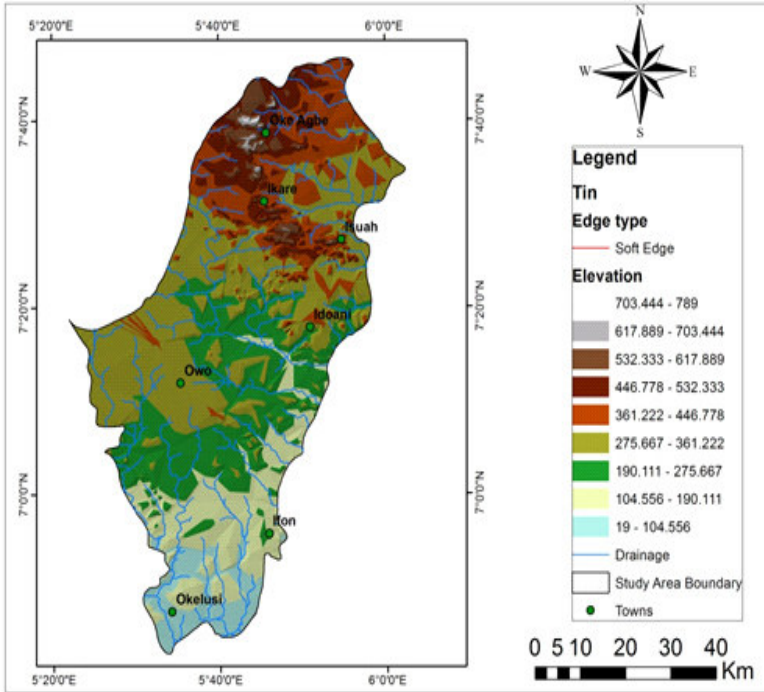

(b)

Figure 2. Topographical Elevation of the study area (a) Hill Shaded obtained from ASTER DEM data

(b) Triangular irregular Network

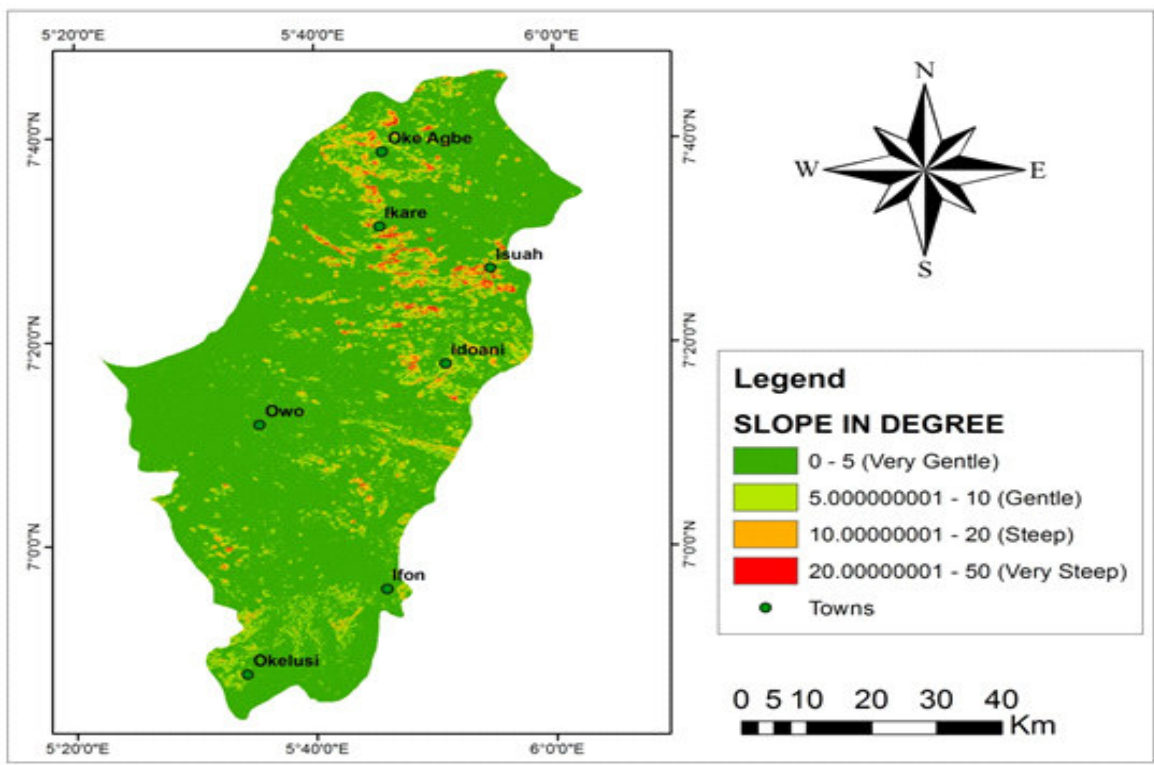

Figure 3. Slope Map of the Study area with northern areas showing very steep gradient, while Owo and Ose are predominantly gentle slope

1.2. Geology and Hydrogeology

The Precambrian Basement rocks of Nigeria include the Migmatized gneissic complex (MGC) of Achaean to early Proterozoic age [6], N-S trending Schist Belts of Upper Proterozoic age [7] and the Older Granitoid of Pan African age. The geology of study area falls within the southwestern basement complex (Figure 5a) and consists of migmatite, granite gneiss, fine grained quartzite, pegmatite and quartzo-feldspathic veins, schist, and quartz schist. These rock types dominate Owo and Akoko areas, notably along Owo - Oba Akoko, Iwaro - Akungba, Akungba - Supare, Ikare, Epinmi, Sosan, Oke Agbe, and Ido Ani. 


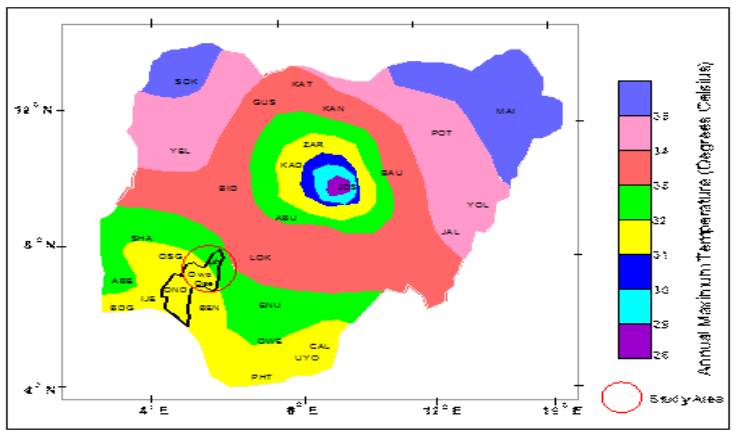

(a)

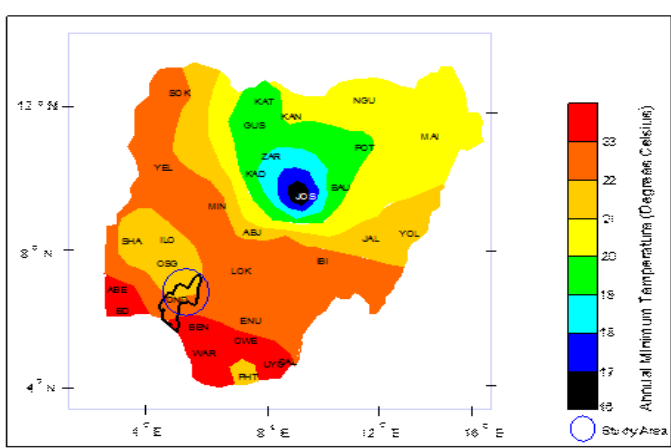

(b)

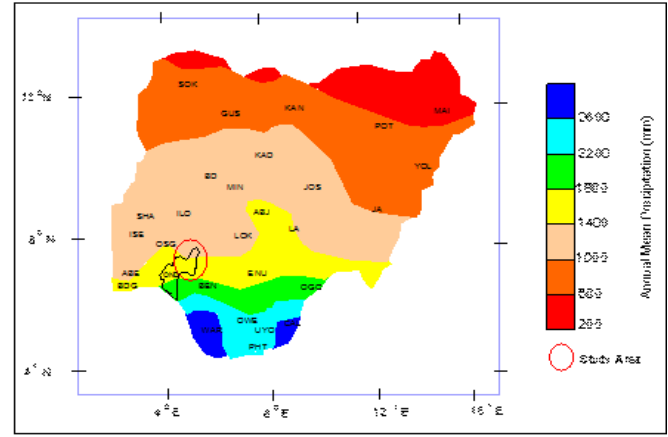

(c)

Figure 4. (a) Annual minimum temperature across Nigeria showing a range of $20-23{ }^{\circ} \mathrm{C}$ in the study area (b) Annual maximum temperature ranging from $31-33{ }^{\circ} \mathrm{C}$ (c) Annual mean precipitation across Nigeria with a range of $1000-1800 \mathrm{~mm}$ in the study area

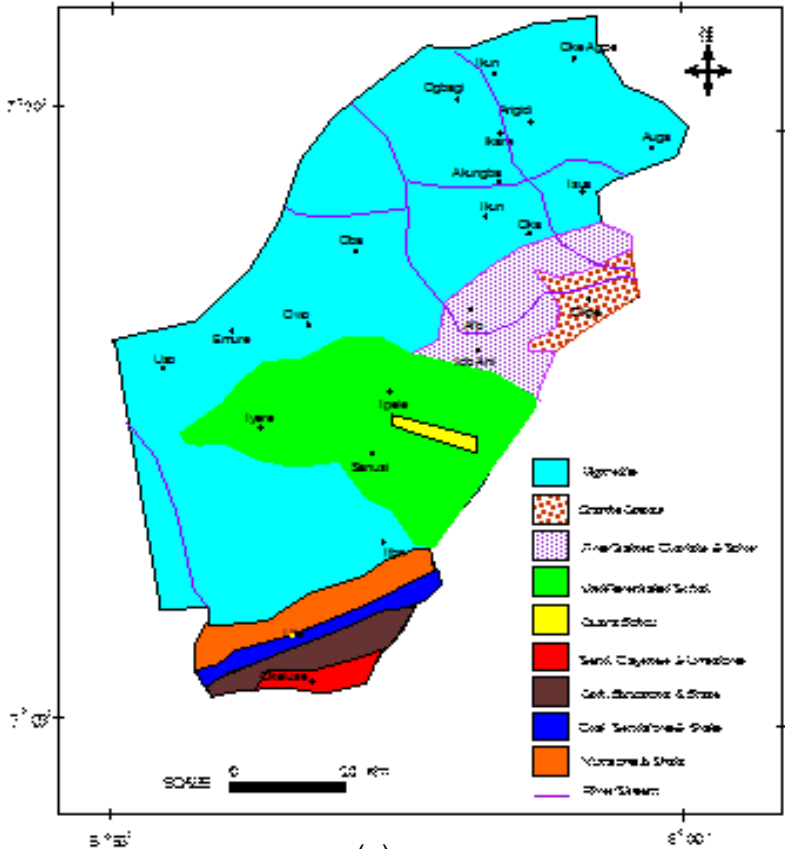

(a)

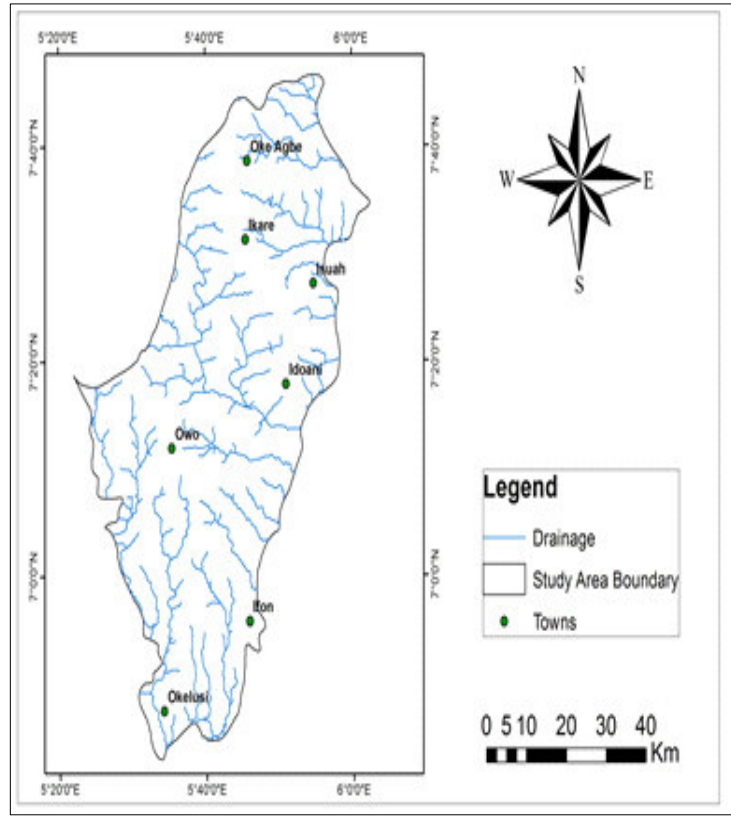

(b)

Figure 5. Local Geology Map of the Study Area with the Basement rocks occupying 90\% of the area, while the sedimentary rocks/deposits occupy a little portion of the southern area [10] (b) Drainage Map of the Study area showing a predominantly Dendritic Drainage Patterns 
The migmatite complex which is the most widespread basement rock in the area is mainly medium grained gneiss. They are strongly foliated rocks frequently occurring as outcrops. On the surface of these outcrops, severely contorted, alternating bands of dark and light coloured minerals can be seen. These bands of light coloured minerals are essentially feldspar and quartz, while the dark coloured bands contain abundant biotite. A small proportion of the area especially to the northeast, overlies the coarse grained granites and gneisses, which are poor in ferromagnesian minerals. These rocks are covered by regoliths with thickness variation across the town.

The sedimentary rocks/deposit is mainly of the post Cretaceous sediments and the Cretaceous Abeokuta Formation. The major surface waters in the study area are rivers Ogbese, and Ose (Figure $5 b$ ). Others are the small tributaries joining the major rivers (Figure 5b). The volume of water in the streams depends on the seasons. During the raining season, there is a great increase in water flow volume in the major rivers while there is hardly water in some of the streams during the dry season. Therefore rainfall is the dominant factor that determines the occurrence of groundwater.

\subsection{Soil}

The soils derived from the Basement complex rocks are mostly well drained, with a medium texture [8]. The major soil associations in the study area are Iwo, Ondo, and Okemesi (Figure 6). The soil, classified as Iwo Association, is the most prominent soil type. All the soil associations are well drained.

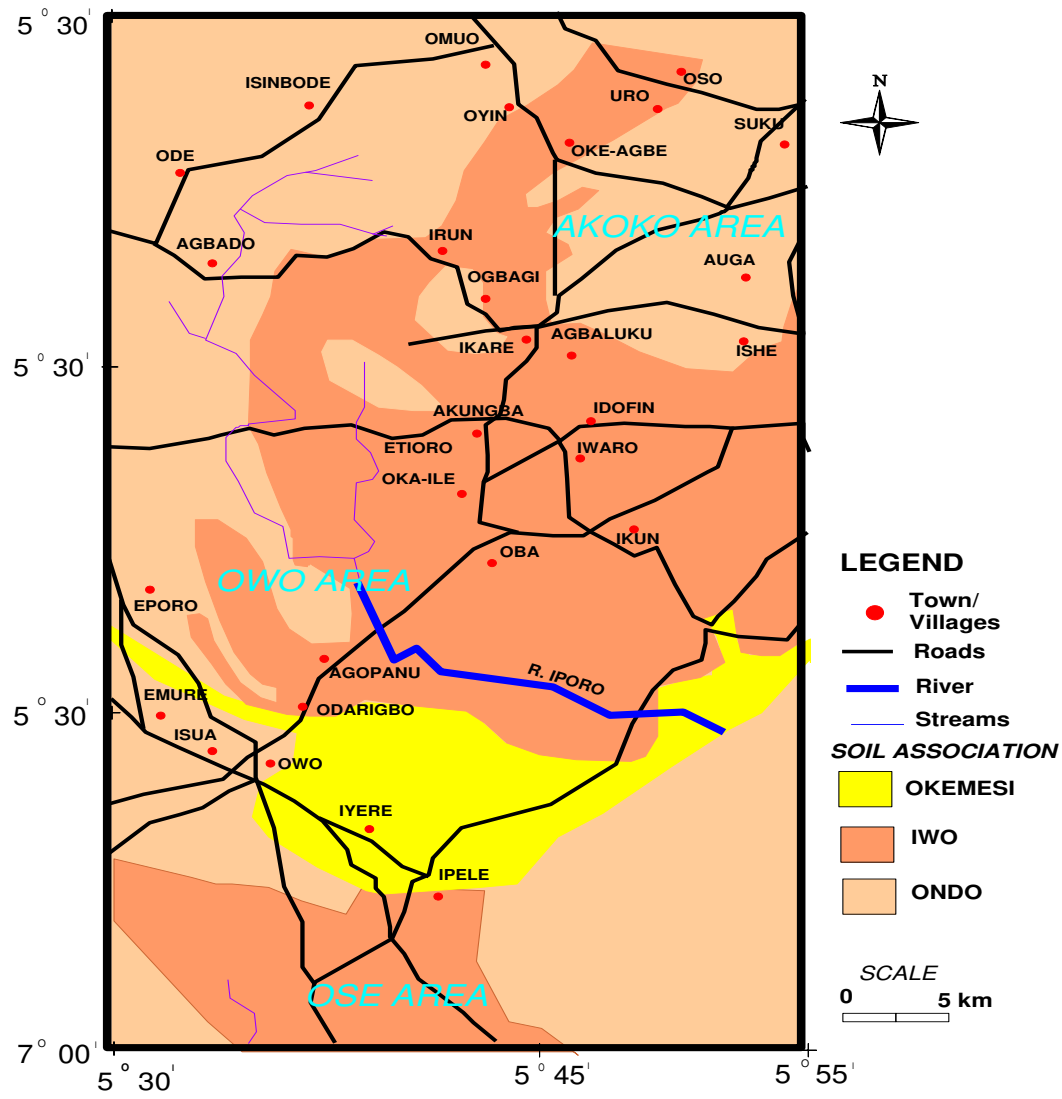

Figure 6. Soil Map of the Study Area (Extracted from [8]) 


\section{Material and Methods}

The investigation involved exploration and sampling of soil likely to be significantly affected by structural loads. The research work entailed:

\subsection{Literature Review}

The research work involved literature review of texts, technical journals, various articles, past projects thesis etc., as related to the uses of geotechnical, remote sensing, and geophysics as tools in engineering site investigation and groundwater studies. Existing Landsat-7 $\mathrm{ETM}^{+}$satellite imageries were used for the production of lineament map of the study area.

\subsection{Reconnaissance Studies and Desk Study}

The purpose of the site reconnaissance is to confirm and obtain additional information from the site. This includes taking notes of the geologic and topographic setting of the area, taking of photography of the site. Personal interview were made with residents of the area with the relevant information which will assist in carrying out the research successfully. Also sample points locations for geotechnical investigation were marked and pegged respectively. The desk study included reviewing/updating and reconciling the information obtained during the reconnaissance study and those obtained during review of journals and various articles. Subsequently the following information was reviewed:

i. Geological Maps/Report: The geological map/report together with an understanding mode of origin of the rocks and the associated depositional process enabled a preliminary assessment of ground condition.

ii. Topographical Map: The topographical map was used to examine the terrain, access and site condition. The topographic map was confirmed through site reconnaissance.

iii. Site Histories and Details of Adjacent Development: Also important information such as land use before the current development and underground services (like buried pipes and utilities) were acquired before the planning and conduct of the field test.

\subsection{Geophysical Investigation}

The geophysical investigation involving electrical resistivity (Vertical Electrical Sounding (VES) and Dipole-Dipole profiling); Very Low Frequency Electromagnetic (VLF-EM) were carried out along thirty six traverses (Figure 7). The geographic co-ordinates of data stations were taken using GARMIN'S GPS 12 - Channel model. One hundred and three (103) sounding stations were occupied with current electrode spacing varied from 1 to $225 \mathrm{~m}$.

\subsection{Geotechnical Investigation}

Twenty four soil samples were taken according to the geology/rock units in the area (at a depth less than $3 \mathrm{~m}$ ) from borough pits (Figure 7). These samples were subjected to grain size analysis, specific gravity determination; natural moisture content test, consistency limit test, compaction test, cone penetrometer test, undrained triaxial test, shear strength and bearing capacity were determined.

\subsection{Hydro-geological Measurement}

This includes determination of hydraulic head of wells/borehole and measurement of static water levels from three hundred and two (302) water wells using water level meter recorder (Figure 7).

\subsection{Data Analysis and Interpretation}

The geophysical data were interpreted qualitatively and quantitatively, as related to the objectives of the study. Profiles, maps, geoelectric section, graphs, chart were produced from the interpretation of both geophysical, geotechnical, and hydrogeological data. 


\section{Results and Discussion}

\subsection{Lineament Analysis}

Some of the lineaments mapped are joints and faults. Other linear features are suspected to be fracture and fissure zones. As shown by the lineament map (Figure 8) four major structural trends that are typical of the Nigerian basement complex are all represented in this area. These include the NE - SW, NW - SE, N- S and E - W trends (Figure 8). The predominant structural trend is NE - SW. The lineament map shows a wide spatial variation as the lineaments are generally sparse in the southern areas (Ifon - Okeluse), and high in Akoko area, especially around Oba, Isua, Ogbagi, Ikun and Irun. The denser lineaments area typified the intensity of rock fracturing, which is a prerequisite for development of hollow passages over an area. According to [11] the zones of relatively high lineament density are identified as zones of high degree of rock fracturing, which are prerequisite for groundwater conduit development which might be inimical to foundation structures especially when they occur at shallow depth. The lineament intersection provides interpretation of hidden subsurface tectonic configuration in the form of linear feature intersection / cross cutting geological structures, which are indicators of deep seated fracture / fault medium. Figure 8a shows that the areas underlain by high density are characterized by relatively high lineament intersection. The zones of high lineament intersection over the study must be seriously taken into consideration during the design process of structures and utilities in study area, especially areas where the rock outcrops.

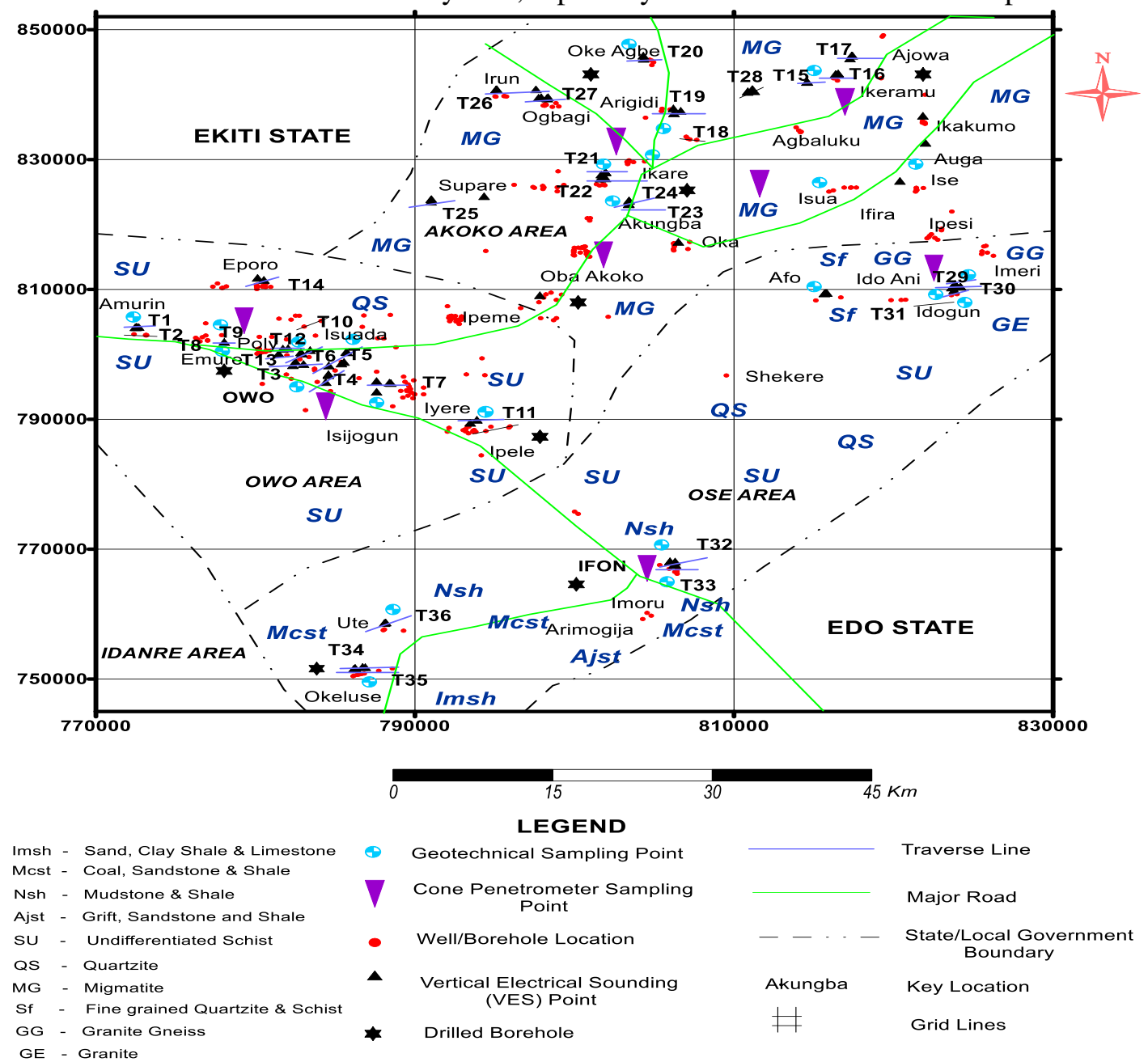

Figure 7. Data Acquisition Map of Study Area showing the Vertical Electrical Sounding Stations, Borehole Points, and Geotechnical Sampling Points 
Volume 2, Issue 2, 2020

ISSN: 2668-0416

Thoth Publishing House

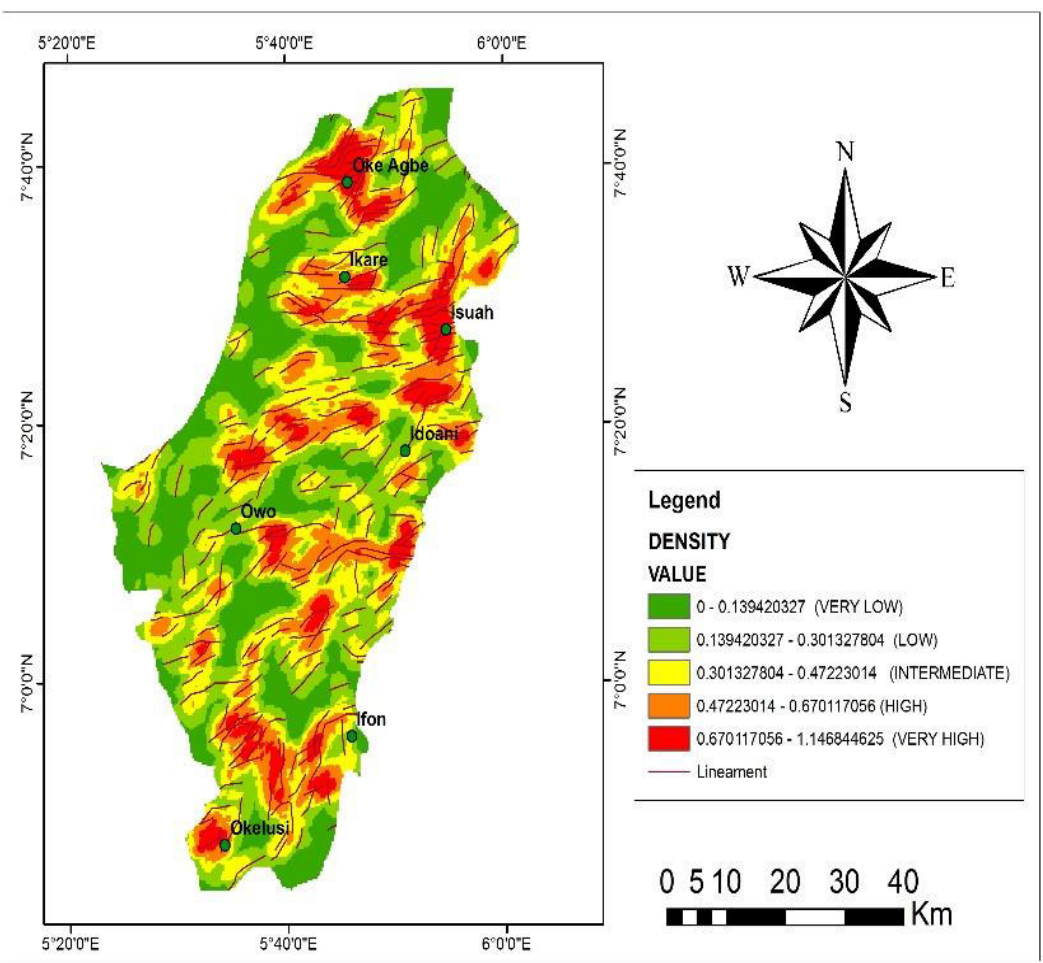

(a)

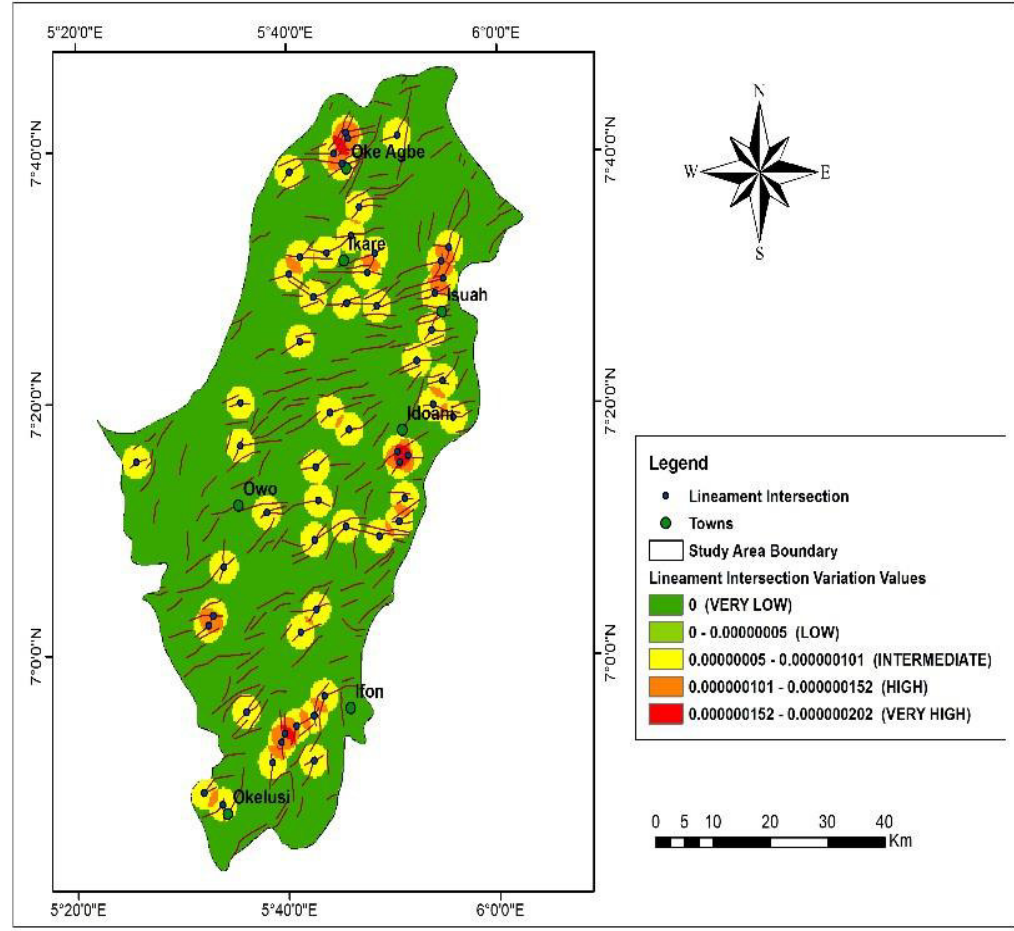

(b)

Figure 8. (a) Lineament Density map (b) Lineament Interception map generated for the study 


\subsection{Geophysical Investigation}

Table 1 gives a summary of the results of the VES curves obtained from the study area. The number of layers varies between three (3) layers and six (6) layers. Ten curve types have been identified: A, H, HA, HK, KQ, KH, QH, HKH, KHK and KHKH (Figure 9) The most occurring curve types identified are H, HA, and KH. Typical curve types are shown in Figure 10. These type curves can be classified into four distinct classes in relation to their engineering competence (table 2) by using their interpreted resistivity and thickness values as Class $1,2,3$, and 4 and are rated very good, good, moderate, and fair respectively. A-curve type is rated "very good" and widely found in Akoko area; KH, KHK, $\mathrm{KHKH}$, and KQ are rated "good"; HK and HKH are rated "moderate"; and H, HA, and QH are rated "fair".

Table 1. Curve Types and their Statistical Frequency obtained from the Study Area

\begin{tabular}{llllllllllll}
\hline $\begin{array}{l}\text { Location/Curve } \\
\text { Type }\end{array}$ & HKH & H & HA & HK & KHKH & KQ & KH & A & KHK & QH & $\begin{array}{l}\text { Total No. } \\
\text { of VES } \\
\text { Curves }\end{array}$ \\
\hline Owo Area & 2 & 15 & 2 & 4 & 3 & 1 & 6 & 2 & - & - & 35 \\
Akoko Area & - & 25 & 9 & - & - & - & 1 & 8 & - & - & 43 \\
Ose Area & 3 & 5 & 5 & - & - & 1 & 8 & - & 1 & 2 & 25 \\
Frequency (unit) & 5 & 45 & 16 & 4 & 3 & 2 & 15 & 10 & 1 & 2 & - \\
Frequency (\%) & 4.8 & 43.6 & 15.5 & 3.8 & 2.9 & 1.9 & 14.5 & 9.7 & 0.9 & 1.9 & - \\
\hline
\end{tabular}

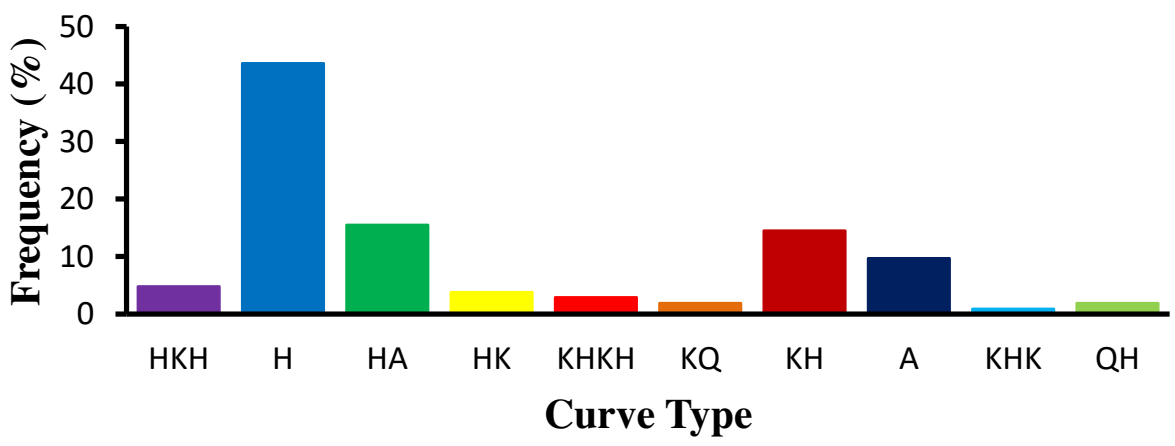

Figure 9. Curve Types obtained in the Study Area with a predominant H-Curve

\subsection{Geo-electrical Maps}

The topsoil competence and corrosivity map of the uppermost $5 \mathrm{~m}$ and depth to basement rock over the study area are presented in Figures 11-13 respectively. The topsoil constitutes the layer within which normal engineering foundation is founded especially in the basement complex [12] and can be qualitatively evaluated from layer resistivity and the geotechnical parameter. Figure 11 shows a predominant moderate competence in Okeluse, Elegbeka, Amurin, Owo, Ipele, Ido Ani, Imeri, and about constitutes about $60 \%$ of Akoko area. The moderate competent soil account for $70 \%$ of topsoil with resistivity between $100 \Omega-\mathrm{m}$ and $350 \Omega-\mathrm{m}$. Areas that show incompetency include Ikun, Oba, and Aiyegunle and account for $15 \%$ with resistivity less than $100 \Omega-\mathrm{m}$. High competent areas are observed in Isijogun, Arigidi, Ehinogbe, Agbaluku and Ajowa These areas are underlain by quartzite, granite, granite gneiss and gneiss, and account for about $15 \%$. Therefore civil engineering foundation structure can be carried out in the study area without any failure expectation (on the basis of resistivity values obtained), while Ikun, Aiyegunle, and Oba can be graded or stabilized with more competent soil like laterite, sand or gravel to increase their density, compaction, and bearing capacity. 

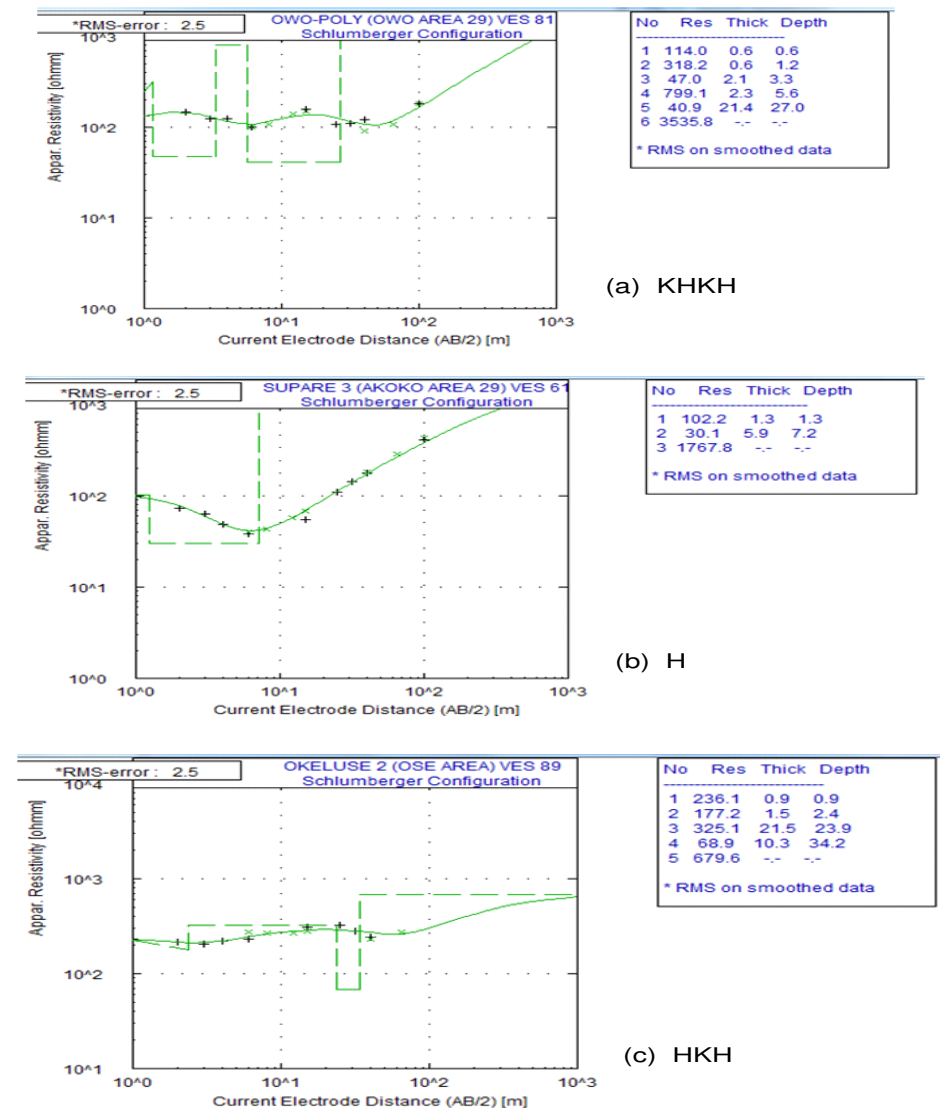

Figure 10. Typical Curve Types obtained in the Study Area

The corrosivity map of the topsoil shows predominant moderate to mildly corrosivity and very prominently in Ose and Akoko areas, and constitute about $70 \%$. The essentially non-corrosive areas which account for $10 \%$ are observed in Ajowa, Agbaluku, Ehinogbe, and Isijogun. However, the corrosivity of the subsoil in the study area shows that Akoko area are essentially non-corrosive except few places like Oba, Ikun, Ipesi, some part of Irun. Owo area and Ose are moderately/mildly corrosive. Figure 13 shows the overburden thickness/depth to basement rock across the study area. It shows that Akoko area (except Oke Agbe, Agbaluku, and part of Ikare) are generally characterized by thin overburden thickness less than $10 \mathrm{~m}$, and signifies shallow depth to basement rock and low depth of weathering; while Owo and Ose have thick overburden thickness ranging from $10 \mathrm{~m}$ to $50 \mathrm{~m}$.

\subsection{Hydrogeological Measurement}

A good set of reliable groundwater level measurements is the best foundation on which to build an understanding of a groundwater system. Groundwater conditions play an important part in the stability of foundations. If the water table lies very close to the base of footings, the bearing capacity and settlement characteristics of the soil would be affected. The water level in the well represents the water table or phreatic surface. Static water level refers to the level of water in a well or borehole under normal, undisturbed, no- pumping conditions. The hydraulic head obtained in the area were used to determine the groundwater flow direction as presented in Figure 14. Static water level measured in Owo varies from $1.2 \mathrm{~m}$ to $14.7 \mathrm{~m}$ with an average of $6.5 \mathrm{~m}$. In Akoko area it ranges between $0.8 \mathrm{~m}$ and 15.2 with an average of $1.8 \mathrm{~m}$; while in Ose area it is between $3.1-15.9 \mathrm{~m}$ and an average of 10 $\mathrm{m}$. The hydraulic head recorded in Ose and Owo ranges between $40 \mathrm{~m}$ (Okeluse) - $390 \mathrm{~m}$ (Ido Ani) and 240 to $390 \mathrm{~m}$ respectively. Akoko area is varies between 290 and $540 \mathrm{~m}$ (Irun, Arigidi, Oke 
Agbe). The general groundwater flow direction is south. Consequently, the SWL in the northern areas are very high indicating a likelihood of high water levels during the rainy season (which could even lead to spring condition), that may affect basement/foundation footings, and subsequently compromise the integrity of such structures.

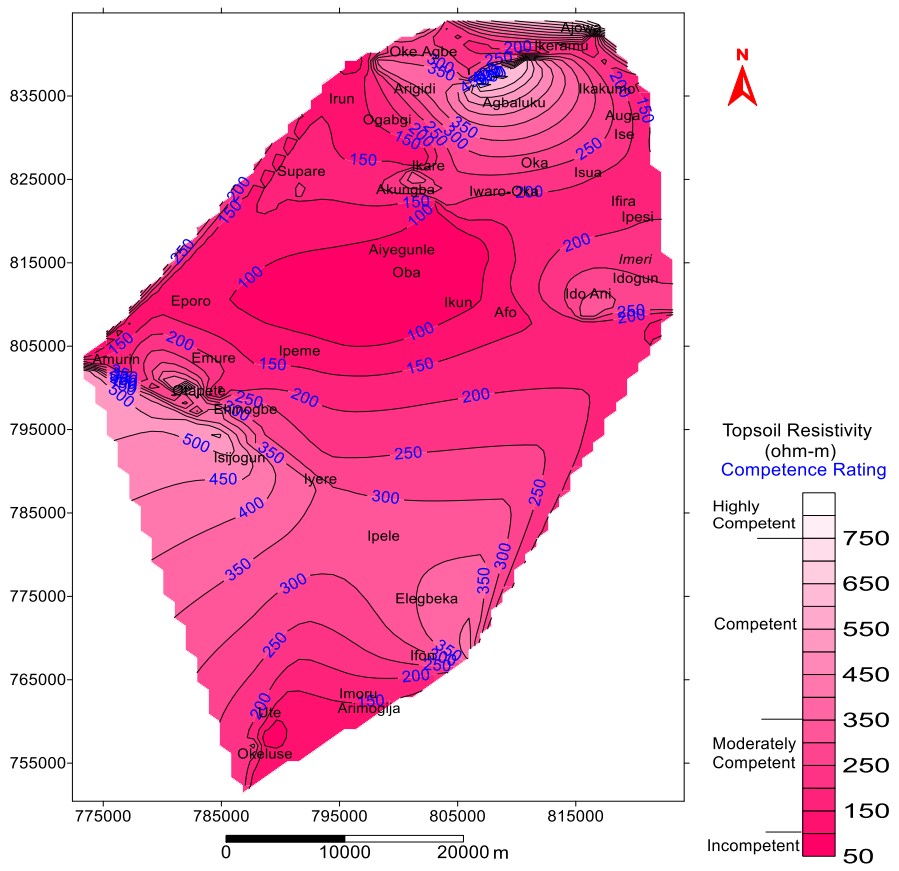

Figure 11. Map showing Topsoil Competence with prominent moderate competence

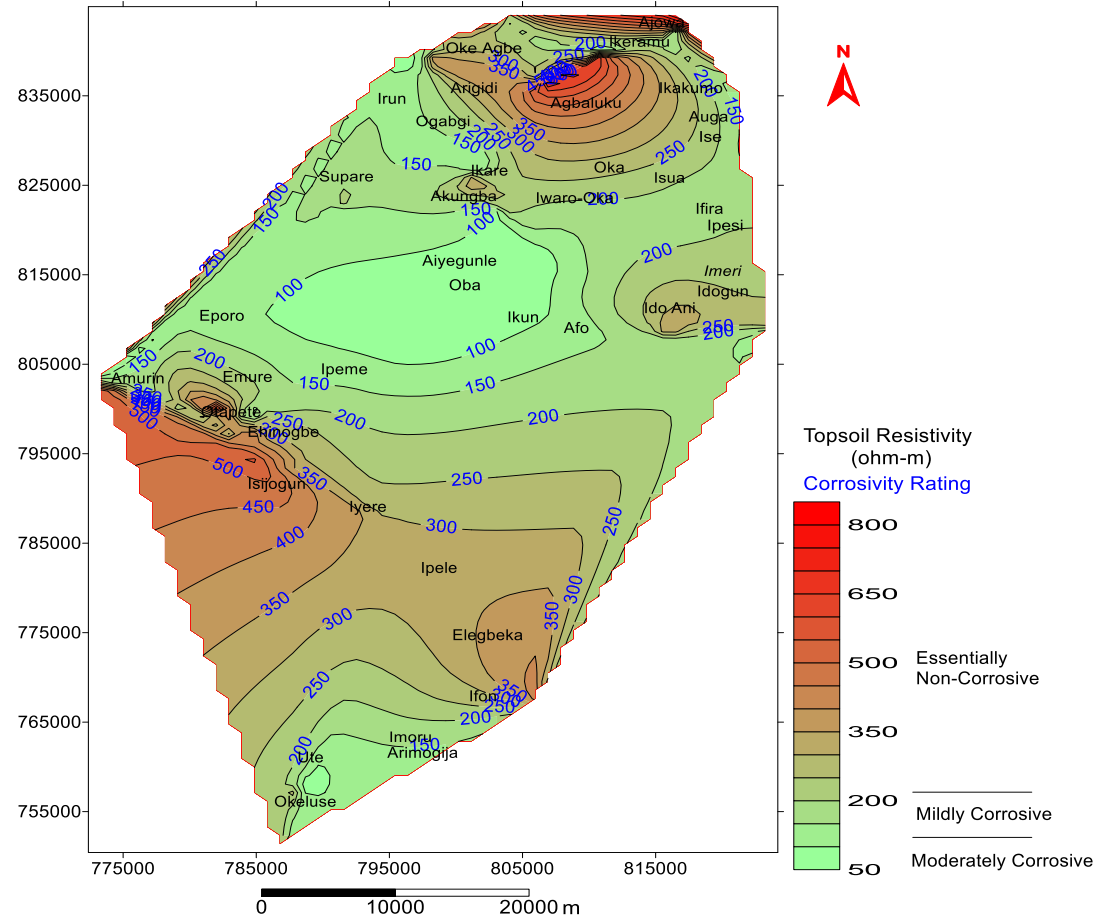

Figure 12. Map showing Topsoil Corrosivity, with pronounced mildly / Essentially non corrosivity 
Volume 2, Issue 2, 2020

ISSN: 2668-0416

Thoth Publishing House

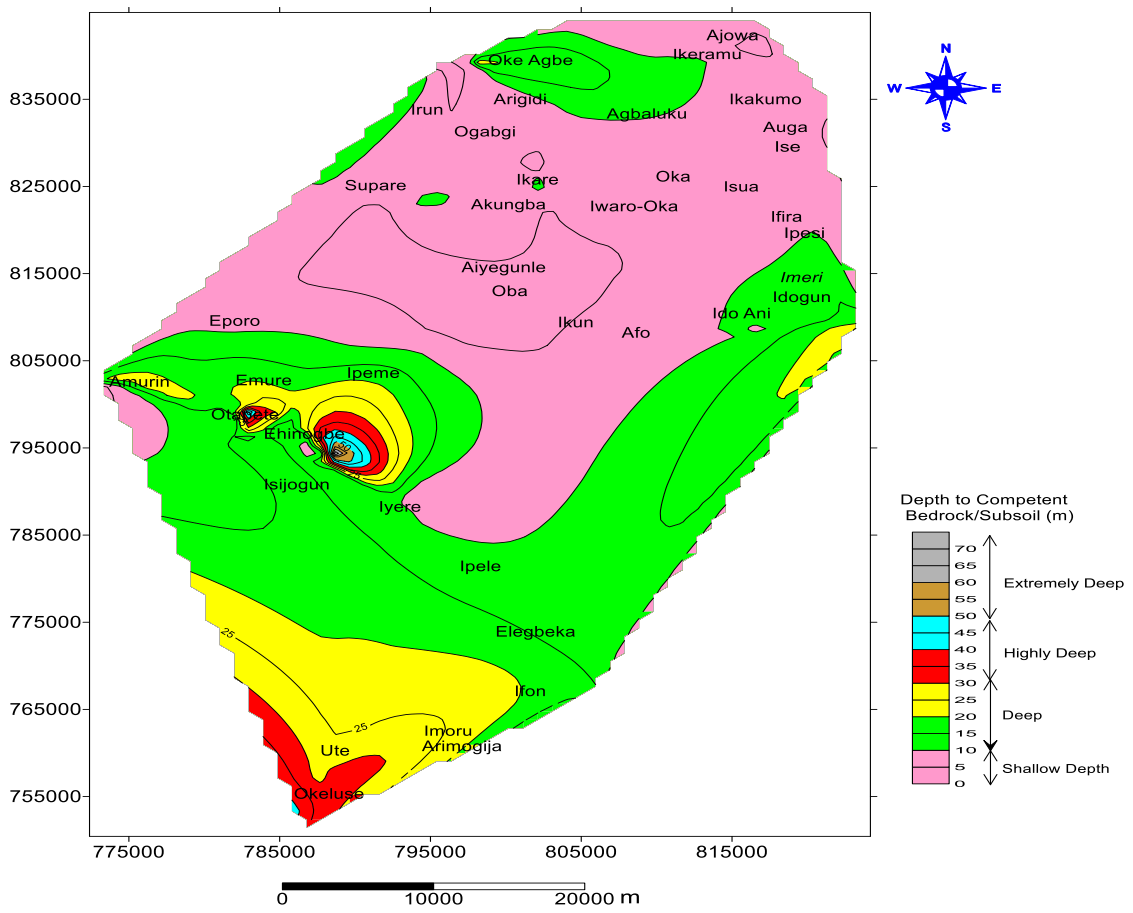

Figure 13. Map of Depth to Basement of the Study area

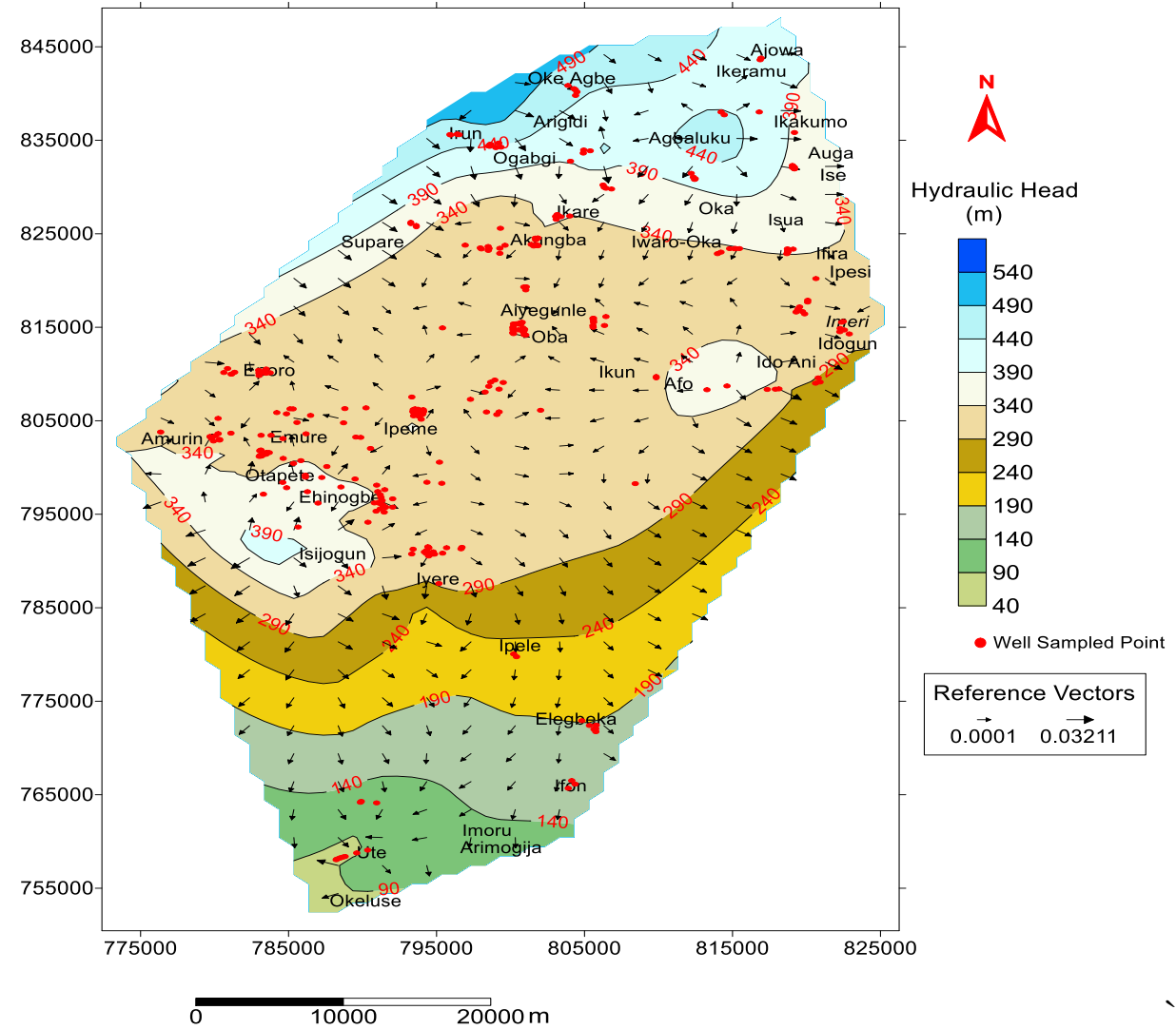

Figure 14. An overlay of Contoured Static Water Level and 1-Grid Vector Layer obtained in the Study Area with presumably North - South Flow directio 


\subsection{Geotechnical Investigation}

The summary of the geotechnical results is presented in tables 3-5. The various values of Natural Moisture Content (NMC) obtained from laboratory tests are presented in table 3. The natural moisture content gives information on the condition of the soil. The natural moisture content of soils varied from $4.3 \%$ to $17.4 \%$, with an average of $10.4 \%$. The samples have low moisture content in their natural state.

The tested soils show $\%$ fines (percentage passing $0.002 \mathrm{~mm}$ ) variation of $14.5-54.6 \%$, with an average of $33.3 \%$. The $\%$ of sand and gravel in the sampled soils vary from $42.2 \%$ to $76 \%$ and $1.1 \%$ to $5.5 \%$ respectively. Therefore the soils are dominated by sand and clay (clayey sand) except in Ose area where the soils are dominantly clay (with classification group of sand-clay). Based on British Standard BS 1377 [13] if percentage fine is less than $35 \%$ it is adjudged a good foundation material. Therefore the soil samples can be generally classified as suitable foundation material since the mean $\%$ of fines is less than $35 \%$. However, samples taken from Ose area needs some level of stabilization due to high $\%$ of fines (clay) with high plasticity [14]. The specific gravity correlates well with the mechanical strength of sub grade and depends on the amount of sand and also on mineral constituents and mode of formation of the soil. The specific gravity (Gs) for all the soil samples and vary between $2.64-2.76$ with an average of 2.70 . These values portray resistant soil material in line with [15].

The liquid limit, plastic limit, and plasticity index of the soil samples vary from $22.2 \%$ to $54.2 \%$, $11.0 \%$ to $26.6 \%$, and $2.95 \%$ to $29.05 \%$, with average values of $39.8 \%, 23.2 \%$, and $16.2 \%$ respectively. Good foundation materials must among other significant criteria be of low plasticity such that its resistance to swelling, total expansion and linear shrinkage should be minimal. The high plasticity index and liquid limit values are indicative of poor engineering properties. The Federal Ministry of Works and Housing [16] recommended liquid limits of $50 \%$ maximum, plastic limits of $30 \%$ maximum, plasticity index of $20 \%$ maximum for civil engineering foundation/construction material. The liquid limit of the soils are generally less than $50 \%$, while the plastic limits are generally lower than $30 \%$ and the plasticity index are generally lower than $20 \%$ except samples AK 5 and 6 which are greater than $20 \%$. Hence, most of the studied soils fall within the specification. Linear shrinkage is an important parameter in the evaluation of material soils for foundation construction. It has been suggested that a linear shrinkage (LS) value below $8 \%$ is indicative of a soil that is good for foundation material $[15,17]$. The lower the linear shrinkage, the lesser the tendency of the soil to shrink when desiccated. The values range between $7.4 \%$ and $13.4 \%$ with an average value of $9.8 \%$. Using table 5 , the soils can be classified as medium good material.

The importance of compaction test is to improve the desirable load bearing capacity properties of a soil as foundation material. The best for foundation engineering structures is one with high MDD at low OMC. The OMC varies from $10.4 \%$ and $27.5 \%$ with an average of $17.1 \%$. The MDD ranges from $1532-2065 \mathrm{Kg} / \mathrm{m}^{3}$, with a mean value of $1820 \mathrm{Kg} / \mathrm{m}^{3}$. The degree of compaction is sensitive to moisture content, thus the higher the value of MDD and the lower OMC, the more suitable the material to sustain any load imposed. All the soil samples have MDD at moderately low OMC. However, MDD values are a little bit lower in Ose area with a range of $1532-1749 \mathrm{Kg} / \mathrm{m}^{3}$. Cohesion is the ability of the soil to resist shearing stress. The cohesion of the studied soils varies between 51.5 $\mathrm{kPa}-102 \mathrm{kPa}$ and average of $88.3 \mathrm{kPa}$. The values of angle of friction is between $20.4^{\circ}$ and $32.5^{\circ}$. This range of value is classified as hard soil material by Holtz and Kovacs18. The shear strength varies from $151.7 \mathrm{kPa}$ to $237.4 \mathrm{kPa}$ and average of $187 \mathrm{kPa}$. These values indicate moderately cohesive material with high shear strength.

The cone penetrometer test was carried out in order to obtain geotechnical parameters required for the design of the foundation support for civil engineering structures. From table 6, the maximum cone resistance values of $100 \mathrm{Kg} / \mathrm{cm}^{2}$ to $126 \mathrm{Kg} / \mathrm{cm}^{2}$ indicative of clayey sand and lateritic material were obtained between depths of $1.4 \mathrm{~m}$ and $3.0 \mathrm{~m}$. Six major geological layers are delineated comprising clay, clay silt, silty clay, sandy clay, clay sand, and lateritic clay. Therefore the soils show high degree of competence at Owo at depth range of $1.0-2.5 \mathrm{~m}, 1.0 \mathrm{~m}$ in Akoko area and $3.0 \mathrm{~m}$ in Ose area. 
The allowable bearing capacity of the soils in Owo, Ose and Akoko areas varies from $17 \mathrm{KN} / \mathrm{m}^{2}$ to $293 \mathrm{KN} / \mathrm{m}^{2}, 20 \mathrm{KN} / \mathrm{m}^{2}$ to $309 \mathrm{KN} / \mathrm{m}^{2}$, and $10 \mathrm{KN} / \mathrm{m}^{2}$ to $270 \mathrm{KN} / \mathrm{m}^{2}$ respectively, while the ultimate bearing capacity varies between $51 \mathrm{KN} / \mathrm{m}^{2}$ and $879 \mathrm{KN} / \mathrm{m}^{2}, 60 \mathrm{KN} / \mathrm{m}^{2}$ and $927 \mathrm{KN} / \mathrm{m}^{2}$, and $30 \mathrm{KN} / \mathrm{m}^{2}$ and $810 \mathrm{KN} / \mathrm{m}^{2}$ respectively. The settlement values obtained from the area are generally less than 20 $\mathrm{mm}$. The minimum settlement values obtained from Owo, Ose and Akoko areas ranged from $0.75 \mathrm{~mm}$ to $1.4 \mathrm{~mm}, 0.68 \mathrm{~mm}$ to $0.80 \mathrm{~mm}$, and $0.78 \mathrm{~mm}$ to $0.86 \mathrm{~mm}$ corresponding to depth(s) of $1.4 \mathrm{~m}-2.4 \mathrm{~m}$, $3 \mathrm{~m}$, and $1.4 \mathrm{~m}-2.0 \mathrm{~m}$ respectively.

Nevertheless for safety purpose Akoko area should not go beyond $1.0 \mathrm{~m}$ due to high water level. The minimum allowable bearing capacity of at least $200 \mathrm{KN} / \mathrm{m}^{2}$ (corresponding to $80-100 \mathrm{~kg} / \mathrm{cm}^{2}$ cone resistance values) for a raft, simple spread foundation and/or structure was recommended by [19]. This average value was found at depth of $1.0 \mathrm{~m}-2.4 \mathrm{~m}$ (Owo), $3.0 \mathrm{~m}$ (Ose) and $1.4 \mathrm{~m}-2.0 \mathrm{~m}$ (Akoko). These allowable bearing pressures are considered appropriate for use in the design of bases, strips or raft foundations. Subsequently, shallow foundation such as pad or raft foundation of reinforced concrete can be adopted in the study area [21]. Therefore the thematic maps of the topsoil resistivity and thickness, plasticity index, soil association, allowable bearing capacity, shear strength, lineament density, and static water level are integrated to generate a sub-soil competence map for the study area by allocating different weights/ratings to each of these parameters as shown in tables 7-9. Figure 15 shows the generated subsoil competence map of the study area. The map classifies the study area into low competence $(<40 \%)$, moderate competence $(40 \%-55 \%)$, and high competence $(55 \%$ $65 \%)$ and very high $(>65 \%)$. Low competence area are not represented on the map, while moderate competence account for $60 \%$. The high and very high competence areas account for of $35 \%$ to 5\% respectively. The very high competence occur as small closures in Ajowa, Ikeramu, Eporo, parts of Ikare, Arigidi, and Ido Ani. The moderate competence areas are prominent in parts of Owo, Ose and Akoko areas. In Owo, it's observed in Ipeme, Ipele, and Amurin. Also in Ose, it is widespread in Elegbeka, Ifon, Imoru, Arimigija, and Okeluse. In addition, moderate competence is noticed in Akoko area around Oba, Ikun, Afo, Iwao Oka, Ikakumo, Irun, Oke Agbe, Auga, and Ise. Furthermore, the high competence subsoil is observed in Owo (Eporo, Otapete, Ehinogbe, Isijogun, Iyere and Ute); and Akoko (Agbaluku, Oka, Isua, Ifira, and Ipesi).

Table 3. Summary of Results of Geotechnical Tests

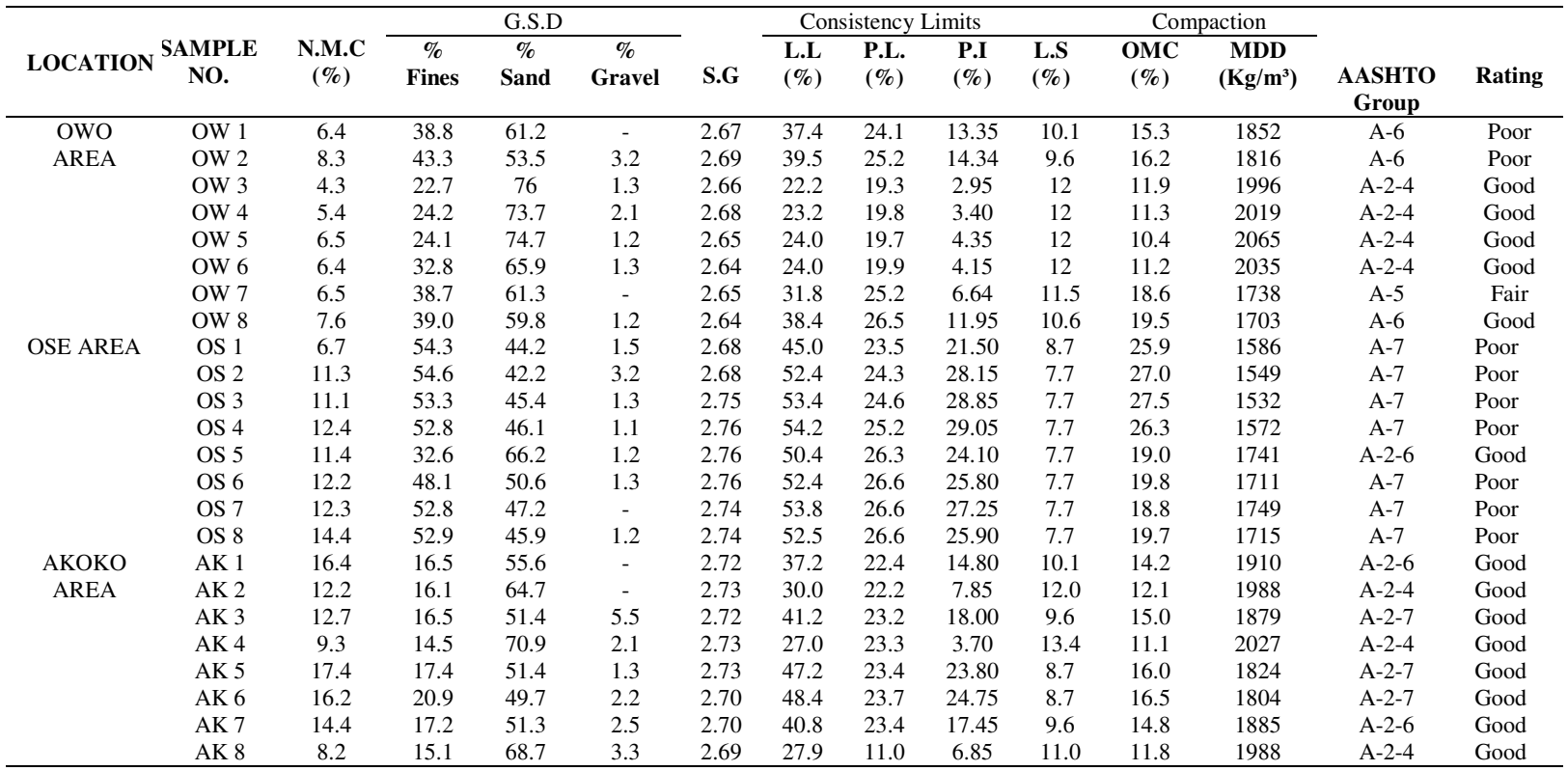


Table 4. Results of the undrained triaxial Test

\begin{tabular}{|c|c|c|c|c|c|c|c|c|}
\hline \multirow[b]{2}{*}{ Location } & \multirow[b]{2}{*}{ Sample No. } & \multicolumn{3}{|c|}{$\begin{array}{c}(\sigma) \text { Deviator stress at } \\
\text { Different Cell Pressures } \\
(\text { KPa })\end{array}$} & \multirow[t]{2}{*}{$\begin{array}{c}\text { Cohesion (c) } \\
\text { Kpa }\end{array}$} & \multirow[t]{2}{*}{$\begin{array}{l}\left(\theta^{\circ}\right) \text { Angle } \\
\text { of Friction }\end{array}$} & \multirow[t]{2}{*}{$\begin{array}{c}\text { Shear Strength } \\
\text { (KPa) } \\
(\tau)\end{array}$} & \multirow{2}{*}{$\begin{array}{c}\text { Undrained } \\
\text { Compressive } \\
\text { Strength } \\
\text { @ Max. Cell } \\
\text { Pressure (Kpa) }\end{array}$} \\
\hline & & 30 & 60 & 90 & & & & \\
\hline OWO & OW 1 & 395 & 470 & 545 & 85.1 & 29.1 & 201.9 & 545 \\
\hline \multirow[t]{7}{*}{ AREA } & OW 2 & 395 & 468 & 542 & 86.2 & 28.8 & 196.2 & 542 \\
\hline & OW 3 & 440 & 532 & 625 & 85.3 & 31.2 & 212.5 & 625 \\
\hline & OW 4 & 440 & 528 & 616 & 88.1 & 30.7 & 230.6 & 616 \\
\hline & OW 5 & 440 & 537 & 633 & 82.9 & 31.7 & 232.4 & 633 \\
\hline & OW 6 & 440 & 545 & 650 & 78.1 & 32.5 & 237.4 & 650 \\
\hline & OW 7 & 337 & 376 & 415 & 98.2 & 21.5 & 175.0 & 415 \\
\hline & OW 8 & 337 & 372 & 408 & 102.0 & 20.4 & 176.4 & 408 \\
\hline \multirow[t]{8}{*}{ OSE AREA } & OS 1 & 337 & 383 & 429 & 91.3 & 23.5 & 173.9 & 429 \\
\hline & OS 2 & 337 & 381 & 426 & 92.7 & 23.1 & 175.0 & 426 \\
\hline & OS 3 & 337 & 378 & 419 & 96.1 & 22.1 & 171.2 & 419 \\
\hline & OS 4 & 337 & 384 & 431 & 90.4 & 23.7 & 173.8 & 431 \\
\hline & OS 5 & 337 & 382 & 427 & 92.3 & 23.2 & 175.1 & 427 \\
\hline & OS 6 & 395 & 459 & 523 & 93.2 & 27.3 & 199.0 & 523 \\
\hline & OS 7 & 395 & 455 & 515 & 96.5 & 26.6 & 198.7 & 515 \\
\hline & OS 8 & 337 & 380 & 422 & 94.7 & 22.5 & 175.5 & 422 \\
\hline AKOKO & AK 1 & 337 & 380 & 422 & 94.7 & 22.5 & 173.8 & 422 \\
\hline \multirow[t]{7}{*}{ AREA } & AK 2 & 296 & 360 & 425 & 65.3 & 27.3 & 160.8 & 425 \\
\hline & AK 3 & 323 & 381 & 425 & 82.9 & 24.6 & 168.5 & 425 \\
\hline & $\mathrm{AK} 4$ & 269 & 339 & 419 & 51.5 & 29.1 & 151.7 & 419 \\
\hline & AK 5 & 337 & 384 & 431 & 90.4 & 23.7 & 175.1 & 431 \\
\hline & AK 6 & 337 & 382 & 427 & 92.3 & 23.2 & 177.6 & 427 \\
\hline & AK 7 & 395 & 459 & 523 & 93.2 & 27.3 & 200.0 & 523 \\
\hline & AK 8 & 395 & 455 & 515 & 96.5 & 26.6 & 198.2 & 515 \\
\hline
\end{tabular}

Table 6. Bearing Capacity and settlements obtained for all the CPT locations at an interval of $0.2 \mathrm{~m}$ Depth

\begin{tabular}{|c|c|c|c|c|c|c|c|c|c|c|c|c|}
\hline \multirow[b]{2}{*}{$\begin{array}{l}\text { Depth } \\
(\mathrm{m})\end{array}$} & \multicolumn{3}{|c|}{ CPT 1 (OWO) } & \multicolumn{3}{|c|}{ CPT 2 (OWO) } & \multicolumn{3}{|c|}{ CPT 3 (OSE) } & \multicolumn{3}{|c|}{ CPT 4 (OSE) } \\
\hline & $\begin{array}{c}q_{a} \\
\left(\mathrm{KN} / \mathrm{m}^{2}\right)\end{array}$ & $\begin{array}{c}q_{u} \\
\left(\mathrm{KN} / \mathrm{m}^{2}\right)\end{array}$ & $\begin{array}{c}\mathrm{S} \\
(\mathrm{mm})\end{array}$ & $\begin{array}{c}q_{a} \\
\left(\mathrm{KN} / \mathrm{m}^{2}\right)\end{array}$ & $\begin{array}{c}q_{u} \\
\left(\mathrm{KN} / \mathrm{m}^{2}\right)\end{array}$ & $\underset{(\mathrm{mm})}{\mathrm{S}}$ & $\begin{array}{c}q_{a} \\
\left(\mathrm{KN} / \mathrm{m}^{2}\right)\end{array}$ & $\begin{array}{c}q_{u} \\
\left(\mathrm{KN} / \mathrm{m}^{2}\right)\end{array}$ & $\begin{array}{c}\mathrm{S} \\
(\mathrm{mm})\end{array}$ & $\begin{array}{c}q_{a} \\
\left(\mathrm{KN} / \mathrm{m}^{2}\right)\end{array}$ & $\begin{array}{c}q_{u} \\
\left(\mathrm{KN} / \mathrm{m}^{2}\right)\end{array}$ & $\begin{array}{c}\mathrm{S} \\
(\mathrm{mm})\end{array}$ \\
\hline 0.2 & 17 & 51 & 12.3 & 41 & 123 & 5.1 & 21 & 63 & 10.25 & 22 & 66 & 9.67 \\
\hline 0.4 & 21 & 63 & 10.01 & 82 & 246 & 2.56 & 20 & 60 & 10.37 & 31 & 93 & 6.78 \\
\hline 0.6 & 54 & 162 & 3.91 & 127 & 381 & 1.67 & 26 & 78 & 8.05 & 43 & 129 & 4.86 \\
\hline 0.8 & 63 & 189 & 3.32 & 174 & 522 & 1.22 & 32 & 96 & 6.67 & 42 & 126 & 5.01 \\
\hline 1.0 & 87 & 261 & 2.41 & 270 & 810 & 0.78 & 43 & 129 & 4.89 & 76 & 228 & 2.79 \\
\hline 1.2 & 102 & 306 & 2.07 & 273 & 819 & 0.77 & 70 & 210 & 2.99 & 10 & 30 & 21.00 \\
\hline 1.4 & 112 & 336 & 1.88 & 293 & 879 & 0.72 & 88 & 264 & 2.41 & 11 & 33 & 19.13 \\
\hline 1.6 & 124 & 369 & 1.71 & - & - & - & 83 & 249 & 2.55 & 21 & 63 & 10.13 \\
\hline 1.8 & 123 & 369 & 1.72 & - & - & - & 98 & 294 & 2.16 & 33 & 98 & 6.47 \\
\hline 2.0 & 131 & 393 & 1.62 & - & - & - & 116 & 348 & 1.82 & 42 & 126 & 5.01 \\
\hline 2.2 & 179 & 537 & 1.18 & - & - & - & 123 & 369 & 1.72 & 61 & 183 & 3.44 \\
\hline 2.4 & 281 & 843 & 0.75 & - & - & - & 156 & 468 & 1.35 & 83 & 249 & 2.54 \\
\hline 2.6 & - & - & - & - & - & - & 172 & 516 & 1.23 & 112 & 336 & 1.88 \\
\hline 2.8 & - & - & - & - & - & - & 215 & 645 & 0.98 & 163 & 489 & 1.29 \\
\hline \multirow[t]{2}{*}{3.0} & - & - & - & - & - & - & 309 & 927 & 0.68 & 262 & 786 & 0.80 \\
\hline & \multicolumn{3}{|c|}{ CPT 5 (AKOKO) } & \multicolumn{3}{|c|}{ CPT 6 (АКОKO) } & \multicolumn{3}{|c|}{ CPT 7 (AKOKO) } & \multicolumn{3}{|c|}{ CPT 8 (АКОКО) } \\
\hline $\begin{array}{l}\text { Depth } \\
\text { (m) }\end{array}$ & $\begin{array}{c}q_{a} \\
\left(\mathrm{KN} / \mathrm{m}^{2}\right)\end{array}$ & $\begin{array}{c}q_{u} \\
\left(\mathrm{KN} / \mathrm{m}^{2}\right)\end{array}$ & $\begin{array}{c}\mathrm{S} \\
(\mathrm{mm})\end{array}$ & $\begin{array}{c}q_{a} \\
\left(\mathrm{KN} / \mathrm{m}^{2}\right)\end{array}$ & $\begin{array}{c}q_{u} \\
\left(\mathrm{KN} / \mathrm{m}^{2}\right)\end{array}$ & $\underset{(\mathrm{mm})}{\mathrm{S}}$ & $\begin{array}{c}q_{a} \\
\left(\mathrm{KN} / \mathrm{m}^{2}\right)\end{array}$ & $\begin{array}{c}q_{u} \\
\left(\mathrm{KN} / \mathrm{m}^{2}\right)\end{array}$ & $\begin{array}{c}\mathrm{S} \\
(\mathrm{mm})\end{array}$ & $\begin{array}{c}q_{a} \\
\left(\mathrm{KN} / \mathrm{m}^{2}\right)\end{array}$ & $\begin{array}{c}q_{u} \\
\left(\mathrm{KN} / \mathrm{m}^{2}\right)\end{array}$ & $\begin{array}{c}\mathrm{S} \\
(\mathrm{mm})\end{array}$ \\
\hline 0.2 & 22 & 66 & 9.78 & 10 & 30 & 21.00 & 61 & 183 & 3.44 & 11 & 33 & 19.57 \\
\hline 0.4 & 20 & 60 & 10.50 & 22 & 66 & 9.67 & 39 & 117 & 5.38 & 25 & 75 & 8.36 \\
\hline 0.6 & 33 & 99 & 6.43 & 52 & 156 & 4.06 & 21 & 63 & 10.01 & 54 & 162 & 3.90 \\
\hline 0.8 & 43 & 129 & 4.86 & 82 & 246 & 2.59 & 54 & 162 & 3.90 & 121 & 363 & 1.75 \\
\hline 1.0 & 53 & 159 & 3.99 & 163 & 489 & 1.29 & 125 & 375 & 1.69 & 162 & 486 & 1.30 \\
\hline 1.2 & 73 & 219 & 2.91 & 195 & 585 & 1.08 & 153 & 459 & 1.38 & 207 & 621 & 1.02 \\
\hline 1.4 & 82 & 246 & 2.59 & 249 & 747 & 0.85 & 197 & 591 & 1.07 & 248 & 744 & 0.85 \\
\hline 1.6 & 109 & 327 & 1.94 & - & - & - & 245 & 735 & 0.86 & - & - & - \\
\hline 1.8 & 173 & 519 & 1.22 & - & - & - & - & - & - & - & - & - \\
\hline 2.0 & 270 & 810 & 0.78 & - & - & - & - & - & - & - & - & - \\
\hline
\end{tabular}


Table 7. Rating of Subsoil Competence using Resistivity values [22]

\begin{tabular}{ccc}
\hline $\begin{array}{c}\text { Apparent Resistivity Range } \\
(\text { ohm-m) }\end{array}$ & Lithology & Competence Rating \\
\hline$<100$ & Clay & Incompetent \\
$100-350$ & Sandy clay & Moderately competent \\
$350-750$ & Clayey sand & Competent \\
$>750$ & Sand/Laterite/Crystalline Rock & Highly competent \\
\hline
\end{tabular}

Table 8. Soil Corrosivity Rating [23]

Soil Resistivity (ohm-m)

\section{$>250$}

$150-250$

$50-150$

UP to 50
Corrosivity Rating Essentially/Practically Non-corrosive

Mildly/Slightly Corrosive

Moderately Corrosive

Very Strongly Corrosive

Table 9. Multi-criteria Evaluation Parameters for the Subsoil Competence Map

\begin{tabular}{|c|c|c|c|c|}
\hline $\mathbf{S} / \mathbf{N}$ & Thematic Map & Attribute & Rating (\%) & Weight-Age (\%) \\
\hline & Topsoil Resistivity (ohm-m) & $<100$ & 1 & \\
\hline \multirow[t]{3}{*}{1} & & $100-350$ & 5 & 15 \\
\hline & & $350-750$ & 10 & \\
\hline & & $>750$ & 15 & \\
\hline & Topsoil Thickness (m) & $<5$ & 3 & \\
\hline \multirow{2}{*}{2} & & $5-10$ & 10 & 15 \\
\hline & & $>10$ & 15 & \\
\hline \multirow{3}{*}{3} & Plasticity Index (\%) & $<10$ & 10 & \\
\hline & & $10-20$ & 5 & 10 \\
\hline & & $>20$ & 1 & \\
\hline \multirow{3}{*}{4} & Shear Strength $(\mathrm{KPa})$ & $200-300$ & 5 & \\
\hline & & $300-400$ & 10 & 15 \\
\hline & & $400-500$ & 15 & \\
\hline \multirow{4}{*}{5} & Allowable Bearing Capacity & $<50$ & 1 & \\
\hline & $\left(\mathrm{KN} / \mathrm{m}^{2}\right)$ & $50-100$ & 5 & 15 \\
\hline & & $100-200$ & 10 & \\
\hline & & $>200$ & 15 & \\
\hline \multirow{3}{*}{6} & Soil Association & Okemesi & 10 & 10 \\
\hline & & Iwo & 7 & \\
\hline & & Ondo & 3 & \\
\hline \multirow{3}{*}{7} & Lineament Density & $0-8$ & 10 & 10 \\
\hline & & $8-12$ & 6 & \\
\hline & & $12-16$ & 2 & \\
\hline \multirow{3}{*}{8} & Groundwater Level & $<3 \mathrm{~m}$ & 2 & 10 \\
\hline & & $3-5 \mathrm{~m}$ & 5 & \\
\hline & & $>5 \mathrm{~m}$ & 10 & \\
\hline
\end{tabular}

\section{Conclusion}

The engineering competence of the subsoil/rock in selected northern area of Ondo State was conducted, and the results of various parameters measured were integrated to generate an engineering competence map for the study area. The research work was able to meet up with its set objectives except that it has not been able to (fully) determine the geotechnical capability of the rock units in the study area to host engineering structures such as building, road, dam etc. The generated subsoil 
competence map classified the study area into low competence $(<40 \%)$, moderate competence $(40 \%$ $55 \%)$, and high competence $(55 \%-65 \%)$ and very high $(>65 \%)$.

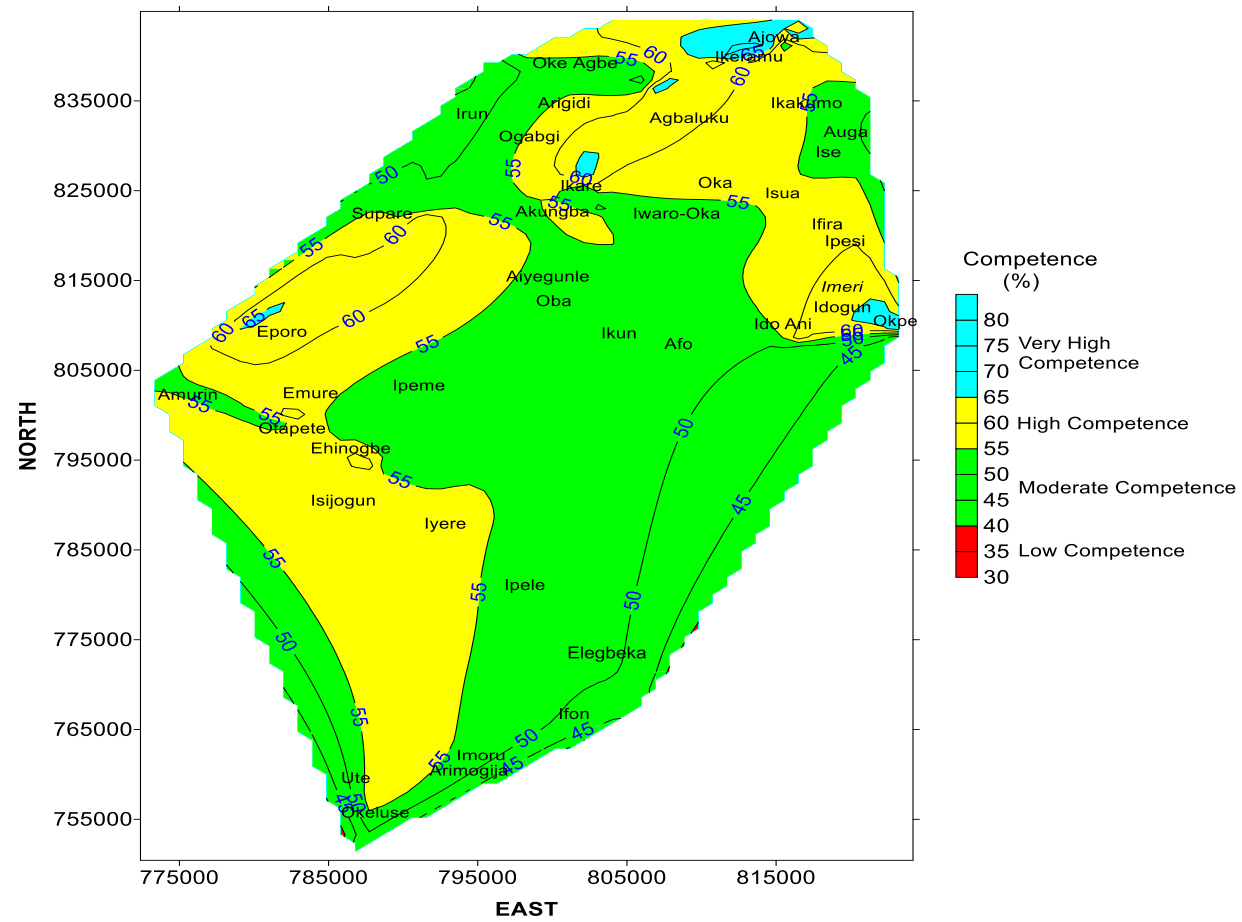

Figure 15. Subsoil Competence Map generated for the Study Area

Low competence area are not represented on the map, while moderate competence account for $60 \%$. The high and very high competence areas shared the remaining $40 \%$ in a proportion of $35 \%$ to $5 \%$. The corrosivity map of the topsoil shows predominant moderate to mildly corrosivity, prominently in Ose and Akoko areas, and constitute about $70 \%$. The essentially non-corrosive areas of the topsoil account for $10 \%$. The corrosivity of the weathered layer (subsoil) generally varies from mildly corrosivity to essentially non-corrosivity. This type of corrosivity is suitable for buried communication equipment and electrodes, as it will protect the instrumentation when there is lighting or thunderstorm; hence any protected steel or metal structure buried within the area may not be "seriously" affected by chemical corrosion

\section{References}

[1] Oyedele K F, Oladele S and Adedoyin O 2011 Application of Geophysical and Geotechnical Methods to Site Characterization for Construction Purposes at Ikoyi, Lagos, Nigeria Journal of Earth Sciences and Geotechnical Engineering vol. 1 (1) pp 87-100. ISSN: 1792-9040 (print), 1792-9660 (online) International Scientific Press.

[2] Olorunfemi M O, J S Ojo F A, Sonuga, O A and Oladapo M I 2000 Geoelectric and electromagnetic Investigations of failed Koza and Nassarawa Earth dams around Katsina, Northern Nigeria Journal of Mining and Geology 36(1) pp $51-65$.

[3] Ofomola M O, Adiat K A N, Olayanju G M and Ako B D 2009. Integrated geophysical methods for post foundation studies, Obanla Staff Quarters of the Federal University of Technology, Akure Nigeria The Pacific Journal of Science and Technology 10(2), pp 93 - 110.

[4] Marans R W and Rodgers W 1975 Toward an understanding of community satisfaction: In 
Hawley A.H. and Rock V.P. (Eds). Metropolitan America in Contemporary Perspective, London: Wiley Publishing.

[5] Federal Meteorological Survey 1982 Atlas of the Federal Republic of Nigeria, Second Edition. Federal Surveys, Lagos, Nigeria 160pp.

[6] Dada S S $1999 \mathrm{~Pb}-\mathrm{Pb}$ and Sm-Nd Isotope Study of Metaigneous Rocks of Kaduna Region: implications for Archaean Crustal Development in Northern Nigeria Global J. Pure Appl. Sci. (6) $7 \mathrm{pp}$

[7] Rahaman M A 1988 Review of the basement Geology of Southwestern Nigeria. In Kogbe (Ed): Geology of Nigeria. Rocks view (Nig) Ltd, Jos. Nigeria. pp. 39-56.

[8] Smith A J and Montgomery R F 1962 Soils and land use in Central Western Nigeria. The Government of Western Nigeria, Ibadan Publication.

[9] Daramola J O, Adekunle M F, Olaniyi M O and Alayaki F M 2009 Diagnostic Survey Report of Ondo State Agricultural Production, Institute of Food Security, Environmental Resources and Agricultural Research, University of Agriculture, Abeokuta, Nigeria pp. 171. Available www.unaab.edu.ng/ifserar

[10] Geological Survey of Nigeria 1984 Geological Map of Southwestern Nigeria. Geological Survey Department, Ministry of Mines, Power and Steel, Nigeria.

[11] Edet A E, Okereke C S, Teme S C and Esu E O 1998 Application of remote sensing data to groundwater exploration: a case study of Cross River State, Southeastern Nigeria Hydrogeology Journal 6(3) pp 394-404. http://dx.doi.org/1010.1007/s100400050162

[12] Olorunfemi M O 2008 Voyage on the Skin of the Earth: A Geophysical Experience. Inaugural Lecture 211 Obafemi Awolowo University, Ile-Ife 75 pp.

[13] British Standard Institution 1990 Methods of Test for Soil for Civil Engineering Purposes. BS1377, London.

[14] Okogbue C O and T U S Onyeobi 1999 Potential of marble dust to stabilize red tropical soils for road Construction. Engineering Geology 53 pp. $371-380$.

[15] Brink A B A, Parridge J C and Williams A A B 1992 Soil Survey for Engineering, Claredon, Oxford.

[16] Federal Ministry of Works and Housing 1972 Highway Manual Part 1, Road and Bridge Design, Federal Ministry of Works and Housing, Lagos.

[17] Madedor A C 1983 Pavement design guidelines and practice for different geological area in Nigeria. In: Ola S.A. (Ed) tropical soil of Nigeria in engineering practice. A.A. Balkema, Rotterdam, pp. 291-297.

[18] Holtz W G and Kovacs W D 1981 An Introduction to Geotechnical Engineering, Prentice-Hall Publishers, New Jersey 733pp.

[19] Bell F G 2007 Engineering geology, second edition, Elsevier Ltd 581pp.

[20] Murthy V N S 2007 Advanced Foundation Engineering, Geotechnical Engineering Series. CBS Publishers and Distributors Ltd., New Delhi - 110002, India 795pp.

[21] Schmertmann J H 1978 Guidelines for Cone Penetration Test: Performance and Design. US Department of Transportation, Washington, DC.

[22] Idornigie A I, Olorunfemi M O and Omitogun A A 2006 Integration of remotely sensed and geophysical data sets in engineering site characterization in a Basement complex of southwestern Nigeria. Journal of Applied Sciences Research, 2(9) pp. 541-552.

[23] Agunloye O 1984 Soil aggressivity along steel pipeline route at Ajaokuta, J. Mining Geol. 21(1 \& 2): pp. 97-101.

\section{Acknowledgments}

Special thanks go to Mr. Samuel Alabi of Engineering geology Laboratory, Federal University of Technology Akure, Ondo State Nigeria. 


\title{
Considerations regarding the relationship between environment, health and life quality
}

\author{
Daniela Cîrțînă ${ }^{1}$, Valentin Nanescu ${ }^{1}$ \\ 1"Constantin Brâncusi” University of Targu-Jiu, Faculty of Medical and Behavioral Sciences, \\ No. 4, Tineretului St., Targu-Jiu, Romania \\ E-mail: danielacirtina@gmail.com
}

\begin{abstract}
This paper presents aspects related to how the factors that define the environment, such as physical, chemical, biological and social factors directly or indirectly exert their influence on human health related quality of life. The phenomenon of air, water, soil pollution, radiation exposure, unhealthy diet, nutritional and microbiological quality of food are elements that have consequences on life quality.
\end{abstract}

Keywords: environment, health, life quality

\section{Introduction}

Different ways of defining the quality of life are known, but it can be appreciated that regardless of the meaning, the quality of life is closely related to the environment. The interaction between the natural environment and the quality of life has led to the need of studying health problems and the appearance of some diseases in certain social, climatic, biological and psychological circumstances in which humans lives and works.

Life quality has been medically defined as physical, mental, and social wellbeing, as well as the patient's ability to perform their usual tasks in their daily lives. A definition given by the WHO in 1998 presents the meaning of life qualityas given by the perceptions of individuals on their social situations, in the context of the cultural value systems in which they live and depending on their own needs, standards and aspirations. Another definition given in 1993 by Revicki \& Kaplan is that "life quality reflects the preferences for certain health conditions that allow improvements in morbidity and it is expressed by a single weighted index - standardized life years, depending on the quality of life". $[1,2]$

The factors that define the environment, physical, chemical, biological and social factors can influence people's health, part of life quality. The phenomenon of air, water, soil pollution, radiation exposure, unhealthy eating, nutritional and microbiological quality of food are just a few examples of factors that have consequences on the quality of life. There is a set of conditions and elements that have an impact on the health of people and the general population. [3,4]

Currently, both sanogenic (health) and aggressive (human pathogens) factors are being studied, which mainly affect the age groups most sensitive to these factors - children and the elderly. The research shows that fast changes in the ecosystem lead to a much difficult ability of the human body to adapt to the new living conditions. In order of their importance, environmental risks to human health can be classified into three main categories. The high environmental risks represent the first category that includes elements such as dangerous meteorological phenomena, the ozone depletion, the degradation of natural habitats and the reduction of biodiversity. The second category is represented by the medium risks that include phenomena such as: acid rain, pollution of water with toxic substances, the impact of 
greenhouse gases, soil pollution with pesticides and the radioactive pollution of the environment. Thermal and noise pollution are forms of pollution with low health risk. [4,5]

\section{Drinking water and ambient air quality and the health risks}

There are a number of substances and concoctions considered to be dangerous for the environment and implicitly for health, substances that, if they penetrate in the environment present or could present in certain conditions an immediate or delayed risk. The quality of life can be influenced by toxic substances and concoctions which, by inhalation, swallowing or penetration through the skin, can cause acute or chronic health disorders. The environmental risk assessment includes, as an important component, the monitoring of persistent organic pollutants, heavy metals, biocidal products and plant protection products, substances that degrade the ozone layer. The presence in the environment of ionizing radiation, carcinogens, irritants or oxidants substances can produce effects starting with altered health to serious diseases of the human body. Through the harmful effects of pollutants on the main environmental factors, there are created conditions that have a direct influence on the health and life quality. [4, 6-8]

Drinking water must not be harmful to the human health, therefore it must not contain pathogenic bacteria. The large amount of water used centrally by the population presents the risk, that under pollution conditions, water can be an important factor of disease. Waterborne diseases can include a large number of people, and can be mass-spreading. Thus, in order to obtain drinking water, natural water is subjected to operations such as decantation and filtration, which aim to reduce the suspended substances. By settling and filtering, the number of microbial germs that are in the water is greatly reduced without, however, achieving the bacteriological conditions required by a drinking water. Although that water decantation and filtration greatly reduce the quantity of microorganisms in the water, do not, however, give a full guarantee of their final removal, which is why water sterilization is applied. This is done in all cases where the water supply source is not sanitary safe. Water disinfection can be performed by chemical methods (chlorine treatmentand chlorogenic substances, ozone, potassium permanganate etc.) and physical methods (distillation, boiling, ultraviolet radiation, ionizing radiation, ultrasonic). $[4,8,9]$

Drinking water quality can be an important factor in the transmission of diseases among the population. Waterborne diseases can be infectious diseases (bacterial, viral, parasitic) and non-infectious diseases. The category of bacterial diseases includes: typhoid fever caused by the bacillus (Salmonella typhi). The disease is specifically human, the germ being eliminated from the human body once with the ingested water, dysentery caused by dysenteric bacilli (Shigella disenteriae) and cholera is another digestive bacterial disease in which water plays a major role.

The viral diseases are polio and epidemic hepatitis. The high danger of spreading polio is based on the fact that polio viruses have a high resistance in the environment, in the water they survive 150-180 days.

In the case of parasitic diseases, water plays a dual role in their transmission. On the one hand, for some parasitic diseases, water has a passive role, namely to serve as a path of transmitting the parasite from the sick or carrier to the healthy person, as in the case of bacterial or viral diseases, and on the other hand, water it is a mandatory environment without which they cannot complete their evolutionary cycle or in other words, they cannot reach the stage of disease production. Amoebiasis or amoebic dysentery is the most common waterborne parasitosis. The parasite is eliminated in the external environment in the form of a cyst, which gives it a high resistance. Another example is lambliasis or giardiasis caused by lamblia or giardia intestinalis. The parasite is also eliminated in the form of a cyst resistant to external environmental factors; in the water it survives for several months. The disease occurs mainly through the ingestion of infested water and less often through food. Trichomoniasis is a parasitosis in which transmission water plays an important role, along with the direct interpersonal contact. [8-10]

Water can also transmit a series of non-infectious diseases caused by polluted water, including endemic goiter or thyropathic dystrophy. This is a mass-spreading disorder which leads not only to a large number of cases but also to endocrine complications. As it is known, iodine is a natural constituent 
of the thyroid gland, being the essential element of thyroid hormone. Iodine deficiency is the cause of endemic goiter as a result of pituitary stimulation due to thyroid hormone deficiency. The goiter has a serious character, up to forms of cretinism and deafness, at concentrations below 2-3 $\mu \mathrm{g} / \mathrm{dm}^{3}$ of water. Other examples can be nitrate poisoning that causes methemoglobinemia, with lead (lead poisoning), mercury poisoning that has symptoms of headache, dizziness, insomnia, memory and visual disturbances and even teratogenic effects. To all of these, can be added cadmium poisoning that has effects on the liver, produces anemia, decreased of calcium, arsenic poisoning that causes metabolic and digestive disorders, headaches, dizziness etc., fluoride poisoning that can have dental, bone and kidney forms. At high concentrations of fluorine (above $5 \mathrm{mg} / \mathrm{dm}^{3}$ of water) fluoride acts on the bones, producing a significant increase in opacity to X-rays. At even higher concentrations (over $20 \mathrm{mg} / \mathrm{dm}^{3}$ of water) there are changes in bone composition with increasing the amount of fluoride in the detriment of calcium. $[10,11]$

Ambient air quality has an important role in triggering certain diseases and can influence the wellbeing and generate a deterioration in quality of life. Air pollutants can be grouped according to their health effects. Thus, we have irritating pollutants such as sulfur oxides, nitrogen oxides, sedimentable or suspended dusts. The powders act on the airways that can be affected by inflammation, rhinitis, pharyngitis, laryngitis, bronchitis or alveolitis. The sulfur dioxide, resulting from the burning of fossil fuels and industrial processes, is considered to be the main harmful substance in the air. The effects of the sulfur dioxide on humans are manifested primarily by a respiratory irritation, salivation, expectoration, spasms and breathingdifficulty that can lead to chronic bronchitis. The synergism of the sulfur oxides with other pollutants present in the atmosphere, leads to new physiological reactions.

The nitrogen oxides produce at the level of the airways the cilia of the bronchial and tracheal epitheliamovementsblocking. At the blood level it combines with hemoglobin resulting in methemoglobin which prevents the transport of the oxygen to the tissues. The asphyxiating pollutants include those substances whose predominant pathogenic effect is hypoxia or anoxia by blocking the supply, transport or use of the oxygen in the metabolic processes. Of these, the most common air pollutant is the carbon monoxide, resulting from incomplete combustion, it combines with hemoglobin generating a lack of oxygen with the most serious consequences, headaches, dizziness, drowsiness, nausea, arrhythmias etc. $[9,10,11]$

The fibrous pollutants contain a group of substances that penetrate the lung causing a fibrous reaction by complex mechanisms, specific to each substance. The dusts persists in the lungs, causing a decrease in the elasticity of lung that leads to fibrosis. The systemic pollutants are very numerous, coming mainly from industrial processes and means of transport. The lead is an environmental pollutant that can enter into the human body along with food or water. The population exposure to lead can be professional or unprofessional. Released into the atmosphere in vapors form that condense quickly, it can enter into the human body through the respiratory or digestive tract. The harmful action takes place at the blood level, anemia occursat the nervous system level as well, it causes a slowdown in the intellectual development in children. Penetrated into the circulation, the lead is found in small amounts in plasma, most part of it is fixed in the red blood cells. The lead is mostly stored in the bones, especially in the long bones. The carcinogenic pollutants - in case of prolonged exposure, polycyclic aromatic hydrocarbons resulting from incomplete combustion of solid and liquid fuels are concentrated in the human body. Carcinogenic substances are also arsenic, chromium, beryllium, cobalt, selenium, elements present especially in industrial environments. The allergic pollutants are responsible for increasing the frequency of allergic diseases, and especially respiratory allergies. The main allergenic factors in the atmosphere are natural products such as pollen, fungi or volatile products came from certain plants. The list can continue with the pollutants with infectious action represented by various pathogenic germs that can be found in the atmosphere.

The air plays an important epidemiological role, constituting the transmission route for a large number of pathogens. Infectious diseases that are transmitted through the air are childhood diseases (measles, rubella, scarlet fever, chicken pox etc.) the flue and other respiratory viruses, microplasmosis, diphtheria, smallpox, tuberculosis, pneumonia, various respiratory mycoses etc. There are diseases that, 
in addition to other routes of transmission, can spread by air, such as polio, tularemia, or less often, plague, coal etc. Also, the pathogenic flora or conditioning pathogenicflora from the air can cause wound or burn infection. The survival of the pathogenic or conditionally pathogenic germs in the air depends on a number of factors. In general, the air does not offer conditions for the development of the microflora of human origin, their survival being limited by the existence of unfavorable conditions. In the air there is no nutritional support for microorganisms that parasitize human or animal organisms. To these unfavorable factors is added the existence of agents with bactericidal or bacteriostatic action, of which the most important is the ultraviolet radiation. [10-12]

\section{Conclusions}

The most known impacts on health and implicitly on the quality of life refer to the pollution of the ambient air, to the inadequate quality of the water and to the insufficient hygiene. There are a number of categories that contain chemicals substances dangerous to the human health, substances and preparations that present, directly or through the interactions they have, risks of disease to the population. In the natural environment there are conditions and elements that, taken separately or as a whole, have an impact on human health and on the population, generally. Drinking water quality can be an important factor in the transmission of diseases among the population. Waterborne diseases can be infectious diseases (bacterial, viral, parasitic) and non-infectious diseases with symptoms. Through the presence in the air of various pollutants with irritating, asphyxiating, carcinogenic, allergenic action, there are created conditions that have a directly influence on the health and quality of life. The air plays an important epidemiological role and is the path by which numerous pathogens are transmitted. Bacteriological analysis of the air allows the hygienic characterization of the potential that the environment has in the aerogenic transmission of the infections.

\section{References}

[1] Berca, M., General ecology and environmental protection, Ceres Publishing House, Bucureşti, 2000.

[2] Ciolpan, O., Integrated monitoring of ecological systems, ArsDocendi Publishing House, Bucureşti, 2005.

[3] Ghizdavu, L., Bioinorganic chemistry, Ed. Poliam Cluj Napoca, 2000.

[4] Săndoiu, I.F, Integrated monitoring of ecological systems, MatrixRom Publishing House, Bucureşti, 2013.

[5] Vitaku, A., Baruti, B., Malollari, I., Shala, F., Journal of Environmental Protection and Ecology, Vol.14, No. 1, Thessaloniki Greece, 2013, p. 29-34.

[6] Traistă E., Madear G., Environmental hygiene. Air and water hygiene, Universitas Publishing House, Petroșani, 2000.

[7] Capatina, C., Simonescu, C.M., Journal of Environmental Protection and Ecology, 2, 2009, p. 313.

[8] Popa, P., Patrichie N., Chemistry of the aquatic environment. General elements of hydrochemistry and ecotoxicology, Ceres Publishing House, București, 2001.

[9] Iordache, V., Ardelean F., Ecology and environment protection, MatrixRom Publishing House, București, 2007

[10] Cîrțînă, D., Traistă E., Traistă C., Danciu C., Environmental sanitary chemistry, Academica Brâncuși Publishing House, Tg-Jiu, 2017.

[11] Dinu V., Truţia E., Cristea-Popa E., Popescu A., Medical biochemistry, Bucureşti, 1996.

[12] Mănescu S., Cucu M., Diaconescu M. L., Environmental health chemistry, Medicală Publishing House, Bucureşti, 1994. 


\title{
Evolutions and structural changes in secondary vocational education in Romania during the last three decades
}

\author{
Marian Zaharia ${ }^{1}$, Aniela Bălăcescu ${ }^{2}$ \\ 1 Association for Democracy, Education, Respect, Targu-Jiu, Romania \\ 2 "Constantin Brancuşi”" University of Targu-Jiu, Romania \\ E-mail: marianzaharia53@gmail.com, anielabalacescu@yahoo.com
}

\begin{abstract}
The study focused on capitalizing on the data provided by the National Institute of Statistics of Romania to outline the amplitude of secondary vocational education, its characteristics and the identification of disparities at regional level. The research carried out within this approach uses a methodology based on regression models that captures the changes that have occurred in the evolution of the investigated phenomenon. The study can be support in the formulation of suitable educational policies.
\end{abstract}

Keywords: education levels, secondary vocational education, development regions, Romania

\section{Introduction}

The continuous development of the economic and social systems, the transition to the knowledgebased economy and the continuous diversification of the labor market requirements, create continuous pressures on the educational systems, both in terms of the applicability of the knowledge provided and in ensuring the compatibility between the national educational systems. Under the conditions of globalization, education systems must be directly linked to the labor market [1] so as to build skills and abilities for future members of society [2], which will lead to sustainable economic and social development $[3,4]$.

Viewed from the point of view of systems theory, education and economics are two open systems that are interconditioned [5]. The connections between them must function in such a way as to produce positive effects in both, in the sense that economic development must stimulate the development of education system, in general and also the vocational education, and this will provide a trained workforce that will produce economic development.

Although secondary vocational education, a few decades ago, was considered inferior compared to general secondary education [6], starting with the last decade of the last century, its role in the formation of the workforce is beginning to be reconsidered [7]. Furthermore, in the study, Silliman and Virtanen [8] point out that the graduates of secondary vocational education have a higher competitive advantage in the labor market compared to those with general secondary education level.

The development of secondary vocational education is closely linked to the need to change and adapt educational systems to the needs of economic and social development [9], all the more so, as this is in direct connection with the economy and the business world, education oriented in this sense, being a key factor in sustainable development, social mobility and raising the standard of living [10].

At the level of European educational policies, by signing in 2002 the Copenhagen Declaration on strengthening European cooperation in vocational training, favorable premises have been created for the compatibility of the national educational process with the tendencies and good practices used in 
the EU Member States. The measures of reform of vocational education were also supported by the implementation of numerous projects carried out within the PHARE program [11].

In Romania, the high school education fields were defined by the Education Law no. 84 of July 24, 1995 [12] which stated in Art. 24. - (1) that "high school education works, as a rule, with the following profiles: theoretically - real and humanist -, informational, pedagogical, technical, economic, administrative, agricultural, forest, agro mountain, military, art, sports and theology". This law was amended and supplemented by Government Ordinance no. 151/1997 that reformulates Art. 24. - (1) defining the following fields and profiles: "a) the theoretical profile with the humanist and real profiles; b) the technological profile with the technical profiles, services, exploitation of natural resources and environmental protection; c) vocational profile with military, theological, sports, artistic and pedagogical profiles".

In the context of the ones outlined above, the paper aims to identify and highlight the main structural and dynamic characteristics of vocational secondary education in Romania, as organized by law 84/1995 and subsequent amendments and completions, the period under review being 1997- 2018.

The paper was structured in four sections, as follows: this introduction, the second section describes the research methodology, respectively the identification of variables used to analyze the evolutions of vocational education in Romania, the use and testing of regression models for variable analysis, section 3 presents the results of the tests and their interpretation, and the last section was dedicated to the general conclusions.

\section{Methodology}

The data series used in the analysis of the evolutions of vocational education in Romania are based on the series of data available in NIS databases [13]. The main data sources were constituted by the data series on enrolled population, by level of education, gender, macro regions, development regions and counties [14] in 1997-2018 period. Of these, in accordance with ISCED [15] and the Law of National Education Law 1/2011 [16], were extracted the data series regarding the evolution of the number of students enrolled in high school education, in the profiles: military, theological, sports, artistic and pedagogical. Starting from this, six main indicators were defined (Table 1).

Table 1. The variables used to analyze the evolutions of vocational education in Romania

\begin{tabular}{llc} 
Indicator & \multicolumn{1}{c}{ Significance } & Units \\
\hline SVE & Students enrolled in vocational education & number \\
SNE & Students enrolled in normal schools (Pedagogical High Education) & number \\
SAP & Students enrolled in high schools with artistic profile & number \\
SPES & Students enrolled in high schools with a physical education and sports program & number \\
SMS & Students enrolled in military high school & number \\
STS & Students enrolled in theological seminars & number
\end{tabular}

To identify the characteristics of the evolution of the variables in the period included in the analysis, as well as for their analysis, regression models were used, of the form:

$$
Y(t)=a+\sum_{k=1}^{m} b_{k} \cdot t^{k}+\varepsilon, \quad t \in[1, n]
$$

In (1), the parameters $a, b_{k} \in \mathfrak{R}, k=\overline{1, m}, m$ is the order of the polynomial model and $n$ represents the number of time points of the analyzed series. 
Testing the validity of the models (1) was performed using the ANOVA methodology [17], and the evaluation of the quality of the estimates was carried out with the correlation ratio (R), and the coefficient of determination $\left(\mathrm{R}^{2}\right)$. The null hypothesis of test $\mathrm{F}$ is:

$\mathrm{HM}_{0}$ : the model is not statistically significant ( $F_{\text {calc }}<F_{\alpha, k, n-k-1}$ or Sig.F $>\alpha$ ).

Testing the statistical meanings of the model parameters (1) was performed using the bilateral $t$ (Student) test, whose null hypothesis is:

$\mathrm{HP}_{0}$ : the parameter $b_{k}$ and / or $a$ does not differ significantly from zero; is not statistically significant $\left(t_{\text {calc }}<t_{\alpha / 2, n-k-1}\right.$ or Sig.t $\left.>\alpha\right)$.

The identification of the models (1), as well as the testing of their statistical significance, and of their parameters, were performed using SPSS, for Confidence level 95\% (significance level $\alpha=0.05$ ).

\section{Results and discussions}

Between 1997 and 2018, the evolution of vocational education in Romania is characterized by a series of particularities at the level of each of the five profiles, both in terms of the number of students enrolled and the weightings of the profiles as a whole.

\subsection{Evolutions of vocational education in Romania}

In Romania, between 1997 and 2018, the number of students enrolled in secondary vocational education (SVE) had an oscillating evolution (Figure 1), both at the general level and at the level of the development regions, determined on the one hand by the changes in structure of the education system, and on the other hand by the demographic dynamics.

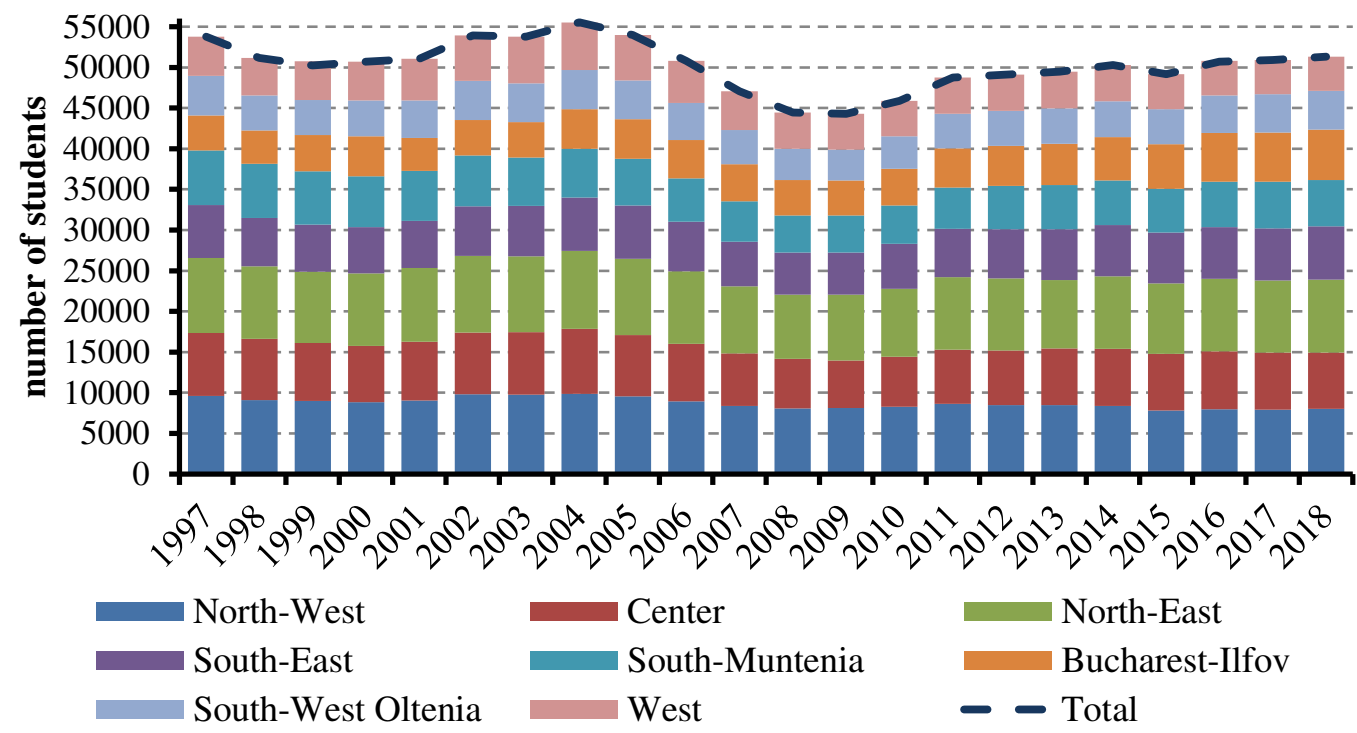

Figure 1. Evolutions of the number of students enrolled in vocational education in 1997-2018 period

During the analyzed period, the number of students enrolled in secondary vocational education has some variations depending on the periods. Thus, it can be seen that the number of students enrolled in secondary vocational education registered slight decreases during the periods 1997-1999, 2005-2009, and increases were registered during the periods 2000-2004, 2010-2018.

Starting with the 2009/2010 school year, the measure of increasing the number of schooling in high school education was applied, as a result of taking over the places of the SAM (school of arts and 
crafts) type of education, thus significantly increasing the number of pupils. enrolled in secondary and vocational education, respectively [18].

If in 1997, 53753 students were included in secondary vocational education, at the end of the period analyzed, in 2018 at this educational level there were 51323 students, representing a decrease of $4.5 \%$, due in particular to the decrease of the school population.

In territorial profile, the evolution of the students from secondary vocational education had the same irregular dynamics, as at national level. It should be noted that if at the beginning of the period analyzed, most of the students enrolled are in the North-West region (9197 students), at the end of the period, this region is surpassed by the North-East Region, which has a number of 8956 students compared to 8017 existing students in the North West Region. The West Region is characterized by a low level of students enrolled in secondary vocational education compared to the other regions.

Regarding the share of the students enrolled in the secondary vocational education out of the total of the students enrolled in the secondary education, at the level of the regions it is possible to find a concave trajectory during the analyzed period. (Figure 2), with a significant decrease in the period 2005-2010 determined by the decrease of the school population and the educational reforms.

The increase of the number of students attending secondary vocational education in the last eight years is explained by the fact that this route has become an attractive option, given that it offers the student qualifications for which there are opportunities in the labor market.

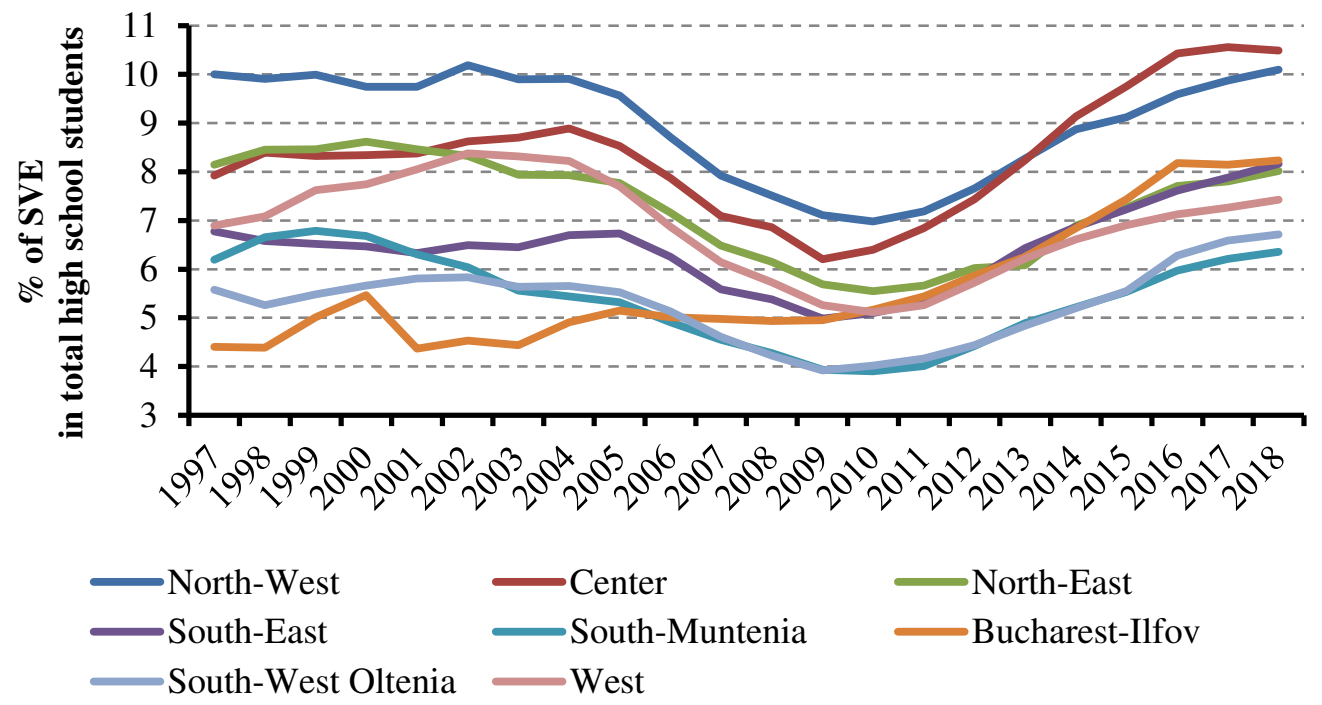

Figure 2. The changes of the shares of students enrolled in vocational education (SVE) in the total of students enrolled in high school in 1997-2018 period

If at the beginning of the period, the highest rate of inclusion in secondary vocational education existed in the North-West Region (10.0\%) at the opposite pole being the Bucharest Ilfov region $(4.4 \%)$, at the end of the analyzed period, at the top of the ranking will be found Center Region (10.49\%), and the last place is South-Muntenia Region (6.35\%)

It is worth noting that for Bucharest-Ilfov Region, the evolution of secondary vocational education was on a different trend compared to the other regions during the period under analysis. Thus, if in 2005, most of the regions recorded significant decreases in the weight of students enrolled in secondary vocational education (SVE) in the total of students enrolled in high school, except Bucharest Ilfov (increase compared to the previous year by 0.24 percentage points) and the region South-East (up from the previous year by 0.03 percentage points).

From 2010 there is an increase in the number of students attending secondary vocational education at both national and regional level, with a more pronounced growth rate for Bucharest-Ilfov Region 
(with a share of students enrolled in secondary vocational education in total students registered in high school in 2018 by 8.23\%), North-West Region $(10.10 \%)$ and Center Region $(10.49 \%)$. The region that registered at the end of the analyzed period the lowest weight of the students who opted for the profiles in the vocational sector was South-Muntenia (6.35\%)

The analysis of participation in secondary vocational education on training profiles in the period 1997-2018 is shown in figure 3.

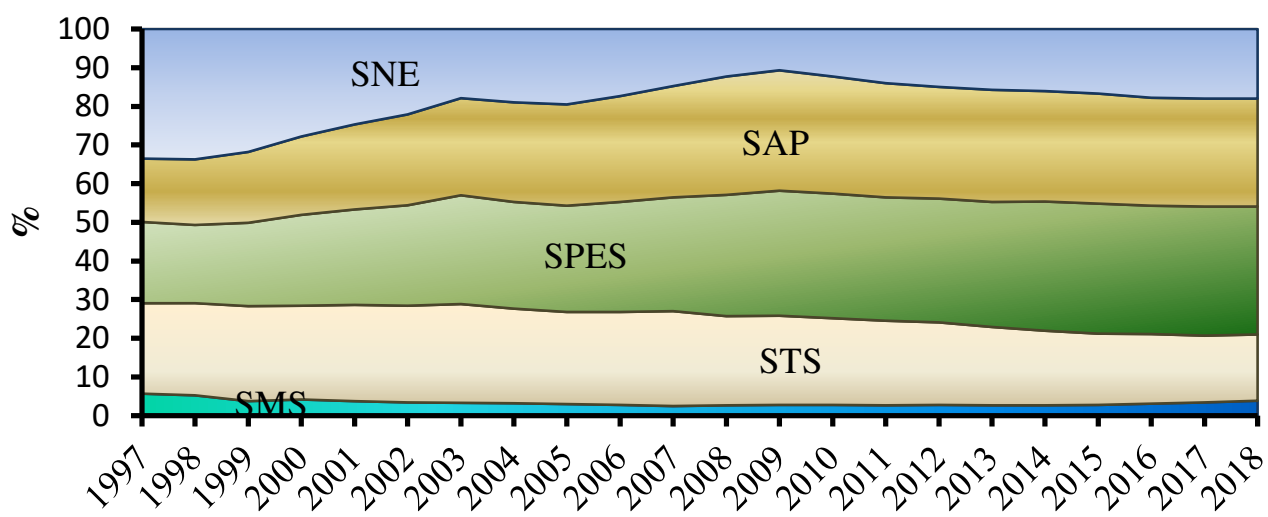

Figure 3. Evolutions of the shares of educational profiles, in total students enroled in secondary vocational education in $1997-2018$ period

On average, during the period analyzed 1997-2018, the highest shares are noted for Students enrolled in high schools with a physical education and sports program (SPES - 28.94\%), followed by Students enrolled in high schools with artistic profile (SAP - 25.94\%), Students enrolled in theological seminars (STS-22.30\%), Students enrolled in normal schools Pedagogical High Education (SNE$19.49 \%$ ) and Students enrolled in military high school (SMS) - 3.32\%).

\subsection{Pedagogical High Education}

The evolution of the number of students enrolled in normal schools in 1997-2018 is generally similar to that recorded in secondary vocational education, with variations of increases and decreases as can be seen in figure 4 .

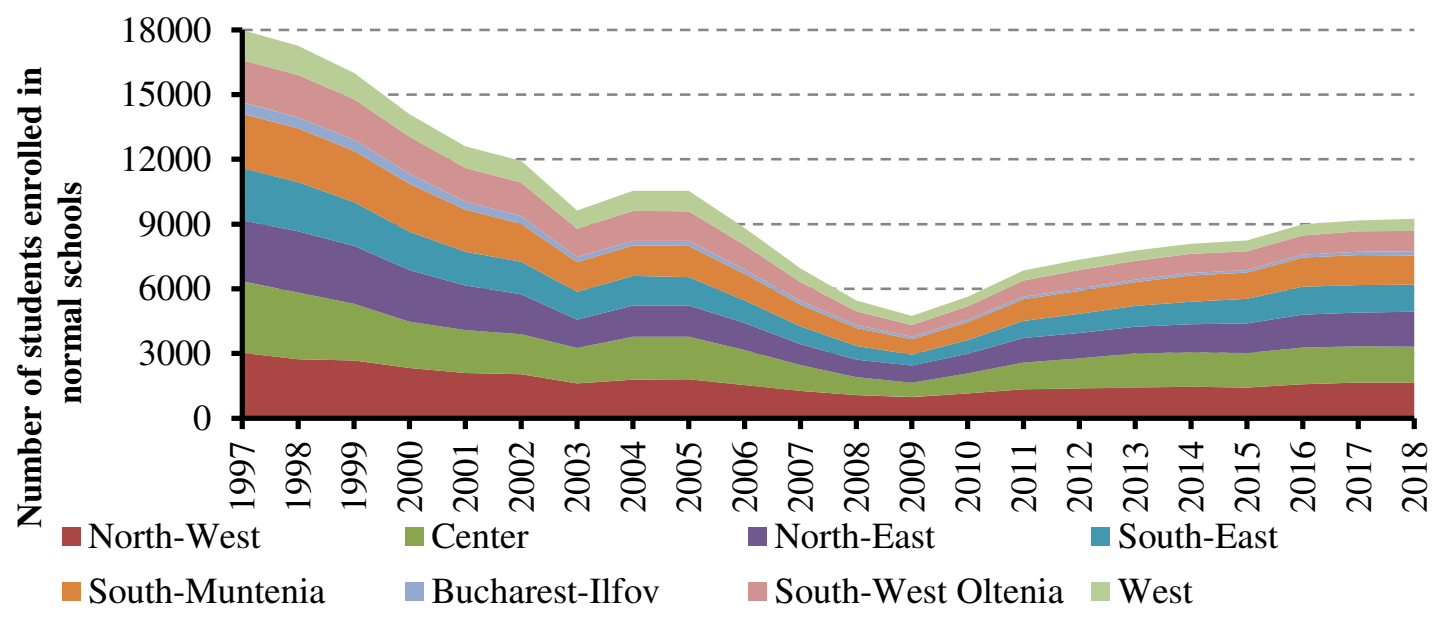

Figure 4. Evolutions of the number of students enrolled in normal schools in 1997-2018 period

The lowest value of the number of students enrolled in normal schools in 1997-2018 was recorded in 2010 (109 students) in Bucharest-Ilfov, and the highest value was recorded in 1997 (3312 students) 
in the Center Region. Unfortunately, the next 12 years were characterized by a decrease in the number of students enrolled in normal schools in all regions, and during 2010-2018, there was a growing trend, but below the level recorded at the beginning of the analyzed period.

As against of 1997, in 2018 there were no significant changes in the share of students enrolled in pedagogical high schools by development regions (figure 5). In 2018, the minimum values of the share of students enrolled in pedagogical high schools were registered in Bucharest-Ilfov Region (2\%), and the maximum values were registered in North-West Region (18\%) and Center Region (18\%). . Between the two values of minimum and maximum, the regional hierarchy according to the share of students enrolled in pedagogical high schools was: North-East (17\%), South-Muntenia (15\%), SouthEast (14\%), South-West Oltenia (10\%), West (6\%).

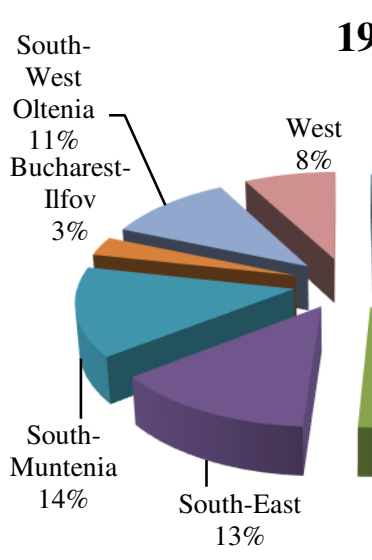

1997

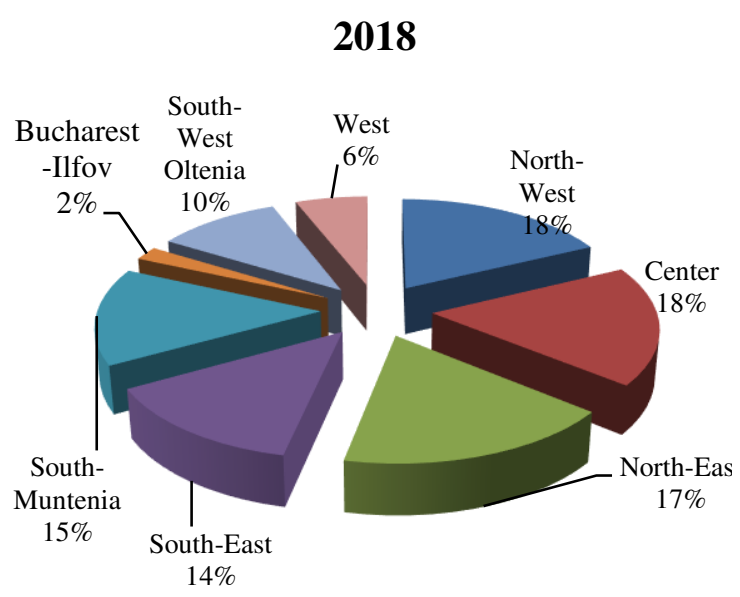

Figure 5. Evolutions of the share of students enrolled in pedagogical high schools by development regions in 1997 and 2018

\subsection{Students enrolled in high schools with artistic profile}

During the analyzed period, both the number of high schools with an artistic profile, as well as the students enrolled in the high schools with this profile, had a significantly different evolution from that of secondary pedagogical education. This evolution is characterized by three distinct periods: a period of upward growth (1998-2004), a crossing of a minimum (2004-2011) and a period of relative stability (2011-2018).

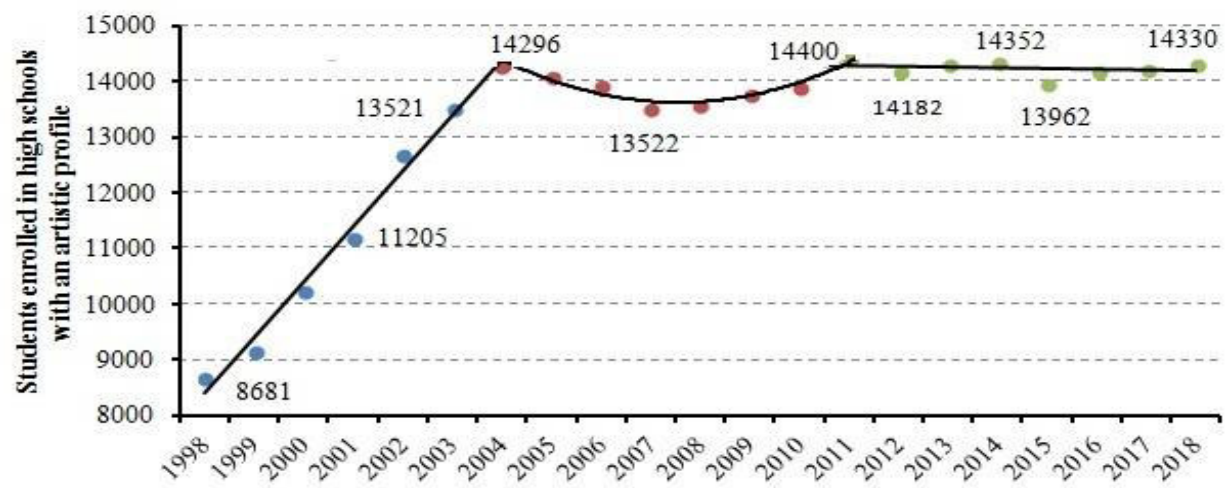

Figure 6. The characteristics of the evolution of the number of students enrolled in high schools with artistic profile between 1998-2018 
Taking these aspects into account, three evolution models were tested. The results obtained (Table 2) show that of the three models, only the first two are valid (statistically significant), for the third one (Model A3), given that Sig.F $=0.597>\alpha=0.05$, the hypothesis is accepted. null $\mathrm{HM}_{0}$.

Table 2. Results of testing the statistical significance of the evolution models of the number of students enrolled in high schools with artistic profile

\begin{tabular}{|c|c|c|c|c|c|c|c|c|c|}
\hline \multirow{2}{*}{ Model } & \multirow{2}{*}{ Period } & \multicolumn{4}{|c|}{ Models validation } & \multicolumn{4}{|c|}{ Regression validation } \\
\hline & & $\mathrm{R}$ & $\mathrm{R}^{2}$ & $\mathrm{~F}$ & Sig.F & \multicolumn{2}{|c|}{ Coefficients } & $\mathrm{t}$ & Sig.t \\
\hline \multirow{2}{*}{ A1 } & \multirow{2}{*}{ 1998-2004 } & \multirow{2}{*}{0.995} & \multirow{2}{*}{0.989} & \multirow{2}{*}{467.653} & \multirow{2}{*}{0.000} & $\mathrm{a}$ & 7402.14 & 35.81 & 0.000 \\
\hline & & & & & & $\mathrm{b}$ & 999.54 & 21.63 & 0.000 \\
\hline \multirow{3}{*}{ A2 } & \multirow{3}{*}{ 2004-2011 } & \multirow{3}{*}{0.949} & \multirow{3}{*}{0.861} & \multirow{3}{*}{22.691} & \multirow{3}{*}{0.003} & $\mathrm{a}$ & 14889.77 & 90.99 & 0.000 \\
\hline & & & & & & $\mathrm{b}_{1}$ & -555.23 & -6.65 & 0.001 \\
\hline & & & & & & $\mathrm{b}_{2}$ & 60.83 & 6.72 & 0.001 \\
\hline \multirow{2}{*}{ A3 } & \multirow{2}{*}{ 2011-2018 } & \multirow{2}{*}{0.222} & \multirow{2}{*}{0.049} & \multirow{2}{*}{0.312} & \multirow{2}{*}{0.597} & $\mathrm{a}$ & 14305.04 & 123.74 & 0.000 \\
\hline & & & & & & $b$ & -12.79 & -0.222 & 0.597 \\
\hline
\end{tabular}

Source: author calculations using SPSS

For the period 1998-2004, taking into account that $\mathrm{R} 2=0.989$, it turns out that the model offers a very good description of the evolution of the number of students enrolled in high schools with artistic profiles during this period. The model is:

$$
S A P_{1998-2004}(t)=7402.14+999.54 \cdot t+\varepsilon, \quad t_{1998}=1
$$

The value of parameter $b$ (the slope of the regression line) shows that in this period, the number of students enrolled in high schools with artistic increased by approximately 1000 students annually, reaching in 2004 to 14298 students, 64.68\% more than in 1998.

The second period, 2004-2011 shows a period of recoil, followed by a return of the number of students enrolled in this education profile. From an econometric point of view, the characteristic model of this period is a parabola of the form:

$$
S A P_{2004-2011}(t)=14889.77-555.23 \cdot t+60.83 \cdot t^{2}+\varepsilon, \quad t_{2004}=1
$$

The peak of the parabola is located in the year 2007 when the number of students enrolled in high schools with artistic profiles registers a minimum of 13552 students. Starting with 2008 there is a comeback so that in 2011 the number of students enrolled in this profile (14400 students) slightly exceeds (104 students) their number in 2004.

The third period (2011-2018) is characterized by alternating trends around a slightly decreasing trend, number of students enrolled in high schools with artistic profiles evolving between a maximum of 14400 students in 2011 and a minimum of 13962 students, in 2015.

To provide an intuitive picture of the evolution of the share of students enrolled in high schools with an artistic profile in the total number of students enrolled in secondary vocational education and their area of distribution at regional level, figure 7 was constructed, which captures the range of minimum and maximum throughout the analyzed period (1997-2018). 


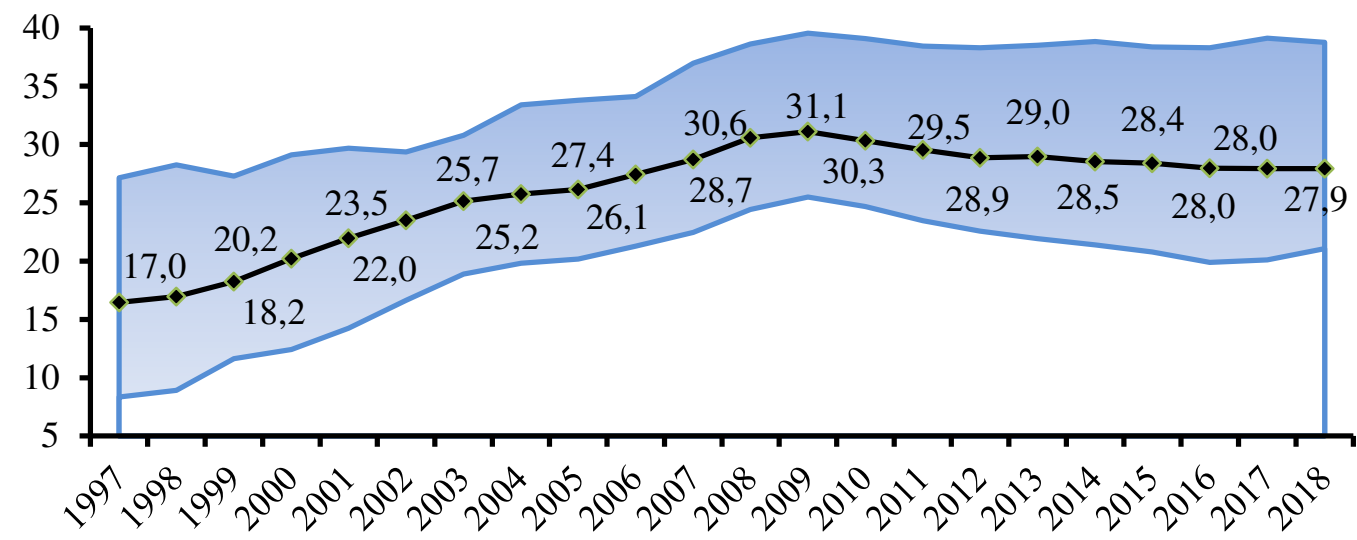

Figure 7. The evolution of the share of students enrolled in high schools with an artistic profile in the total number of students enrolled in secondary vocational education and their area of distribution at regional level

If in 1997, at the regional level, the highest share of students enrolled in high schools with an artistic profile in the total number of students enrolled in secondary vocational education was found in Bucharest-Ilfov (27.15\%), and the most low value in South-Muntenia (8.33\%), at the end of the period South-Muntenia recorded the lowest share (21.07\%), while the highest value is registered in the West Region (38.77\%). Therefore, during the period analyzed there are changes in the regions regarding the share of students enrolled in high schools with an artistic profile in the total number of students enrolled in secondary vocational education.

Compared to 2008, in 2018 there were no significant changes in the share of students enrolled in high schools with an artistic profile by high school types (figure 8). In 2018, the minimum values of the share of students enrolled in high schools with an artistic profile by high school types were registered at the high schools with plastic arts profile (46\%), and the maximum values were registered at the high schools with choregraphy profile ( $2 \%$ ). Between the two minimum and maximum values, the hierarchy the share of students enrolled in high schools with an artistic profile by high school types was: music (31\%), visual arts (14\%), theater (7\%).
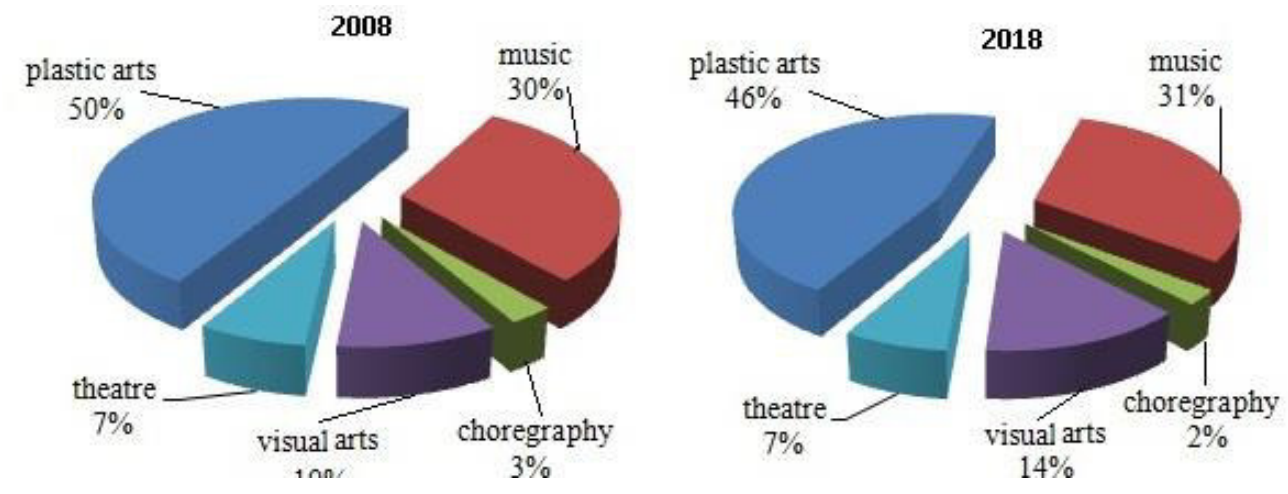

Figure 8. The share of students enrolled in high schools with an artistic profile by high school types in 2008 and 2018

\subsection{Students enrolled in high schools with a physical education and sports program}

The evolution of the number of students enrolled in high schools with a physical education and sports program is also characterized by three periods. 
Between 1998-2003, the evolution of students enrolled in high schools with a physical education and sports program shows an upward trend. Thus, compared to 1998 when a number of 10331 students was registered, in 2003 a number of 15068 students was registered, which represents an increase of 45.85\%. At the regional level, between 1998-2003, the highest value of Students enrolled in high schools with a physical education and sports program was registered in 2003 in the North-East region (2894 students), and the lowest in 1998 in Center Region (723 students).

Between 2004-2007, the evolution of students enrolled in high schools with a physical education and sports program shows a downward trend. Thus, compared to 2004 when a number of 15313 students was registered, in 2007 a number of 13863 students was registered, which means a decrease of 9.47\%. At the regional level, in 2004-2007, the highest value of students enrolled in high schools with a physical education and sports program was registered in 2004 in the North-East region (2952 students), and the lowest in 2007 in Center Region (1070 students).

Between 2008-2018, the evolution of students enrolled in high schools with a physical education and sports program shows an upward trend. Thus, compared to 2008 when a number of 13947 students was registered, in 2007 a number of 16982 students was registered, which represents an increase of $21.76 \%$. At the regional level, in 2008-2018, the highest value of students enrolled in high schools with a physical education and sports program was registered in 2018 in the Bucharest-Ilfov region (3195 students), and the lowest in 1998 in West Region (1034 students).

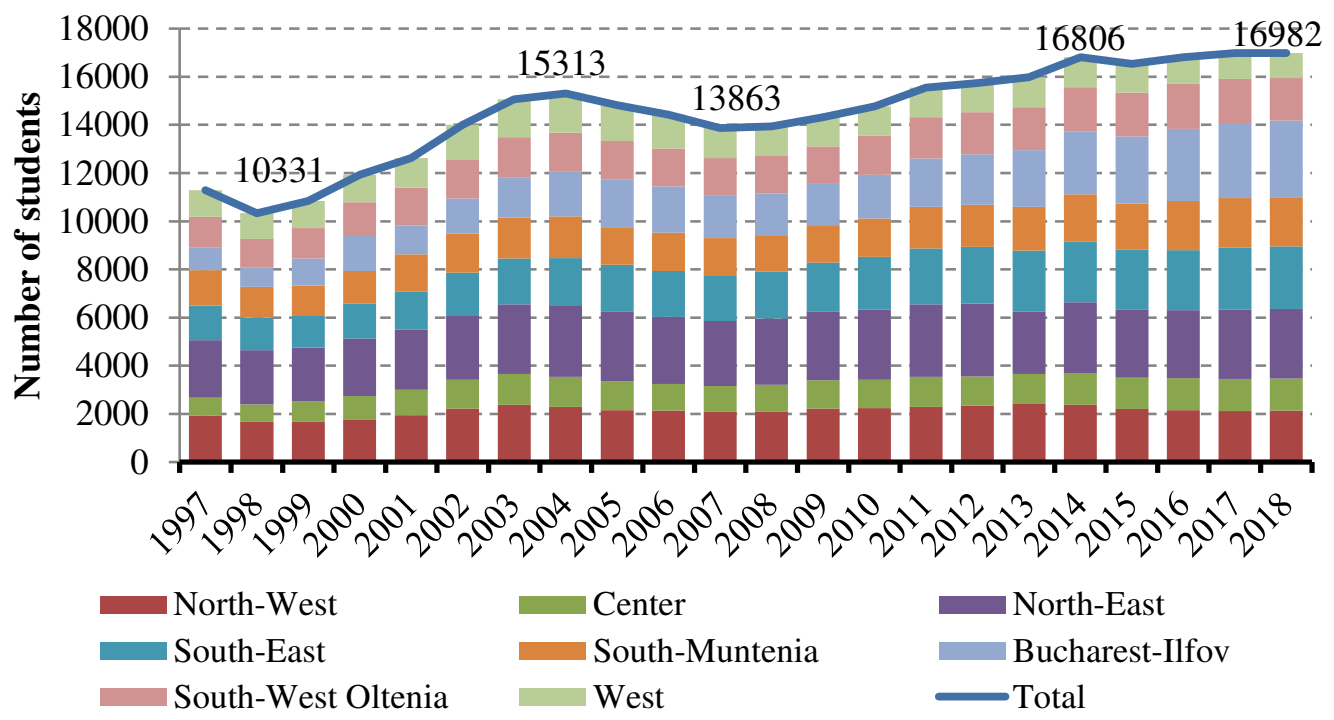

Figure 9. Evolutions of the number of students enrolled in high schools with a physical education and sports program, in 1997-2018 period

Between 1998 and 2004 the number of students increases from 10331 to 15313 students. It should be noted that the annual increase is approximately constant which led to a linear upward evolution of the form:

$$
\operatorname{SEPES}_{1998-2004}(t)=9081.2+966.94 \cdot t+\varepsilon, \quad t_{1998}=1
$$

After 2008, was recorded a regression of the number of students enrolled in high schools with a physical education and sports program, described by model (5), a regression that continues until 2008, so that in 2008 their number was $9.46 \%$ lower only in 2004.

$$
\operatorname{SEPES}_{2004-2008}(t)=15795.5-476.0 \cdot t+\varepsilon, \quad t_{2004}=1
$$

At the level of the school year 2008-2009, there is a slight stabilization around 13900 students, followed by an upward evolution (model 6) which is maintained until the end of the analyzed period. 
In 2018, a number of 16982 students enrolled in high schools with a physical education and sports program were registered.

$$
\operatorname{SEPES}_{2008-2018}(t)=13946.8+318.24 \cdot t+\varepsilon, \quad t_{2008}=1
$$

The results of the tests performed to verify the validity of the models (4-6) are presented in table 3. Given that all Sig.F values corresponding to the three models are lower than the significance threshold $(\alpha=0.05)$, as well as that the values of the ratio of correlation $(\mathrm{R})$ and of the coefficient of determination (R2) are very close to 1 , it results that the null hypothesis $\mathrm{HM}_{0}$ is rejected and, consequently, models (4-6) describe very well the evolution of number of students enrolled in high schools with a physical education and sports program, during the analyzed period.

Also, considering that on the one hand the Sig.t values are lower than the significance threshold, and on the other hand the confidence intervals for $95 \%$ confidence level do not include the value 0 , it follows that the values of the slope of the regression line (parameter b) are statistically significant.

Table 3. Test results of statistical significance of the evolution models of the number of students enrolled in high schools with a physical education and sports program.

\begin{tabular}{|c|c|c|c|c|c|c|c|c|c|r|r|}
\hline & & \multicolumn{4}{|c|}{ Model validation } & \multicolumn{6}{|c|}{ Regression validation } \\
\hline & Period & $\mathrm{R}$ & $\mathrm{R}$ & $\mathrm{F}$ & Sig.F & $\mathrm{b}$ & Std.Err & $\mathrm{t}$ & Sig.t & \multicolumn{2}{|c|}{$\begin{array}{c}\text { 95\% } \\
\text { Conf.Interval }\end{array}$} \\
\cline { 5 - 12 } & & & & & & & & & & Lower & Upper \\
\hline S1 & $1998-2004$ & 0.992 & 0.984 & 248.6 & 0.000 & 966.94 & 61.32 & 15.7 & 0.000 & 796.7 & 1137.2 \\
\hline S2 & $2004-2008$ & 0.998 & 0.997 & 612.6 & 0.002 & -476.0 & 19.10 & -24.9 & 0.002 & -558.1 & -393.8 \\
\hline S3 & $2008-2018$ & 0.958 & 0.981 & 101.3 & 0.000 & 318.24 & 31.62 & 10.1 & 0.000 & 246.7 & 389.8 \\
\hline
\end{tabular}

Source: author calculations using SPSS

Compared to 2008, in 2018 there were significant changes in the share of students enrolled in high schools with a physical education and sports program by regions (figure 8). In 2018, the minimum values of the share of students enrolled in high schools with a physical education and sports program were registered in the West region (6\%), and the maximum values were registered in Bucharest-Ilfov (19\%). Between the two minimum and maximum values, the hierarchy of students enrolled in high schools with a physical education and sports program by regions was: North-West (13\%), North-East (17\%), South-East (15\%), South-Muntenia (12\%), South-West Oltenia (10\%), Center (8\%). It is noted that the most pronounced changes were in the North-East region (a decrease by 5 percentage points) and Bucharest-Ilfov (an increase by 11 percentage points).

1998

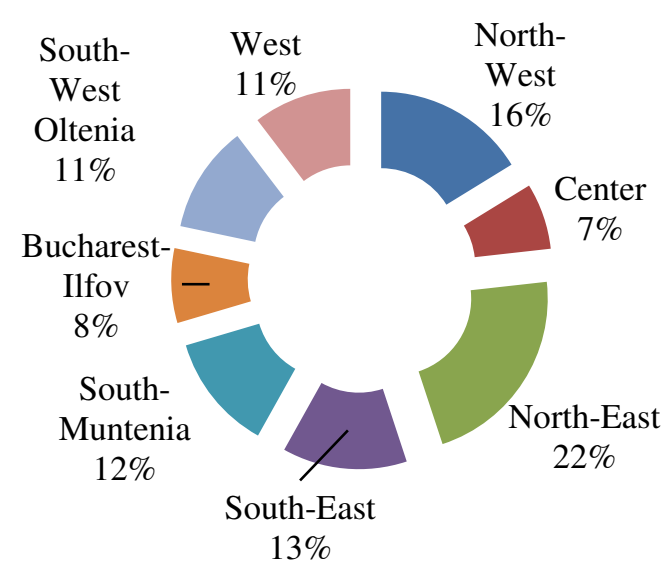

2018

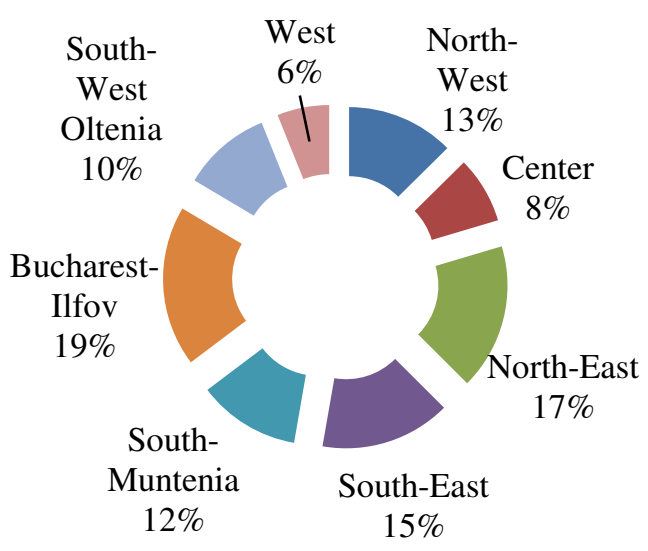

Figure 9. The share of students enrolled in high schools with a physical education and sports program in 1998 and 2018 


\subsection{Students enrolled in theological seminars}

During the analyzed period, after a slight increase until 2003, the number of students enrolled in theological highs decreases significantly in most of the development regions.

As can be seen from figure 10 and figure 1, the evolution of the number of students enrolled in the theological high schools is not similar to the one registered in the secondary vocational education.

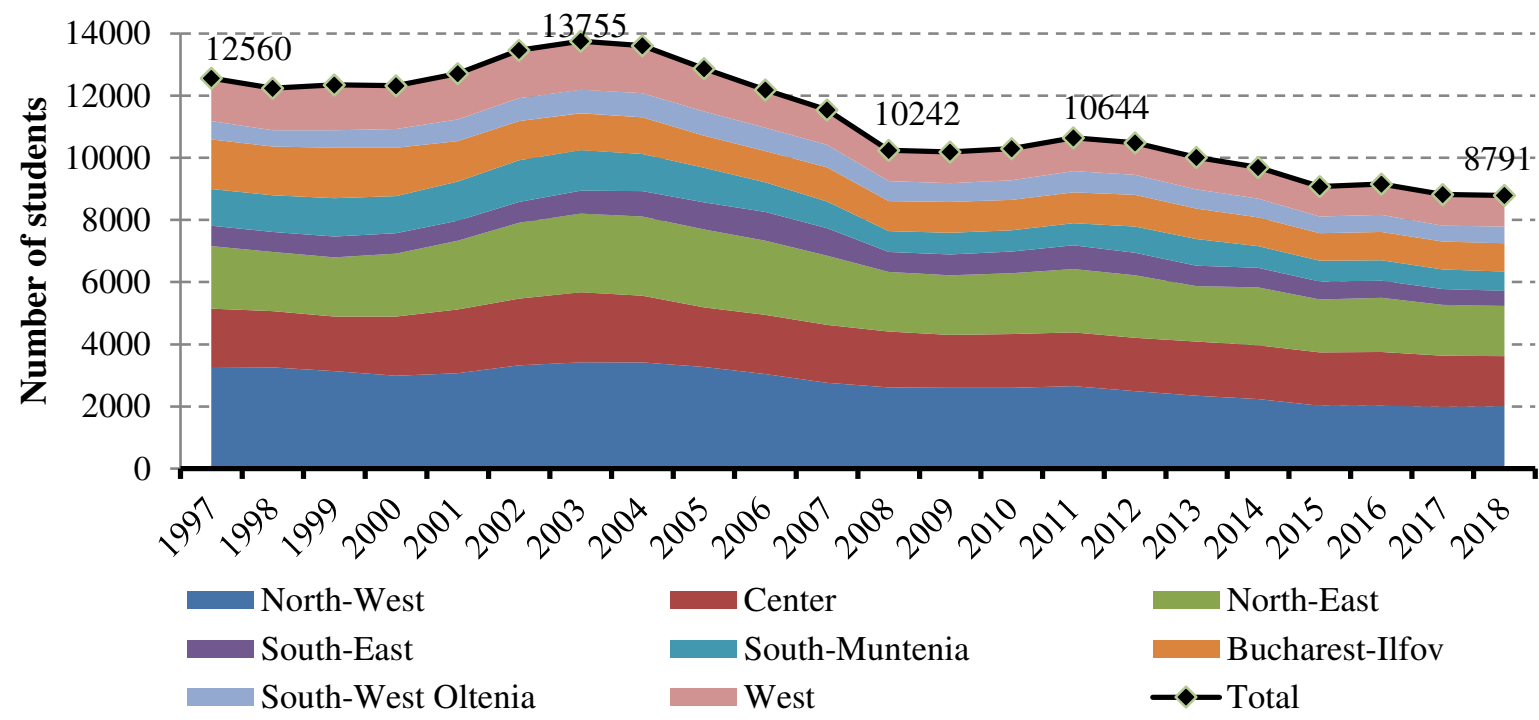

Figure 10. Evolutions of the number of students enrolled in theological seminars, in 1997-2018 period

From figure 10, it can be seen that after the period of increase (1997-2003), the number of students enrolled in theological seminars is on a downward trend both at national and regional level.

If in 1997, in the theological seminars were included 12560 students, at the end of the period analyzed, in 2018 there were 8791 students, representing a 70\% decrease, due on the one hand to the decrease of the school population, but especially to the reduced opportunities offered by the labor market.

In the regional profile, the evolution of the number of students enrolled in theological seminars had the same downward trend, as at national level. The West region is characterized by an increased level of theological seminars compared to the other regions, at the opposite pole being the South-East region.

Table 4. Results of testing the statistical significance of the evolution models of the number of students enrolled in theological seminars

\begin{tabular}{|c|c|c|c|c|c|c|c|c|c|}
\hline \multirow{2}{*}{ Model } & \multirow{2}{*}{ Period } & \multicolumn{4}{|c|}{ Models validation } & \multicolumn{4}{|c|}{ Regression validation } \\
\hline & & $\mathrm{R}$ & $\mathrm{R}^{2}$ & $\mathrm{~F}$ & Sig.F & \multicolumn{2}{|c|}{ Coefficients } & $\mathrm{t}$ & Sig.t \\
\hline \multirow{4}{*}{$\mathrm{T} 1$} & \multirow{4}{*}{$1997-2008$} & \multirow{4}{*}{0.967} & \multirow{4}{*}{0.935} & \multirow{4}{*}{38.601} & \multirow{4}{*}{0.000} & $\mathrm{a}$ & 12891.57 & 27.53 & 0.000 \\
\hline & & & & & & $\mathrm{b}_{1}$ & -635.13 & -2.12 & 0.067 \\
\hline & & & & & & $b_{2}$ & 194.68 & 3.71 & 0.006 \\
\hline & & & & & & $\mathrm{b}_{3}$ & -13.45 & -5.06 & 0.001 \\
\hline \multirow{2}{*}{$\mathrm{T} 2$} & \multirow{2}{*}{ 2009-2018 } & \multirow{2}{*}{0.908} & \multirow{2}{*}{0.824} & \multirow{2}{*}{37.405} & \multirow{2}{*}{0.000} & $\mathrm{a}$ & 10879.87 & 50.69 & 0.000 \\
\hline & & & & & & $\mathrm{b}$ & -211.52 & -6.12 & 0.000 \\
\hline
\end{tabular}

Source: author calculations using SPSS

At the level of Romania, the evolution in time of the number of students enrolled in theological seminars can be highlighted by two regression models (Table 3 ). The first model characterizes the 
evolution of the number of students enrolled in this profile during the period 1997-2008 and is of the form:

$$
\operatorname{STS}_{1997-2008}(t)=12891.57-635.13 \cdot t+194.68 \cdot t^{2}-13.45 \cdot t^{3}+\varepsilon, \quad t_{1997}=1
$$

With the exception of coefficient $b 1$, which is statistically significant for $90 \%$ confidence level $(\alpha=$ $0.10)$, the others are statistically significant for $95 \%$ confidence level $(\alpha=0.05)$. On the other hand, the value of the coefficient of determination $(\mathrm{R} 2=0.935)$ shows that model $(7)$ gives a very good description of the analyzed process, highlighting the two extreme points of the evolution of the number of students enrolled in theological seminars during this period. The first extreme point is a minimum, and corresponds to the needle 1998 (12242 students), and the second is a maximum, corresponding to 2003 (13733 students). The model further describes the downward evolution of the number of students enrolled in this profile until 2008, when their number reaches 10242 students.

The second period (2009-2018) corresponds to a linear model of form:

$$
\operatorname{STS}_{2009-2018}(t)=10879.87-211.52 \cdot t+\varepsilon, \quad t_{2009}=1
$$

The model (7), by the value of parameter $b$ (slope of the regression line) shows that during this period, the number of students enrolled in theological seminars decreased annually with approximately 212 students, reaching in 2018 to 8791 students enrolled in high schools with this profile.

\subsection{Students enrolled in military high schools}

The evolution of students enrolled in military high schools in the period 1997-2018 registered an oscillating evolution both at national and regional level, characterized by two periods, respectively a period of decline (1997-2007) and a period of growth (2008-2018). It should be noted that the level reached in 2018 is well below the level recorded in 1997, 1972 students compared to 3061 students.

At the territorial level, there are significant differences regarding the number of students enrolled in military high schools in the period 1997-2018. (Figure 11)

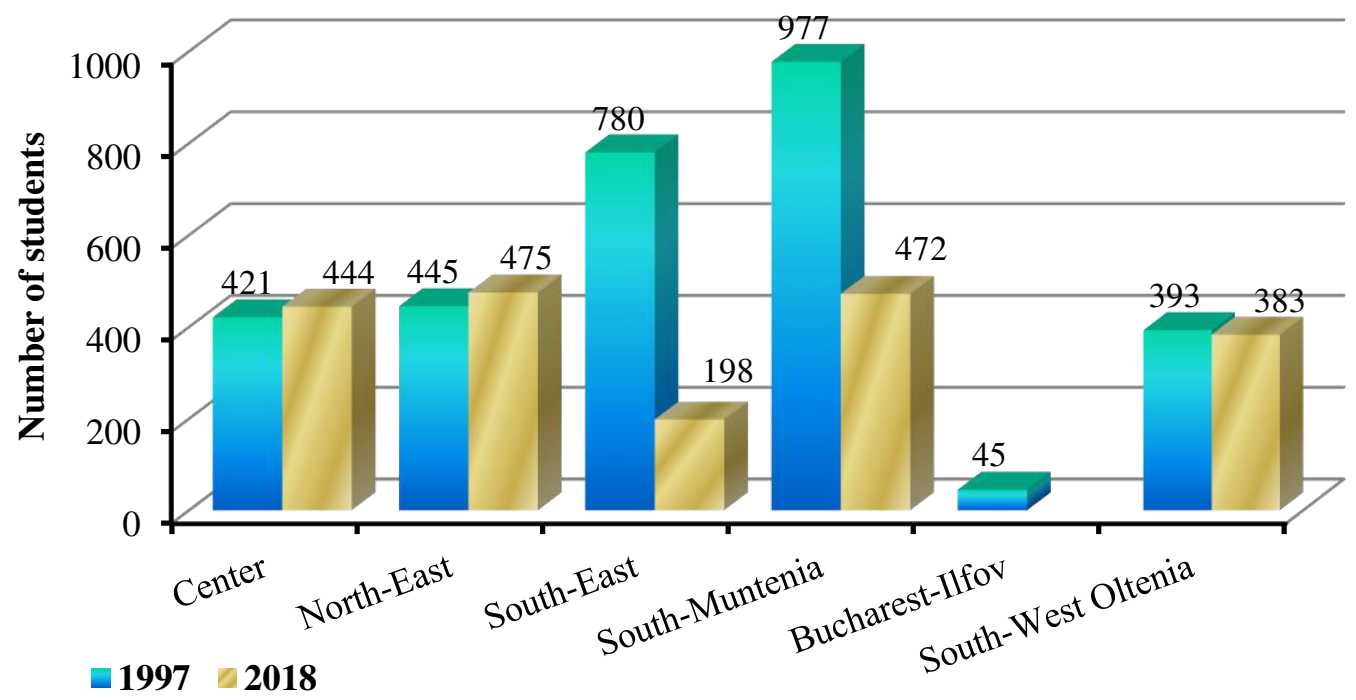

Figure 11. The number of students enrolled in military high school, in 1997 and 2018 at the level of the development regions

It is worth noting the significant decreases between the end and the beginning of the analyzed period in terms of Students enrolled in military high schools in the South-East regions $(-74.62 \%)$ and South-Muntenia (-51.69\%). In the rest of the other regions, except Bucharest-Ilfor and South-West Oltenia, there were small increases in the number of Students enrolled in military high schools. 


\section{Conclusions}

The secondary vocational education aims the specialization in various profiles (military, theological, sports, artistic and pedagogical) of all graduates in order to prepare for the labor market or to continue their studies.

The analysis of the number of students enrolled in secondary vocational education emphasizes that the demographic pressures, the reforms in the national education system and the opportunities offered by the labor market have produced structural changes at this level of education.

Between 1997-2018, the school population decreased by $17.8 \%$ for the level of secondary school education. Secondary vocational education was on the same downward trend, the school population enrolled in the vocational chain reaching in 2018 to be $4.5 \%$ lower than in 1997. For all the profiles in the vocational sector there were fluctuations during the analyzed period, with sub periods of decrease, especially at the beginning of the period analyzed, and sub periods of growth in the last years, but without reaching the level from the beginning of the period analyzed.

The structure by profiles of the students enrolled in secondary vocational education, in 2018, reflects the choice of most students to study at the physical education and sports program $(33.0 \%$ of total vocational), following artistic profiles (27.9\%), pedagogical high education (18.2\%), theological seminars $(17.1 \%)$, military high school $(3.8 \%)$.

The tendency of increasing in the last years of the number of students in secondary vocational education has been influenced by the action of multiple factors, of which the most significant were the desire to continue the studies, the educational offer and the access to the labor market.

\section{References}

[1] Nistoreanu T and Răduț E 2010 Strategies on Preparation by Education Pre-University of Resources Work for the Correlation of Request with Offer on Labor Market Annals of University of Craiova - Economic Sciences Series 1 issue 38 pp. 134-142

[2] Dima I C, Ciurea Vl and Man M 2010 Positioning Of Pre-University Education Into the National System of Education of Romania Polish Journal of Management Studies 1 issue 1 pp. 102-110

[3] Badea, Liana and Țîrcă (Pociovalisteanu), Diana-Mihaela, (2014), Education and sustainable development - a connection for the future, Annals - Economy Series, 4, issue , p. 87-93.

[4] Andrusca, Andreea-Oana and Negura, Elena-Luiza, (2014), Education - Part of Sustainable Development, Knowledge Horizons - Economics, 6, issue 2, p. 170-173.

[5] Papakitsos, Evangelos C., (2016), Systemic modelling for relating labour market to vocational education, International Journal for Research in Vocational Education and Training (IJRVET), 3, issue 3, p. 166-184.

[6] Meer, Jonathan, (2005), Evidence on the Returns to Secondary Vocational Education, No 04014, Discussion Papers, Stanford Institute for Economic Policy Research.

[7] Agodini, Roberto, Uhl, Stacey and Novak, Timothy, Factors That Influence Participation in Secondary Vocational Education, Mathematica Policy Research Reports, Mathematica Policy Research.

[8] Silliman, Mikko and Virtanen, Hanna, (2019), Labor Market Returns to Vocational Secondary Education, No 65, ETLA Working Papers, The Research Institute of the Finnish Economy.

[9] Đurić, Igor, Đurić, Dejan and Živković, Predrag, (2013), Secondary vocational education in service of economic growth and society development, Economics of Agriculture, 60, issue 4, number 162031.

[10] Mihaela, Maer Matei Monica, Cristina, Mocanu and Ana-Maria, Zamfir, (2018), Educational paths in Romania: choosing general or vocational education, HOLISTICA - Journal of Business and Public Administration, 9, issue 2, p. 127-136. 
[11] Pavelescu F M (2018), Învățământul din România în perioada 1919-2017, Academia Română, Institutul Național de Cercetări Economice, p.18, available on-line at: http://www.studii-economice.ro/2018/seince181221.pdf

[12] ISE (2004) Antologia legilor învăţământului românesc, Institutul de Științe ale Educației București, available on-line at: http://www.ise.ro/wp-content/uploads/2019/01/ANTOL_LEG_RO_2004.pdf

[13] National Insitute of Statistics, Romania, available on-line at http://www.insse.ro/cms/en

[14] International_Standard_Classification_of_Education, available on-line at: https://ec.europa.eu/eurostat/statisticsexplained/index.php/International_Standard_Classification_of_Education_\%28ISCED\%29

[15] National Insitute of Statistics, http://statistici.insse.ro:8077/tempo-online/\#/pages/tables/inssetable SCL103F - Enrolled population, by level of education, gender, macroregions, development regions and counties. Accesed on 2019 June 20

[16] Law of National Education ( Law 1/2011), Section 6, High school education, Art. 31. - (1) The Official Monitor of Romania, Year 179 (XXIII) - Nr. Monday, January 10, 2011 http://oldsite.edu.ro/index.php/articles/14847

[17] Zaharia Marian, Gogonea Rodica-Manuela - Econometrie. Elemente fundamentale, Editura Universitară, Bucureşti, 2009

[18] Ministerul Educației, Cercetării, Tineretului și Sportului Raport privind starea învăţământului preuniversitar din România 2011, available on-line at: https://www.edu.ro/sites/default/files/_fi\%C8\%99iere/Minister/2016/Transparenta/2016/ Raport_privind_starea_inv_preuniversitar.pdf 


\title{
Considerations regarding the evolution of COVID-19 in the South-Muntenia Region between June 11 and August 31, 2020
}

\author{
Rodica Manuela Gogonea ${ }^{1}$ \\ ${ }^{1}$ The Bucharest University of Economic Studies, Romania \\ E-mail: manuela.gogonea@csie.ase.ro
}

\begin{abstract}
Internationally, after the Second World War, the health and economic sector is facing a major challenge with a new disease: COVID-19. The transmission of the virus was quite fast so that the population of each country was affected. Given that quite a few cases of COVID-19 infection have been reported both internationally and regionally for Romania, we considered it important to observe and analyze the evolution of this disease in Taking into account the daily number of COVID-19 infections in each county in the South Muntenia region, between June 11 and August 31, 2020, the research included the analysis of evolutions of absolute and relative values compared to the total of Romania, the region included in the study, from one county to another or overnight. The results showed an overall growth trend for each county, mainly for Argeș, Prahova and Dâmbovița. Thus, it is necessary both to take new measures appropriate to the existing situation, customized at the level of each county, and to comply as drastically as possible with the measures to eliminate and prevent COVID-19 disease.
\end{abstract}

Keywords: COVID-19, counties, South Muntenia Region, Romania

\section{Introduction}

The year 2020 began with the rapid spread of the COVID-19 pandemic, which caused thousands of deaths worldwide. This has led to an international public health concern declared by the WHO since 30 January 2020 [1].

The problems facing the pandemic are many and quite little known. They have a spatial dimension that requires a detailed and in-depth approach [2]. In terms of health, there is a gradual need for research into the different dimensions and spatial aspects of disease and medicine. They intertwine spatial analysis, spatial-temporal dimensions with demographic aspects of health, presenting evidence of health inequalities and pandemics. [3, 4].

In this context, the concept of health geography can be highlighted with a predominantly utilitarian and analytical perspective in the territory. It includes structuralize approaches, either as a cultural and sociological view of social welfare, or as a sense of "place" for people [5].

Like any infectious disease, its rapid spread endangers public health by requiring important measures and actions, starting at the community level, then at the regional level and last but not least at the national level. In this context, due to measures that encourage hygiene and social distancing, the damage caused by blocking economic and social life has been gradually recognized in all countries. The measures taken were varied. 
They have undergone a different evolutionary trajectory from one state to another, including issues aimed at either intensifying hygiene by carefully washing hands, or closing certain units from small shops, restaurants, pubs, to malls, and even to banning public meetings. Governments have gradually resorted to quarantine of vulnerable people and restrictions on national and international travel [6].

In this context, Romania has gone through difficult situations, a fact confirmed by the number of cases that are quite high, from one period to another. Thus, during the pandemic, Romania faced different experiences and implemented various health and economic policies, at different times and in different forms, in order to end the pandemic and economic activities appropriate to the context were carried out, with favorable investments.

However, as in other countries [7,8], the heterogeneity of its impact in geographical areas was acute, people with high incomes abruptly reduced spending in mid-March 2020, enterprises laid off most low-income employees, leading to a rising unemployment in the more economically developed regions. At the same time, macroeconomic instruments in the form of stimulating aggregate demand or providing liquidity to enterprises had a reduced capacity to restore jobs because consumer spending was constrained by health problems.

At the Romanian level, considering the need to identify and develop for the future both health policies and economic and social strategies, the paper presents a dynamic, spatial explanatory description of the distribution of COVID-19 cases by counties, during 11 June - August 31, 2020, at the level of the South Muntenia region. The research elaborated from June 11 to August 31, 2020 focused on studying the evolution of COVID-19 during the summer. The aim is to conduct future research in the fall and maybe even winter, studying the differences that occur in the evolution of the disease from one season to another. The results obtained could be supplemented with aspects that highlight the impact in economic and social terms, thus determining, specifying and adopting measures to be applied in order to economic recovery of the South-Muntenia region.

Thus, the introductory part of the article is followed by a framework for presenting the characteristics of the number and weights of COVID-19 cases determined at the level of the period included in the analysis. In the chapter results and discussions are presented multiple aspects that highlight a general growth trend.

After presenting the evolution of the share of cases registered in the South Muntenia region between June 11 and August 31 in the total number of COVID-19 cases registered in Romania is analyzed both the number and the weights of COVID-19 cases registered until June 11 in counties of the South Muntenia region. The research continues with a rendering of the evolution of the total number of COVID-19 cases in the counties of the South Muntenia development region in the period included in the analysis.

The analysis of the evolutions of the daily increase of COVID-19 cases in the counties of the South Muntenia development region between June 11 and August 31 is followed by a description of the daily evolutions of the structural weights by counties for the number of COVID-19 cases in the South Muntenia development region. June 11 - August 31. The chapter ends with an overview of the number and weights of COVID-19 cases registered until August 31 in the counties of the South Muntenia region.

The article concludes with a chapter of conclusions that highlights that the counties of Arges, Prahova and Dâmbovița represent the counties of the South-Muntenia region which during the mentioned period registered the most significant increases in terms of the number of COVID-19 cases. In view of this fact, as a final conclusion it can be mentioned that, especially for these counties, it is necessary to adopt strict preventive measures and restrictions to be imposed and applied by local governments and health units involved in this extensive eradication process of COVID-19 disease. 


\section{Methodological aspects}

Taking into account the objective of the study to identify the evolution of COVID-19 disease in the counties of the South Muntenia region (Argeș, Călărași, Dâmbovița, Giurgiu, Ialomița, Prahova and Teleorman), seven variables were identified and used (Table 1).

Given the motivation to conduct the study, to identify and develop in the future health policies and strategies in economic and social terms during the article aimed to highlight the similarities and differences between them in terms of indicators analyzed, taking into account the data available in study period (June 11-August 31, 2020).

Table 1 List of variables

\begin{tabular}{|c|l|c|}
\hline No. & \multicolumn{1}{|c|}{ Variables } & Units \\
\hline 1 & The total number of COVID -19 cases in Romania (TNC_Rom) & number \\
\hline 2 & $\begin{array}{l}\text { Total number of COVID -19 cases in the South Muntenia development region } \\
\text { (TNC_SM) }\end{array}$ & number \\
\hline 3 & The total number of COVID -19 cases in county X (TNC_CX) & number \\
\hline 4 & Daily number of new COVID -19 cases registered in the county X & number \\
\hline 5 & $\begin{array}{l}\text { The share of the number of COVID -19 cases at the level of the South Muntenia } \\
\text { development region in the total number of cases registered in Romania }\end{array}$ & $\%$ \\
\hline 6 & $\begin{array}{l}\text { The share of the total number of COVID -19 cases in county X in the total number of } \\
\text { cases registered in the South Muntenia region }\end{array}$ & $\%$ \\
\hline 7 & $\begin{array}{l}\text { Share the daily number of new COVID -19 cases registered in county X in the total } \\
\text { number of cases registered in the South Muntenia region }\end{array}$ & $\%$ \\
\hline
\end{tabular}

The highlighting of the similarities and differences between the counties was based primarily on some important characteristics of the variables that represented basic indicators in the analyzes performed in the paper (table 2).

Table 2 Main characteristics of the total number of COVID -19 cases

\begin{tabular}{|l|l|r|r|r|r|r|}
\hline \multicolumn{2}{|c|}{} & Mean & Median & Maximum & Minimum & Std. Dev. \\
\hline \multicolumn{2}{|l|}{ TNC_Rom } & 46122.63 & 39648 & 87540 & 21182 & 20948.00 \\
\hline TNC_SM & 7187.49 & 6131 & 15111 & 1668 & 4525.80 \\
\hline \multirow{7}{*}{} & TNC_CAG & 2464.54 & 2220.5 & 5017 & 306 & 1686.01 \\
\cline { 2 - 7 } & TNC_CCL & 276.05 & 245 & 540 & 109 & 121.85 \\
\cline { 2 - 7 } & TNC_CDB & 1485.15 & 1271 & 3080 & 342 & 931.96 \\
\cline { 2 - 7 } & TNC_CGR & 384.96 & 329 & 690 & 237 & 136.20 \\
\cline { 2 - 7 } & TNC_CIL & 641.18 & 606.5 & 962 & 397 & 198.37 \\
\cline { 2 - 7 } & TNC_CPH & 1635.22 & 1218 & 4230 & 130 & 1321.401 \\
\cline { 2 - 7 } & TNC_CTL & 300.39 & 241 & 592 & 147 & 147.85 \\
\hline
\end{tabular}

Between June 11 and August 31, 2020, out of the average number of COVID-19 cases determined in Romania (approximately 46123 cases), $15.58 \%$ is represented by the one registered for the South Muntenia region (approximately 7188 cases).

The analysis of the average number of COVID-19 cases at the level of each county, shows that Argeș County is on the first place with 2465 cases, i.e. $34.29 \%$ of the average of the South Muntenia region, registering the highest amplitude of diseases of 4711 cases compared to other counties. Less, with approximately 829 cases, Prahova County is also in the top of the ranking by the average number of diseases, given that it represents $22.75 \%$ of the average of the region. 
With a difference of only 150 cases compared to Prahova, Dâmbovița ranks third with a fairly large amplitude of 2741 cases. At a difference of approximately 844 cases compared to the first three counties and approximately 256 cases compared to the last three counties in the ranking, Ialomita County is in the middle of the ranking.

The lowest shares in the number of COVID-19 cases registered in the South Muntenia region, of $5.36 \%$, respectively $4.18 \%$ and $3.84 \%$ of the total are registered in Giurgiu, Teleorman and Călărași counties.

Starting from these basic indicators (the total number of COVID-19 cases in Romania, the one in the South Muntenia development region and the total number of COVID-19 cases in the component counties of that region), as well as their characteristics, the analysis of the evolutions of the cases of COVID-19 diseases was further approached both in number and in weight compared to the total of Romania, of the region included in the study, from one county to another, as well as from one day to another.

\section{Results and discussions}

The study begins with an analysis of the share of COVID-19 cases registered in the South Muntenia region in the total number of cases in Romania.

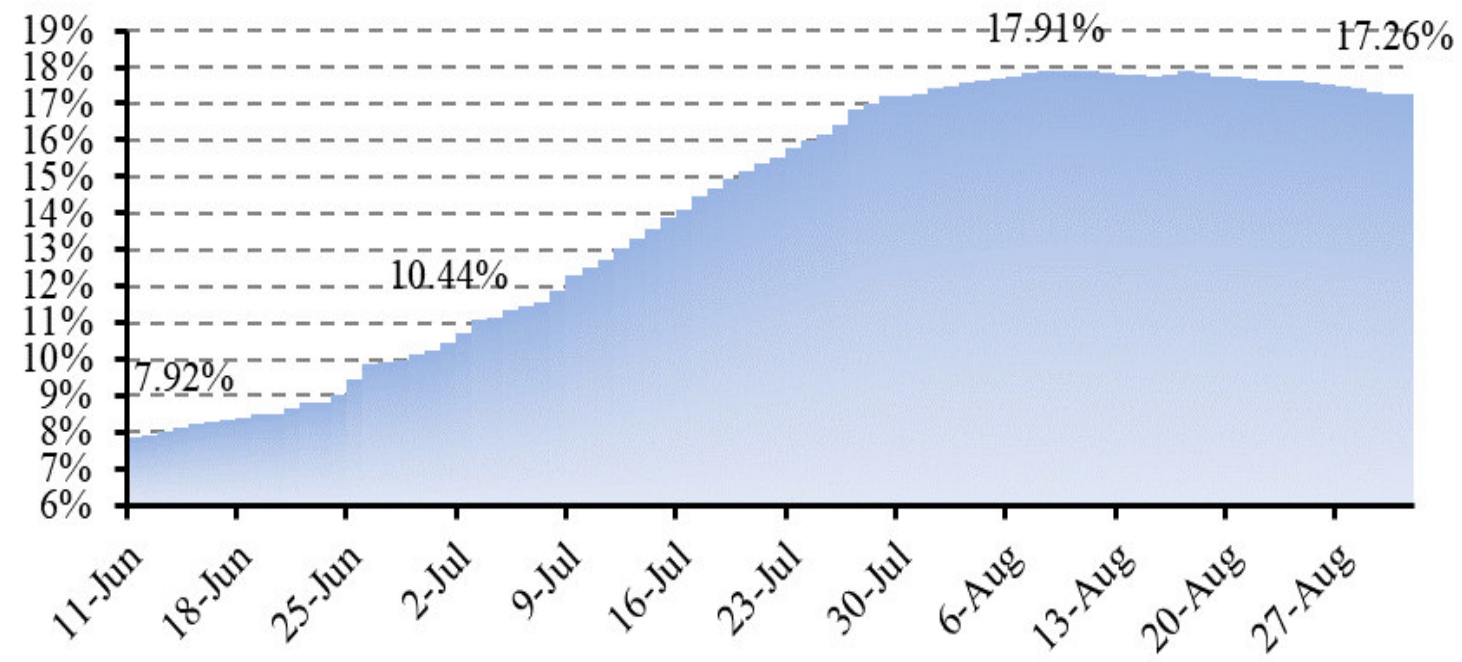

Figure 1 Evolution of the share of the number of cases registered in the South Muntenia region between June 11 and August 31 in the total number of COVID-19 cases registered in Romania

Figure 1 shows very clearly the sharp increase from one day to another, the weights of the number of cases in the South Muntenia region compared to the total number of COVID-19 cases in Romania, from $7.87 \%$ determined on June 11 to $17.91 \%$ when they were calculated for the 17th of August. During this period there are exceptions on June 19 and 20 when the share is the same of $8.52 \%$, respectively on June 22 and 23 when the same percentage of $8.82 \%$ is determined.

A small fluctuation occurs on July 29, 30 and 31 when percentages of $17.20 \%, 17.18 \%$ and $17.28 \%$ are recorded. In the next analysis period (August 17-August 31), the cases were lower, a fact noted by the decreasing weights from one day to another from 17.82\% from August 18 to $17.26 \%$ on August 31. 


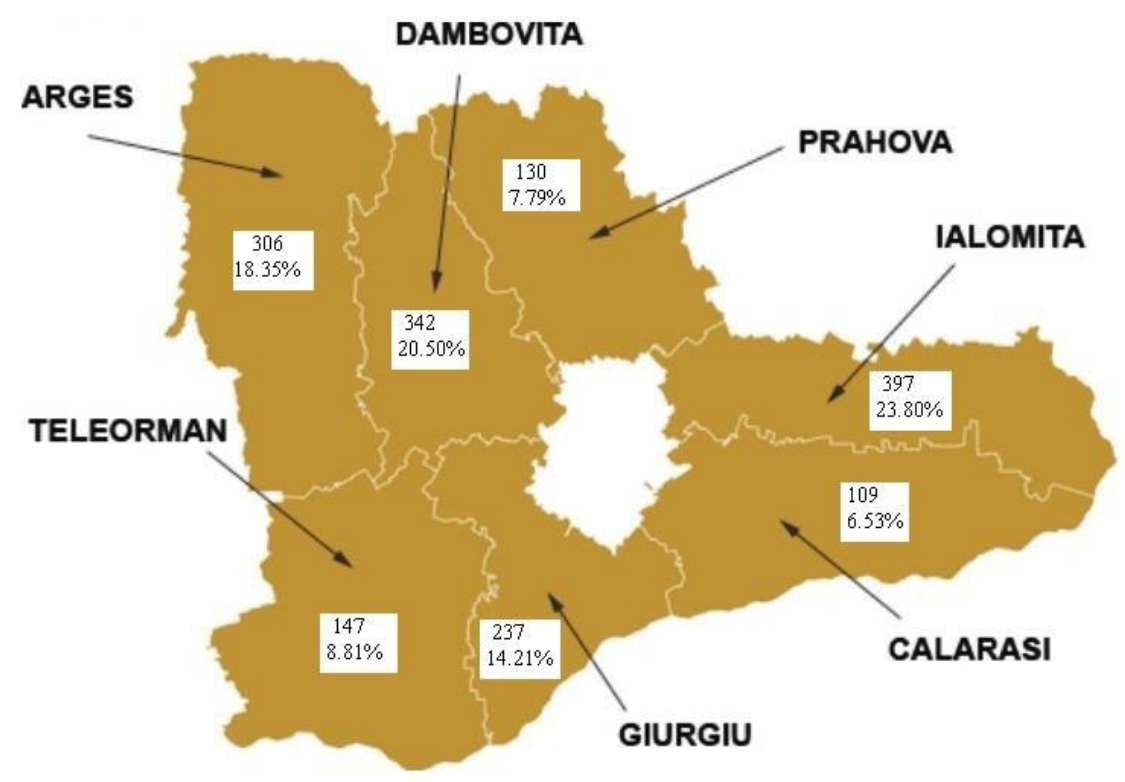

Figure 2 Number and weights of COVID-19 cases registered until June 11 in the counties of the South Muntenia region

With over 300 COVID-19 cases registered until June 11, Ialomița, Dâmbovița and Argeș counties are at the top of the ranking, representing $23.80 \%, 20.50 \%$ and $18.35 \%$ of all cases in the South Muntenia region. With 237 cases, Giurgiu County has $14.21 \%$ of the total in the South Muntenia region. The ranking of counties in relation to the number and weights of COVID-19 cases registered until June 11 in the counties of the South Muntenia region places the counties on the last places with over 100 cases: Teleorman (with $8.81 \%$ in the total region), Prahova (with $7.79 \%$ ) and Călărași with $6.53 \%$ (figure 2 ).

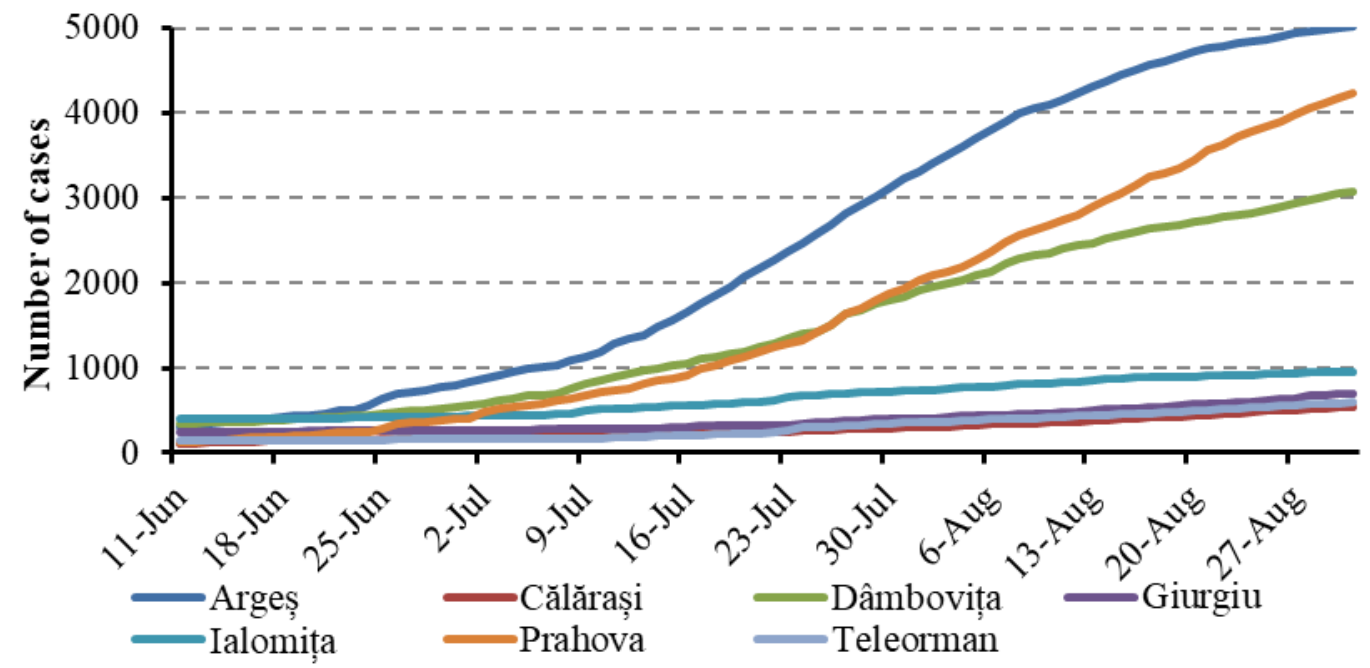

Figure 3. Evolutions of the total number of COVID-19 cases in the counties of the South Muntenia development region between June 11 and August 31

After June 11 to August 31, in the South Muntenia region, the evolution of the number of COVID19 cases is constantly increasing, but it differs numerically from one county to another (figure 3). Thus, Argeș County registers the highest increase, with approximately 58 cases / day (from 306 cases on June 11 to 4711 cases on August 31), followed by Prahova with approximately 51 cases / day (from 
a minimum of 130 cases to a maximum of 4100 cases) and of Dâmbovița with approximately 33 cases / day (minimum 342 cases, maximum 2708 cases). With a maximum of 565 cases on August 31 from 397 cases to June 11, the average increase was determined to approximately 7 cases / day for Ialomita County. Giurgiu, Teleorman and Călărași represent the counties with the lowest average increase in cases registered between June 11 and August 31, of approximately: 6 cases / day in the case of the first county, 5 cases / day for the last two.

Taking into account the number of COVID-19 cases from each day compared to the previous day, starting with June 11, at the level of each county was determined the daily increase whose evolution is shown in Figure 4. Thus, on June 23, the lowest increase in the number of COVID-19 cases is registered on the whole of the South Muntenia development region, with only 19 cases in addition to the previous day (June 22), which represents a growth rate daily by only $0.89 \%$. At this date, the distribution of the daily increase in cases by counties is different. Thus, Dâmbovița County registers the most significant increase ( 9 cases more than in the previous day), compared to the other counties (the rate is $2.10 \%$ ). This county is followed by Ialomița and Prahova (5 cases more than on June 22 ).

Although they have only 5 more cases than on June 22, the daily growth rates are different: Ialomita has an increase of $1.22 \%$, and Prahova County with $2.13 \%$ on June 23 compared to June 22 . Călărași County registers only 1 case more on June 23 than the previous one, represented by a rather low daily growth rate, by $0.68 \%$. On June 23 , the counties of Argeș, Giurgiu and Teleorman registered the same number of cases as on June 22 (of 510 cases - Argeș, 255 cases - Giurgiu, respectively 154 cases - Teleorman)

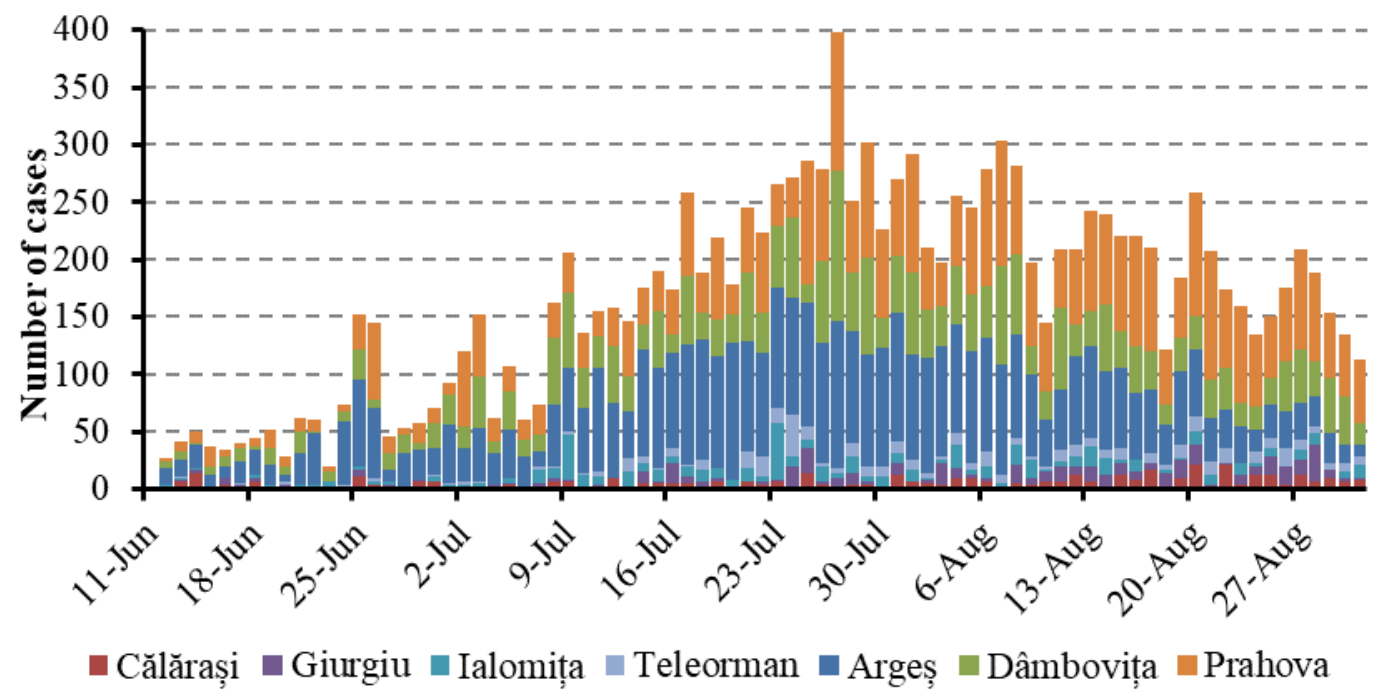

Figure 4. The evolutions of the daily increase of COVID-19 cases in the counties of the South Muntenia development region between June 11 and August 31

At the level of the South Muntenia development region, the biggest increase in the number of COVID-19 cases is on July 27, when there are 398 more cases than on July 26, the zinc rhyme of growth being $5.42 \%$. The distribution of the daily increase in cases by counties on the mentioned date varies. Thus, the most significant increases in July 27 compared to the previous day are reported in Dâmbovita counties with a cynical increase of 131 cases and a rate of $8.73 \%$, Argeș with 129 cases, respectively $4.80 \%$ and Prahova with 120 cases representing 7.94\%. Then, for Giurgiu County, the difference between the two days of analysis is 9 cases, which represents a relative increase of $2.43 \%$. The situation of the increase from one day to another on July 27 compared to July 26 is the same for Ialomița and Teleorman with 4 cases, but with different rates of $0.58 \%$ for the first county and $1.28 \%$ for the second. Regarding Călărași County, the difference of July 27 compared to the previous day is also 1 case, as on June 23 , only that the daily growth rate is only $0.36 \%$. 
Between June 11 and August 31, as mentioned, the counties of Dâmbovița, Argeș and Prahova correspond to the most significant increases on July 27. Ialomita has a maximum increase of 50 daily cases COVID-19 on July 23 compared to July 22 transposed in a relatively daily increase of $8.21 \%$, followed by Teleorman with a daily increase of 36 cases on July 24 (by 13.74\%) and Giurgiu with 32 cases on August 28 for which the daily growth rate is $4.95 \%$. Călărași County registers the highest daily increase in cases on August 20, with 21 cases transposed by a relatively daily increase of $4.99 \%$.

The total number of COVID-19 cases from the counties of the South Muntenia development region between June 11 and August 31 allowed the determination of the structural weights that in time, from one county to another, had significant fluctuations (figure 5).

At the level of the South Muntenia development region, the structural weights for the number of COVID-19 cases of Argeș and Prahova counties compared to those of the other counties, changed from one day to the next in the sense of an increasing trend over the entire analysis period at $18.35 \%$ and $7.79 \%$ (June 11) at $37.08 \%$ and $27.99 \%$ (August 5 and August 31).

The general trend of reduction of the structural weights determined by region at the county level is manifested first of all in Ialomita, the oscillation being of 16.74 percentage points between the maximum of $23.80 \%$ on June 11 and the minimum of $6.34 \%$ from August 30 and Giurgiu with 10.06 percentage points maximum of $14.21 \%$ on June 11 and minimum of $4.15 \%$ on August 7). The same decreasing trend, however, is recorded by only 5.16 percentage points for Teleorman County (maximum of $8.81 \%$ on June 11 and minimum of $3.65 \%$ on August 16) and only by 4.22 percentage points for Calarasi (from $7.36 \%$ on June 18 to $3.14 \%$ on August 9). Dâmbovița represents the county with the smallest oscillation of the number of COVID-19 cases compared to other counties, the structural weights being only between the minimum of $18.85 \%$ from June 26 and the maximum of $22.04 \%$ from July 12 .

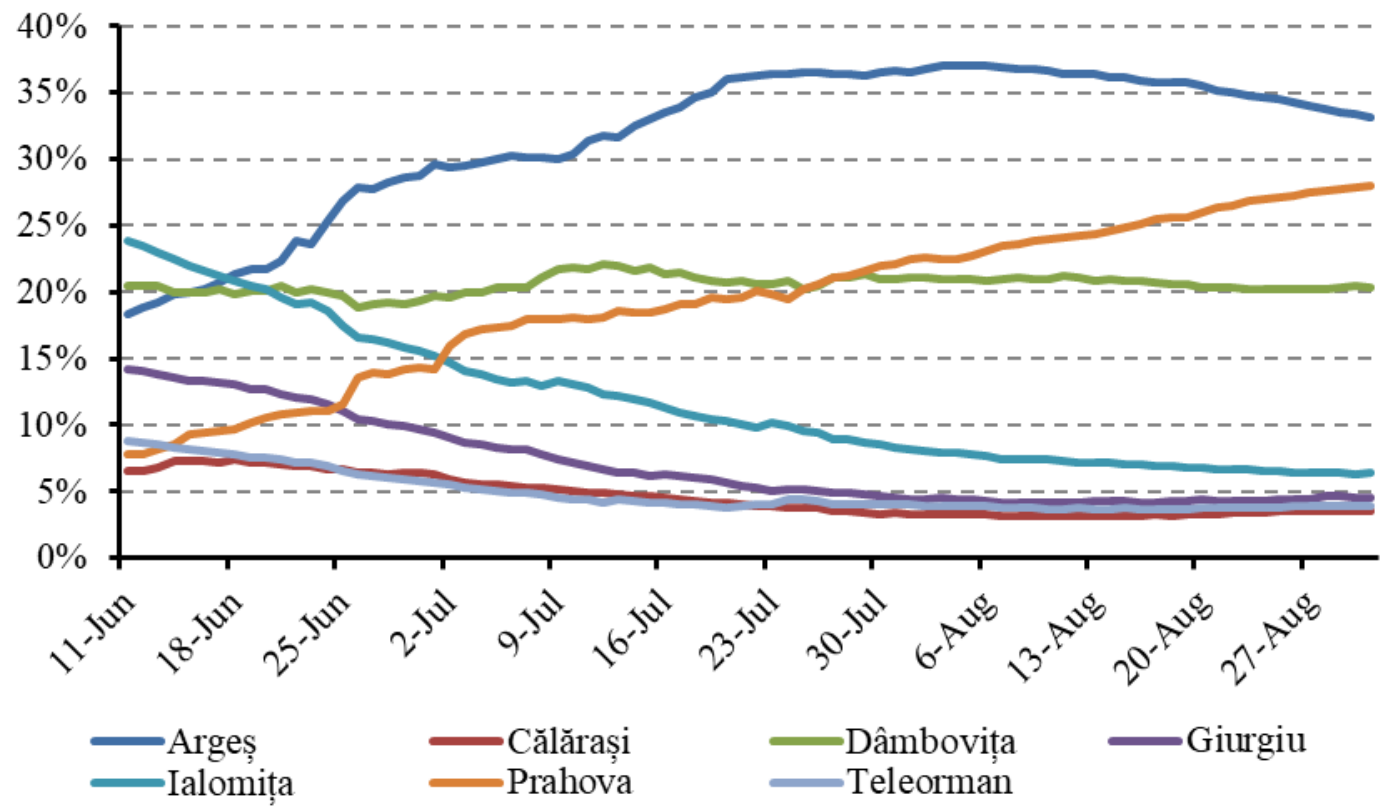

Figure 5. Daily evolutions of the structural weights by counties for the number of COVID-19 cases at the level of the South Muntenia development region between June 11 and August 31 


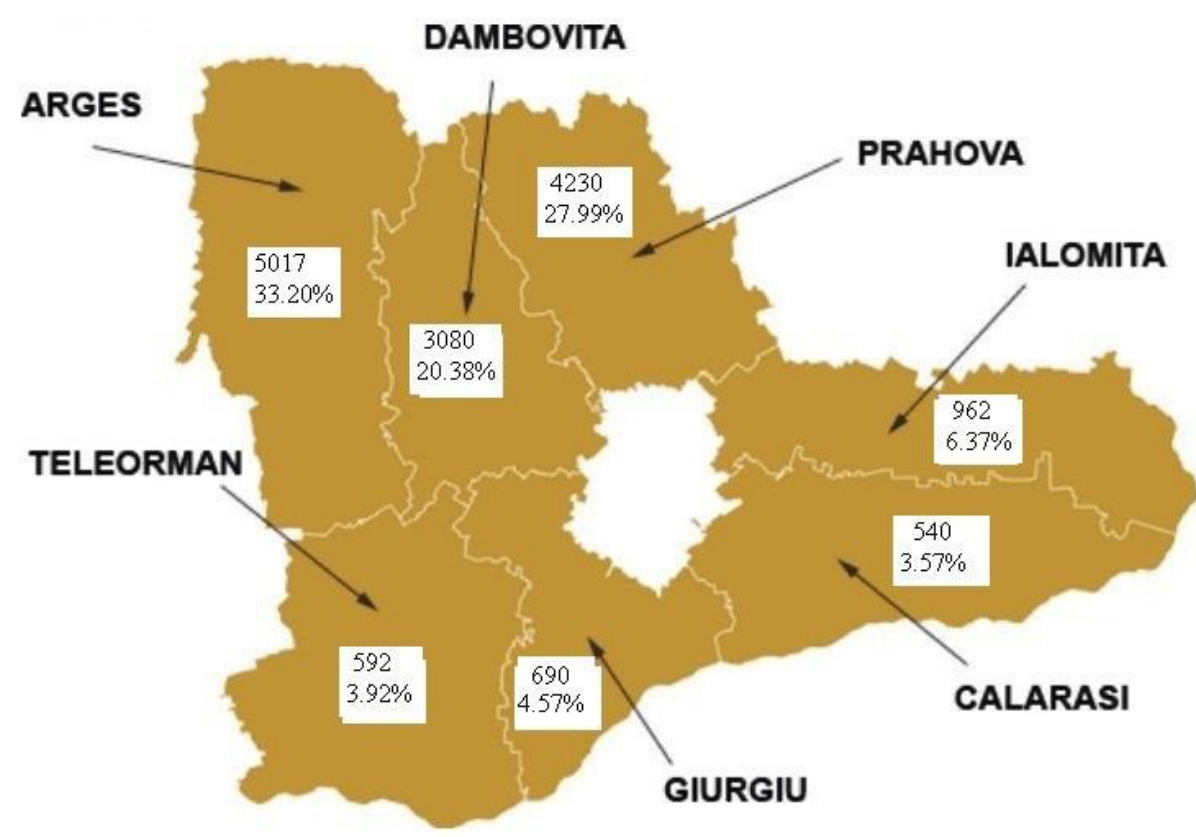

Figure 6 Number and weights of COVID-19 cases registered on August 31 in the counties of the South Muntenia region

If the analysis carried out during the article started with a presentation of the number and weights of COVID -19 cases registered on June 11 in the counties of the South Muntenia region, it will end with the presentation of the level of the same indicators but on August 31 (figure 6). Thus, it can be mentioned that Argeș County has faced a significant increase in COVID -19 cases. The process of rapid spread (growth) of the disease brought it to the first place on the last day of analysis (August 31) compared to the first day (June 11) in which it ranked third.

With 4711 more cases than in June 11 in the South Muntenia region, compared to other counties, this county has $33.20 \%$. Prahova is the second county with serious problems in terms of the spread of the disease. It rose in the ranking of COVID-19 cases, returning to August 31, 27.99\%, given that at this time their number is 4100 cases higher than the first day of analysis when it was on the penultimate place. Dâmbovița remains among the first three counties with a large number of cases (2738 more cases than on June 11) which, compared to the other counties, has a percentage of $20.38 \%$.

Ialomita, from the first place occupied on June 11, reaches the fourth place on August 31, with 962 COVID -19 cases, representing 6.37\% of the total cases of the South Muntenia region. At the same time, on August 31, Giurgiu County has a higher number of cases than on June 11, but, compared to the other counties, a small number, the percentage being only $4.57 \%$.

The last two places are occupied by Teleorman with 3.92\% of the total cases of the South Muntenia region (445 cases more than those registered on June 11) and Călăraşi with $3.57 \%$ (compared to the number of cases registered on June 11 are more with 431 cases).

The last two places are occupied by Teleorman with $3.92 \%$ of the total cases of the South Muntenia region (445 cases more than those registered on June 11) and Călărași with $3.57 \%$ (compared to the number of cases registered on June 11 are more with 431 cases)

\section{Conclusions}

Knowledge of COVID-19 dynamics at the regional level is important to clarify the magnitude and impact of the pandemic. This context creates the necessary premises for the adoption and implementation of decisions at the level of local and implicitly regional communities. In this sense, the study offers an analysis of the evolutions of COVID-19 cases at the level of each county in the SouthMuntenia Region, under different aspects, for the entire period from June 11 to August 31. 
The evolution of the number of COVID-19 cases registered in the South Muntenia region in the total number of cases registered in Romania is highlighted in the form of the weights determined for the period June 11 - August 31. If from June 11 to August 17 there were increasing weights from one day to another, in the next period, until August 31, they will be oscillating below the maximum value of $17.91 \%$.

The most drastic situation, due to the large number of COVID-19 cases and the corresponding weights by counties compared to the total registered in the South Muntenia region is encountered until June 11 in Ialomița, Dâmbovița and Argeș, and on August 31 in Argeș, Prahova and Dâmbovița. If Giurgiu is placed in the middle of the ranking on June 11, until the end of the analysis period, the place of this county is taken by Ialomița. Furthermore, if by June 11 the counties of Teleorman, Prahova and Calarasi, in descending order, face fewer cases of infection than those recorded in the South Muntenia region, the situation is quite good on August 31 for Giurgiu, Teleorman and Calarasi.

The evolutions of the total number of COVID-19 cases, between June 11 and August 31, are different from one county to another. The largest increases in the number of COVID-19 cases from one day to the next were reported for the counties of Argeș, Prahova and Dâmbovița. In the middle of the ranking is Ialomița, followed by Giurgiu, Teleorman and Călăraşi counties with the smallest daily increases in the number of COVID-19 cases.

At the level of the South Muntenia development region, the smallest increase and daily rhythm (minimum values) is registered on June 23, when, compared to June 22, the smallest increase in the number of COVID-19 cases is observed from one day to the next. . At the mentioned date, taking into account the two reference indicators (daily increase and rhythm), the counties of Dâmbovița, Ialomița and Prahova correspond to the most significant increases. The three counties are followed in ranking by Călărași County, and the lowest daily increments and rhythms on the mentioned date belong to Argeș, Giurgiu and Teleorman counties. Regarding the fastest increases (maximum values of increase and daily rate) recorded in the same region included in the analysis, the date of July 27 can be reported. And by counties, in July 27 compared to July 26, the most significant increases are registered for the counties of Dâmbovița, Argeș, and Prahova. These counties are followed by Giurgiu County, so that the last three counties, Ialomița, Teleorman and Călărași correspond to the lowest daily increments and rhythms.

The analysis of the evolution of the increase and of the daily rhythm of COVID-19 cases on each of the counties of the South Muntenia development region, between June 11 and August 31 places, through the highest values, on the first place Dâmbovița, Argeș and Prahova on July 27 , followed by Ialomița on July 23. With lower values are Teleorman County on July 24, followed by Giurgiu on August 28 and Calarasi County with the highest daily increase in cases on August 20.

Comparing daily the number of cases in each county with the one in the South-Muntenia region, the determined weights allowed the presentation of some evolutions between June 11 and August 31 . The evolutions show that the structural weights for Argeș and Prahova changed from one day to the next in the sense of an increasing trend over the entire analysis period, compared to those of the other counties. For the rest of the counties, the structural weights registered a rather significant decrease. The exception is Dâmbovița County, which, during the entire study period, the number of COVID-19 cases compared to the one in the region as a percentage, compared to the other counties, oscillates insignificantly from one day to the next, highlighting a fairly constant evolution.

The regional distribution of COVID-19 cases can be explained by environmental conditions, various social processes, including those based on unplanned population growth, social inequalities, living standards and civilization [9]. This statement considers on the one hand the deficient water infrastructure, and on the other hand the built infrastructure, in the South Muntenia region, i.e. the availability of water and the relations between the prevalence and the level of overcrowding. At the same time, socio-economic factors in the region are targeted with significant spatially significant impact on the spread of COVID-19 cases, such as social processes that shape the epidemiological vulnerability of localities, overcrowding and access to health services, which require the design of urban and health policies effective. 
Understanding the distribution of the number of cases confirmed by COVID-19 in the counties of the South Muntenia Region is relevant for the elaboration of health policies, future economic and social strategies, aspects that should be included in the 2030 Sustainable Development Goals.

A critical analysis of current literatures shows that considerable changes will occur in local, regional and international trade patterns. Thus, the trajectory from boom, recession, changing environment to general trade policies will return to the forefront for many countries [10].

The paper provides useful information and provides a perspective for future bibliographic queries as a resource for understanding the evolution of tools used in the management of this pandemic. At the same time, it represents an opening of future research that should include other development regions in Romania.

The decisions to be taken against COVID-19 should be tailored to the spatial-temporal dimensions and demographic aspects of health. In this way they must represent challenges from an interdisciplinary perspective, imposing proactive planning, and international solidarity in close interdependence with the global perspective.

\section{References}

[1] Hamzaha F A B, Laub C H, Nazric H, Ligotd D V, Leee G, Tanf C L, Shaibg M K B M, Zaidonh U H B, Abdullahi A B, Chungj M H, Ongk C H, Chewl P Y, Salungam R E, 2020, Corona Tracker: worldwide COVID-19 outbreak data analisys and prediction, Bull World Health Organ, doi: http://dx.doi.org/10.2471/BLT.20.255695; /10079/20

[2] BM Napoletano, F Rosete-Verges, L Billa, 2020 Spatial analysis and GIS in the study of COVID19. A review, Science of the Total Environment, 739, 140033, www.elsevier.com/locate/scitotenv, https://doi.org/10.1016/j.scitotenv.2020.140033

[3] C Bambra, R Riordan, J Ford, F Matthews, 2020 The COVID-19 pandemic and health inequalities, J Epidemiol Community Health, 10.1136/jech-2020-214401, http://jech.bmj.com/

[4] Dorn Avan, Cooney RE, Sabin ML, 2020 COVID-19 exacerbating inequalities in the US. Lancet; 395:1243-4

[5] Kearns, R., Moon, G., 2020 From medical to health geography: novelty, place and theory after a decade of change, Progres. Hum. Geogr. 26 (5), 605-625.

[6] R Rowthorn, J Maciejowski, 2020 - A cost-benefit analysis of the COVID-19 disease, Oxford Review of Economic Policy, Volume 36, Number S1, pp. S38-S55, https://academic.oup.com/oxrep/article/36/Supplement_1/S38/5899017

[7] R Chetty, JN Friedman, N Hendren, M Stepner, 2020 How did covid-19 and stabilization policies affect spending and employment? a new real-time economic tracker based on private sector data, NBER Working Paper, No. 27431, DOI: 10.3386/w27431, https://www.nber.org/papers/w27431 https://iepecdg.com.br/wp-content/uploads/2020/06/tracker_paper.pdf,

[8] G Bonaccorsi, F Pierri, M Cinelli, 2020 Economic and social consequences of human mobility restrictions under COVID-19, PNAS July 7, 117 (27) 15530-15535; https://doi.org/10.1073/pnas.2007658117

[9] D Sinha, P Manna, 2020 The effect of Lockdown due to Covid-19 on Post-traumatic Stress and Depression among College Students of Kolkata, hotspot district of West Bengal, India, IOSR Journal Of Humanities And Social Science (IOSR-JHSS), Volume 25, Issue 5, Series 9 (May. 2020) 58-64 e-ISSN: 2279-0837, p-ISSN: 2279-0845, www.iosrjournals.org, DOI: $10.9790 / 0837-2505095864$

[10] KM Shuaib, 2020 The Changing Pattern of International Trade: Import Substitution Policy and Digital Economy in Nigeria. A Review, IIARD International Journal of Economics and Business Management, Vol 6. No. 4, E-ISSN 2489-0065 P-ISSN 2695-1878, www.iiardpub.org; http://iiardpub.org/get/IJEBM/VOL.\%206\%20NO.\%204\%202020/The\%20Changing\%20Patter n\%20of\%20International.pdf 


\title{
Considerations on the posting of workers within the European Union
}

\author{
Dorina Niță ${ }^{1}$ \\ ${ }^{1}$ Assoc. Prof., Ph.D., Faculty of Science, University of Petrosani, Romania \\ E-mail: dorinamagda@yahoo.com
}

\begin{abstract}
This paper is limited to the current concerns at European level generated by the scale and consequences of the phenomenon of posting of workers in cross-border services. The different, sometimes opposite, perception of these issues has led to the active involvement of many stakeholders, from the European institutions to the governments of national states, trade unions and employers' organizations in trying to give the strongest possible foundation to initiatives to change the legal framework.

The adoption of new regulations and the creation of mechanisms that enable the collection of complete and accurate information are considered necessary to outline a topical picture of the posting of workers within the Community and to develop strategies that contribute to the manifestation of an 'equitable' labour market and fair competition between European companies, as well as to provide an adequate level of protection of the rights of workers posted for the provision of cross-border services.
\end{abstract}

Keywords: transnational posting, posted workers, cross-border services, labour force mobility

\section{Setting out a roadmap for the posting of workers at European Union level}

Currently, a number of studies addresses the issue of posted workers with an emphasis on wage provisions and working conditions, but there is also the need to ensure a climate of fair competition and respect for the workers rights, presenting the current situation in a country (Italy in the case of Ianuzzi Francesco, Finland in the case of Lillie Nathan and Markku Sippola or Germany in the case of Vladimir Bogoeski), as well as at the level of the European Union (Lillie Nathan, KairitKall, Ian Greer, Aukje Van Hoek, Mijke Houwerzijl) or a field of activity (Pablo Sanz de Miguel, Michiel Rogierrs, Sonila Danaj). Choosing as a research methodology, the analysis based on an extensive literature review, it can highlight the ongoing concerns of adapting European and national legislations to labour migration and to workers' rights, but also a number of issues that remains unresolved: "either lack (effective )of strategies focused on posted workers or considered this as a target group outside their jurisdiction or just too difficult to engage with. " [11].

Ensuring economic growth and a standard of living as high as possible for the citizens are the desideratum of all states, imposing an economic development that requires a demand for labour which, in the case of developed countries, often exceeds the 'internal resources' at the level of certain activities, economic sectors or skills, despite the phenomenon of labour force migration. One of the solutions that companies use for the temporary supplementation of the workforce is the use of workers posted for certain periods of time from other states, a process regulated in the European Union since 
1996 through Directive 96/71/EC regarding the posting of workers in the framework of the provision of services [18] comprising a set of minimum conditions relating to wages, maximum work period, annual leave or conditions of employment which apply to all posted employees. Based on the fundamental principles of the internal market set out in the Treaty on the Functioning of the European Union (TFEU), namely the free movement of workers, the freedom of establishment and the freedom to provide services, companies have been guaranteed the right to provide services in another Member State of the European Union and to temporarily post their workers to the territory of that Member State for that purpose; posted workers have the same legal status as their own employees, except for the social security system (pension insurance, accidents at work and occupational health, health insurance, family benefits) and tax obligations, in which case employees are subject to the law of the state of origin. The legal regime of the host country also applies, in general, to the length of the working day, the minimum rest period, paid annual leave, the minimum wage, the place of work, health, as well as to measures for the protection, safety and hygiene at work, working conditions for pregnant women or women who have recently given birth, to equal treatment for men and women and other anti-discrimination measures [3].

Allowing for the fact that labour market conditions have changed over time and that a number of issues have either not been regulated at all or have been insufficiently addressed (insufficient administrative supervision, poor communication between Member States on the exchange of information etc.) - due to abusive or fraudulent practices, European legislators considered it necessary to revise the rules, initially set out through Directive 2014/67 and followed by Directive 957 in 2018. The rules imposed by Directive 2014/67 aim to "improve access to information for both Member States and service providers, the information being transparent, free of charge, in an accessible format and published on a single official website, in multiple languages, taking into account the demands of the labour market in the host countries. In the same context, cooperation between Member States was expected to be improved through the use of the Internal Market Information System (IMI)." [3]. At the same time, the Directive improved the implementation of workers' rights, including the case of subcontractors, by introducing joint liability of companies using posted workers, which is compulsory in the construction and transport sectors, with the possibility of extending it to other sectors. [...] In order to monitor the correct implementation of the Directive, a list of control measures at national level was provided, which could be amended by host countries, if they thought it necessary." [3].

The adjustment made by Directive 957 of the European Parliament and of the Council of 28th June, 2018 amending Directive 96/71/EC on the posting of workers in the framework of the provision of services (Directive (EU) 2018/957) was aimed at 'encouraging the free provision of services across borders, in a climate of fair competition, respecting workers' rights and adapting to new economic and social conditions, as well as an improvement of the EU legislation in this field'. Its adoption due to a vote in the European Parliament gave EU member states a two-year deadline to transpose this directive into national law.

The rights of posted workers relate to working conditions, accommodation, health and safety (which must comply with the national rules of the Member State where the workers are posted), wages (the principle of equal pay has been implemented through secondary legislation and covers not only equality between men and women, but also equality between fixed-term workers and permanent contract workers carrying out similar work, between part-time and full-time workers and between temporary agency workers and employees of the host company carrying out similar activities), covering accommodation costs, transport and meal expenses (posted workers must benefit from at least the same allowances or the same level of reimbursement of transport costs and accommodation applicable to local workers in the host country), non-discrimination provisions, as well as the right to receive, from the host Member State, general information on national law and/or national practices applicable to them. $[17,18]$.

Taking into account the fact that the posting takes place for a fixed period (and this period may exceed 12 months or even 18 months), and that the posted worker may be made available to a host company by a temporary employment company or a temporary employment agent, the aforementioned 
Directive 2018/957 can be corroborated with European Directive 2008/104/EC of the European Parliament and of the Council of 19th November, 2008 on temporary agency work, the principle of which is that the basic working and employment conditions applicable to temporary agency workers should be at least those which would apply to such workers if they were recruited by the user undertaking for the same job. [20].

The main amendments made by Directive 2018/104 to the previous Directive relate to [22]:

- remuneration of posted workers is made in accordance with the law and practices of the host country; Remuneration means both wages and other elements (bonuses, allowances, salary increases, etc.), Member States being obliged to specify in a transparent manner the elements that make up the remuneration in their country;

- the employer must cover the costs of travel, accommodation and meals (instead of deducting them from employees' wages);

- the maximum period of posting was set at 12 months, with a possible extension of up to 6 months. After that, all labour rules in the host country will apply;

- temporary employment agencies must guarantee posted workers the same conditions applied to temporary workers employed in the country where they work;

- cooperation in the field of fraud is strengthened. The new rules will apply to the transport sector once the legislation on this sector comes into force.

Although the European Commissioner for Employment, Marianne Thyssen, believed that the vote in the European Parliament 'constitutes an important step in the process of building a more equitable single market', this directive has led to the creation of two opposing camps (made up of European Union institutions, trade unions, employers' organisations and other stakeholders): one that shares the European representative's point of view and includes in particular defenders of the interests of states where the share of posted workers in their country is large (e.g. France, Germany, Austria, Belgium, the Netherlands, Sweden or Luxembourg). Of these, France, Germany and Belgium hosted together 50\% of the workers received in 2016 [7]) and considered that by not intervening at the level of Directive 96/71/EC, posted workers from Eastern European countries such as Romania, Bulgaria or Poland, 'accustomed' to lower wages, will take over the jobs in these countries. Although companies that use these workers can increase their earnings as a result of lower labour costs, at the level of the national economy, the losses are estimated to be higher as a result of the increase in unemployment among the resident population and their social welfare expenditures. In fact, this has been the case since the establishment of the European Union and it expanded when the newly acceded states, with a lower standard of living than in the EU started the 'export' of labour force either indefinitely, in the form of external migration, or for a fixed period of time in the form of posted workers by a subcontractor. Even if the supporters of this directive admit that 'companies that post workers in low-wage sectors, such as constructions, will be affected and that the new rules will increase wage costs for companies that post workers, they can still remain competitive due to lower costs of social security and the income tax which is lower than in some host states'. [3].

On the opposite side, there are the defenders of the interests of the countries "exporting" mainly posted workers (Bulgaria, Czech Republic, Estonia, Hungary, Lithuania, Latvia, Poland, Slovakia and Romania) who see in this vote an elimination of their competitive advantage compared to competing economic agents from the developed countries of the European Union, represented by the practice of remuneration at the level of their country, not of the country where they posted the workers. In Romania, the National Council of Small and Medium Private Enterprises (CNIPMMR) had a sharp point of view by which it asked the Romanian MEPs to oppose the proposal to revise Directive 96/71/EC based on considerations such as [5]:

- 'there is a comprehensive legal framework: Directive 96/71/EC on the posting of workers in the services sector has already laid down a set of mandatory and restrictive rules on employment terms and conditions applied to posted workers and it has also established additional rules on the posting of workers by addressing issues related to fraud, circumvention of regulations and the exchange of information between Member States'; 
- there is a need for a broad and rigorous analysis of the available data on the challenges and specifications of cross-border services and the SMEs Test to change the legal framework in this area;

- "free movement of services" is a fundamental principle of the internal market of the Union, enshrined in the Treaty on the Functioning of the European Union (TFEU);

- the principle that posted workers should be subject to the same pay rules as local employees is incompatible with a genuine single market, in which sustainable economic development is driven by efficient, innovative and competitive companies, with pay gaps being a legitimate element of the competitive advantage that service providers have;

- the principle that posted workers should be subject to the same pay rules as local employees is not feasible in practice because: cross-border service providers incur costs that are not borne by local service providers; local employers pay for their employees only staff salaries, taxes and insurance contributions; significant differences in wages do not distort the conditions of fair competition between companies, the total cost (including wages, daily allowances, transport costs, administrative costs) of a cross-border service provider is not significantly lower than the one borne by local businesses and the profit of a cross-border service provider has very low margins in order to be competitive; one must also take into account the differences that exist between Member States, resulting from different levels of economic development, tax systems, labour law and social protection regulations, etc.

The transnational movement of workers is amplified not only by wage disparities between EU member states, but also by the need for skilled and highly skilled labour force, which can be found mainly in developed countries. [7].

The concerns of all states in managing the issue of posting of workers from cross-border services (even if their position is influenced by the place occupied within the framework of posting: senders or receivers of posted workers), is justified by the evolution and size of this phenomenon: in 2016 in the EU, the number of posted workers reached 2.3 million (chart 1), with a high frequency of posting occurring in certain economic sectors such as industry $(69.1 \%$, of which $45 \%$ in constructions), services (29.4\% comprising mainly education, health and social services) and $1.5 \%$ in fishing and agriculture (chart 2).

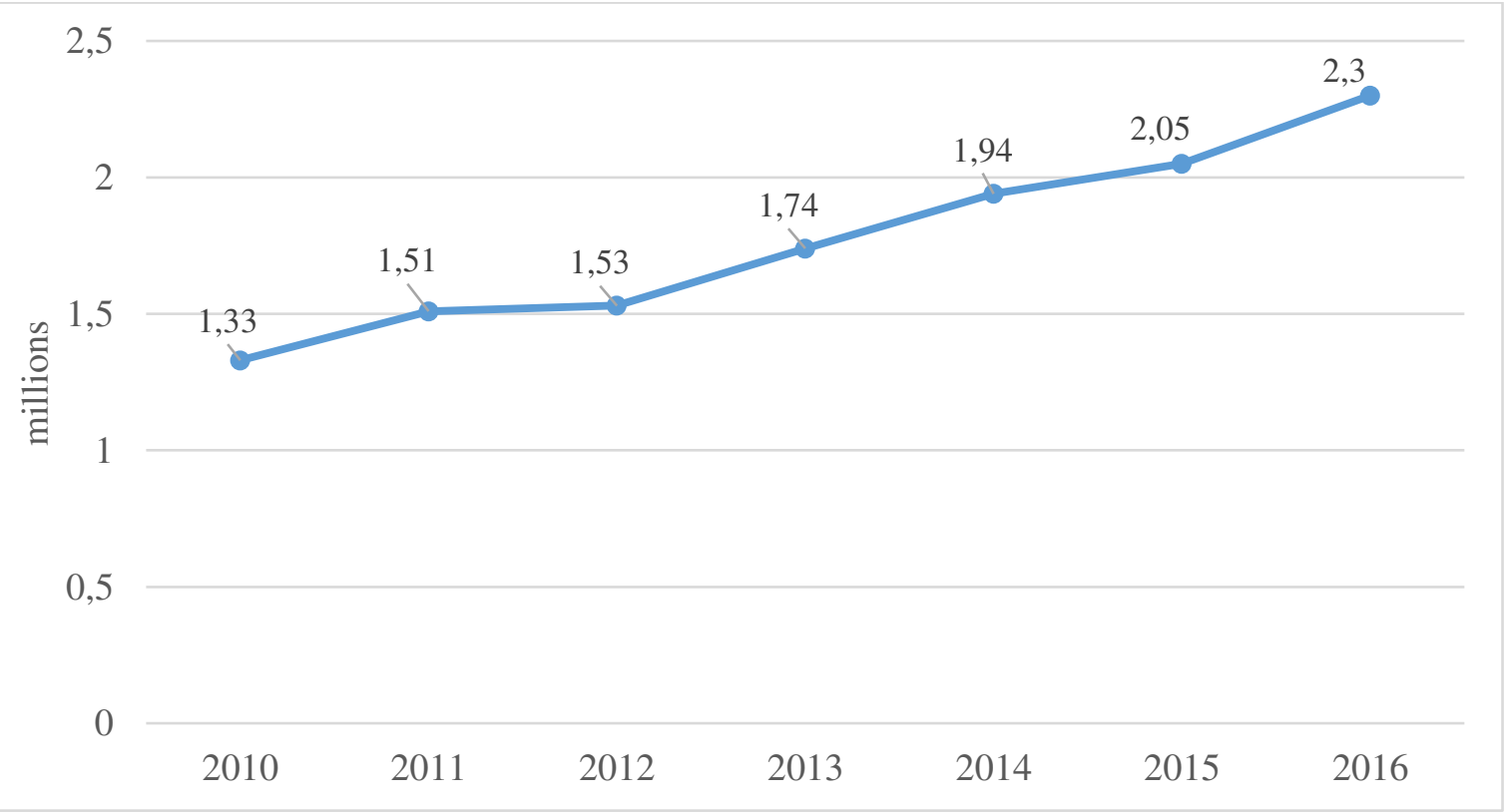

Chart 1 Evolution of the number of posted workers in the European Union 


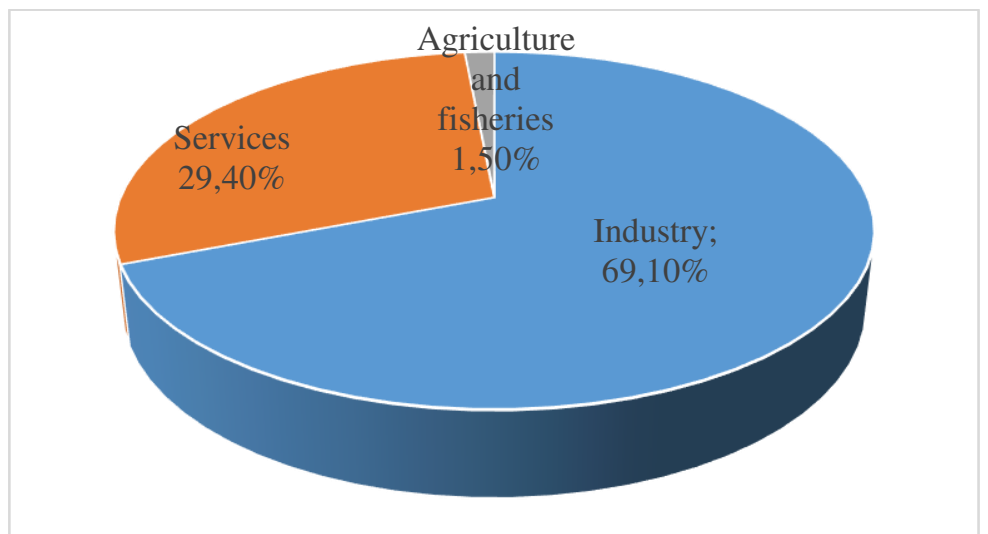

Chart 2. Number of posted workers by economic sectors (2016)

Although between 2010 and 2016, their number increased by 41\%, the share of posted workers in the total labour force is low, at $0.4 \%$ in the European Union [2], which makes the impact of postings to be limited if total employment rates are taken into account; however, if we consider the employment rates at the level of certain sectors of economic activity, such as construction, or of certain countries, such as Germany, France or Belgium, these numbers will increase significantly.

$82.3 \%$ of the number of secondments was made to 15 countries. Germany, France, and Belgium received the largest number of posted workers, hosting together $50 \%$ of the workers received. [22]. For example, in 2015, 285,000 workers were posted to France (the second most sought-after host country); by comparison, in 2000 there were only 7,500 posted workers working in France [14]. The average duration of secondments to the EU is less than 4 months. [2].

In the study conducted by the European Parliament - Posting of Workers Directive - current situation and challenges. Study for the EMPL Committee (2016), the authors noted 'a significant lack of reliable information on the posting of workers within the European Union, most statistics being made for the purpose of ensuring social protection [...] the estimation method used by the EU Commission is based on an analysis of the number of portable social security documents A1'. The discrepancies between the real situation and that provided by these data can be significant and are due, according to the study, to the fact that, for example, companies may not request the A1 forms if the worker is being posted for a very short period of time, but they are needed for social security only. In addition, postings lasting more than 12 months are not considered secondments in terms of social security. In conclusion, the same worker may be registered several times within a year; therefore, the A1 forms would only reflect the number of registrations and not the number of posted workers. At the same time, the study carried out by the European Commission in 2016, Impact Assessment. Accompanying the document Proposal for a Directive of the European Parliament and the Council amending Directive 96/71/EC concerning the posting of workers in the framework of the provision of services, shows how large differences can be between the actual situations and those provided by the A1 documents by presenting the case of three States: Belgium, Denmark and France at the level of 2014:

Table 1 Comparison between EU and national data sources on received posted workers (2014)

\begin{tabular}{|l|c|l|}
\hline Country & $\begin{array}{c}\text { Number of PD A1 received } \\
\text { (EU data) }\end{array}$ & \multicolumn{1}{c|}{$\begin{array}{c}\text { Number of registrations } \\
\text { (national data) }\end{array}$} \\
\hline Belgium & 159,753 & $\begin{array}{l}\text { Number of declarations: 499,840 } \\
\text { Number of unique persons: 205,279 }\end{array}$ \\
\hline Denmark & 10,869 & 59,351 \\
\hline France & 190,848 & 228,650 \\
\hline
\end{tabular}

Source: European Commission, IMPACT ASSESSMENT. Accompanying the document Proposal for a Directive of the European Parliament and the Council amending Directive 96/71/EC concerning the posting of workers in the framework of the provision of services, SWD(2016) 52 final, https://ec.europa.eu/transparency/regdoc/rep/10102/2016/EN/SWD-2016-52-F1-EN-MAIN-PART-1.PDF 


\section{Legal Romanian framework for posting workers}

According to the Labour Law, the secondment is 'the act by which an employee is assigned on a temporary basis to work for another host employer, in order to carry out work in his interest. Exceptionally, secondment may also change the type of work carried out, but only with the written consent of the employee.' [24].

In Romania, the regulation of the aspects derived from the posting of employees to carry out transnational services is subject to Law No. 16/2017 which establishes 'a common framework of provisions, measures and control mechanisms applicable in Romania to posted employees in the context of carrying out transnational services, including measures to prevent and sanction any abuse or circumvention of the rules' [23]. When posted workers are taken into account, the provisions of the law apply to both the companies established within a Member State other than Romania, or on the territory of the Swiss Confederation which, within the provision of transnational services, sends employees to Romania with whom they have struck up working relations and to enterprises set up in Romania which, within the framework of the provision of transnational services, posts employees to EU Member States, other than Romania or to Switzerland.

The institutional framework for implementing and complying with the provisions of Law no. $16 / 2017$ in the sense of identifying the cases of transnational posting and preventing abuses and circumvention of the provisions of the law is provided by the Labour Inspectorate, through the territorial labour inspectorates. The Labour Inspectorate is the public authority with liaison offices, which exchanges information with the competent institutions of the EU Member States or the European Economic Area. Thus, in the light of the administrative cooperation, at the level of 2019 [8] the Labour Inspectorate has received:

- requests for communication of the decisions imposing financial-administrative sanctions on various Romanian employers whose employees provide transnational services (from Austria 23 and Italy - 4);

- requests for information requesting details of: the Romanian company which posts employees (head office address, proof of RECOM registration, activities carried out and the period of time, authorizations in the case of temporary work agents); employees of the company (individual employment agreements, duration of posting, salary rights as per employment contracts registered in the country, etc.); the existence of special allowances relating to secondment; payment of contributions to the consolidated budget of the state; A1 forms issued by the National Office of Public Pensions; wages paid to workers during posting (from Austria - 242, Belgium - 103, France - 52, Italy - 49).

During the same period, the liaison office of the Labour Inspectorate sent a number of 34 requests for information to offices in Italy, France, Germany, the Netherlands, Hungary, Bulgaria, Sweden, Belgium, etc. on the posting of employees in transnational services. The main shortcomings identified as a result of checks on the legality of the work carried out by undertakings established in an EU or EEA Member State which post employees in Romania, are the following:

- non-compliance with the obligation to send a notification in Romanian regarding the secondment of employees to the territorial job centre within the boundaries the activity is to be carried out;

- non-compliance with the deadline for submitting the notification;

- submission of incomplete or erroneous notification;

- failure to contact the representative of the company from abroad has the effect of not being able to communicate the results of the checks carried out.

In 2015, 46,871 Romanian workers were posted in the Member States of the European Union, representing $2.3 \%$ of the total number of posted workers in the EU, the main fields of activity being construction $-40.7 \%$, industry - $38.3 \%$, business services $-7.3 \%$, transport $-5.5 \%$, while the destination countries were: Germany $-37.6 \%$, Spain - 15\%, Italy - $13.9 \%$, Belgium - $13.4 \%$. The highest number was reached in 2011, when 59,363 posted workers were registered. [12] 
Currently, the provisions of the Labour Code are not fully harmonized with those of Law no. 16/2017 and the Directive 2018/957 on the posting of workers from cross-border services.

The rules imposed by law no. 16/2017 take over the rules imposed by the European Directive 96/71/EC on the posting of workers in the framework of the provision of services, so that amending and supplementing them by Directive (EU) 2018/957 also requires amending the national legislation in the field. The first steps towards aligning national regulations with European ones are a bill submitted to Parliament where new provisions would apply from July 30, 2020, if adopted in due time by Parliament, until then the provisions of the Law no. 16/2017 remain valid. According to the explanatory memorandum [25], the new draft law seeks to clarify some notions, such as the minimum wage applicable to the employee posted to Romania, remuneration, collective labour agreements, administrative financial sanction, administrative cooperation, etc.; completing the provisions of Law no. $16 / 2017$ on the activity of the temporary work agent within the transnational posting; regulation of the working and employment conditions applicable to employees posted on Romanian territory if the posting exceeds 12 months, and the method of calculating the duration of the posting in case of a posted worker replacing another posted worker.

\section{Conclusion}

Although with an extremely low share of the employed population in the European Union, the deployment of workers has received special attention from the European institutions, Member States, trade unions and employers' organizations, depending on the gains and losses associated with the amplification of this phenomenon.

As a beneficiary of a legal framework since 1996, the posting of workers in cross-border services has divided states and stakeholders at European level, given that certain issues considered insufficiently regulated has allowed, from the point of view of the 'recipient' states of a large number of workers posted from other EU Member States to lead to 'social dumping' and an unfair labour market. On the other hand, countries that post a significant number of workers to other Member States consider that the amendments made to the legal framework in 2018 by Directive 957, do not take into account some of the basic principles that govern the functioning of the European Union, such as the freedom of companies to provide services.

No matter how 'solid' the arguments of each party are, the attempts to justify them as thoroughly as possible have revealed that the dimensions of this phenomenon are insufficiently known, that there is no reliable information on which one can build a complete picture and an accurate assessment of the dimensions, consequences and trends of the movement for posting workers to other States within the Community.

In this context, the development and implementation of measures, policies and strategies aimed at stimulating fair competition, at eliminating social dumping and ensuring adequate social protection of posted workers, are considered either premature or necessary to create the most complete legal framework possible and more adapted to current realities.

The two-year period granted to the Member States of the European Union as a deadline for transposing the new provisions into national laws, requires that Romania, both a 'sender' of a large number of posted workers to EU Member States especially in the industrial field and construction, and a 'recipient' of posted workers from other non-EU countries, in particular, to be in a position to adopt a new legislative initiative as soon as possible in order to amend the existing legal framework, regardless of its reluctance and different standpoint on the new regulations.

\section{References}

[1] Bogoeski V. (2017), Chain liability as a mechanism for strengthening the rights of posted workers: The German chain liability model, [Online], Avalaible at: https://www.academia.edu/38385097/Chain_liability_as_a_mechanism_for_strengthening_the 
_rights_of_posted_workers_The_German_chain_liability_model, [Accessed 5 May 2020]Monitorul

[2] Comisia Europeană, Detaşarea lucrătorilor în UE [Online], Avalaible at: https://ec.europa.eu/commission/sites/beta-political/files/posting-workers_ro.pdf, [Accessed 22 April 2020]

[3] Direcția pentru Uniunea Europeană, FIŞ̧̆ DE INFORMARE Directiva 96/71 privind detaşarea lucrătorilor în cadrul prestării de servicii, [Online], Avalaible at: http://www/cdep.ro/afaceri_europene/afeur/2016/fi_1981.pdf [Accessed 15 April 2020]

[4] Dobrotă N. (coord.) (1999), Dicţionar de economie, Ed. Economică, Bucureşti

[5] Dumitru I. (2017), Detașarea lucrătorilor în Uniunea Europeană, Ed. Universul Juridic, București

[6] European Commission (2016), IMPACT ASSESSMENT. Accompanying the document Proposal for a Directive of the European Parliament and the Council amending Directive 96/71/EC concerning the posting of workers in the framework of the provision of services, $\operatorname{SWD}(2016)$ 52 final, [Online], Avalaible at:

https://ec.europa.eu/social/main.jsp?catId=738\&furtherPubs=yes\&langId=en\&pubId=8262 [Accessed 19 April 2020]

[7] European Parliament (2016), Posting of Workers Directive - current situation and challenges. Study for the EMPL Committee, 2016, [Online], Avalaible at: https://www.europarl.europa.eu/RegData/etudes/STUD/2016/579001/IPOL_STU\%282016\%2 9579001_EN.pdf [Accessed 18 April 2020]

[8] Inspecția muncii, Raport de activitate pentru anul 2019, [Online], Avalaible at: www.inspectiamuncii.ro [Accessed 24 April 2020]

[9] Kall K., Lillie N. (2016), Protection of Posted Workers in the European Union: Findings and Policy Recommendations based on existing research, [Online], Avalaible at: www.academia.edu [Accessed 5 May 2020]

[10] Lillie N., Sippola M. (2011), National unions and transnational workers: the case of Olkiluoto 3, Finland, [Online], Avalaible at: https://www.academia.edu/1401888/National_unions_and_transnational_workers_the_case_of_Olkiluoto _3_Finland [Accessed 5 May 2020]

[11] Lillie N. (2018), Enhancing Economic Democracy for Posted Workers: The Case of Finland COUNTRY STUDY FINLAND, [Online], Avalaible at:

https://www.academia.edu/37697893/Enhancing_Economic_Democracy_for_Posted_Workers_The_Cas e_of_Finland_COUNTRY_STUDY_FINLAND [Accessed 5 May 2020]

[12] POOSH, Occupational Safety and Health of Posted Workers (2017), Delegare versus detașare. Lucrătorii români în Europa, [Online], Avalaible at: http://www.poosh.eu/media/1064/assignment-vs-posting-romanian-workers-in-europe-rodicanovac.pdf [Accessed 26 April 2020]

[13] Sanz de Miguel P. (2017), Fraudulent Contracting of Work: Construction Sector, [Online], Avalaible at:

https://www.academia.edu/39768677/Fraudulent_Contracting_of_Work_Construction_Sector [Accessed 5 May 2020]

[14] Teacă C. (2016), Opt responsabili europeni cer reformarea sistemului prin care sunt detaşaţi muncitorii in spaţiul UE, [Online], Avalaible at: https://www.rfi.ro/special-paris-91790responsabili-europeni-reformarea-sistem-muncitori-detasati-ue, [Accessed 14 April 2020]

[15] Van Hoek A., Houwerzijl M. (2011), 'Posting' and 'Posted Workers': The Needfor Clear Definitions of Two Key Concepts of the Posting of Workers Directive, Cambridge Yearbook of European Legal Studies, Volume 14 2011-2012, [Online], Avalaible at: https://www.academia.edu/11524664/_Posting_and_Posted_Workers_The_Need_for_Clear_D efinitions_of_Two_Key_Concepts_of_the_Posting_of_Workers_Directive 
[16] ***, Decizia 2009/17/CE a Comisiei din 19 decembrie 2008 de instituire a Comitetului de experți privind detașarea lucrătorilor, în Jurnalul Oficial al Uniunii Europene L 8 din 13.1.2009, [Online], Avalaible at: www.eur-lex.europa.eu [Accessed 12 April 2020]

[17] ***, Directiva 2018/957 a Parlamentului European și a Consiliului din 28 iunie 2018 de modificare a Directivei 96/71/CE privind detașarea lucrătorilor în cadrul prestării de servicii, în Jurnalul Oficial al Uniunii Europene L 173/16 din 9.7.2018, [Online], Avalaible at: www.eur-lex.europa.eu [Accessed 12 April 2020]

[18] *** Directiva 2014/67/UE a Parlamentului European și a Consiliului din 15 mai 2014 privind asigurarea respectării aplicării Directivei 96/71/CE privind detașarea lucrătorilor în cadrul prestării de servicii și de modificare a Regulamentului (UE) $n r .1024 / 2012$ privind cooperarea administrativă prin intermediul Sistemului de informare al pieței interne (,,Regulamentul IMI”), în Jurnalul Oficial al Uniunii Europene L 159/11 din 28.5.2014, [Online], Avalaible at: www.eur-lex.europa.eu [Accessed 12 April 2020]

[19] *** Directiva 96/71/CE a Parlamentului European și a Consiliului din 16 decembrie 1996 privind detaşarea lucrătorilor în cadrul prestării de servicii, OJ L 18 din 21.1.1997 [Online], Avalaible at: www.eur-lex.europa.eu [Accessed 12 April 2020]

[20] *** Directiva 2008/104/CE a Parlamentului European și a Consiliului din 19 noiembrie 2008 privind munca prin agent de muncă temporară, în Jurnalul Oficial al Uniunii Europene L 327 din 5.12.2008, [Online], Avalaible at: www.eur-lex.europa.eu [Accessed 12 April 2020]

[21] ***, Directiva 91/533/CEE a Consiliului din 14 octombrie 1991 privind obligația angajatorului de a informa lucrătorii asupra condiților aplicabile contractului sau raportului de muncă, în Jurnalul Oficial al Uniunii Europene L 288 din 18.10.1991 [Online], Avalaible at: : www.eur-lex.europa.eu [Accessed 12 April 2020]

[22] *** \#EUROPEANPARLIAMENT. Vot în PE privind lucrătorii detașați: Remunerație egală pentru aceeași muncă în același loc, [Online], Avalaible at: https://www.euractiv.ro/social/vot-inpe-privind-lucratorii-detasati-remuneratie-egala-pentru-aceeasi-munca-in-acelasi-loc-10885 [Accessed 7 April 2020]

[23] *** Legea nr. 16/2017 din 17 martie 2017 privind detaşarea salariaţilor în cadrul prestării de servicii transnaţionale, publicată în Monitorul Oficial nr. 196 din 21 martie 2017

[24] ***, Legea nr. 53/2003 Codul Muncii, republicată în Monitorul Oficial, Partea I, nr. 345 din 18 mai 2011, [Online], Avalaible at:

http://www.mmuncii.ro/j33/images/Documente/MMJS/Legislatie/Munca/2018/20190207L_53-Codul_muncii_ian-2019.pdf [Accessed 24 April 2020]

[25] *** Expunere de motive la proiectul de act normativ Lege pentru modificarea și completarea Legii nr. 16/2017 privind detaşarea salariaţilor în cadrul prestării de servicii transnaţionale, [Online], Avalaible at: http://www.mmuncii.ro/j33/images/Documente/MMJS/Transparentadecizionala/2019/expun ere_de_motive_detasare_prop_legea_16-2017.pdf [Accessed 24 April 2020]

[26] *** CNIPMMR: Evaluarea situației de ansamblu a IMM-urilor din România, [Online], Avalaible at: https://www.argumentpress.ro/cnipmmr-evaluarea-situatiei-de-ansamblu-aimm-urilor-din-romania/ [Accessed 26 April 2020] 


\title{
The Economy and food security in the Arab World in the Midst of the Corona Crisis
}

\author{
Alexe Eva ${ }^{1}$, Plesoiu Marius Daniel ${ }^{2}$ \\ ${ }^{1} \mathrm{PhD}$ Police Academy Alexandru Ioan Cuza, \\ ${ }^{2} \mathrm{PhD}$ student University of Bucarest. History Faculty \\ E-mail: evaalexee@gmail.com
}

\begin{abstract}
The Corona pandemic as bad as it seen can opens an opportunity for the revival of local agriculture and fill a large part of food shortages in which demography along with other factors plays a major role key by saving the informal Employment on the black market that surround major cities in the Arab World inhabited by tens of millions who went from their countryside to big cities in search for a better life. This in itself constitutes a rare opportunity for all governments in the Arab World helping to stabilize the rural population by making them a source in providing food security, not to add that this would reduce congestion and pollution and considering that the Arab states are, by virtue of their geographical location, among the dry areas with fragile ecosystems we can think of: investing in modern technologies, following the recommendations made by the experts, using rainfall skyscrapers, converting buildings into power generators, applying vertical farming, innovation for afforestation of deserts, taking into account the local experiences, and using biodiversity by cultivating many new plants proven their feasibility.
\end{abstract}

Keywords: Pandemic, Economy, Arab World, Geography, Demography, International and Arab Organizations

\section{Introduction}

Corona returns agriculture to center the of preoccupation and the orientation towards quality crops is a necessity nowadays in the Arab World due to the closure of border crossings avoiding the global pandemic caused by Corona virus and knowing that the success of economies depending on it is indicating that many countries, not only in the Arab World, will revert to the importance of agriculture and pay attention to it as well after the pandemic.

Food security is greatly affected due to mobility restrictions which further reduces the purchasing power and as cases of contagion increase, governments may take a more drastic measures to stop the spread of the virus influencing the global food system. The premise of any measure adopted should be to protect the health and food security of the population in detriment of economic growth. How damaging this approach 
turns out to be for food security will depend on policy responses over the short, medium and long term. In the short term, governments must manage multiple demands such as: responding to the health crisis, managing the shock to the economy and ensuring a smooth functioning of the food system. While the pandemic poses some serious challenges for the food system in the short term, it is also an opportunity to accelerate transformations in the food and agriculture sector and to build its resilience according to the specific of the individual country.

\section{The economy of the Arab region on the ground}

The fatal flaws of the current economic pattern in the midst of the Corona crisis are not only apparent in the shortage of medical protections, but also in the lack of food and other vital products. What is the position of the Arab countries regarding to these flows and do they learn the lessons and work to overcome them?

The changes in our world find their reflection in the dramatic change in our daily lifestyle. Within less than couple of months of the escalation of the Corona crisis, the lives of a third of the universe's populationmore than 2.5 billion people-have become confined between the place of residence, food, beverage stores and household. Overnight, thousands of factories and institutions, along with tens of millions, stopped operating, with losses estimated by the United Nations Conference on Trade and Development at about two trillion dollars. In this situation, e-commerce is flourishing and the status of our virtual lives on the Internet and its multiple means of communication are enhanced like never before.

The Corona pandemic has caused violent economic effects on the Arab economy [1], as the total losses so far have reached about $\$ 1.2$ trillion, amid expectations that about 7.1 million workers will lose their jobs, according to a report issued by the League of Arab States [2], which called for the creation of a crisis fund that can push to alleviate the burden caused by the Corona crises.

In detail, the report indicated that the losses are of 420 billion dollars of market capital, losses of 63 billion dollars of income (gross domestic product) of member states, additional debts amounting to 220 billion dollars, and a loss of 550 million dollars per day of oil revenues, a $\$ 28$ billion decline in exports, a loss of more than $\$ 2$ billion in tariff revenue, and a loss of about 7.1 million jobs in 2020.

According to a preliminary assessment by the International Labor Organization [3], the "Covid-19" epidemic will have a significant impact on labor markets around the world with high unemployment, indicating that financial markets have been negatively and significantly affected by the outbreak of the virus regarding the growing global connection between countries worldwide from the beginning of the millennium so to say the economists is predicting the occurrence of stagflation, that is recession and stagnation in the markets coupled with high levels of inflation.

Oil demand drastically [4] declined following lockdowns and travel restrictions due to the coronavirus pandemic. Initial outlooks and uncertainty surrounding the course of the pandemic led to a disagreement between two of the largest oil producers, Russia and Saudi Arabia in early March. Bilateral talks between global oil producers ended in agreement on April 13th, with promises to cut petroleum output and hopes rising that these might help stabilize the oil price. However, with storage facilities and oil tankers quickly filling up, fears grew over where to store excess oil, leading to benchmark prices seeing record negative prices.

Table 1. An example of some crude oil prices from the Weekly Brent, OPEC basket and WTI crude oil prices from December 30.2019 to September 14, 2020 [5].

\begin{tabular}{|l|c|c|c|}
\hline Date & OPEC Basket & Brent & WTI \\
\hline Sep 14 2020 & 38.96 & 39.61 & 37.26 \\
\hline Aug 10 2020 & 45.01 & 44.99 & 41.01 \\
\hline Jun 15 2020 & 35.09 & 39.72 & 37.12 \\
\hline
\end{tabular}




\begin{tabular}{|l|c|c|c|}
\hline Date & OPEC Basket & Brent & WTI \\
\hline Apr 14 2020 & 19.7 & 29.6 & 20.13 \\
\hline Mar 16 2020 & 30.63 & 30.05 & 28.7 \\
\hline Feb 10 2020 & 54.17 & 53.27 & 49.57 \\
\hline Dec 30 2019 & 68.89 & 68.44 & 61.68 \\
\hline
\end{tabular}

In the world as we saw the health care field and food security are among the branches that are greatly affected by the crisis and the most affected branch by them all of this epidemic in the Arab countries are the oil, tourism and air transportation. This call paying attention to the medical supply industry, communication and information technology as a result of "Corona" crises and last but not least to agriculture and the demographic disposal of the work force across the Arab nations. A report distributed by the General Secretariat of the Arab League [6] calls for the establishment of an Arab Crisis Fund to address Small and Medium Enterprises as a Support Fund, reviewing the conditions necessary to provide financial support to member states, by setting a more flexible conditions and postponing the installments owed by Arab countries during that period by this granting them additional facilities or bearing any fees for this postponement.

Another proposal is the formation of work teams from the relevant joint Arab action institutions and Arab financing institutions whose task is to monitor the impact of the crisis on Arab countries in order to prepare to conduct sectoral studies on the impact of the crisis and to suggest the necessary policies and measures to be taken.

As part of the efforts of the Organization of Islamic Cooperation (OIC) and its relevant organs to contain the effects of the coronavirus pandemic, the Islamic Solidarity Fund (ISF), an OIC subsidiary organ, has disbursed the first payment of its urgent financial grant to the least developed countries among OIC Member States to strengthen their capabilities in the face of the novel coronavirus disease (COVID-19) pandemic, especially in the health sector.

\section{Food Security in the Arab Countries}

It is widely known that the Arab region is facing rising economic, socio-political and environmental challenges, which are impacting food security, first of all for its growing rapidly increasing population [7]. The region [8] is witnessing a rise in the prevalence of undernutrition, overnutrition and nutrient deficiency, classified as the triple burden of malnutrition. Undernourishment is increasing in conflict-plagued and Least Developed Countries, obesity is a high concern in the Gulf Cooperation Council, the Maghreb and the Mashreq countries, while nutrient deficiency is spreading and is especially rife among Arab women.

Generally, we must acknowledge, for first, that the Arab countries [9] do not have sufficient nutrition supplies to meet the needs of there people making them unable to enhance food security for several reasons such as: regional water crises, low rainfall, desertification and dry, weak technical possibilities, the increased dependency on the international markets due to conflicts in the region "oil for food policy" making the region one of the area's most vulnerable to food crisis [10] knowing that the region is the largest food importer, most depend on imports for over half of their needs.

According to the International Monetary Fund [11], regional growth will be around 3 percent negative in 2020. The sharp drop in oil prices and demand hit hard the oil exporters and those dependent on them. All countries worldwide will see a sharp drop in tourism and remittances.

Unemployment and poverty numbers will increase which lead Large countries from the region like Iran and Egypt to buy more wheat as a precaution against social unrest. Morocco will also import more due to climate change which caused a decrease in wheat production in 2020 by over 50 percent. In Yemen [12], 24 million people, 80 percent of the population require humanitarian assistance. 
In Syria [13], 9.3 million people, over half the population, are food insecure, in need of food and livelihood assistance. The new U.S. sanctions and the pandemic will surely increase these numbers. The about 6 million Syrian refugees in Lebanon, Jordan and Turkey those days are dependent on informal employment for daily wages make them vulnerable to closures and economic downturns. In the region there is about a 11 million people [14] internally displaced many of whom are concentrated in Libya, Iraq, Yemen and Syria whom are among the most vulnerable.

In Iraq, the displacement caused by the Islamic State group (ISIS) persists with food aid. For the most of those parts health systems are inadequate to confront a pandemic. Out of the 3 million Palestinians [15] in the West Bank and the 2 million in Gaza, 1.7 million (mostly in Gaza) are food insecure in need for assistance. Further a number of 841,000 people are marginally food secure. The pandemic, its closures, and economic slowdown will lead in worsen the situation.

Lebanon [16] is facing nowadays the biggest economic and political crisis in its history. The financial crisis constitutes in a currency depreciation of 80 percent, a sharp increase in unemployment and poverty and hurdle with food imports. Lebanon's World Food Program Director [17] Abdallah Al-Wardat stated that a one million Lebanese could drop under the food poverty line in 2020. The Interior Ministry says that 60 percent of the population, 2.4 million Lebanese people will drop below the poverty line in 2020. In Libya [18] food security is compromised by conflict and the pandemic, most of the cities facing shortages of basic food items, an increase in prices and supply chain disruptions.

Addressing further the issue of regional Economic migrants [19] we can uphold to a challenge with 35 million people just in the Gulf Cooperation Council countries, Jordan, and Lebanon. Many those days are unemployed and stranded which leads to a cramped living condition and further an invitation to pandemic outbursts so the access to food looms as challenge.

The Gulf states [20], like UAE and Saudi Arabia, was not alone in fearing the disruptions in international supply chains and the risk of governments imposing protectionist measures which could trigger a food crisis especially that the Gulf states and are in no permanent rivers, lakes or minimal rainfall, importing almost $90 \%$ of its consumptions which lead to an upsurge in overseas investments [21] in agriculture.

UAE and Saudi Arabia, the region's political and financial heavyweight, are accelerating their food security programs after the crises revived back memories from 2008 when rice and cereal prices soared. Back then, the wealthy countries rushed to secure overseas farming projects, particularly in African countries, stoking criticism that they were "land grabbing" which lead for many of those projects to fail and since then the Gulf States have been refining their strategies combining more targeted overseas investments with the development of technologies to produce at home.

The Iranian economy [22] is the second largest in the Middle East after the Kingdom of Saudi Arabia. Iran has large reserves of oil and natural gas. The country is largely dependent on revenue from the export of hydrocarbon products. Therefore, its economic growth is directly affected by developments in oil market. In the last 20 years, Iran has tried to pursue an economic policy aimed at diversifying its revenues and reducing its dependence on oil.

Agriculture in Iran accounts for 8 percent of the gross national product. And 19 percent of the workforce is employed in the agricultural sector. Iran, an important agricultural country, is among the world's 20 largest producers of products such as wheat, barley, chicken and potatoes. Both traditional and modern methods are used in the Iranian agricultural system. In addition to small and medium-sized farms, Iran has largescale commercial farms.

According to the Food and Agriculture Organization [23] of the United Nations (FAO), the total cultivated land in Iran is 15 million hectares. And cultivation is more widespread in the western, northwest and northeastern areas of the country. Iran gets $\$ 80$ billion annually from agricultural products, and consumes $\$ 75$ billion worth of agricultural products inside the country. Agricultural production has increased in Iran in recent years. Among the primary products grown there are wheat, barley and corn. 
Wheat is one of the most important grains in Iran. This product constitutes 70 percent of the total grain production in general. Domestic production of wheat covered the entire country's needs in 2006. However, due to the decline in production after the drought that struck the country in 2008, a decision was taken to start again to import wheat. In 2008, a severe cold wave hit the country, followed by a drought, which hit the production of grains, especially wheat and since then Iran was unable to achieve the same level of production.

Table 2. An example of the volume of wheat imports.

\begin{tabular}{|l|c|}
\hline \multicolumn{1}{|c|}{ State [24] } & The volume of wheat imports million tons \\
\hline Egypt & 12,5 \\
\hline Algeria & 7 \\
\hline Morocco & 4,8 \\
\hline Iraq & 3,3 \\
\hline Yemen & 3,3 \\
\hline Saudi Arabia & 3,2 \\
\hline Sudan & 2,7 \\
\hline UAE & 1,8 \\
\hline Tunisia & 1,7 \\
\hline
\end{tabular}

The reality of food security in the Arab World is unstable and may fluctuate [25] from time to time; there is also no self-sufficiency to cover the needs of the people from the Arab states. In addition, food security is connected with the power of water security, as all water resources come from non-Arab states, a shortage that may lead to famines, poverty and divisions.

Therefore, this affects the social security due to the emergence of unemployment and the inability to develop and sustain the general services considered necessary, not to add the infrastructure for the Arab citizens.

The weaknesses of technical abilities [26], rainfalls, desertification, drought are the main reasons for decreasing food security and increasing food subordination or dependency, which become significant in the Arab World, but the Corona crisis might be an opportunity to revive the local agricultural production, along with other medical and essential products analyzing the last successful experiences in Egypt, Tunisia and the Gulf States in growing dates, olives, aloe vera, grains and producing medicines.

Demography [27] may play a major role key by saving the informal Employment on the black market because the slums that surround major cities such as Cairo, Casablanca, Beirut and so on was inhabited by tens of millions who went from their countryside to the big cities in search for a better life. The majority of those people work on the black market having a low wage without unemployment insurance.

There is no doubt that the Corona crisis will cause unemployment to these people more than any other group due to home quarantine and lack of work opportunity. This will push many of them to return to their countryside or to think of returning to it in order to carry out an agricultural or professional economic activity that helps them earn their daily livelihood where the state can be a major contributor by providing them the necessary means to be productive according to the state needs.

\section{Conclusions}

Experiences can be used in all the agriculture from cultivation of legumes and medicinal plants, oil and industrial plants on the basis of exploitering the agricultural lands abandoned by their owners in search of work in major cities such as Cairo, Casablanca, and Beirut or living in the major cities suburbs that lack the most basic elements of a healthy life. 
This constitutes a rare opportunity for all governments in the Arab World helping to stabilize the rural population by making them a source in providing food security. Reducing congestion and pollution in the overcrowded cities is required because nowadays it is widely known that pollution contributes to the spread of diseases and epidemics that cost tens of billions to confront annually worldwide.

As we saw, the Arab states are classified, by virtue of their geographical location, among the dry areas with fragile ecosystems climate which plays an important role in their makeup. The fragility of ecosystems, the prevalence of dry climates, and the scarcity of water have exacerbated desertification in these countries which can be overcome by: investing in modern technologies, taking into account the recommendations made by the experts worldwide and by the International Organizations involved in agriculture like the AOAD [28] and the many UN organizations involved in the field, rainfall using skyscrapers, converting buildings into power generators, applying vertical farming, innovation for afforestation of deserts following the recommendations the local experiences, and using biodiversity by cultivating many new plants that have been identified to have been successfully grown in some Arab countries or other countries having similar desert conditions proven their feasibility in entering the Arab agricultural system, while recognizing the need for research to produce suitable and productive varieties. We can say that the Corona pandemic as bad as it seen can opens an opportunity for the revival of local agriculture and fill a large part of food shortages. The importance of local agriculture resides in saving transportation costs and supplies the consumer with healthy and fresh products benefiting even further from demography itself.

\section{References}

[1] https://reliefweb.int/report/algeria/arab-states-region-covid-19-situation-report-no-6-reporting-period1-31-july-2020.

[2] https://www.oic-oci.org/topic/?t_id=23393\&t_ref=14002\&lan=en.

[3] https://www.ilo.org/global/topics/coronavirus/impacts-and-responses/lang--en/index.htm.

[4] https://www.statista.com/statistics/326017/weekly-crude-oil-prices.

[5] www.statista.com.

[6] https://www.google.com/amp/s/www.alarabiya.net/ar/amp/coronavirus/2020/05/03.

[7] 2017 United Nations Economic and Social Commission for Western Asia (ESCWA) and Food and Agriculture Organization of the United Nations (FAO) publication, "Arab Horizon 2030:" Prospects for Enhancing Food Security in the Arab Region.".

[8] E/ESCWA/SDPD/2019/4/SUMMARY.

[9] The Political Economy of Arab Food Sovereignty, Harrigan J., Palgrave Macmillan, 2014, pp 79101.

[10] Encyclopedia of Food Security and Sustainability, editors in chief Pasquale Ferrante, Elliot M. Berry, Lock L. Anderson, publisher Oliver Walter 2019, pp 25-150.

[11] https://www.imf.org/en/Publications/REO/MECA/Issues/2020/04/15/regional-economic-outlookmiddle-east-central-asia-report.

[12] https://www.fsinplatform.org/sites/default/files/resources/files/GRFC_2020_ONLINE_200420.pdf.

[13] https://www.nytimes.com/2020/06/30/world/europe/syria-aid-refugees-united-nations.html.

[14] https://reliefweb.int/sites/reliefweb.int/files/resources/2019-grid-pressrelease-mena-en.pdf.

[15] https://www.fsinplatform.org/sites/default/files/resources/files/GRFC_2020_ONLINE_200420.pdf.

[16] ashingtonpost.com/gdprconsent/?next_url=https $\% 3 \mathrm{a} \% 2 \mathrm{f} \% 2 \mathrm{fwww} . w a s h i n g t o n p o s t . c o m \% 2 \mathrm{fopinions} \% 2 \mathrm{f} 2020 \% 2 \mathrm{f} 05 \% 2 \mathrm{f}$ $20 \% 2$ flebanese-prime-minister-coronavirus-is-pushing-lebanon-toward-major-food-crisis $\% 2 \mathrm{f}$.

[17] http://english.ahram.org.eg/NewsContent/50/1203/370383/AlAhram-Weekly/World/Lebanonthreatened-by-famine.aspx

[18] https://www.who.int/news-room/detail/13-05-2020-joint-statement-on-libya. 
[19] https://www.ilo.org/beirut/areasofwork/labour-migration/lang--en/index.htm.

[20] https://www.ft.com/content/b5d5019d-9335-4cad-a3ad-9752b3938946.

[21] https://www.thenational.ae/business/abu-dhabi-attracts-four-agri-tech-companies-with-100minvestment-1.1003740.

[22] http://millerarabic.com.

[23] http://www.fao.org/3/az571e/AZ571E.pdf.

[24] http://mubasher.aljazeera.net/news.

[25] The Polities of Food - The Global Conflict Between Food Security and Food Sovereignty, William D. Schanbacher, Library of Congress Cataloging in Publication Data 2010, pp 86-101.

[26] Feeding Frenzy, Paul McMahon, Greystone Books, 2014, pp. 15-35.

[27] Agricultural Urbanism, Editors Janine de la Salle, Mark Holland, Green Frigate Books, 2010,p 3584.

[28] Arab Organization for Agricultural Development. 


\title{
Aspects regarding the consequences of chemical contamination of food
}

\author{
Daniela Cîrţînă ${ }^{1}$, Maria Modoran ${ }^{2}$ \\ 1 “Constantin Brâncusi” University of Tg-Jiu, Faculty of Medical and Behavioral Sciences, No. \\ 4, Tineretului St., Tg-Jiu, Romania \\ 2"Constantin Brâncusi” University of Tg-Jiu, Department for International Relations and \\ Community Programmes, No. 4, Tineretului St., Tg-Jiu, Romania \\ E-mail: danielacirtina@gmail.com
}

\begin{abstract}
The present paper aims to present some interest aspects of the use of adjuvant and contaminating chemicals on food quality and implicitly on the human body. The intake of harmful substances through food has a significant influence as an ecological factor on humans, producing food imbalances and even the appearance of diseases that influence health.
\end{abstract}

Keywords: food, chemical contaminants, adjuvants

\section{Introduction}

Chemical treatment and pollution of food represents currently a particular interest in terms of food quality control and the consequences that the aforementioned processes have on the human body. Changes and interventions made in the technologies for obtaining, preserving, marketing food have more or less justified consequences, which have often led to imperative decisions or behavior on the part of the responsible bodies for the public health safety. From the category of components of the environment that influence health, food has a major importance. The quality of food has, in fact, a significant impact from an ecological point of view, being in a position competing with food imbalances due to its excess or deficiency. [1]

Over time, there have been a number of causes that have underpinned food conditioning by humans, causes determined by increasingly sophisticated subjective or objective consumer claims that have led to the diversification and accelerated growth in the number of assortments, causes due to the growing needs of a growing population or causes determined by the need to ensure an additional stock in order to supply rationally and efficiently the large urban agglomerations. Finding viable solutions for the production of foods that are enriched, concentrated or of major interest under certain conditions (dietary, used in certain physiological periods of childhood, pregnancy, for certain types of activities etc.) is also another cause of conditioning food. The need for food safety and food safety conditions has always been a priority objectives for those who are working in the field of food quality control and assurance. All these causes and needs have forced the emergence of a series of new manufacturing technologies, which often involve, although not necessarily, certain chemical treatments. Often, food undergoes purely chemical treatments or is simply contaminated, like the rest of the components of the environment, in a way that is difficult to avoid or irresponsible. [2,3]

A series of synthetic chemical compounds, without nutritional value, reach the food in various ways, in an increasing number, through the chemical treatments to which the food is subjected, frequently 
burdened by the probability of a harmful intake appearance. The scale of the processes of chemical treatment and pollution of food has reached such high levels, and the particularities of these processes are so obvious that it is now important to investigate possible harmful effects and potential toxicological risks that some foods can manifest it. [4]

\section{The main causes and consequences of chemical pollution of food}

The causes of chemical pollution of food are represented by the complexity and diversity of chemicals added to food deliberately or by illegal ways that raise serious public health problems. The action of these compounds can have effects on food and implicitly on the human body by manifesting various disorders, depending on the substances nature found in the food. The evaluation process of the potential risk to humans is a difficult one and necessarily requires constantly updated legislation at an appropriate level of knowledge and development.

A classification of the main substances that reach the food implies the existence of two main categories, namely: adjuvants or food additives and contaminants or pollutants themselves.

The legislative implications of the society for the possible existence of these substances in food, determinates that the difference between these two categories be made in relation to their usefulness, justification of their existence or toxicity. [5,6]

Food adjuvants are a category of chemicals intentionally added to food for various purposes, their use is either a technological necessity, helping to improve the yield, thus avoiding losses and with a protection effect on the nutrients during the preparation process etc., or as a practical necessity (indispensable stabilizers or preservatives for the storage process). Also, their use can be accepted as a necessity of some modifications, improvements of the treated food, from an organoleptic point of view.

The addition of adjuvants is generally preceded by a study regarding their technological necessity and safety. Due to the structural diversity characteristic of these substances and the fact that a number of difficulties arise in the toxicological evaluation process, their admissible number is in a continuous dynamic influenced by the information on the possible direct or indirect harmful action that adjuvants may have. The amount of such substances allowed to be found in food is regulated by the legislation in each country, as well as the nature of the food in which they can be added. [7,8]

The chemical structure of the adjuvants used in the food industry is a complex one, the number of these substances is high and constantly growing, and a coherent classification of them takes into account the purpose for which they are used. Thus, food adjuvants are divided into preservatives substances: substances that oppose biological changes (antiseptics, antibiotics, antigerminatives), substances that oppose chemical changes (antioxidants) and substances that oppose physical changes (anti-caking, emulsifiers, binders etc.), respectively organoleptic (or ameliorative) substances: dyes and bleaches, flavorings and flavor enhancers and synthetic sweeteners. The contaminants (food pollutants) are found in a virtually unlimited number, which effectively depends on the possibilities of contamination or pollution under the influence of various environmental factors. The diversity of the chemical structure of these substances in relation to that of the adjuvants is bigger. [6-8]

The qualitative and quantitative quantification of contaminants in food is strictly limited by food safety and security standards. The acceptance of their presence is allowed within certain limits, rigorously established by the current legislation which underlies the substantiation of food manufacturing technology and the prevention of its contamination. If the existence of contaminants becomes harmful to the human body, they cause the inability of the food and its exclusion from consumption.

Among the sources of food chemical contaminants can be mentioned: chemical treatments in agriculture and animal husbandry (pesticides, biostimulators, fertilizers), excessive and traumatic physical treatments (formation of toxic polymers, degradation compounds), use of impure raw materials, solvents etc., contamination in packaging, contamination in the unpacking or handling process, contamination with toxic compounds resulting from biological processes (amines, mycotoxins), harmful compounds concentrated in the plant or animal tissues from the water, air, soil (carcinogenic hydrocarbons, metals, toxic metalloids) or pre-existing harmful compounds in some products. [8,9] 
The action of chemicals on food assumes that adjuvants or contaminants and especially technological processes often have secondary actions on food. As a result of the heat treatments to which foods are subjected, toxic compounds, such as aldehydes, ketones or polymers with toxic action, can appear in food fats. Harmful compounds can also be formed through the reaction of some adjuvants and nutrients in food. The formation of sulfoximine in flours treated with nitrogen trichloride, the formation of nitrosamines in the presence of excess nitrates or the formation of ethylene chlorohydrin from ethylene oxide, used as a pesticide can be considered that type of examples. The nutrients destruction, namely inactivation of vitamins $C, B_{1}$, heat treatments, inactivation of vitamins $A, E$ and $B_{2}$, due to oxidation, loss of water-soluble vitamins or mineral salts by washing, inactivation of the protein amino acids as a result of heat treatments or treatments with adjuvants such as carbon dioxide, bromates, ethylene oxide, methyl bromide, hydrogen peroxide etc., are also forms of the action of technological processes on food quality. [9-11]

The influence of food contamination with foreign substances added or introduced illegally in the human body is materialized in direct or indirect actions. The toxic potential of foreign substances in food can only be assessed to the extent that these substances cause obvious manifestations or endanger the life of the consumer.

A number of chemicals present in food may not be harmful themselves, but may facilitate the toxic action of others or may simply not be tolerated by the human body in a certain form of processing. Thus, examples can be a series of emulsifiers used in confectionery and bakery, or in the fat industry. Another example in which food can undergo changes caused by technology is modified starches, mechanically or enzymatically, in the sense of reducing the polysaccharide granule and obtaining improved organoleptic products with an increased digestive utilization coefficient for children's nutrition. In the case of these products, a certain harmful action was highlighted, due to the absorption without hydrolysis of the too finely divided polysaccharide, which causes allergic manifestations etc.

The consequences of the use of contaminants can have for humans, an influence that can manifest itself from a simple action of digestive or metabolic interference, to oncogenesis. Thus, we can mention the local anti-enzymatic action of food preservatives that act by mechanisms similar to those that make them active against microorganisms. [10,11]

They exert inhibitory or destructive influences on the enzymatic system of the digestive tract and cause changes in the digestive utilization coefficient (preservatives, antiseptics, salicylic acid, benzoic acid etc.). Other forms of action are: irritating or keratinizing action on the digestive mucosa (salicylic acid, phenol, formic aldehyde, etc.), the organotropic action determined by a certain preference of chemicals for some tissues (tissues rich in lipids, bones etc.), or the possibility of the organs to metabolize, detoxify or excrete these substances as well as the allergenic action. The mutagenic, teratogenic, oncogenic actions explain the increased percentage of neoplasms caused by pollutants that reach the body through food. The explanation consists in the great diversity of carcinogenic compounds that can appear in food or coming from the intentional addition of substances with malignant, mutagenic, teratogenic potential. Another example is the possibility of the formation of carcinogenic compounds produced by a series of common molds, which populate food (aflatoxins). [10-12]

\section{Conclusions}

Although it has long been considered a secondary problem, the action of chemicals on food must be taken into account, which either results in a decrease in nutritional value or possible harm to the human body. Adjuvants or contaminants and technological processes often have side effects on food. The thermal, chemical, physical treatments to which the food is subjected, can generate toxic, harmful compounds, formed, in part, by the reaction between some adjuvants and the nutritional components of the food. The influence of foreign substances in food, added or introduced illegally is materialized in direct or indirect actions on the human body. A number of chemicals present in food may not be harmful themselves, but may facilitate the toxic action of others or may not be tolerated by the human body in some form of processing. The use of contaminants can have for humans, an influence that can manifest itself from a simple action of digestive or metabolic interference, to oncogenesis. Harmful effects can 
be aggravated by the high incidence of contamination, by prolonged preservation of the harmful agent and the possibility of coexistence of co-carcinogenic factors, accessible to the consumer throughout life. The possibility of contaminating food with harmful, carcinogenic substances, which cause serious biological disorders, is higher than for other components of the environment.

\section{References}

[1] Banu, C., Nour, V., Vizireanu, C., Mustaţă, Gr., Răsmeriţă, D., Rubţov, S., Quality and control food quality, AGIR Publ. House, Bucureşti, 2002.

[2] Mihele, D., Physico-chemical analysis and control of food, Multi Press International Publ. House, Bucuresti, 2003.

[3] Ciobanu, D., Ciobanu, R., Food chemistry. Analytical investments, Tehnica Info Publ. House, Chişinău, 2002.

[4] Dumitrescu, H., Milu, C., Dumitrescu, C.D., Ciubotaru-Bordeianu, A., Albulescu, V., Physicochemical control of food, Medicala Publishing House, Bucuresti, 1997.

[5] Tofana, M., Food additives and conservability, AcademicPres Publishing House, Cluj-Napoca, 2003.

[6] Banu, C., Preda, N., Vasu, S., Food and their safety, Tehnica Publishing House, Bucuresti, 1982.

[7] Cîrțînă, D., Traistă E., Traistă C., Danciu C., Environmental sanitary chemistry, Academica Brâncuși Publishing House, Tg-Jiu, 2017.

[8] Barnea, M., Calciu, Al., Human ecology, Medicala Publishing House, Bucuresti, 1979.

[9] Bulancea, M., Rapeanu, G., Authentication and identification of food counterfeits, Didactica and Pedagogica Publ. House, Bucuresti, 2009.

[10] Simion, C., Albu, H., Simion, A., Food quality and control, Printech Publ. House, Bucuresti, 2007.

[11] Mănescu S., Cucu M., Diaconescu M. L., Environmental health chemistry, Medicală Publishing House, Bucureşti, 1994.

[12] Popa, G., Dumitrache, S., Segal, B., Segal, R., Apostol, C., Teodoru, V., Food toxicology, Academiei Publ. House, București, 1986. 


\title{
Integration of minorities in the EU states through public policies
}

\author{
Andrei Ghimisi ${ }^{1}$ \\ ${ }^{1}$ National University of Political Studies and Public Administration \\ E-mail: ghimisi4567@gmail.com
}

\begin{abstract}
The paper "Integration of minorities in the EU states through public policies" wishes to present the problem of the integration of minorities within the EU states and to present how these problems are tackled through public policies. There are presented types of policies and how they affect direct and indirect the people that are the subject of these public policies and also what are the main areas in which visible changes have been made through the years. Another important subject that is presented, the problem of migration and refugees, is connected with the topic of integration, as being inter-dependent. Key findings are presented that show the main areas of focus, the main targeted people and concerns regarding the near future and how to improve the process of integration within the EU states
\end{abstract}

Keywords: minorities, public policies,

\section{1,Introduction}

The integration of minorities has been a much-disputed subject through time and suffering many changes because of its complexity. Because of this, the researches on the topic needed to be expanded in order to fully grasp the meaning of the term "integration" and in order to create public policies that go through all the steps that are necessary for this process to be a success.

International migration evolved as an important component in the process of liberalization and economic expansion, which took place in Western Europe after the Second World War. Whether as migrant receivers (north Western Europe) or as migrant-senders (southern Europe), all states became connected into an expanding migration 'systern', which soon extended beyond the region, incorporating former colonies and other states to the south and to the east.

As presented earlier, the term "integration" has a very vast understanding and because of this it makes the process for it to be defined in a precise way even harder. For a proper integration of minorities, this integration must be made at every level and in every sector of society. Its range ca vary from a long list of social actors: political decision-makers, public officials, employers, fellow-workers, trade union officials, neighbours and so on. Members of minorities also play a crucial role in this process.

Seeking to accommodate minority claims implies searching for a balance between separation and unity, cohesion and respect for diversity. If one prefers solely unity, the risk is assimilation and the disappearance of a minority as a distinct group; if one chooses exclusively diversity, then the result can be the cultural 'ghettoization' of a minority group with consequent separation and marginalisation from society. 
In order to understand this process we must go deeper and study it from not only a single social science, but almost all. Economics, law history, political science, sociology, anthropology, geography, urban studies, demography and psychology all have a part to play. As hard as it is to put a definition on integration, it can be assumed that the terms is generally attributed to be a universal, singular, stagesequential and regular paces process which all members of minorities are exposed. It is within these presumed universal stages that minorities are often judged in public discourse to have either 'successfully' or 'unsuccessfully' integrated.

\section{Public policies: types and areas of focus}

In Europe, as the case study, a deteriorated political, economical and social situation is generally unfavourable towards the encouragement and promotion of policies regarding diversity through for instance, affirmative exemptions or actions from general rules. Indeed, in some countries that have celebrated multiculturalism, such as the Netherlands, this model is experiences a reverse process even if there are more and more evidences that multiculturalism is still a current valid policy option.

Several Government programmes, most notably those of Hungary, the Czech Republic, Bulgaria and Romania - reflect a comprehensive approach in regards to minority protection, clearly stating an intent to address discrimination as well as to promote minority identity. In Latvia and Estonia, where the principal target is Russian-speaking populations, Government programmes do not purport to guarantee comprehensive minority protection and instead promote societal integration through acquisition of proficiency in the State language.

It is important to perceive minorities as active participants in the individual collective process of integration. One of the first steps in the process of integration operates through the consolidation of relationships with family and extended kin groups, then sub-groups and wider ethnic groups, then neighbourhood and cities, and finally into what is called a national society as a whole. All of this so called "nested processes" should and must be recognized in policy terms, since there are so many different domains of policies that can impact on each level of integration in this process.

Although, for example, the protection of Roma culture is a priority for many Roma civil society organisations, this dimension of minority policy is not fully elaborated by any of the Government programmes, though integration is often identified as an objective. In fact, the inclusion of "socialisation" elements in many programmes (Lithuania, Hungary, Poland, and Slovenia) suggests that Roma culture is still identified with deviance, poverty, and other negative characteristics, and is viewed as being at odds with majority society.

There are four dimensions regarding the process of integration that can be differentiated: legal or structural integration, which means the acquisition of rights and the access to membership, statuses and positions in the cores institutions of the society (training system, education system, labour market, citizenship, housing, trade unions and more). Another dimension in this process is the Cultural integration, which is a precondition of participation and refers to the process of cognitive, behavioural, cultural and attitudinal change in people. This change is mostly focused and concerned on minority groups, but is also an interactive, mutual process that changes the dominant/majority society as well. Cultural integration is a rather heterogeneous area relating to, cultural competences, popular culture, values and beliefs, and everyday practices.

Another important factor that can share some light in the process of the integration of minorities in the private sphere is presented in the people's private relationships and group memberships (friendships, social intercourse, marriages, and voluntary associations). All of these refer to the third dimension, which is social integration. The membership within a new society is manifested in the sense of identification and belonging, particular in the form of ethnic and/or national identification. This leads to the identification of the fourth dimension that is identification integration.

As a result, the meaning of integration policies can be explained as an access to position and statuses, an acquisition of rights, a building of social relations, a change in individual behaviour and a formation of feeling of identification and belonging by minorities towards the community in which they live. 
Speaking in general terms, integration policies can be split into two types: targeted policies only aimed at specific types of persons that are disadvantaged and general policies aiming to improve the position of all people who are discriminated or marginalized or are at risk of becoming so. This can also be explained as direct and indirect integration policies. Some examples regarding indirect and direct policies could be those in which long-term unemployed have access to job schemes or retraining programmes, or, on a different front, urban renewal schemes, improving house quality, infrastructure and the like, in principle equally benefiting minority and majority groups or natives and immigrants ${ }^{1}$. Good examples regarding direct integration policies are those that assist minorities who lack the basic attributes needed to participate on the labour market, such as language courses or training courses to bring immigrants skill up to the necessary level.

A secure residence status for immigrants is a necessary prerequisite for their integration. Without security, a person cannot feel part of the receiving society and has little incentive to take steps to become part of it. Public authorities too have little to no incentive to include immigrants with uncertain status in social welfare programmes, and they may have limited access to social housing and healthcare. Temporary status also reduces employability, and restricts immigrants to temporary, low skilled work. It is important for residence permits to be issued in a relatively short time.

Governmental minority protection programmes are moreover policy documents, rather than legislative acts. As such, in most of the cases the bodies primarily responsible for fully elaborating them and overseeing their implementation are specialised departments within Government ministries. However, these bodies seldom are authorised to do more than compile reports using information voluntarily supplied by participating ministries, and lack the mandate to coordinate the activities of other Government institutions efficiently and effective

Other measures that were adopted by some governments regarding integration policies consist in the form of 'introduction programs' for the early phase of immigrants stay ${ }^{2}$. The introduction programmes consists in general of three main components: civic orientation, language tuition and professional labour market training. In particular, in those countries in which immigrants and refugees that are newly arrived do not have yet the knowledge of the native language through colonial or other ties, the language teaching programmes constitutes the centrepiece of introduction by the efforts of the respective state governments.

Beside language, 'social orientation' is another important factor that is presented in the introduction courses and also the importance of giving immigrants the knowledge of the functioning and the values of the host city is another element which is discussed. In these courses, the people can find the fundamental elements regarding the constitution, such as the respect for democracy and human rights, and the functioning of the political system including opportunities for participation in civil and political society. Gender equality and children's rights are other crucial components of many orientation programs. Regarding this subject, Joppke and others have interpreted integration programmes as those encouraging minorities to learn the official language or promoting citizenship ceremonies and others, citizenship education, or those labelled ' society orientation classes' as a 'retreat from multiculturalism'3.

Other types of integration policies are the ones that extend the right to vote to non-citizens in order to increate their political participation and sense of belonging to a society. Also, it can help the established institutions to know what are the minorities problem by hearing and understanding their claims. In addition to this, policies are also conceivable whereby minorities are offered facilities for retaining some of their core aspects in their culture, such as religion or are even encouraged to do so.

Broad public support is generally considered to be necessary for the implementation of any largescale political programme, but the rapid pace of the accession process has meant that building public support for governmental policy often has been given short shrift in the wake of the broader accession

\footnotetext{
${ }^{1}$ EU, A Common Agenda for Integration, 2005, CBP 1

${ }^{2}$ EU, Handbook on Integration Policies, 19

3 Joppke Christian "Towards Assimilation and Citizenship", 2003.
} 
imperative. Measures that need to be adopted to comply with economic requirements can be more easily justified by political leaders in terms of the economic benefits that Union membership is widely expected to produce. However, the case for the advantages and benefits to society as a whole of improving the situation for minorities has not been so persuasively made.

There are some problems regarding these types of direct integration policies, especially those that are brought under the general heading of positive action. Quota may be laid down in law or be institutionalized practice by which people that are belonging to disadvantaged ethic groups are receiving some kind of preference when applying for places in educational system or jobs.

These types of policies can be active, for example, when employers face the obligation to give preference to members of such specified population categories in working places, or they can be passive, when they are under an obligation, for instance, to report the relative numbers of such persons in their work force. Somewhere between passive and active policies are those whereby government institutions prefer to offer projects to employers with a certain minimum number of disadvantaged workers among the employees.

As presented, integration policies touch upon very different aspects of the majority-minority relationship, not only the cultural, legal, and social dimension, but also the sense of belonging and citizenship, the identification aspects that come along with it, complementary identities, they all represent a crucial aspect of the integration process.

\section{Migration: a challenge for Europe}

Integration is an open-ended, long-term process that requires a range of police actions that are taken at different stages and directed at a combination of targeted groups. Many of these policies address the impact and the consequences of migration and, as such, are targeted at refugees and migrants at various stages of the settlement process. Other policies are shaped in order to address racial, religious or ethnic differences, and thus focus on the management of diversity, regardless of its relation to migratory environments.

Regarding the aspect of migration management, a number of states offer, or plan to provide, special programmes for recognised refugees or newcomers holding residence permits. This comes as a reflection of the European Commission suggestion to offer "settlement packages", 4 In terms of naturalisation and its process. Candidates are sometimes required to take classes on citizenship and pass language tests, for example in Germany, Netherlands and Austria, which are thought to serve as integration helps for prospective citizens. Even though all the measures can seem to be potentially valuable, they can also shape barrier to participation and tend to be reserved for certain groups of migrants( for example if training expenses are involved. For spouse of primary migrants, 'guest workers', asylum seekers and irregular migrants, the restriction of socio-economic opportunities and rights at the begging of their stay can have a serious adverse impact on their integration trajectory.

Because of this, it is important that the measures are not only developed for all types of migrants, but are also accompanied by policies that want to minimise any disadvantages that may be caused bu a restricted legal status upon arrival.

Policies that are lead from initial arrival measures and address the long-term settlement of migrants are required to focus on the promotion of equal opportunities in relation to the native population. Such measures overlap with general policies that are aimed at managing diversity with a view to ensuring social cohesion ${ }^{5}$. Where the policy management of diversion intersects with that of the diversity, targeted groups are identified according to their migration experience on the one hand, and their ethnic, religious and racial background on the other. While migrants are often seen as ethnic or racial minorities, there is no necessary correlation between these two-targeted groups, which can also include large numbers of

\footnotetext{
${ }^{4} \operatorname{COM}(2000) 757$ final, Communication from the Commission to the Council and the European Parliament, (Brussels, 22.11.2000), 20.

${ }^{5}$ Mary Coussey, Framework of Integration Policies, Council of Europe (Strasbourg 2000)
} 
white migrants from Western countries who face no particular problem of integration. There can also be some racial and ethnic minorities in the EU, who have no recent migratory background, and yet encounter the same obstacles to full inclusion. Finally, there are some white migrants, for example from Eastern Europe, who suffer from exclusion, which may be related to their distinct ethnic, cultural or religious identification. As integration policies are formed, they need to take into account the main factor that is affecting the integration of migrants and that is the prevalence of racism. An example is presented in the case of asylum seekers where they are often racially designed and stereotyped in public discourse, even though many are in fact white.

While some EU member states now aim to capture second-generation migrants into their statistics by adding the category of nationality at birth, it is also perceived that this is only a temporary stopgap before the introduction of detailed ethnic minorities' categories. It is also important for the people that shape these policies to recognise that the adoption of policies targeted at specific ethnic groups as well as ethnic monitoring does not constitute a division of human beings into fixed groups, but is moreover a vital tool for delivering successful outcomes and for identifying the needs of the targeted people.

The aspect of the integration of migrants in the labour market has been and, in the light of the recent events, still is, one of the main priorities in the framework of the European Union. Because of this, the European Commission recommends greater resort to a combined strategy with the help of the European Social Inclusion Process in order to eliminate the barriers of integration. This initiative is created in order to support innovative good practices that can prevent unemployment and fight labour marked discrimination of immigrants, including xenophobia and racism.

In regards to the problem of migration and its continuous increase to an unpreceded level in the last years we must understand the meaning and what does it truly mean for the process of integration. The aspect of social cohesion is raised when we talk about migration and it reveals an unequivocal urgency for many if not most of the countries that consider themselves to be reasonably homogenous and cohesive. The result consists in the process of integration of minorities to be adopted by most countries in order to retain an adequate level of social prosperity and cohesion.

Because of the unfavourable situation of immigrants in respect to unemployment and wages compared with native workers in many Member States, their integration is identified as one of the main and top priorities by the European governments. Enhanced integration could lead to a massive reduction in the unemployment gap between non-EU and EU nationals that exists in the Member states.

Integration is perceived now, and ever since the Amsterdam Treaty, as a process that can be achieved by appropriate common, proactive and comprehensive policies. In this regard, EU has moved forward towards establishing a legal framework for managing migration, calling for " more efficient management of migration flows at all their stages" and providing for a common migration policy that included legal migration and integration"6.

The Communication on Immigration, Integration and Employment of the Thessaloniki Summit of 3 June 2003 was perceived as a basis for developing EU integration polices. One of the most important message for this Communication was the in creation of immigration flows that are necessary in the EU. With this in mind, the second message that was outlined was that a better integration if immigrants should be achieved as a condition of future immigration. Not only this, but another important topic that was discussed is that more coherent framework of integration policies must be created at the EU level.

The European Commission underlines the necessity for minorities and migrants to be able to access the labour marked and integrate with an equal status to the native workers. In 2006, the problem of migration was considered to be by the European Council Presidency's Conclusions as "'one of the major priorities for the EU at the start of the $21^{\text {st }}$ century".

The problem of migration and how it can be properly dealt with was a topic to be discussed also over the following years. 'Strengthening the Global Approach to Migration, 'A Common Immigration Policy for Europe, Pact on Immigration and Asylum are also other important moments that helped shaped the

\footnotetext{
${ }^{6}$ European Council (TAMPERE), “Tampere European Council, 15 and 16 October 1999, Presidency Conclusions", 1999
} 
public policies that are directed towards migration and the integration of minorities in the EU states. The main focusses in the examples above are focused mainly on legal immigration and integration, border controls. The control of illegal immigration, migration and development, and the finalisation of a common European asylum system. In these pacts, the need to treat migrants fairly and promote their integration into society with an emphasis on measures promoting language acquisition and access to employment are emphasized. It also invites the Members States to combat any forms of discrimination to which migrates may be exposed.

The integration of refugees is another important topic, which the EU has been covering especially in the last years. Within its specialized body, the European Council on Refugees and Exiles several steps have been made in order to help improve the situation of refugees. Firstly, there are some legal steps, such as facilitating the application and acquisition of citizenship and easing the restriction on family reunification. After this step, some practical actions are needed, such as free language and orientation programmes, including during the reception phase, and policies encouraging and promoting civic, cultural and socio-economical participation.

\section{Conclusion}

In conclusion, there are several factors that are important to see when we are to discuss the problem of integration. Because of the fact that the term is very complex in its understanding, it makes it difficult to put a precise definition. Through the years, the EU has made more and more steps towards the implementation of a healthy and balanced environment in which the people to feel welcomed and can easily integrate in the respective society. There are several challenges that need to be fixed and dealt with properly in order for this environment to nourish. Changes need to be made in all sectors, especially in the educational and labour market system, in order to facilitate the integration of minorities in the EU states.

The problem of migration is another topic that concerns the EU and tis member states. Because of the huge waves of refugees that came across Europe in the last years, the system and its structure was not prepared and presented some flaws within its mechanism. In order to fix them, several steps were made by the European Union Council in order to eliminate, as much as it could, the gap socioeconomical gap between the migrants, refugees and the native people of the respective states.

To sum up, the problem of migration, refugees and minorities are in strong connection one and other. Changes within the system of all member states are needed in order to facilitate their integration in the states. From language courses to training courses in order to initiate in the labour market, all represent key steps towards the integration of people from different states, even if they are of different religion or other consideration, inside the European Union system within the respective state. All people should have equal chances and compensation when applying for a job and must not be judged by the colour of their skin, religion or any other different considerations.

\section{References}

[1] EU, A Common Agenda for Integration, 2005,

[2] EU, Handbook on Integration Policies.

[3] Joppke C., Morawska, E. (2003): Towards Assimilation and Citizenship, Macmillan

[4] Communication from the Commission to the Council and the European Parliament, (Brussels, 22.11.2000), 20.

[5] Coussey, M.(2000): Framework of Integration Policies, Council of Europe (Strasbourg)

[6] European Council (TAMPERE), (1999) Tampere European Council, 15 and 16 October 1999, Presidency Conclusions

This paper was elaborated within the Human Capital Operational Program 2014-2020, co-financed by the European Social Fund, under the projectPOCU/380/6/13/124708 no. 37141/23.05.2019, with the title "Researcher-Entrepreneur on Labour Market in the Fields of Intelligent Specialization (CERTANTREP)", coordinated by the National University of Political Studies and Public Administration. 


\title{
Aspects of the Evolution of Secondary Education Development in South Muntenia Region of Romania in the Last Decades
}

\author{
Loredana Păunescu ${ }^{1}$ \\ ${ }^{1}$ Lecturer economist, Petroleum-Gas University, Ploiesti, Romania \\ E-mail: loredana.paunescu@yahoo.com
}

\begin{abstract}
In terms of sustainable development and improving living standards at the local and regional level, secondary education plays an important role. The main objective of the study was to identify the characteristics of the evolution of secondary education development in South-Muntenia region and the counties included in this region for the last 25 years. Its efficiency is also evaluated in terms of the number of Baccalaureate graduates awarded with a degree, compared to the high school level graduates in each county. The paper highlights the similarities and disparities between districts, on equipment and efficiency of secondary education in this region.

Keywords: education, secondary education, development regions, students' progress, the curriculum in the educational units.
\end{abstract}

\section{Introduction}

The sustainable development of human society, the development of technologies for environmentally friendly production, information technology and communication of a society based on knowledge are the main goals of the utmost importance for long-term growth of quality of life, both at EU level and in Romania and with regard to regional development [1]. In these circumstances, education is a fundamental prerequisite for poverty reduction and increased social welfare at both the local and regional levels [2]. In terms of society, the free movement of labour, education and skills acquired are factors which contribute to building and maintaining a functional labour market [3] and ensure a standard of living adequate for the human communities.

On the other hand, the social, environmental quality and social characteristics to educate and form the young population is an important factor of transition for the school-age population (and not only) from one level of education to another [4]. This forms a feedback loop that can lead local and regional communities towards sustainable living standards. Development and performance depend on the quality of educational stakeholders in the process. Firstly, we should consider the quality of teachers. Their attitudes and their involvement in both urban and rural areas, are key factors of educational performance [5, 6].

Quality and performance of the educational systems depend on the quality of education infrastructure. In this regard, the development in the current telecommunication, computer equipment with high performance in schools is vital [7]. Last, but not least, the quality of education depends, on one hand, on the attention of the rulers of this area [8] and, on the other hand, on the quality of management at regional, county and local levels [9]. 
Another influence on sustainable development is the number and percentage of students enrolled in various levels of education, including the level of high school secondary education. In Romania, high school secondary school population decreased continuously. Thus, if in 1995 the number of students was 644 085, in 2010 there were only 523362 students, and in 2018-447026 students [10]. After 2010, the gross enrolment rate in secondary education has been steadily decreasing, from $96.7 \%$ in the school year 2010/2011 to $96.0 \%$ in the school year 2011/2012; school year 2015/2016 reached only $85.6 \%$ [11]. At the regional level, the direct effect of demographic developments, is generated by the following: reducing the birth rate, natural growth and external migration of the population of Romania, adjusted net enrolment rate in the school year 2011/2012, recording the lows in the North East $(69.1 \%)$ and South-Muntenia (71.6\%), corresponding to their level of economic development [12]. Given these aspects, the purpose of this article was to analyse the evolution and performance of secondary education development in South-Muntenia region in the recent decades.

\section{Methodology and key steps}

The analysis of the secondary education development in South-Muntenia region was performed on the data series on the number of students [10] and high school teachers in the region and within the seven counties [13] contained therein, on equipping high school students with personal computers [14]. Also, in order to obtain a qualitative evaluation of the development of high school education in this region's development there were included in the analysis data sets on the number of high school graduates [15] and graduates with a Baccalaureate degree [16] both at regional and at county levels. For this were used and analysed five indicators. The codes and their meanings are shown in Table 1.

Table 1. The main variables used

\begin{tabular}{|c|c|c|}
\hline Indicator & Signification & Units \\
\hline BAC & Graduates with a baccalaureate degree. & number \\
\hline TS & Teaching staff & number \\
\hline PC & Personal computers & number \\
\hline STD & Students & number \\
\hline HSG & High school graduates & number \\
\hline
\end{tabular}

In this paper the developments are analysed according to five variables (identifiers) for the periods for which data were available. Thus, analysis of the number of students enrolled in high school and staff related, and the number of high school graduates is conducted during 1995-2018 and the evolution of the number of PCs during 2001-2018. Regarding the graduates with a Baccalaureate degree, the serial data is much shorter, covering only the period from 2010 to 2017. This is a consequence of the changes to complete the Baccalaureate, which induced a discontinuity in the data series.

\section{The case study. Detailed analysis}

In the analysed periods regarding secondary education, both in terms of the number of students and teachers involved in the education process experienced periods with different characteristics determined on the one hand, by the rate of birth, and on the other hand, by the characteristics of social media and legislation at different points in time.

\subsection{Students, teachers, IT resources}

In the South-Muntenia region, during 1995-2018, the evolution of the number of students enrolled in high school (STD), is characterized by three periods with slightly different characteristics (Figure 1). The first period was between 1995 and 2000. At the regional level, in 2000 compared with 1995, the number of students enrolled in secondary education was lower with 18177 students (a 
decrease of $16.22 \%$ ), due, in particular, to reducing birth rates in the period 1982-1986, as well as changing attitudes towards education in the next period of 1989. The descendent trend is registered at the level of the region and its counties. The same downward trend is recorded in each of the seven counties. In terms of numbers, the largest decreases were recorded in Prahova (5669 students) and Arges (3858 students). In relative numbers, the largest reduction was recorded in Giurgiu (24.87\%). This was followed by Prahova (19.42\%), Teleorman (15.82\%) and Ialomita (15.35\%).

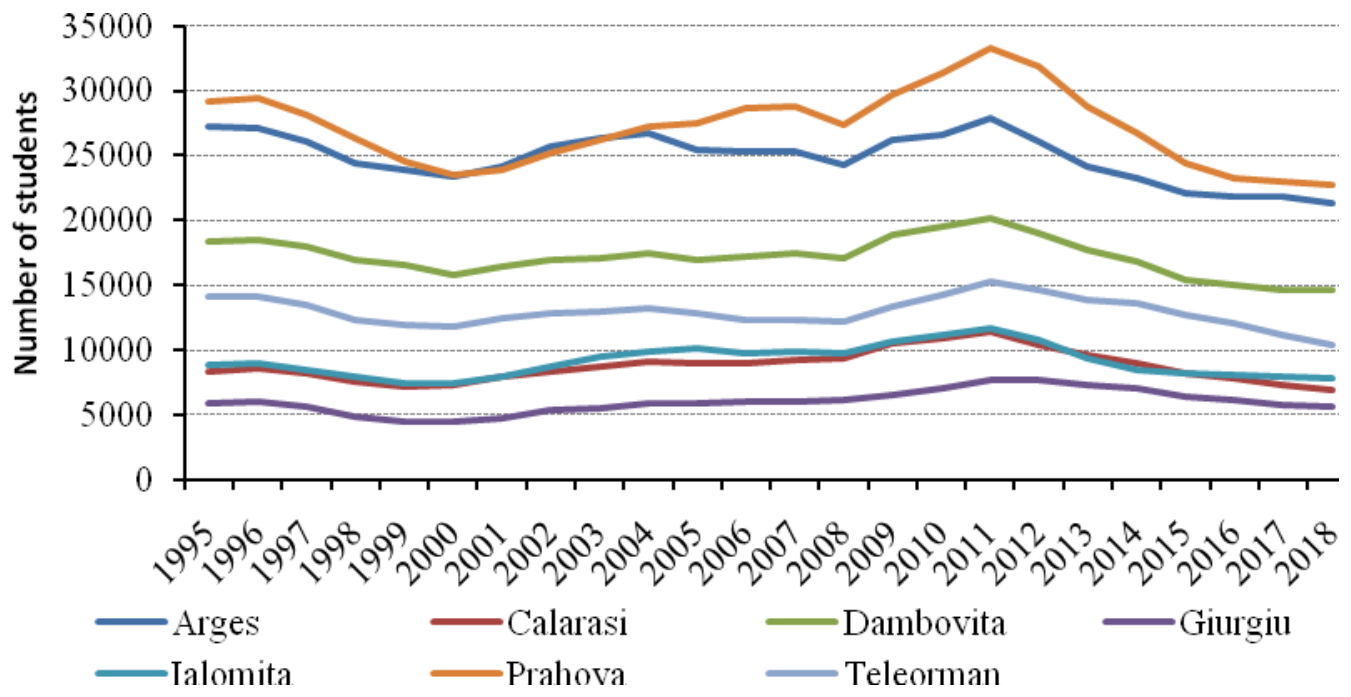

Figure 1. Evolutions of the number of students enrolled in secondary high school in the counties from the South Muntenia region during 1995 until 2018 period

The second period (2000-2011) is characterized by the relative increase in the number of students in the secondary high school education in the South region. At the regional level in 2011, compared to 2000 in the education school enrolment there were 127412 students, with 33525 more than in 2000 (an increase of $35.71 \%$ ). In numerical terms, the highest increases were registered in Prahova (9732 students), Arges (4438 students) and Dambovita (4336). In relative numbers, the highest increases were recorded in Giurgiu (72.89\%) and Calarasi (57.01\%). After 2011 the number of students registered for secondary school decreased continuously. At the regional level, the decrease was continuous and linear, described by a model of the following form:

$$
S T D(t)=129622.4-5576.11 \cdot t+\varepsilon, \quad t_{2011}=1
$$

Given that the level of significance of the test $F($ Sig.F $=0.00)$ and $R 2=0.951$, that model (1) is statistically significant and accurately describes the evolution of the number of students registered for secondary school during 2011 and 2018. At county level, more than one third reduction in the number of students registered for secondary school were recorded in Călăraşi $(39.93 \%)$ and Ialomita (33.22\%). Another characteristic of the number of pupils registered for secondary school development in South-Muntenia region is that while during 2000-2011 there were increases, however, at the end of period, in 2018, their number was lower than in 1995, both at regional level and in each county. The evolution of the teachers is slightly different to the number of pupils (Figure 2). At the regional level, the development of a number of high-school teacher is characterized by a downward expressed by the linear model of the form:

$$
S T D(t)=8856.56-62.73 \cdot t+\varepsilon, \quad t_{1995}=1
$$


If the model (2) the significance test $\mathrm{F}$ (Sig.F $=0.00$ ) leads to the conclusion that it is statistically important. Meanwhile, although the determination coefficient $\mathrm{R} 2=0.595$, we believe that this model describes quite well the evolution of teaching staff numbers throughout the period.

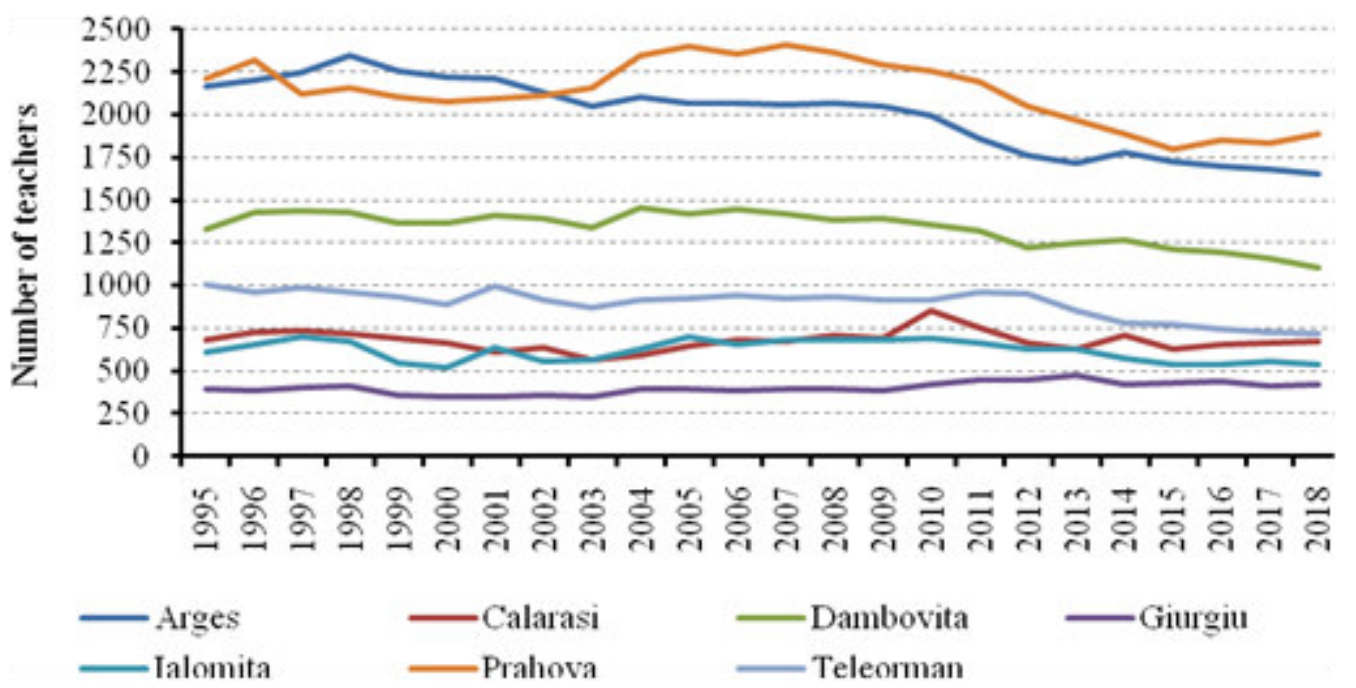

Figure 2. Evolutions of the number of teachers enrolled in secondary high school in the counties from the South Muntenia region during 1995 until 2018 period

At the county level there have been two trends, one which was characterised by a decline and another by an increase in the number of teachers. Consequently, while counties such as Arges, Prahova, Teleorman and Dambovita, the number of teachers in secondary education fell by an average of values between 10 and 22 persons, in the counties Calarasi and Ialomita the number was constant, and Giurgiu slightly increased.

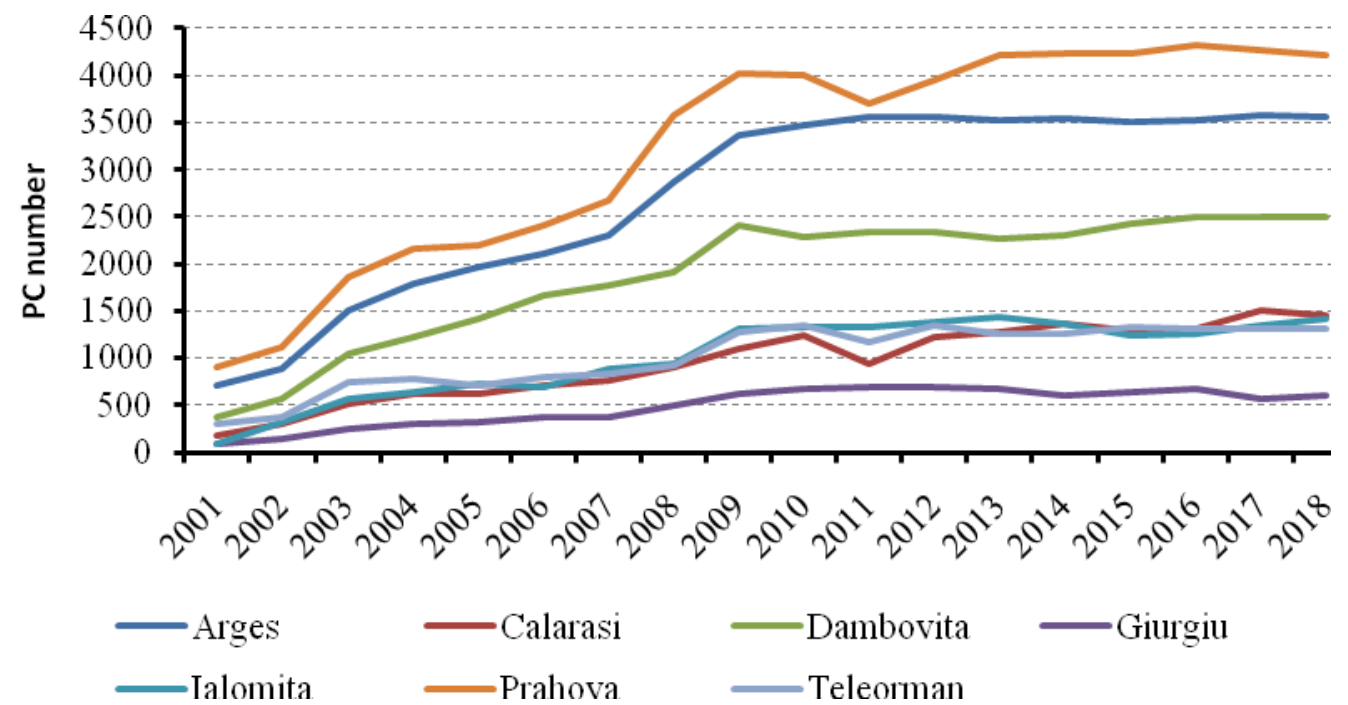

Figure 3. Evolutions of the number of PC in secondary high school in the counties from the South Muntenia region during 1995 until 2018 period 
Among the superstructure fundamental to the quality of education provided in schools in general, and high schools, in particular, there is the ICT infrastructure. The development of these media and improved accessibility and their usefulness has made after 2000, the number of high schools to grow significantly in a first period (Figure 3) then tending to stabilize. In the South-Muntenia region, changes in the number of computers in schools, in the period 2001-2018 can be described by a model of the form:

$$
P C(t)=1058.6+5083.4 \cdot \ln (t)+\varepsilon, \quad t_{2001}=1
$$

For the model (3), according to the significance level of the test F (Sig.F $=0.000$ ), and the coefficient of determination $\mathrm{R} 2=0.943$, it is clear that the model is highly statistically noteworthy and describes the evolution of the number of computers in high schools that are in the South -Muntenia region. Analysis of the number of computers available in schools, in the county, revealed that both in 2001 and 2018, most of them are in Prahova (34.04\% and 28.06\%, 2018), Arges (26.86\% and 23.6 $\% \%, 2018)$ and Dâmboviţa $(18.83 \%$ and $16.56 \% \%, 2018)$, and the least in the region Giurgiu (3.5\% and $4.1 \% \%, 2018)$. A clear and conclusive ICT infrastructure development in South-Muntenia region is the number of pupils per PC. Thus, if in 2001, a PC was available for 37 high school students, in 2018 the number drops to 6 students per PC, situation underlined in the model of the following form:

$$
P C(t)=31.62-9.69 \cdot \ln (t)+\varepsilon, \quad t_{2001}=1
$$

The 4-th model is also statistically significant $(\mathrm{Sig} . \mathrm{F}=0.00)$ and describes the evolution of the number of high school students per PC $(\mathrm{R} 2=0.902)$ in the period 2001-2018. Similar evolutions are recorded at county level except that the stabilizing trend that highlights the differences on the level of equipment of high school with the PC on the one hand, and on the other hand, the discrepancies existing in 2001 also maintaining in 2018. As a result, in 2001, although at regional level PC is back to 37 students in Ialomita their number reached 87 (over two times higher) in Giurgiu was 51 students in Dâmbovița 45, and Calarasi, Teleorman 42 students, in Prahova County, one PC was used by 27 students. Although during 2001-2018 the number of PCs in high schools in the South region increased significantly, some discrepancies maintained so that, while in Prahova and Calarasi one PC was used by 5 students in Teleorman their number reached 8, in Giurgiu county and a PC was available for 9 students enrolled in high school.

\subsection{Efficiency aspects of high school education in the South-Muntenia}

The number of graduates of secondary high school education (HSG) in South Muntenia development region during 1995-2017 followed, to some extent, changes in the number of students enrolled in high school in the same period specifying that it covers only the last year of high school graduates, while the number of students enrolled in high school (STD) includes all high-school students. The difference is, however, that the number (Figure 4) is more uncertain because of the changes over the period of evolution of the birth, of structural changes, the requirements of the labour market on the level of training and the level exigency. But here distinguish three periods. 1995-2001 period aims on a new scale, type downward trend in the number of students enrolled in high school in that period. For the mentioned counties, the number of graduates of secondary education in 2001 was lower than in 1995 to 1790 in Arges (a decrease of 15.75\%), with 1638 in Prahova (a decrease of 12.19\%), with 812 in Dambovita (a reduction of 12.18\%), with the Teleorman 742 (a decrease of 13.17\%), with 433 Giurgiu (a $15.62 \%$ reduction) and $11 \%$ Călăraşi and Ialomiţa. The second period (2001-2011) is one of oscillation around a trend slightly upward, so that the number of high school graduates in 2011 at regional level with 6701 graduates was higher than in 2001 (an increase of 33.75\%), exceeding by 657 the number of graduates in 1995. at the county level, the level in 2011 was higher than in 2001 at between 22.59\% in Arges county, and 79.39\% in Giurgiu. Except Arges County, in all other counties Muntenia Sud, the number of high school graduates was higher than in 1995. 


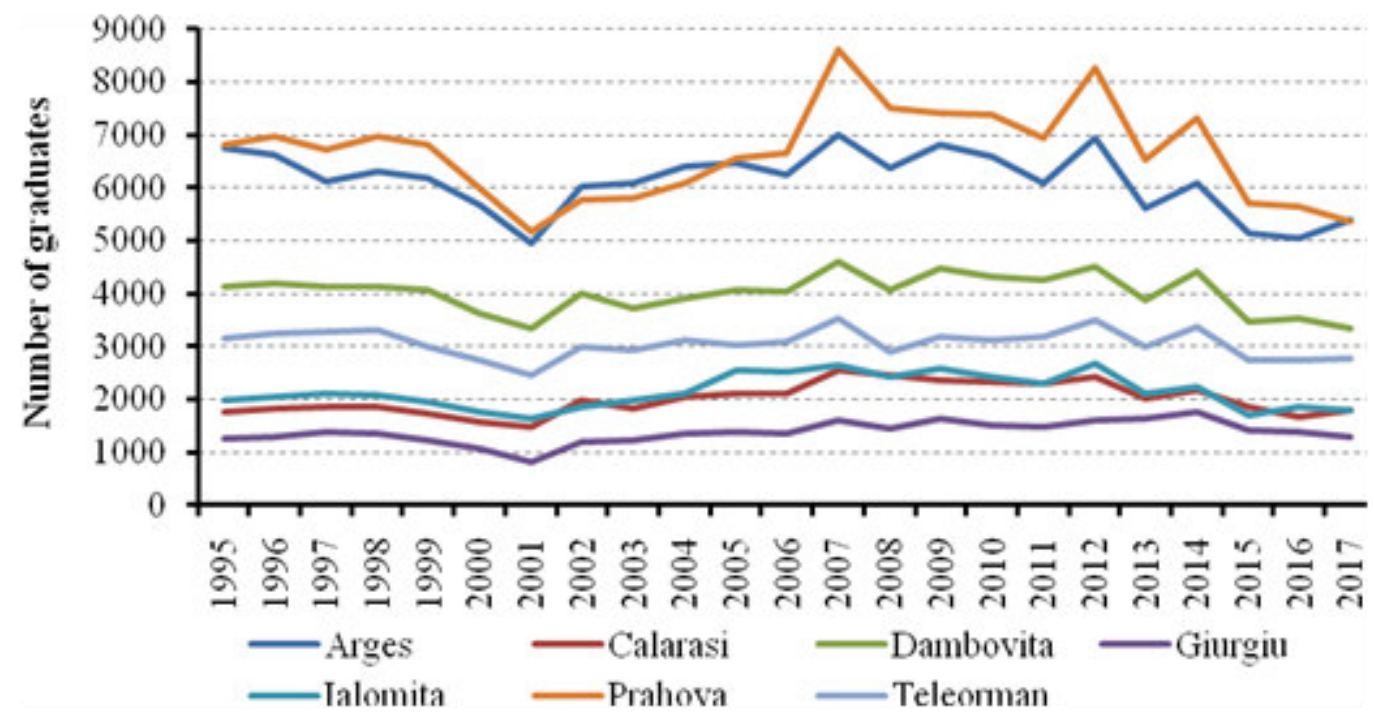

Figure 4. Evolutions of the number of graduates in secondary high school in the counties from the South Muntenia region during 1995 until 2018 period

In the third period (2012-2017) it has been a continuous decline, therefore, in 2017, at regional level, the number of graduates was lower with 4846 than in 2011 (a decrease of 18.25\%). In the counties, the number of graduates has decreased between 11.43\% in Argeş, and 22.85\% in the Prahova region.

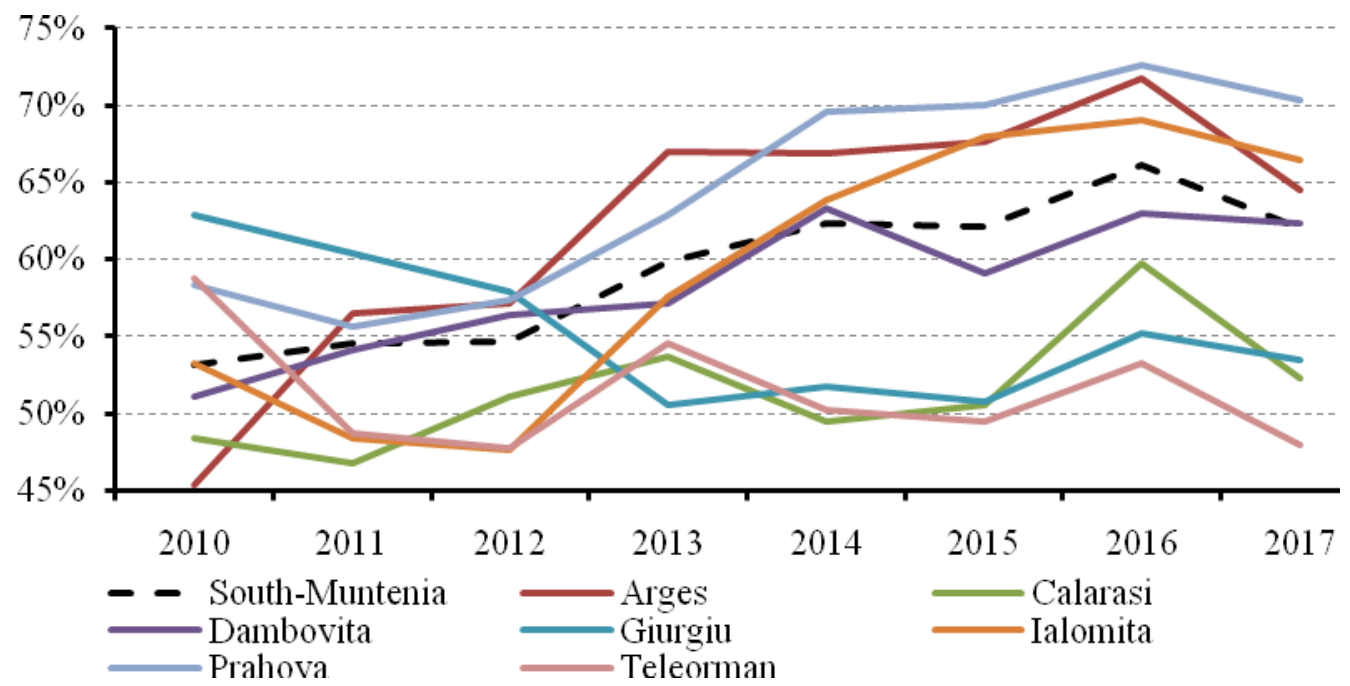

Figure 5. Evolutions of the percentage of graduates with a Baccalaureate degree in secondary high school in the counties from the South Muntenia region during 1995 until 2018 period

The most conclusive indicator of the efficiency of secondary education is the number and percentage of Baccalaureate graduates awarded with degree. In this respect, the measures taken by the Ministry of Education since 2010, on the organization of the Baccalaureate national exam, have highlighted both similarities and differences between counties in this regard. The development of the number of graduates with a Baccalaureate Degree, in the region of South-Muntenia and at the county 
levels (Figure 5) highlights a regional upward trend based on a percentage of $53.13 \%$ in 2010 to $66.07 \%$, in 2016, followed by a slight decrease of 4.01 percentage pointed in 2017 .

At the county level in the last four years, with shares above the average level of the region were Prahova, Arges and Ialomita, and in 20017 Dambovita. By contrast, there are the counties Calarasi, Giurgiu and Teleorman. Analysing the evolutionary trajectories of the percentage of Baccalaureate graduates with a degree shows that disparities between counties, from this point of view is troublesome. Thus, in 2012, in Prahova the percentage of graduates with a Baccalaureate degree was $57.36 \%$ and in Teleorman county was $47.78 \%$ (a difference of 6.96 percentage points), in 2017 the difference between the percentages of Graduates with a Baccalaureate degree in the two counties reached 22.40 percentage points. Significant differences between Prahova and Calarasi counties are highlighted (18.1 percentage points) and Giurgiu (16.85 percentage points). It thus forms, in the South-Muntenia, two groups of counties efficiency opposite trends of high school which, if not corrected, can lead to lasting damage to regional development in this region.

\section{Conclusions}

The results of the research confirmed the counties in the region of South-Muntenia development issues raised in the first part, however, they also highlight a number of peculiarities. A first difference between counties is given by the weight reduction in the number of students enrolled in high school. Giurgiu County was $24.88 \%$, in Prahova County of $19.24 \%$, and on the opposite is Calarasi County where registered numbers were only $12.19 \%$. Reducing the number of pupils enrolled in secondary education increased in the period 2011-2018, the most significant being in Călăraşi $(39.93 \%)$ and Ialomita $(33.22 \%)$.

In terms of the teaching staff, although at regional level, between 1995-2018 the number of teachers has decreased annually by an average of 61 people in the counties have registered two trends, one of decrease, and other growth. While in counties such as, Arges, Prahova, Teleorman and Dambovita, the number of teachers in secondary education fell by an average of values between 10 and 22 people in the counties Calarasi and Ialomita the number was approximately constant, and Giurgiu County recorded a slight increase.

Although after 2000 the number of PC raised significantly, discrepancies are still maintained so that, while in Prahova and Calarasi a PC is used by 5 students in Teleorman their number reaches 8 and in Giurgiu a PC is used by 9 students enrolled in high school. An important conclusion is also that, although in the South-Muntenia region there is an increase in the number of graduates with a Baccalaureate degree out of the total graduates high school education, there are still evident the differences between the group of Prahova, Arges, Dambovita and Ialomita counties that weights the degree of graduation above the average level of the region (61.98\% in 2017) and the group Giurgiu, Calarasi and Teleorman counties which weights far below the average percentage of graduation.

Evolutions in the health status of the population, such as restrictions aimed at reducing the degree of infection of the population with the new coronavirus (Covit-19), have and will have implications for education in the analysed development region. Given this fact, an important direction for future research is to identify the impact of Covit-19 on the school population taking into account local particularities regarding the level of development of electronic communications.

\section{References}

[1] Zaharia M. (2019).Considerations on the Evolutions and Particularities of the Human Development Index in European Countries, Journal of Research and Innovation for Sustainable Society (JRISS). Volume 1, Issue 1, 2019. http://jriss.4ader.ro/pdf/201901/15_JRISS_1-114-123.pdf

[2] Urean C. A. (2017), An Overview of the Romanian Education System, Annals - Economy Series, 3, issue, p. 146-153. 
[3] Masuda K., Sakai Y. (2018), Secondary education and international labor mobility: Evidence from the free secondary education reform in the Philippines, CEI Working Paper Series, Center for Economic Institutions, Institute of Economic Research, Hitotsubashi University. No 2018-5.

[4] Emer S. (2016), Social Relationships and the Transition to Secondary Education, The Economic and Social Review, 47, issue 4, p. 451-476.

[5] Logofatu M., Stefanescu C. (2016), Particularities Of Human Resource Management in the Romanian Secondary Education, Annals - Economy Series, 6, issue , p. 77-84.

[6] Mavric F. (2006), Women in Secondary Education Management, Management, 1, issue 1, p. 7991.

[7] Zaharia M., Patrascu A., Tanasescu A. (2016), Cluster Analysis of PC Endowment in PreUniversity Education at Romanian Counties Level, Annals - Economy Series, 2 Special, issue , p. 191-195.

[8] Pribac I. L. (2012), Education - a factor in the economic growth. Romania's case, Annals Economy Series, 1, issue, p. 146-149.

[9] Calinescu I., Costache G., Frasineanu C. (2018), Quality Management in the Romanian Upper Secondary Education: A Different Internal and External Perspective, Proceedings of the International Management Conference, 12, issue 1, p. 957-967.

\section{Statistical data sources}

[10] National Institute of Statistics of Romania (2020) SCL103E, Populaţia şcolară pe niveluri de educaţie, medii de rezidenţă, macroregiuni, regiuni de dezvoltare şi județe, http://statistici.insse.ro:8077/tempo-online/\#/pages/tables/insse-table. Accessed February 2, 2020.

[11] Ministerul Educatiei Nationale (2016). Raport privind starea învătământului preuniversitar din România. Guvernul României, Ministerul Educatiei Nationale, p. 22.

https://www.edu.ro/sites/default/files/_fi\%C8\%99iere/Minister/2017/transparenta/Stare\%20preuniv\%2 02016.pdf

[12] Costache L (coord. UNICEF), Fartusnic C (coord), Jigau M. (coord), (2014), Participarea la educatie în învătământul secundar superior. UNICEF România, Institutul de Stiinte ale Educatiei p.9-10, 22, http://www.unicef.ro/wp-content/uploads/Raport-OOSC-InvatamantSecundar-Superior_final.pdf,

[13] SCL104E, Personalul didactic pe niveluri de educaţie, medii de rezistenţă, macroregiuni, regiuni de dezvoltare şi judeţe, http://statistici.insse.ro:8077/tempoonline/\#/pages/tables/insse-table. Accessed February 10.2020.

[14] SCL112C, PC-uri pe niveluri de educaţie, macroregiuni, regiuni de dezvoltare şi judeţe, http://statistici.insse.ro:8077/tempo-online/\#/pages/tables/insse-table. Accessed February 10, 2020

[15] SCL109B, Absolvenţi pe niveluri de educaţie, forme de învăţământ, macroregiuni, regiuni de dezvoltare şi judeţe, http://statistici.insse.ro:8077/tempo-online/\#/pages/tables/insse-table. Accessed February 10, 2020

[16] SCL109G, Numărul elevilor care au promovat examenul de bacalaureat, pe sexe, macroregiuni, regiuni de dezvoltare şi judeţe, http://statistici.insse.ro:8077/tempoonline/\#/pages/tables/insse-table. Accessed February 10, 2020. 


\title{
Potential association of vitamin D in preventing COVID-19
}

\author{
Delia Nica-Badea ${ }^{1}$, Tudor Pungan ${ }^{2}$ \\ 1"Constantin Brâncuși" University of Târgu-Jiu, Faculty of Medical and Behavioral Sciences, \\ No. 4, Tineretului St., Târgu-Jiu, Romania \\ ${ }^{2}$ Tudormed SRL, No 1B, 23 August St., Târgu-Jiu, România \\ E-mail: nicabadeadelia@yahoo.com
}

\begin{abstract}
This paper presents the role of vitamin D in the body, namely: calcium absorption, maintaining muscle function, but also in strengthening the immune system. Vitamin D exerts its biological functions dependent on vitamin D receptor (VDR), which is a member of the superhuman family of nuclear hormone receptors and clearly expressed in a wide variety of cells. Vitamin D is mainly obtained by synthesizing Vitamin D3 in our skin using ultraviolet light B (UVB) and in small amounts from food sources. Respiratory epithelial cells can convert vitamin $\mathrm{D}$ to the active form and that vitamin D metabolites increase the cytokines involved in immunity in response to respiratory viruses. Studies have shown that the most vulnerable population group for COVID - 19 is also the one with the highest vitamin D deficiency.

Keywords: vitamin D, metabolism, prevention, COVID-19.
\end{abstract}

\section{Vitamin D: synthesis and metabolic pathways}

Vitamin D is the name given to a wider group of vitamins. Vitamin D2 (ergocalciferol, which is found in plants) and vitamin D3 (cholecalciferol, which is found in animal tissues) are inactive pharmacological forms that can be metabolically converted into active compounds by hydroxylation in the liver and then in the kidneys.

The liver converts vitamin D3 into 25-hydroxycholecalciferol, which is weakly active. The kidneys then convert this compound to either 24,25-dihydroxycholecalciferol, which is also weakly active, or $1 \alpha, 25$-dihydroxycholecalciferol, the most active form of vitamin D [1] (Figure 1).

Vitamin D is important for bone metabolism and regulates calcium levels in the blood, increases the absorption of calcium from the intestine and reduces the amount lost by the kidneys. Many tissues have vitamin D receptors, and vitamin D may have other roles [2]. 


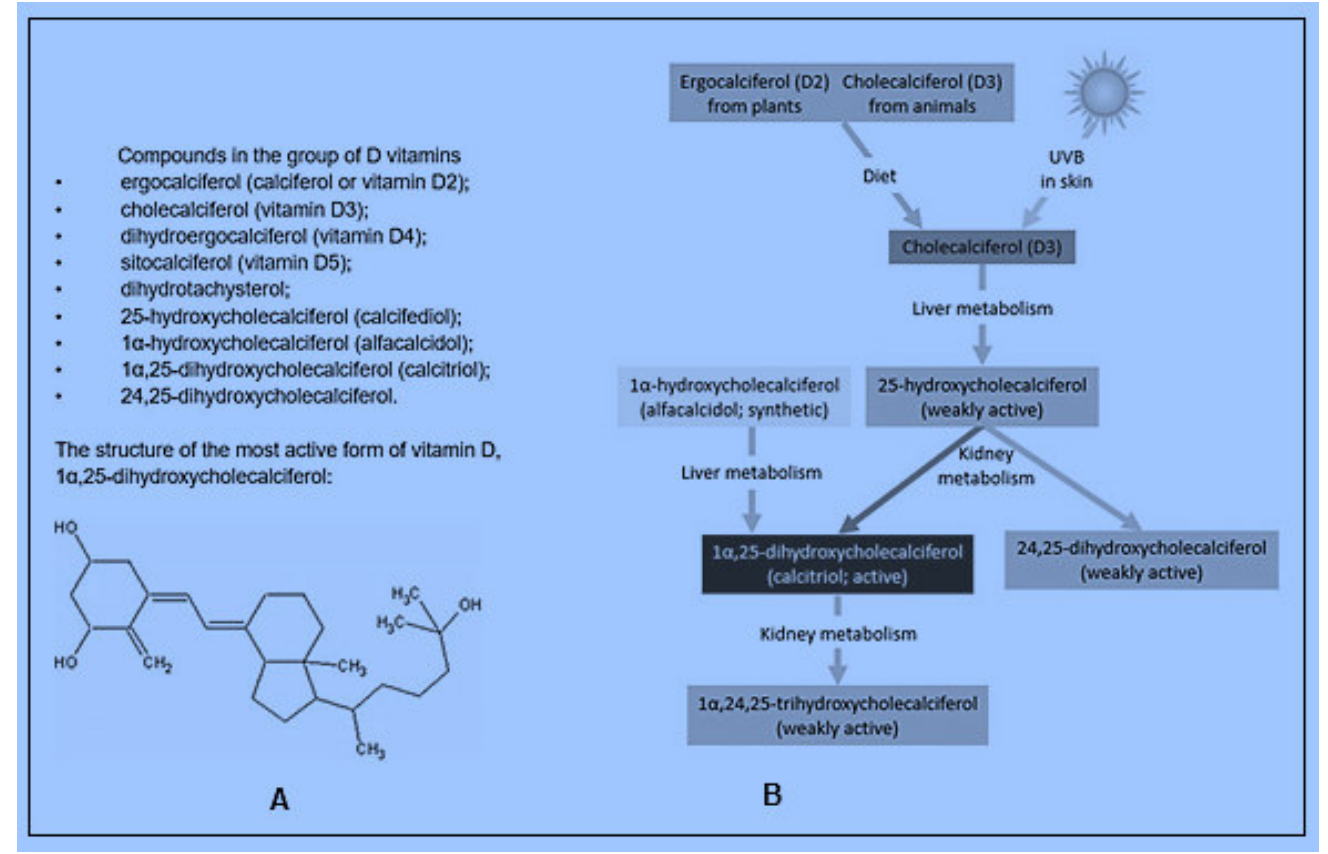

Figure 1. Vitamin D: A. Compounds of the vitamin D group; B. Metabolic pathways in the body

The role of vitamin D in the body is to absorb calcium and in maintaining muscle function, but also in strengthening the immune system, say experts from Cleveland Clinic, (USA). Its concentration in the skin depends on a number of factors, including the amount of vitamin D that the body produces in the epithelial tissue due to the sun's rays. Essentially, this is to be completed at the time of day, the season and the latitudes (Central or Northern Europe), [3].

Vitamin D exerts its biological functions dependent on vitamin D receptor (VDR), which is a member of the superhuman family of nuclear hormone receptors and clearly expressed in a wide variety of cells. While vitamin D / VDR signaling is known for its effect on bone homeostasis, its suppressive regulation of the inflammatory response is becoming increasingly attractive [4]. It has long been established that vitamin D / VDR signaling regulates duodenal transport of transcellular calcium. Recent studies have shown that intestinal epithelial VDR plays a key role in protecting the integrity of the mucosal barrier. The intestine is one of the tissues in the body that has the most abundant VDR expression.

\section{Sources of vitamin D}

Vitamin D is mainly obtained by the synthesis of Vitamin D3 in our skin using ultraviolet light B (UVB) and in small amounts from food sources (Figure 1). In countries with high latitudes, UVB in winter is not enough to synthesize the optimal need, so oral intake becomes more important. Dietary sources include products of animal origin, such as fatty fish, red meat, liver and egg yolks, as well as fortified foods such as infant formula, breakfast cereals and margarines. Some fungi can provide vitamin D if grown under ultraviolet light [5]. The Scientific Advisory Committee on Nutrition (SACN) recommends a daily intake of $10 \mu \mathrm{g}$ (micrograms) (400 international units / day) for all four-year-olds living in the UK to ensure musculoskeletal health [6], and for adults, the standard dose of vitamin D deficiency prevention is $10 \mu \mathrm{g}$ (400 IU) daily [7].

\section{Vitamin D deficiency}

Vitamin D deficiency is very common, especially in winter. Vitamin D is usually measured in blood serum in the relatively stable form of 25-hydroxycholecaliferol (25 (OH) D3). In the UK, $25 \mathrm{nmol} / \mathrm{L}$ $(10 \mathrm{ng} / \mathrm{ml})$ is used as a reduction for deficiency, but there is no universally agreed definition, so clinical trials have used different values to define vitamin D deficiency. [6] 
People at high risk of disability:

- Infants and children under four years of age;

- Pregnant and lactating women, especially adolescents and young women;

- People over 65;

- People who have little or no exposure to the sun, for example, those who cover their skin for cultural reasons and those who are covered in or inside the house for long periods;

- People with darker skin, for example, people of African, African-Caribbean or South Asian descent.

\section{Opportunity for vitamin D supplement in COVID-19}

There is in vitro evidence that vitamin $\mathrm{D}$ is involved in immune cell responses to some viral and bacterial respiratory pathogens. Vitamin D appears to regulate genes involved in immune cell responses that are exposed to Streptococcus pneumoniae [8].

There are laboratory studies that show that respiratory epithelial cells can convert vitamin $\mathrm{D}$ to the active form and that vitamin D metabolites increase the cytokines involved in immunity in response to respiratory viruses. However, vitamin D metabolites do not appear to prevent viral replication in cell cultures $[9,10]$.

\section{Evidence of the vitamin D - COVID-19 correlation}

There are opinions that people with low serum vitamin D may have a higher risk of COVID-19 infection or worsen if infected [11]. There is also an overlap between the high-risk groups of vitamin D deficiency and the high-risk groups of severe COVID-19. Examples include people with chronic illness, old age and people with black and minority ethnic heritage (BAME). However, infants and children are at risk of vitamin D deficiency, but are not considered at high risk for severe COVID-19 [12].

On 10 April 2020, the UK National Center for Intensive Care Audit and Research (ICNARC) reported that $31 \%$ (310/993) of patients in need of advanced respiratory support defined their ethnicity in a white category compared to $24 \%$ of patients (99/408) receiving basic respiratory support [13]. These data are intriguing, but we must be careful about their over-interpretation.

If vitamin $\mathrm{D}$ has a role in preventing or mitigating the effects of COVID-19 infection, supplementation would be a cheap and low-risk intervention. Therefore, we aimed to review the clinical evidence that vitamin D has a role in the prevention or treatment of COVID-19.

\section{A) Planned studies}

With PubMed and Google Scholar as a source, several studies have been found that are registered, but have not been reported yet. None seemed to be masked compared to placebo.

o A study with vitamin D3 plus zinc, compared to regular care, is planned in an open-label randomized controlled trial (RCT) in adults over 60 who are "institutionalized" but asymptomatic [14]. The dose of vitamin D3 is $2000 \mathrm{IU}(50 \mu \mathrm{g})$ plus $30 \mathrm{mg}$ of zinc gluconate per day for two months. The main measure of outcome is mortality; the incidence of COVID-19 infection is a secondary outcome.

o One study tests whether a single oral dose of 25,000 IU ( $625 \mu \mathrm{g}$ ) of vitamin D (form not specified) will improve mortality in patients infected with SARS-CoV-2, but has no severe symptoms compared to regular care [15]. The reason is based on veterinary findings that low levels of vitamin D in calves have been associated with bovine coronavirus infection.

o Another RCT will compare single doses of vitamin D3, 50,000 IU to 200,000 IU (1250 Vs 5000 $\mu \mathrm{g}$ ) in people with COVID-19 pneumonia who are over 75 years old or over 70 with low oxygen saturation; the main measure of outcome is mortality at 14 days [16].

A single open-label study uses a combination of hydroxychloroquine, vitamins $\mathrm{C}$ and $\mathrm{D}$ (unspecified form) and zinc as prophylaxis in health workers who are healthy and at risk of COVID-19, by exposure to infected patients [17].

The same investigator recorded another study, which will provide all participants with hydroxychloroquine, vitamins $\mathrm{C}$ and $\mathrm{D}$ (unspecified form) and zinc plus azithromycin, in order to determine whether this combination can effectively treat COVID-19 [18]. It is not clear how these studies will meet their stated objectives without comparison groups. 


\section{B) Reported studies}

The Seneca study reported mean serum D value in the elderly in a number of European countries compared to severe deficiency defined as a $25(\mathrm{OH}) \mathrm{D}$ serum less than $30 \mathrm{nmol} / \mathrm{L}$ [19]. Such values are reported as follows: $26 \mathrm{nmol} / \mathrm{L}$ in Spain, $28 \mathrm{nmol} / \mathrm{L}$ in Italy and $45 \mathrm{nmol} / \mathrm{L}$ in the Nordic countries. In Switzerland, average vitamin D levels are $23(\mathrm{nmol} / \mathrm{L})$ in nursing homes, and in Italy, $76 \%$ of women over the age of 70 have found that they have circulating levels below 30nmol / L [219]. These are the countries with a large number of cases of COVID - 19, and the elderly are the group with the highest risk of morbidity and mortality with SARS-Cov2. The study concludes that significant relationships were found between vitamin D levels and the number of COVID-19 cases, but especially the mortality caused by this infection.

The most vulnerable population group for COVID-19 is also the one with the highest vitamin D deficiency. The authors believe that we can recommend vitamin $\mathrm{D}$ supplementation to protect against COVID-19 infection.

Vitamin D has already been tested as a protector against acute respiratory infections and has been shown to be safe. Martineau A.R. et al. (2017), concluded in a meta-analysis that vitamin D supplementation was safe and protective against acute respiratory tract infections. They described that patients with severe vitamin D deficiency showed the greatest benefit [20].

The importance of vitamin D deficiency is shown by a recently published analysis of COVID-19 deaths in 780 COVID-19 patients in Indonesia [21].

Table 1 illustrates that old age (old age), comorbidities and vitamin D deficiency or insufficiency have been associated with increasing chances of death. Based on these data, the plasma level of vitamin $\mathrm{D}$ is an independent precursor of mortality.

Table 1. Data of patients with COVID-19 related to vitamin D levels and disease outcome.

\begin{tabular}{|l|l|l|l|}
\hline & Vitamin D: $<20 \mathrm{ng} / \mathrm{ml}$ & $20-30 \mathrm{ng} / \mathrm{ml}$ & $>30 \mathrm{ng} / \mathrm{ml}$ \\
\hline Overall, N & 179 & 213 & 388 \\
\hline Mean age & $66.9 \pm 13.8$ & $62.9 \pm 14.7$ & $46.6 \pm 12.6$ \\
\hline Comorbidity, \% & 80.0 & 73.8 & 18.8 \\
\hline Death, \% & 98.9 & 87.8 & 4.1 \\
\hline Active, \% & 1.1 & 12.2 & 95.9 \\
\hline $\begin{array}{l}\text { Odds ratio } \\
\text { Adjusted for age, sex and comorbidity }\end{array}$ & $10.12(\mathrm{p}<.001)$ & $7.63(p<.001)$ & \\
\hline
\end{tabular}

Recently, a number of 8 studies have begun to test the effect of vitamin D supplementation at various doses (up to 200,000 IU) during COVID-19 disease. The aim is to clarify whether vitamin D supplementation at different doses has an influence on the course of the disease or, in particular, on the immune response, or whether it can prevent the development of acute respiratory distress syndrome (ARDS) or thrombosis [22].

A recent study (E Laird. May 2020) [23] assumes that vitamin D status may influence the severity of Covid-19 responses and that the prevalence of vitamin D deficiency in Europe will be closely aligned with Covid-19 mortality. The calculated mortality rate of Covid-19 (per million) in European countries according to the average concentration of $25(\mathrm{OH}) \mathrm{D}$ is shown in Figure 2.

The correlation between the concentration of $25(\mathrm{OH}) \mathrm{D}$ and the mortality rate has a conventional significance $(\mathrm{P}=0.046)$ of Spearman's rank correlation. 


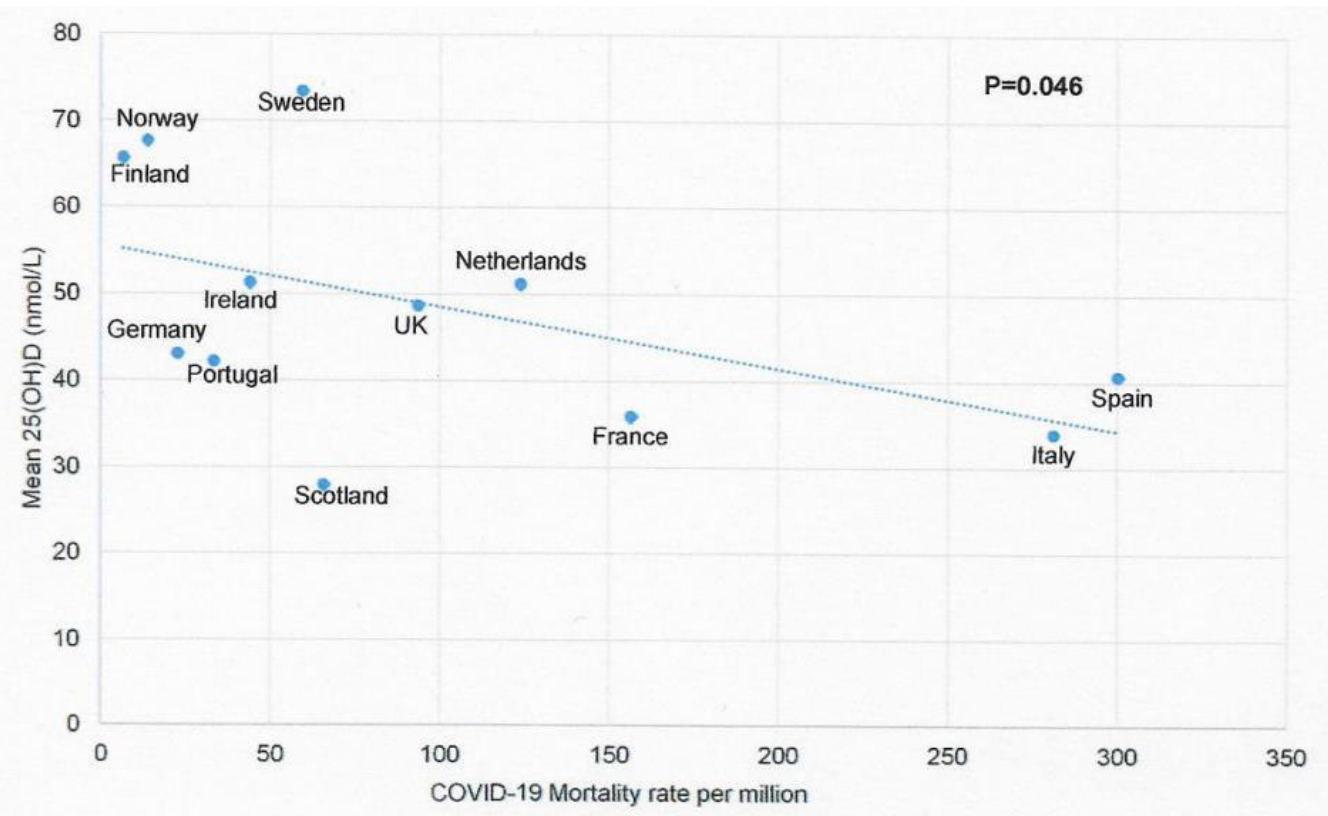

Figure 2. Mortality rate for a number of countries in relation to vitamin D levels (conc. Averages)

\section{Conclusion}

An inadequate intake of vitamin D has a variety of skeletal and non-skeletal effects. There is ample evidence that various noncommunicable diseases (high blood pressure, diabetes, CVD, metabolic syndrome) are associated with low levels of vitamin D in plasma. These comorbidities, together with the often concomitant vitamin D deficiency, increase the risk of severe COVID-19 events. More attention should be paid to the importance of vitamin D status for the development and evolution of the disease.

In particular, in the methods used to control the pandemic (blockage), the skin's natural synthesis of vitamin D is reduced when people have few opportunities to be exposed to the sun. Specific dietary advice, moderate supplements or fortified foods can help prevent this deficiency.

\section{References}

[1] Grahame-Smith DG, Aronson JK. The Oxford Textbook of Clinical Pharmacology and Drug Therapy. Oxford: Oxford University Press; 2002.

[2] Hansdottir S, Monick M, Hinde S, Lovan N, Look D, Hunninglake G. Respiratory Epithelial Cells Convert Inactive Vitamin D to its Active Form. J. Immunol. 2008; 181: 7090-7099

[3] Heike A, Ferrari B, Shao A, Hughes BD, Hathcock J, Giovannucci E et al. Benefit - Risk Assessment of Vitamin D Supplementation. Osteoporos Int. 2010; 21(7): 1121-1132.

[4] Michael F., Holick P., The Death D-fying Vitamin.Mayo Clin Proc.nJune 2018;93(6):679 681 nhttps://doi.org/10.1016/j.mayocp.2018.04.014www.mayoclinicproceedings.orgna2018 Mayo Foundation for Medical Education and Research

[5] Cardwell G, Bornman JF, James AP, Black LJ. A review of mushrooms as a potential source of dietary vitamin D. Nutrients 2018; 10: 1-11.

[6] Public Health England. Vitamin D and Health 2016 [Internet]. Sci. Advis. Comm. Nutr. 2016 Available from: https://www.gov.uk/government/publications/sacn-vitamin-d-and-healthreport.

[7] Joint Formulary Comittee. British National Formulary [Internet]. London: BMJ Group and Pharmaceutical Press; 2019, available from:

https://bnf.nice.org.uk/drug/colecalciferol.html\#indicationsAndDoses 
[8] Olliver M, Spelmink L, Hiew J, Meyer-Hoffert U, Henriques-Normark B, Bergman P. Immunomodulatory effects of vitamin $\mathrm{D}$ on innate and adaptive immune responses to Streptococcus pneumoniae. J. Infect. Dis. 2013; 208: 1474-1481.

[9] Hansdottir S, Monick M, Hinde S, Lovan N, Look D, Hunninglake G. Respiratory Epithelial Cells Convert Inactive Vitamin D to its Active Form. J. Immunol. 2008; 181: 7090-7099

[10] Greiller CL, Martineau AR. Modulation of the immune response to respiratory viruses by vitamin D. Nutrients 2015; 7: 4240-4270.

[11] Grant WB, Lahore H, McDonnell SL, Baggerly CA, French CB, Aliano JL, Bhattoa HP. Evidence that Vitamin D Supplementation Could Reduce Risk of Influenza and COVID-19 Infections and Deaths. Nutrients 2020; 12: 988.

[12] Coronavirus (COVID-19): Shielded patients list [Internet]. Available from: https://digital.nhs.uk/coronavirus/shielded-patient-list.

[13] ICNARC. ICNARC report on COVID-19 in critical care. 2020; : 1-9.

[14] Seguy D. Impact of Zinc and Vitamin D3 Supplementation on the Survival of Aged Patients Infected With COVID-19 (ZnD3-CoVici) [Internet]. Available from: https://clinicaltrials.gov/ct2/show/NCT04351490.

[15] Castillo MJ. Vitamin D on Prevention and Treatment of COVID-19 (COVITD-19) [Internet]. NCT04334005 2020. Available from: https://clinicaltrials.gov/ct2/show/NCT04334005.

[16] Annweiler C. COvid-19 and Vitamin D Supplementation: a Multicenter Randomized Controlled Trial of High Dose Versus Standard Dose Vitamin D3 in High-risk COVID-19 Patients (CoVitTrial) [Internet]. 2020. Available from: https://clinicaltrials.gov/ct2/show/record/NCT04344041.

[17] Haza S. A Study of Hydroxychloroquine, Vitamin C, Vitamin D, and Zinc for the Prevention of COVID-19 Infection (HELPCOVID-19) [Internet]. 2020.Available from: https://clinicaltrials.gov/ct2/show/record/NCT04335084.

[18] Haza S. A Study of Quintuple Therapy to Treat COVID-19 Infection (HAZDpaC) [Internet]. 2020.Available from: https://clinicaltrials.gov/ct2/show/NCT04334512

[19] Lips, P., Cashman, K., Lamberg-Allardt, C., Bischoff-Ferrari, H., Obermayer-Pietsch, B., Bianchi, M., Stepan, J., El-Hajj Fuleihan, G., and Bouillon, R. (2019). Current vitamin D status in European and Middle East countries and strategies to prevent vitamin D deficiency: a position statement of the European Calcified Tissue Society. European Journal of Endocrinology 180, 4, P23-P54, available from: 〈https://doi.org/10.1530/EJE-18-0736>

[20] Martineau Adrian R, JolliffeDavid A,Hooper Richard L, Greenberg Lauren, Aloia John F, Bergman Peter et al. Vitamin D supplementation to prevent acute respiratory tract infections: systematic review and meta-analysis of individual participant data BMJ 2017; 356 :i6583 https://www.researchsquare.com/article/rs-21211/v1,

[21] Raharusuna P, Priambada S, Budiarti C, et al. Patterns of COVID-19 Mortality and Vitamin D: An Indonesian Study. April 26, 2020; Available at SSRN: https://ssrn.com/abstract=3585561, doi:10.2139/ssrn.3585561.

[22] https://clinicaltrials.gov/ct2/results?cond=vitamin+D+and+Covid-19 (access 05.20.2020).

[23] E. Laird1, J. Rhodes2, R.A. Kenny1. Vitamin D and Inflammation: Potential Implications for Severity of Covid-19. Ir Med J;may 2020; Vol 113; No. 5; P81 


\title{
Profile of family business in Republic of Moldova
}

\author{
Liudmila Stihi ${ }^{1}$, \\ ${ }^{1}$ Management Department, Academy of Economic Studies of Moldova, Chisinau, Republic of \\ Moldova \\ Email: 1stihi@gmail.com \\ ID ORCID: https://orcid.org/0000-0002-7063-0863
}

\begin{abstract}
The current national and international economic environments have the hallmark of a high degree of uncertainty and are characterized by significant fluctuations under the influence of various factors. Thus, business sustainability becomes more sensitive to these influences, regardless of the business model applied. The results of multiple research and analysis of family business at the international level show that this type of entrepreneurial activity is sustainable and efficient from several points of view, contributing not only to the economic growth of the country of origin but also at international level. Since in the Republic of Moldova the entrepreneurial activity has been practiced for about 30 years, we found that, until now, the family businesses have not been analyzed as a separate segment and their specific features have not been identified. Through this research we intended to perform a scan of family businesses in order to identify their profile in the context of the existing business environment. The study carried out allowed us to establish the Portrait of family businesses in the Republic of Moldova, to find some common ground and differences between family businesses in both developed and developing countries. The results of the study can serve as grounds for other more in-depth and specific research, and for decision makers as support in developing and implementing policies and support tools for the development of this important segment of entrepreneurship.

Keywords: family business, sustainability of the family business, successions, family members, business plan, conflict solving, business environment, decision making, business support instruments, future development.
\end{abstract}

\section{Introduction}

There could be used various models to carry out an entrepreneurial activity, family business being one of them. This model proved in time to be sustainable not only as regards the financial results, but also the attitude towards clients, society and traditions. Well-known trademarks such as Ommo, Oral-B, Adidas, Siemens, Samsung, Wal-Mart, Ford Motor, Koch Industries, Standard Oil, IKEA, thanks to successful combination of more factors have developed quickly and transformed into big well-known family companies.

Family business is an important force of the world economy and a basic pillar in the economic systems of many countries worldwide. As to representativeness, family businesses cover between $75 \%$ and $90 \%$ of all enterprises in the world, where in Europe over $75 \%$ of businesses are family businesses, where over $50 \%$ of the total of manpower is employed. According to Forbes Magazine [1], family businesses generate about $50 \%$ of the gross domestic product; less than one third of family companies 
survive the transition from the first to the second property generation and another $50 \%$ of family businesses do not survive the transition from the second to the third generation.

Lots of regular surveys conducted by specialized research companies, family business associations and universities ( $\mathrm{PwC}$ - Global Family Business Survey, EY Family Business Year book, The MGi Australian Family and Private Business survey, Kreischer Miller Family Business Survey, etc.) regarding the family business in different countries highlighted a few peculiarities that distinguish it from the non-family business, namely [2]

: a faster and more flexible decision-making process, greater involvement and responsibility, a simpler and less bureaucratic management structure, entrepreneurial spirit doubled by creativity and innovation. There are features that provide for a stronger motivation for some persons to launch and to develop a family business despite difficulties that influence on its stability and competitiveness.

Why family companies are important? Field studies of family companies carried out so far showed that this type of company has significant benefits for the economy and society in general, namely:

- Family companies have a higher financial performance and are more profitable in time;

- Family businesses are less susceptible to dismiss staff and have a higher probability of employment;

- Family businesses in whole are better for communities they live in both for business development and philanthropic activities;

- Family businesses' perspective to survive in time is higher and, therefore, they have a better balance between short-term remuneration in long run.

Even if the entrepreneurial activity in Republic of Moldova is rather young, the family business has already succeeded to show that it is an important sector for the economic development, but which practically is unknown and unstudied. The first steps to draw the attention to this sector have been taken by the Ministry of Economy, which was included in the action plan for 2018 under the action - the Draft Law on the activity of family companies worked out and approved, but unfortunately not implemented.

The majority of family businesses in Republic of Moldova are included in the SME sector, which has been studied under various aspects since 1990, and the financial and non-financial support, management, association and cooperation, new market penetration, innovation and research models were identified and applied, which are obviously valid for family businesses too. The results of those studies laid the basis for developing and adjusting along the standard framework related to SME. There were created structures meant to support this sector and significant resources were attracted from the national budget and development partners in order to support the SME sector, and the family businesses as part of the latter benefit from it too. Despite this, there was conducted no specific research focused on the analysis of this area, on the development and management specifics, on ensuring succession as such type of business is analyzed in many developed and developing countries.

This survey is designed to conduct the first qualitative study of the family business sector in Moldova in order to identify its profile, specific features and to analyze by comparing the position of owners of family businesses as regards the process of management, settlement of difficult situations and further visions.

We acknowledge that this is a first step and obviously just one research cannot study and analyze all aspects regarding the specifics of the local family businesses. At the same time, we are confident that the survey results shall serve to identify some specific elements to this important segment of the business environment and to lay the basis for subsequent studies and analyses.

\section{Study methodology}

This research has been conducted in order to identify the profile of family business in Republic of Moldova as a specific segment and model of sustainable entrepreneurial activity.

The qualitative research was used as method to carry out this study, namely an online questionnaire was provided to about 325 local companies and answered by 196 respondents. The survey was conducted in the period September 2018 - February 2019. Most respondents were those who benefited 
from SME Support Programs implemented by the Organization for Small and Medium Enterprises Sector Development (ODIMM) and residents of 11 business incubators in Moldova. The motivation for involving them in this study based on the acknowledgement of situation and their assignment to the category/class of family business. Pursuant to the distribution of respondents as to the duration of activity, a greater share was covered by FB with rather little experience (compared to other developed countries), but which was enough to voice their opinion regarding the questions included in the questionnaire. As regards the size of FB participating in this study, in line with the SME definition [3], more participants are included in the category of micro-enterprises based on the number of employees and the annual turnover (at least according to the answers provided).

The questionnaire is divided into 4 units: family business profile, family business management, family business perspectives and demography. To work out this questionnaire aspects researched by regular surveys conducted by PwC - Global Family Business Survey, EY Family Business Year book, were considered, so that to make a comparison of opinions and visions, questions from the mentioned 2 surveys, especially to sections 2 and 3 were included in. As regards the question structure, different types were implemented: direct questions, opinion questions, quiz question, and hierarchic ones. The SPSS data statistical analysis program was used to process the study results.

The most important obstructions in conducting this study was the entrepreneurs' reluctance, the high occupancy rate, the low on-line operation skills and diminished responsibility towards such method of research.

Declaration: I hereby declare that this article has not been published elsewhere.

\section{Study results}

\section{Family business description}

Firstly, we were set to find out the reasons that laid the basis for decision-making on launch a family business.

About $48 \%$ of respondents highlighted - to provide family with financial stability - as main reason. This is influenced by the political and economic situation over the past period, which does not provide any stability and certainty in a non-family company. Another motivating factor for setting-up a family business was mentioned that of working together with family members $-30 \%$, which the respondents consider more efficient and more sustainable (see Figure 1).

Figure 1. What type of funds did you use to set up your business?

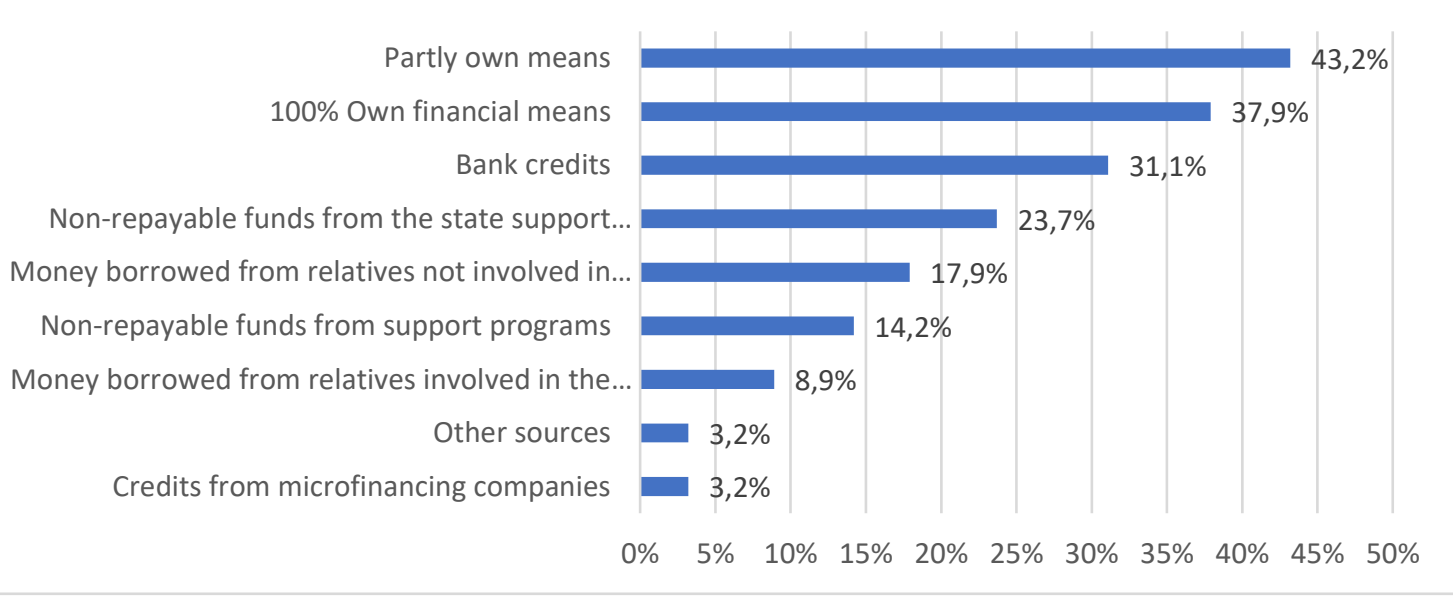

According with figure 1 we found out that Moldovan entrepreneurs make use of various funds to initiate a family business. The combined financial means are the most used ones: own and foreign means, $100 \%$ own financial means, bank credits etc. As many as $24 \%$ of respondents mentioned that they have accessed non-repayable funds provided by various national support organizations as financing source. 
This variety of financing sources used to launch a family business shows that certain opportunities do exist, and the financing resources do not top the list of issues faced when initiating a business. On the other hand, local entrepreneurs are more reluctant to initiating a business with crediting sources, due to more reasons such as high bureaucracy among financial institutions, interest rate, document package and/or amount of pledge requested. Or banks are more reluctant to financing a business that could generate significant financial risks for them. But entrepreneurs are opened to this type of funding when the business is developing and extending, steps when usually a business needs significant funds.

Most family businesses in Republic of Moldova as in many countries in Eastern Europe and Russia [4] are at their first management generation (93.2\% of participants) with slight passing to the second one. Only $0.5 \%$ or 5 family businesses participating in the study mentioned that they are managed by the third generation. In line with the surveys conducted by PwC [5], EY și KPMG and other research institutions in this field, in most developed countries a significant share is covered by family businesses at the 2-3 generations [6], [7] followed by those managing businesses in the third and later generations [8]. Regarding the structure of family members involved in the business there is a diversification based on the I and II grades kin, which means that there is a willingness to concentrate the capital in the circle of closest family members in order to reduce related entrepreneurial risks (see Figure 2).

Figure 2. Who exactly of the family is involved in your business?

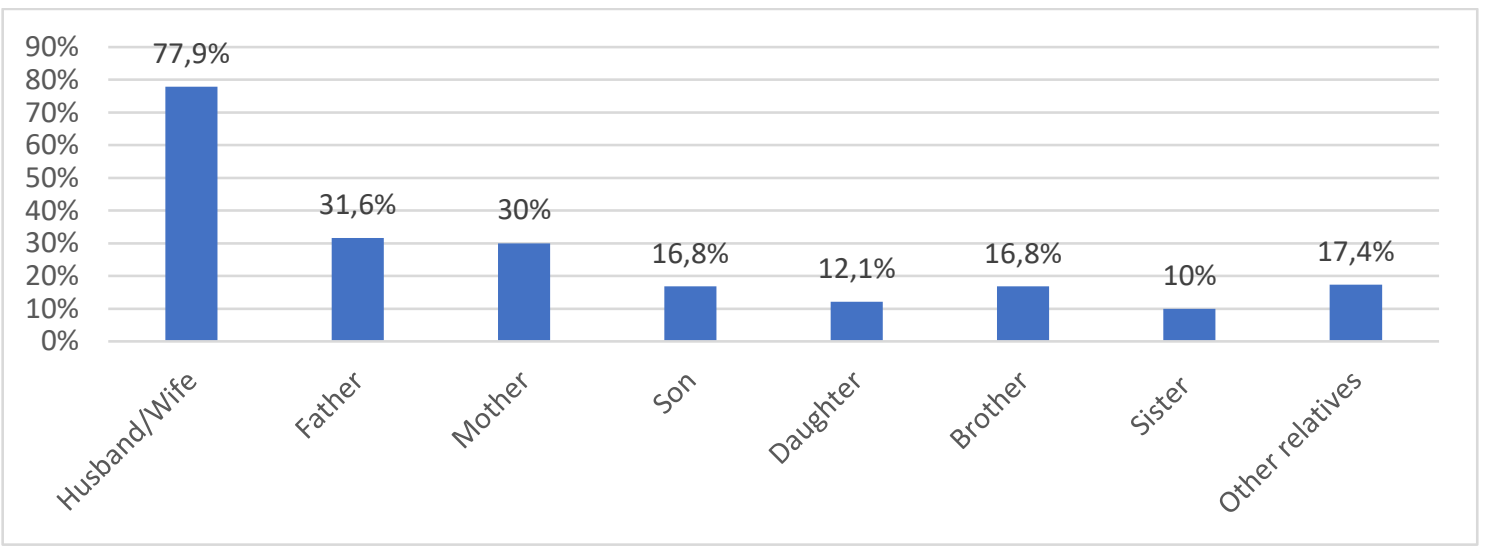

Thus, the greatest share of FB, namely about 78\%, is launched together with the spouse, other $30 \%$ represent FB with mother and father, and third ranks FB with children and brothers/sisters. A significant percentage of respondents mentioned the involvement of other categories of relatives in the family business (see Figure 3).

Figure 3. What position do family members hold in the company

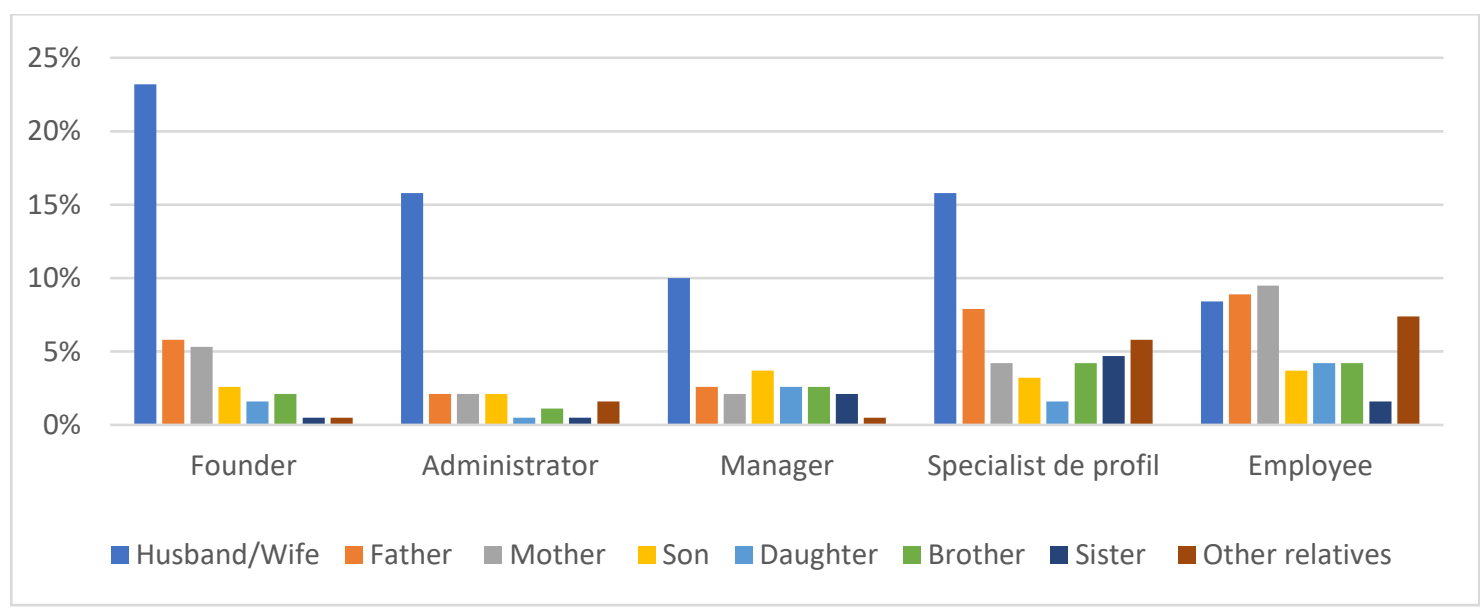


The trend of power focus is also kept as regards the distribution of positions in a FB. Therefore, most key positions such as founder and administrator are held by the husband/wife in about $23 \%$ and, respectively, $16 \%$, then and by other family members. Instead the specialist positions are held by different categories of family members, which in our opinion is a long-term strategy with great benefits for business's sustainability. This distribution contributes to create efficient teams and, at the same time, to facilitate the transfer of know-how and to keep the FB secret and innovation. At the same time, referring to the business management and development strategy, this allows controlling all processes and keeping a high quality for long periods - which is one of the peculiarities and strong points of a family business. Not less important is the fact that other relatives are hired as employees in different subdivisions, which shows that this type of business does not focus only on financial benefits, but it is also socially responsible.

The number of family members involved in a business varies between 1 and 7 persons, the highest share of FB consisting of 2 members in about 35\% of respondents (figure appropriate to the average share of employees in a microenterprise in EU members states and RM [9]), followed by 3 members $27.4 \%$ and 4 members $-19.5 \%$. This is not much different from the situation known in the developed countries, as the number of family members is often limited and the eagerness of some family members to work together is not enhanced, especially among the young generation. But as regards Republic of Moldova, where in average a family is made up of 4-6 members, this situation is rather good, showing that more than $50 \%$ of family members are involved.

At the same time, the next diagram shows that most members of a family involved in the entrepreneurial activity are employed on a contract basis, except for the seasonal activities when other categories of relatives are involved. This shows the level of maturity of the FB management and a higher level of responsibility towards the company's employees, regardless of the status and degree of relationship.

As regards the share of employment of family members in the business's activities, we found out that only about $46 \%$ of respondents mentioned a full (100\%) involvement. In rest, one could observe small shares of entrepreneurs who mentioned a level of employment of family members of $90 \%$ and less. We consider that this distribution of share of employment of family members is directly connected to such criteria as: the number of family members involved in business, the family members' status, the founder's management style, the business's stage of development etc. Certainly it is important for the founder to involve as many family members as possible in the business's activities if a common vision regarding the development strategy exists, the same values and principles of activity are shared.

According to statistical data, the trends of SME's development over the past years show a rather stable situation [10]. As most of FB in RM and in other countries are part of this sector, we wanted to analyze how they developed in 2017 compared to 2016.

To carry out this analysis we have identified some relevant indicators. The basic trend shaped showed that to all indicators proposed over 50\% of entrepreneurs mentioned an increase in 2017 against 2016, and a greater share being covered by the mild increase. Most businessmen mentioned the indicator of increase of investments in the business development $-74.2 \%$, followed by sales profits $-73.7 \%$ and number of customers $-72.6 \%$. On one hand these indicators refer to the long-term development perspectives, which characterize and distinguish the family businesses from the non-family ones pursuant to lots of researches [11], [12], and on the other hand those show a certain level of performance. At the same time, entrepreneurs highlighted no change in the number of employees, about $42 \%$ of respondents, no change in the sales market - $29 \%$ and no change in the variety of services $26 \%$, which shows the level of stability of businesses, but which considering the increase of incomes from sales and in number of clients, in our opinion, represents a qualitative performance. Considering that about $64 \%$ of entrepreneurs participating in this study manage their business for a rather short period 7-8 years, we may conclude that the situation mentioned by them, based on the indicators analyzed, could be described/considered as good, both due to how businesses are managed and the variety of instruments to support SME's that were and are offered by the business support organizations, public authorities, business associations etc. [13]. 
The analysis of opinions of FB entrepreneurs allowed us concluding that:

- FB is a segment relevant for this type of entrepreneurial activity considering that most of FB are part of the SME sector, which presently represent about $98 \%$ of the total of enterprises at country level;

- The activity experience of FB is little, as most FB are at their first management generation;

- To initiate a family business, firstly the entrepreneurs were motivated by the opportunity to secure the financial stability to their family and by the willingness to work together with their family members;

- Most often the core family members are involved in the FB activity, namely: husband/wife, mother, father, sister/brother.

- Most key positions such as of founder or administrator are held by the husband/wife and those of specialists in different subdivisions are held by other relatives or persons do not intimate to a family;

- Similar to situation in other countries the number of family members involved in FB vary from 1 to 7 persons, and the most common FB are those made up of 2 members that confirms the hypothesis that FB in RM are mainly from the SME sector;

- As to attracting family members in a FB, their level of involvement is rather high in most FB, showing that there is a strong and inherent motivation to achieve the goals set;

- Regarding the dynamic of economic development, most entrepreneurs underlined the positive trend in growth to more indicators, thus confirming that FB is a sustainable model of entrepreneurial activity.

\section{Family business perceptions as model of entrepreneurial activity}

Considering that the FB sector in Republic of Moldova has not been almost researched, we thought necessary to analyze the main visions and opinions of entrepreneurs regarding this model of entrepreneurial activity popular all over the world.

At the same time, we were set to identify the FB managerial features in order to have a clearer vision about the type of management that provides for the business's sustainability.

To question Which in your opinion are the advantages of a family business, entrepreneurs mentioned more advantages provided in Figure 6 below.

As you could notice the first ranks the advantage related to the level of dedication/degree of involvement of family members, being mentioned by about $54 \%$ of entrepreneurs. This shows a high risk read by the entrepreneurs as to situation when non-family employees have a distant attitude towards the company and dedicate themselves to work strictly to within the limits of their duties, this being sometimes difficult or expensive to motivate them to get more involved.

The second position is shared between the following advantages: Family members are ready to use even the last pecuniary means for the sake of business and the concentration of capital within the family - $45 \%$ of respondents.

One can observe that both refer to the financial component, a very important element for all businesses not only for the family business, and this, on one hand, gives them the opportunity to use accessible and almost no-cost possibilities for long periods, and on the other hand this contributes to reduce risks related to the illegal taking over, expropriation usual to non-family businesses (see Figure 4). 
Figure 4. Which in your opinion are the advantages of the family business?

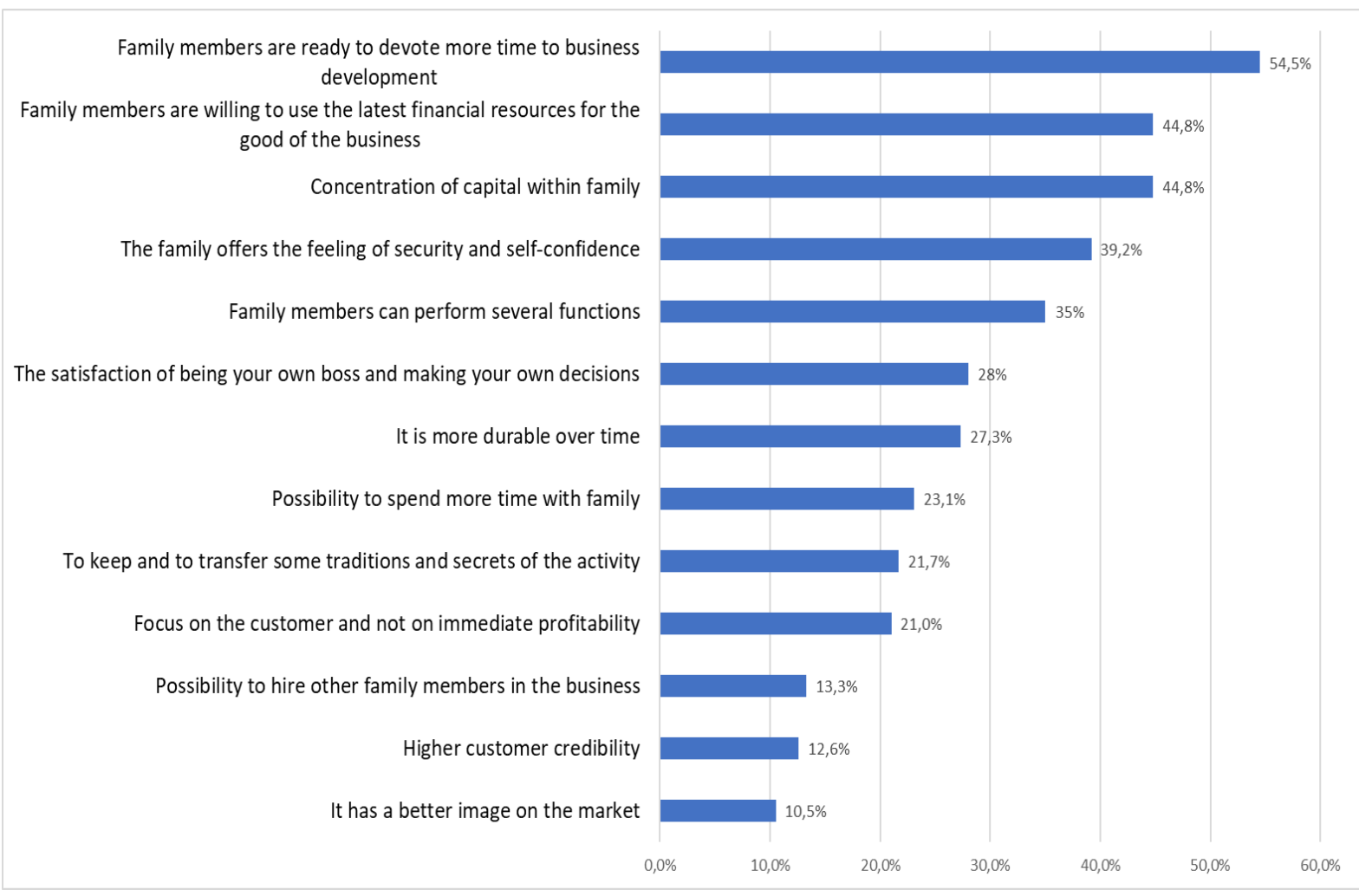

Another advantage important for FB that relates more to the psycho-social and cultural aspect is Selfconfidence and safety, placed on the third place by entrepreneurs. We consider that this advantage has a higher influence on the family business compared to the advantages ranking first and second positions, as it has at the basis a certain organizational culture fed up by certain values and principles educated in the family, developed and transferred through generations [14]. This is a situation typical to FB in other countries too, where social aspects prevail over the material and pecuniary ones [15] by providing a planning and decision-making framework and a foundation for building a competitive advantage for the family business.

In the context of human resources crisis, especially in the rural area, it is relevant and important the advantage, underscored by about $35 \%$ of entrepreneurs, regarding the involvement of family members in more activities, thus holding more positions by plurality of offices. On one hand, savings to the salary fund are made, a family member has a diversified work and less organizational tasks set. But on the other hand, the burden of responsibilities increases, the shortness of time appears, which at their turn lead to the increase of stress situations, to mistakes in work and finally to losses that could be avoided. Respectively, the highest risk relates to finding a balance that would provide for the good operation of business without generating negative effects for employees, either family members or new members.

Another advantage mentioned by $1 / 3$ of entrepreneurs is that a FB is sustainable in time compared to non-family businesses [16], thus securing both to family members and partners a higher level of confidence in cooperation and conditions for long-term investments. At the same time, over $20 \%$ of respondents also mentioned other FB advantages, such as: the Satisfaction with being your own boss and taking decisions on your own; the Possibility to spend more time with the family; To keep and to transfer some business traditions and secrets; To focus on customer and not on the immediate profitability. 
It was interesting to analyze these advantages as from the viewpoint of gender, namely, to see what is important for women and men when launching a family business.

Table 1. Top of FB advantages per gender (first 5 positions)

\begin{tabular}{|l|l|l|}
\hline \multirow{2}{*}{ Advantage } & \multicolumn{2}{|c|}{ position } \\
\cline { 2 - 3 } & Women & Men \\
\hline Concentration of capital within the family & 2 & 5 \\
\hline Family members may hold more positions & 5 & 3 \\
\hline Family members are ready to devote more time to the business & 1 & 1 \\
\hline Family members are ready to use the last money for the sake of business & 3 & 2 \\
\hline Family provides for safety and self-confidence & 4 & 4 \\
\hline
\end{tabular}

Based on the answers provided, we found that the same advantages are priority for both sexes, but the degree of importance is partly different, that could serve as reasons for which the family businesses taking part in the study have been set up.

We consider that cumulatively all advantages mentioned by most entrepreneurs participating in the study set up the specific FB profile and represent a reliable model of entrepreneurial activity, position confirmed by the scientists in the field and more studies conducted [17]. As presently there is no unanimous accepted definition for family business or each country prefers to have its own interpretation for this type of entrepreneurial activity, we considered important to analyze the opinion of local businessmen - managers of family businesses. So, they were proposed to analyze more definitions for family business in order to set the main criteria for identifying this type of business. Based on the opinions shared, we are set to give our own definition of family business, characterizing its specific in Moldova.

Table 2. Which of the following definitions for FB do you agree with?

\begin{tabular}{|l|l|c|}
\hline 1 & $\begin{array}{l}\text { Proposed definitions } \\
\text { The ownership and management of the organization are concentrated in the } \\
\text { hands of a family }\end{array}$ & $\begin{array}{c}\text { \% of } \\
\text { according }\end{array}$ \\
\hline 2 & $\begin{array}{l}\text { The family members hold a share of at least 50\% of the company's equity; } \\
\text { At least 2 family members participate in strategic decision making; } \\
\text { At least one family member holds a management position in the established } \\
\text { family business }\end{array}$ & $16.8 \%$ \\
\hline 3 & $\begin{array}{l}\text { Most decision-making rights are in the possession of the natural person who } \\
\text { created the business or who is in the possession of the spouses, parents, direct } \\
\text { heirs of the child or children; } \\
\text { At least one representative of the family or relatives is formally involved in } \\
\text { governing the organization; } \\
\text { If the person who founded or acquired the company or family holds at least } \\
\text { 25\% of the decision rights to which it is proved by holding the capital. }\end{array}$ & $11.1 \%$ \\
\hline 4 & $\begin{array}{l}\text { The majority of votes are held by the person who set up or acquired the } \\
\text { company (Or by the spouses, parents, children or direct heirs of the child) and } \\
\text { (2) at least one of the family representatives is involved in the management } \\
\text { or administration of the family business }\end{array}$ & $8.4 \%$ \\
\hline
\end{tabular}


The finding made is that for most respondents, about $64 \%$, the business family means the concentration of ownership and management within the family, opinion shared in the definition provided by the scientists such as [Barnes and Hershon,1989], [Litz, 1995], [Donckels and Fröhlich ,1991)], [Ward and Dolan, 1998] [18]. This definition shows the high level of concentration and control of power and management of a company. As regards the structure of respondents per age regarding the above definition, it was found that most entrepreneurs out of $64 \%$ are young generation entrepreneurs and only $11 \%$ were aged 50-65, who are on the eve to transfer their businesses to the next generation. As to the organizational and legal type of company, about $40 \%$ are LLC, $15 \%$ - farms and $9 \%$ - Private Companies. This might be influenced by more factors, such as: the unstable situation in the country, mistrust in other persons/partners, different visions regarding the business development/future, no willingness to share profits etc.

Second position was occupied by the definition proposed by the author and shared by about $17 \%$ of interviewed entrepreneurs, mainly by young businessmen, namely: Family members hold at least $50 \%$ of the company's capital; At least 2 family members take part in strategic decision-making; At least a family member holds a management position in the family company created.

Thus, one could conclude that the Moldovan entrepreneurs managing a family business have different opinions regarding the family business basics and how it could be defined, thing that gives room to scientists to carry out deeper researches about this type of entrepreneurship.

To develop and to implement certain common policies to support family business, in 2009, EU member states agreed on a general definition based on some specific criteria, as provided below [19]:

1) The majority of decision-making rights is in the possession of the natural person(s) who established the firm, or in the possession of the natural person(s) who has/have acquired the share capital of the firm, or in the possession of their spouses, parents, child or children's direct heirs.

2) The majority of decision-making rights are indirect or direct.

3) At least one representative of the family or kin is formally involved in the governance of the firm.

4) Listed companies meet the definition of family enterprise if the person who established or acquired the firm or their families or descendants possess 25 per cent of the decision-making rights mandated by their share capital.

\section{Family business management}

Considering that FB is a model of entrepreneurial activity, we decided to analyze how the management process takes place and if there are any features specific only to this type of business.

The first positive finding set by us is that about $2 / 3$ of respondents mainly from the field of agriculture, processing industry and services mentioned that they have developed a business plan which is one of the main instruments for managing a business. Considering that a significant percentage of participants in the study have been beneficiaries of support programs provided by the state and implemented by ODIMM (PARE 1+1 Program, residents of business incubators, Women in Business Program), allowed us to conclude that drafting this managerial document was rather a need imposed by the requirements to take part in those programs that an initiative by those businesses both from the viewpoint of structure and of time, but it also had beneficial effects on the development of skills in the entrepreneurial field, such as: studying, training, development, putting into practice. As regards the period for which the business plan has been developed for, one could observe that short-term business plans (that often are mandatory requirements for different SME support projects) prevailed, followed by the medium-term and long-term ones. This is a typical situation for most SMEs and not only in Moldova, as they mainly depend on the changes in the environment, they carry out their activities.

Another important aspect of a business management process is that of participation/involvement of members/employees in decision-making. Respectively, we intended to see to what extent non-family employees take part in working out and making strategic decisions in a family business. Based on the answers provided by entrepreneurs we found out that mostly only family members and the founder of 
the family business are involved in elaborating and taking strategic decisions. This means that a high level of power concentration within the family persists in this process too, which additionally confirms the replies given referring to business family definition (see Figure 5).

Figure 5. Who does participate in the strategic decision-making of the company?

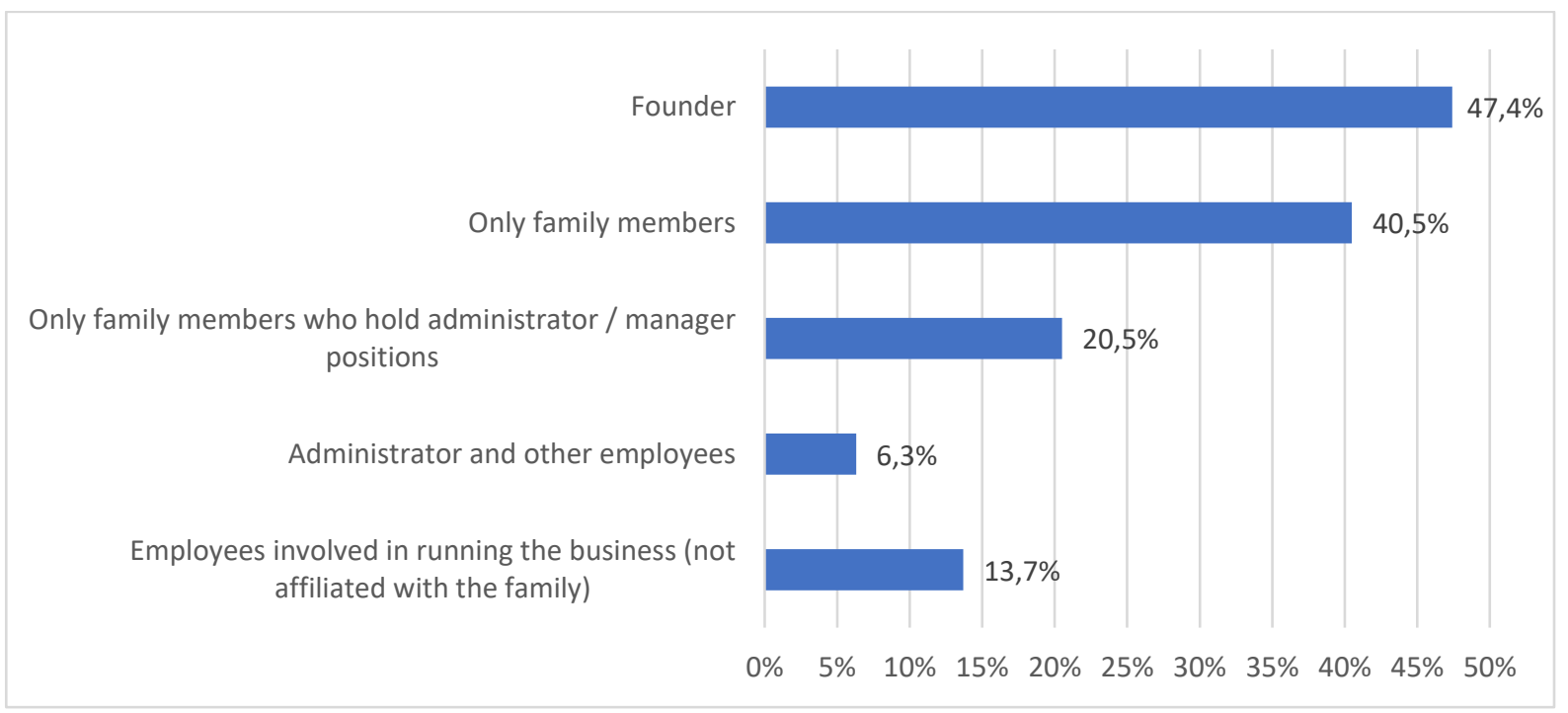

At the same time, some entrepreneurs mentioned that not only family members are involved in this process, but also non-family related employees, especially those holding managerial offices or key specialists, take part too. Many studies on family business underscored an acute problem dealt by FB namely that of succession and specialization of children in the field of family business (often children when taking over the business management do not have or do not want to acquire the know-how specific to that field, as they have other passions or predilections) [20], [21]. Therefore, rather often appears the need to employ in the business specialists qualified in the field that the family has no skills and, respectively, the level of involvement of those specialists in the company decision-making increases.

The $21^{\text {st }}$ century's greatest challenge is related to the lack/insufficiency of qualified staff, especially of technical and vocational specialists, and very specific and narrowly specialized areas professionals. So we were also set to find out how family business deals with this provocation, namely what are the criteria it uses to hire family members and non-family members or possibly this situation is not appropriate to it.

Referring to the requirements of employment of family members, over $60 \%$ of interviewed entrepreneurs mentioned - the willingness of that family member to actively involved in the family business. This is an important factor that is less taught at school, but it is cultivated through examples, behavior, early involvement of children and kin, traditions and business culture. For about $30 \%$ of entrepreneurs there is no difference when hiring relatives or non-family related persons and, respectively, it is important the level of education acquired and the work experience gained in the field (inclusively in other companies), showing a high level of maturity of family business in RM that focuses on the added value that an employee could bring to the business and not only on the fact of holding formally a position.

The trend for the agricultural sector is to acquire education specific for the field by the members successors of the business, which both is an instrument to diminish risks of the crisis of specialists mainly in the rural area and a strategy to keep and transfer the secrets/innovations of the family business.

The financial resources shortage was mentioned amongst the main challenges by more analyses carried out by local and foreign scientists and as well during roundtables, workshops with local businessmen. In the context of expanding the possibilities to attract financial resources and expertise to 
manage a business provided by the national legislation through new financing instruments, such as: venture capital funds, business angels, crowdfunding, mezzanine financing etc. [22], and support programs by the development partners [23], we were set to analyze how open entrepreneurs managing family businesses to develop those opportunities are.

A key positive conclusion we have made based on the entrepreneurs' answers was that in general family business owners in Moldova are open towards attracting financial resources and management expertise necessary to develop a business by using tools available and legally regulated. At the same time, as regards the acceptance of different categories of sponsors as co-founders, opinions were different (see Figure 6).

Figure 6. To what extent will you accept as co-founder other entities/persons to develop the business?

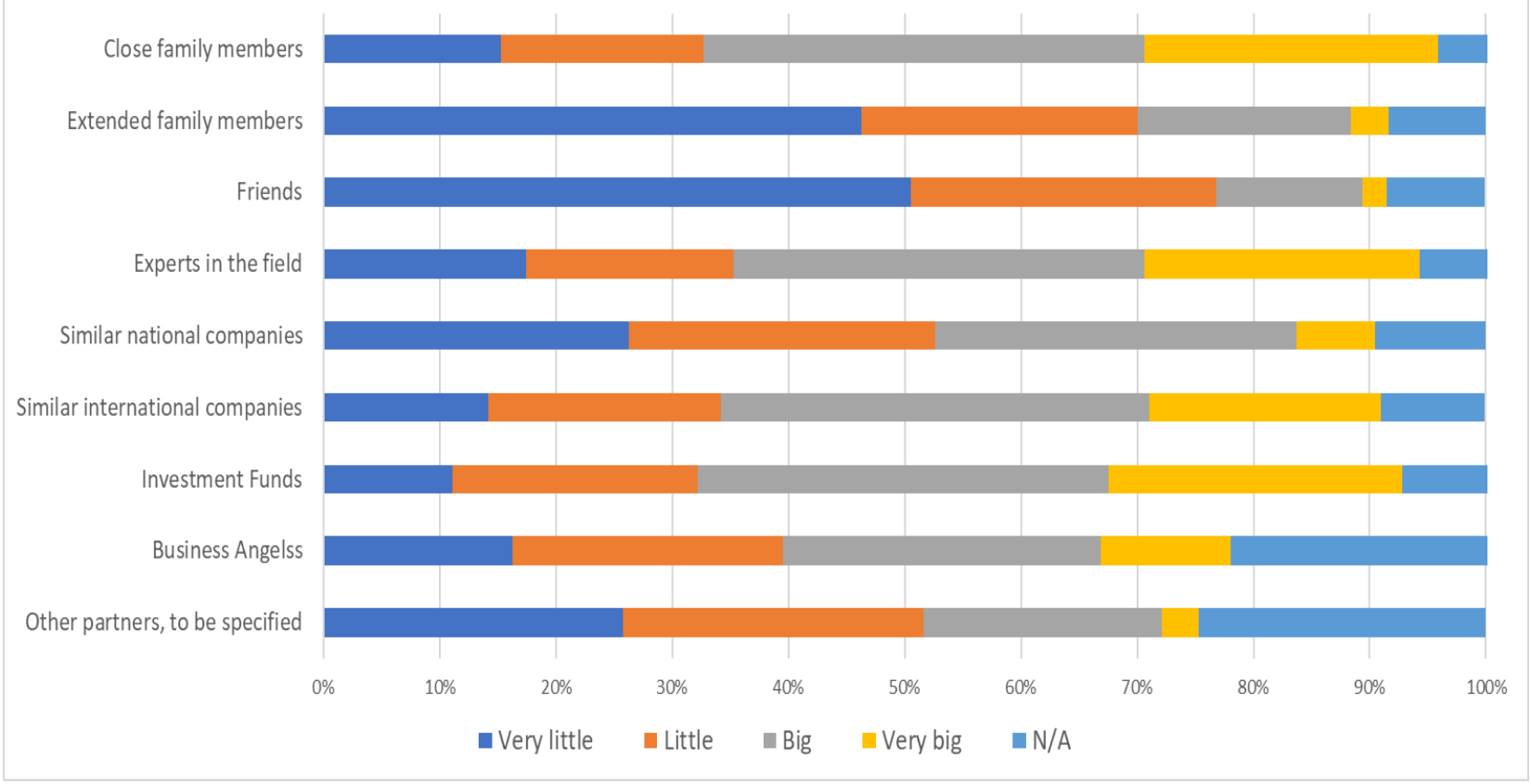

According to the above figure, a high level of openness as co-founders is shown towards the core family members (this answer also shows the above-mentioned peculiarity of capital and power concentration within the family), investment funds, experts in the field, similar international companies, business angels.

At the same time, a low level of openness as co-founder is shown towards friends, extended family members and similar national companies. This could be explained by more objective and subjective reasons.

An objective explanation certainly would be the higher level of trust in the core family members and in international institutions/organizations. At the same, a subjective explanation would refer to the low level of culture of business, especially with the non-family related partners (friends, extended family members) for whom this business is rather a source of income, inclusively on short term, than a sustainable model of entrepreneurial activity.

As regards similar national companies this would mean a closer cooperation, but examples in this context are less successful, showing a higher reluctance by the local entrepreneurs towards cooperation with partners within the country.

Regarding the granting of sustainability to family business based on the management principles, we found out that the majority of respondents mentioned that these principles are the key elements in developing their businesses, but they are not all the time implemented appropriately and, respectively, do not generate the expected results (see Figure 7). 
Figure 7. Do you agree with the statements below?

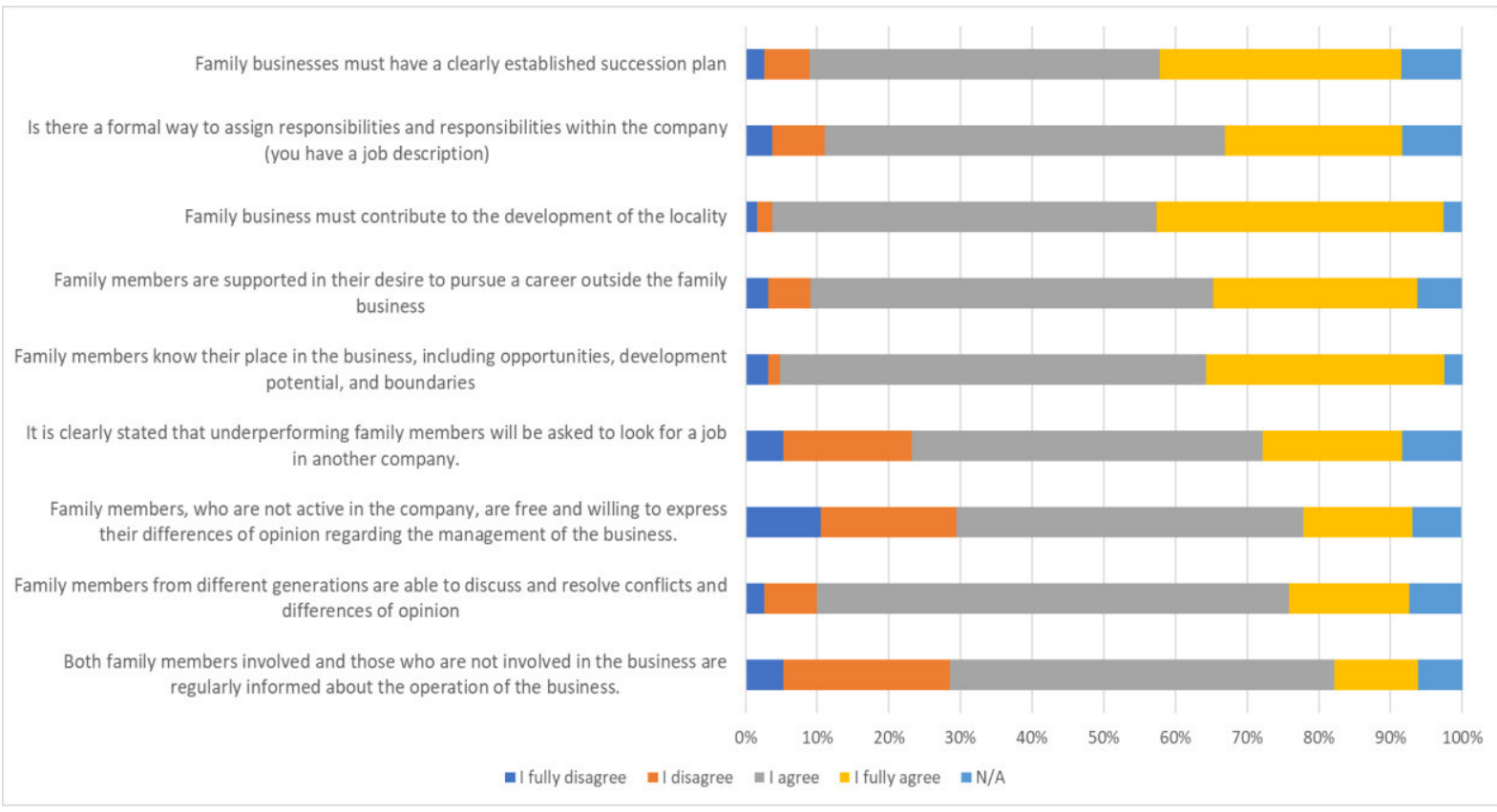

Some elements are entirely accepted by the family business entrepreneurs, namely: the need for a succession plan, the important role of society in this type of business, a clear separation of tasks and duties, conflict solving and sharing opinions. As to other elements of the management process, among which: working out of job descriptions for all family members involved in the business, free voicing of opinions different from the manager's ones, regular informing about the business evolutions, were accepted less. This appreciation shows that the managers of family business need to develop their managerial skills either in formal studies or some continuing development programs.

\section{Family business conflict management}

This section focuses on the analysis of how conflict situations in a family business are treated and settled, considering the specifics of this activity.

As to the frequency of conflicts arising and persons involved in a conflict, we found out the following (Figure 9): conflicts arise rather rare between family members hired in the business, between the founders and other employees not related to the business; but conflicts arise oftener between different generations and between family members and non-family related employees. (see Figure 8). These conflict situations often arise due to differentiated treatment, unfair remuneration, unjustified promotions of family members hired against non-family employees.

Figure 8. How often conflicts arise between the following persons hired in your company?

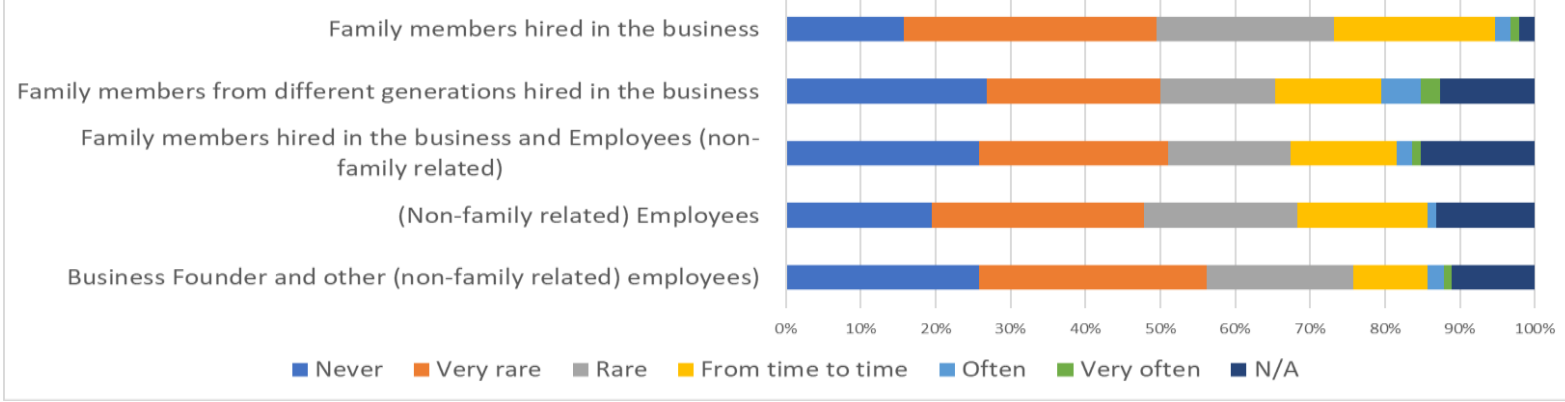


Another reason would be the weak communication between the family members hired and the nonrelated employees, the first group considering unimportant this communication. Unfortunately this situation is proper not only to family business, but also to other types of businesses, within which the management staff does not consider important to inform employees about situations and evolutions within the business, fact that leads to different interpretations, rumors, dissatisfaction and inappropriate reactions.

Therefore, the top of consultations where a problem arises is provided in Figure 9. The majority of entrepreneurs mentioned that when a problem arises, they firstly consult the family members hired in the business, who in their opinion know better the situation and could provide efficient and actual solutions. They also prefer to consult the company's specialists, who are not family-related members, but are well acquainted with this field/activity carried out, which is a positive aspect, allowing them to identify result-oriented solutions. At the same time, we noticed that over $70 \%$ of respondents prefer to solve issues arisen on their own, due to the fact that they do have nobody to consult (are very small) or do not want to be consulted (do not tackle the issues arisen).

Figure 9. Who do you consult when a problem arises within the company?

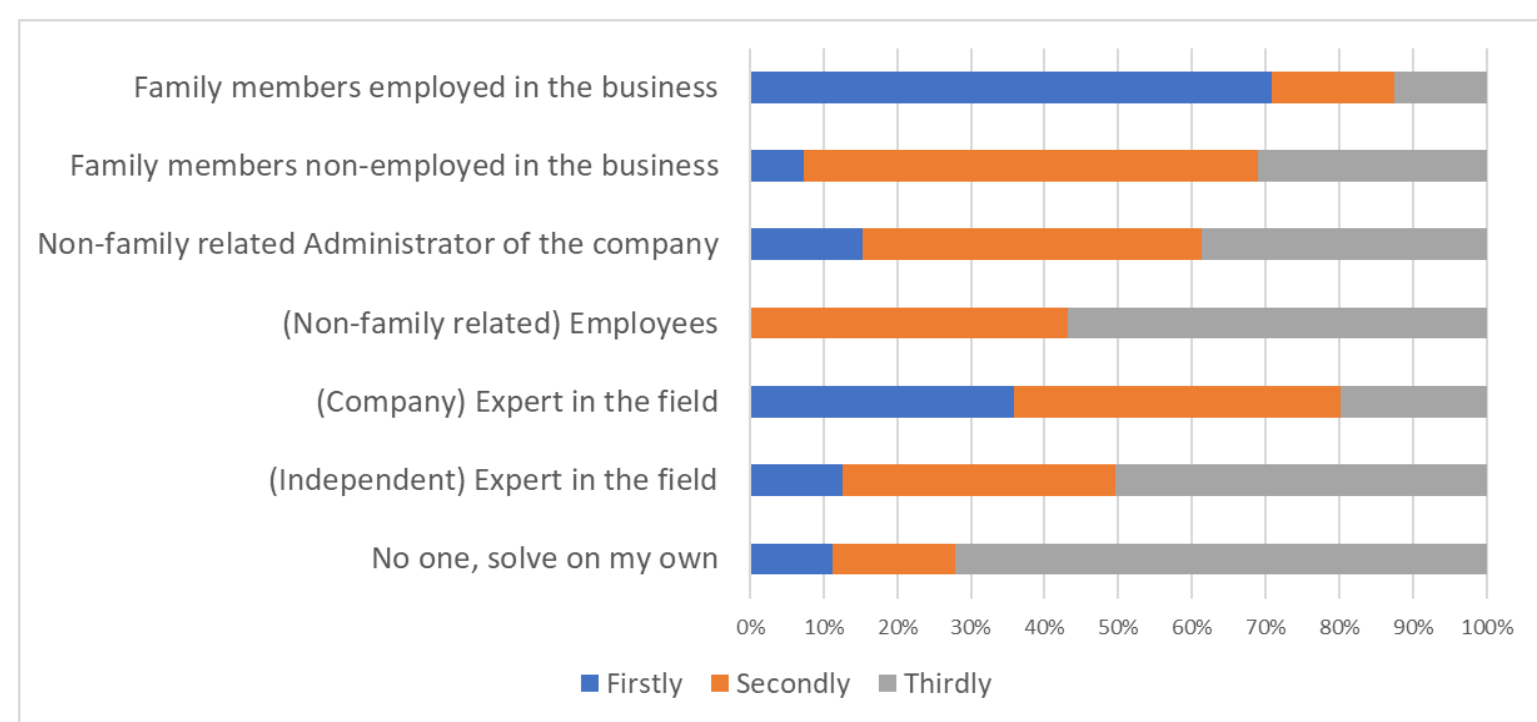

But once a conflict arisen, they should be solved. Thus, we could note that there is a variety of solutions for entrepreneurs to choose from, but these are influenced by more factors namely: the structure of the family committee, the period of activity of the company, the age of the business founder, the management style etc. Despite this, the majority of respondents $-72 \%$ choose to discuss that issue with the parties involved and, at the same time, all together look for a solution, showing that the entrepreneurs managing a family business got to a certain level of maturity. Other businessmen, about $35 \%$ mentioned that they choose to discuss separately with the parties involved in a conflict and, respectively, solutions are also taken separately, meaning that the final decision is up to the business owner. We consider that the role of the Family Committee in solving conflict situations is a positive factor that was pointed out by about $33 \%$ of respondents, which shows that there is a formalized structure for the management of a family business.

It is also important the fact that some family businesses implement existing/worked out regulations and rules, which in our opinion represents a good indicator for the implementing of scientific approach in the process of management of a business. About $18 \%$ of respondents underlined that a conflict situation is unacceptable and, respectively, they try to settle it as soon as possible, without involving other persons, which on one hand would be a positive aspect, but on the other hand does not provide for 
a long-term solution to that issue that could lead to its repeated burst out but in a more difficult way and with more painful effects for the business and its team members.

Another important aspect to determine the profile of a family business in Republic of Moldova referred to identifying the main problems it faces. According to many researches in the field [24], [25] the most important to be mentioned are: ensuring succession, the balance between the business and the family, business sustainability, competitiveness etc.

The top 3 difficulties highlighted by the local entrepreneurs' lists

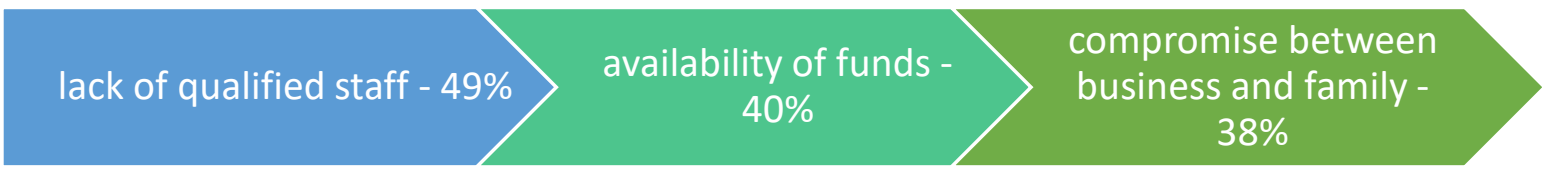

These problems are almost similar to those faced by the non-family business, but to solve them you need to make great financial and non-financial efforts.

Other problems mentioned by the entrepreneurs refer to weak financial resources necessary to develop/maintain the business, tax policy implemented, unfair conditions created for the business (facilities for foreign-owned companies compared to the national ones). Cumulatively these difficulties do not facilitate the development of businesses in general and especially of family ones. What distinguishes the variety of problems for family business in Moldova and that in the developed countries is the subject of succession and reorganization, which represent the bottom of the top of problems underlined by the local entrepreneurs, who are still at a young age and for whom the stage of transfer/succession is to last for a few years.

As regards the business management process, one could notice that the range of problems mentioned by respondents is rather diversified, which confirms the lack of knowledge and competences in this field by the family business owners that could be developed through some educational programs, namely the license degree and master's degree in business and business management, including via some continuing education programs.

\section{Development perspectives}

Any business, regardless of the model implemented, is willing to have a long and sustainable lifetime. In this context, we were eager to find out what the perspectives of interviewed family businesses are and how that future is planned. Over $67 \%$ of respondents intend and plan to keep this business under the management of family members. This is a good intent, but difficult to achieve as it was proven based on the examples of family businesses in other countries. A more realistic option mentioned by $27 \%$ of respondents was that to continue the family business through a joint management by the family members and non-family persons, which is a trend specific to more states where the family business has a significant share in the economic development.

You could notice that a small share of $1.6 \%$ sees the business future to be handled by other persons, to be managed by other persons who have nothing to do with the family who founded and developed it.

This is a way that could contribute to maintain this area of work, the type of products/services, but launched under other model of business possibly more efficient compared to that implemented by the founding family.

The perspective to close the business was underlined only by $2.1 \%$ of respondents, which makes us more optimistic about that regardless of the management model, the business family founders focus mainly on the development, expanding and diversification as provided in the figure below.

Further intentions are very ambitious, especially in the context of opportunities provided to local entrepreneurs once the Association Agreement signed in 2014 (see Figure 10). 
Figure 10. Which are you further intentions as to develop the company?

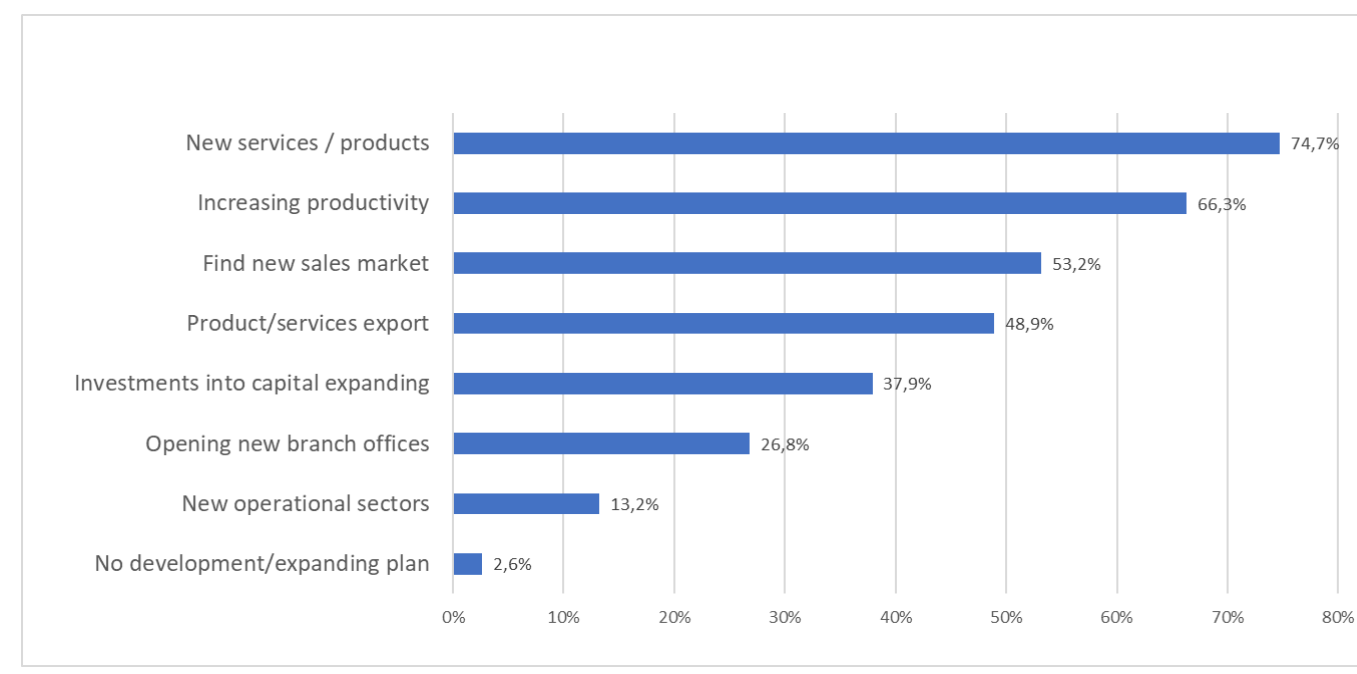

Most entrepreneurs, about $75 \%$ intend to develop new products and services that will provide them with opportunities to enter new markets. This is a very good scope, but it needs significant efforts to develop, to test, to implement and to trade such new products and services. In our opinion this path is a risky and expensive one for family business in Republic of Moldova, inclusively due to weak cooperation between the research-development institutions and the business environment. The strategy to increase productivity is more realistic for the majority of local family businesses, which can be implemented both by creating consortiums and through technological development. Not less important it is the entrepreneurs' vision regarding the entry on new markets, including via exports, which presently is supported actively by different support policies and tools. It is also welcomed the entrepreneurs' vision related to business expanding by opening new branch offices, which was mentioned by about $27 \%$ of respondents.

What are the main challenges / problems that may arise in the next 5 years for your business? Most respondents mentioned 3 main problems specific for emerging countries:

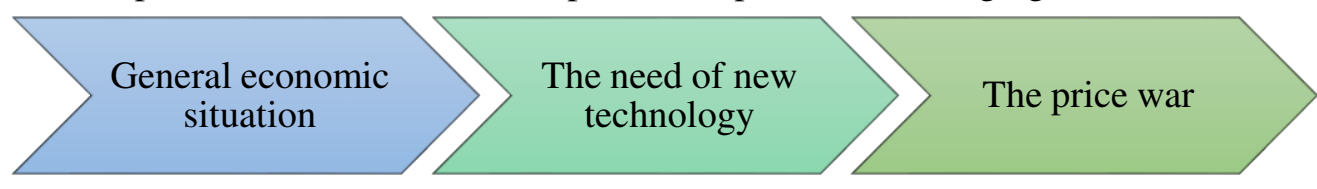

Also, for our FB entrepreneurs are important to find solutions for following challenges: needs on innovation, needs to professionalize the business, retention on key employees, costs control.

These challenges are common to all types of business, which require entrepreneurial efforts of knowledge, financial but also implications from the authorities who can provide various tools to support the development of this business model.

\section{Conclusions}

By this survey, we aimed to make a first input to the research of family businesses in the Republic of Moldova in order to identify the peculiarities of this business model.

The analysis allowed us to identify some common peculiarities of the interviewed family businesses in Moldova and from other countries (based on the multiple analysed studies), including: it is a relatively new, but already widespread, model of entrepreneurial activity, at its first generation of management moving towards the second generation (specific to emerging and developing countries); most of them represent the SME sector; family business activities involve most frequently the members of the nuclear family; business management is mostly done intuitively, without resorting to scientific managerial approaches and methods (especially in micro and small family businesses); only the members of the 
nuclear family are involved in the decision-making process; succession in family business is a challenge the founders are still struggling with; family members are primarily employed based on qualification criteria (especially in very specific, technological fields); Family Council plays a significant role in the process of settling conflict situations; the range of difficulties is mostly the same, with the following being mentioned: finding a compromise between business and family, insufficient financial resources to develop/keep the business, tax regime, lack of qualified staff, ensuring the succession and competitiveness.

At the same time, the survey allowed us to identify some specific features of family businesses in Moldova, namely: the financial motivation for starting up a family business is dominant; launching a business mainly with own resources or resources from relatives versus financial instruments available on the market (credits, investment funds etc); in defining a family business we can notice a trend toward the concentration of property and management in the hands of one family, an opinion that corresponds to the definitions given by scholars Barnes and Hershon (1989), Litz (1995), Donckels and Fröhlich (1991), Ward and Dolan (1998); failure to develop long-term strategies and visions (a ground of justification would be the great uncertainty of the environment in which they operate); family members are primarily employed on the basis of the family member's willingness to be actively involved in the business activity; openness for the nuclear family members, investment funds, experts in the field, similar international companies to become cofounders, and lesser openness for the friends, members of the extended family and similar domestic companies; as for the existing issues, family businesses in Moldova are, however, less focussed on those related to succession (the reason being the development stage that does not imply business transfer to successors yet); family business development strategies are focused on the development of new services and products, which is a longer and fairly expensive way; high risk level (due to the uncertain operating environment); entrepreneurial training programmes do not include any modules dedicated to this form of entrepreneurship and do not provide any continuous training programmes in this field.

Entrepreneurs running a family business have different views on its essence and management, giving space for researchers to further analyse this form of entrepreneurship. We believe that the conducted research can be further developed on different dimensions, providing us a clearer and much more specific picture of family businesses. For the relevant institutions (ministries, implementing units, chamber of commerce and industry, SME support organization, investment agency, LPAs) these researches will serve as a sound information basis inspiring national support policies and instruments (as many developed countries have) for this relevant subsector of entrepreneurial activity.

\section{Acronyms and abbreviations}

FB - Family Business

RM - Republic of Moldova

ODIMM - Organization for Small and Medium Enterprises Sector Development

SME - Small and Medium-sized Enterprises

PwC - Price waterhouse Coopers

EY - Ernst \& Young

KPMG - Global Client Program Financial Services

LLC - Limited Liability Company

$\mathrm{PE}$ - Private Enterprise

\section{References}

[1] The Facts of Family Business. http://www.forbes.com/sites/aileron/2013/07/31/the-facts-of-familybusiness/ Jul 31, (2013).

[2] PwC Family Business Survey (2012/2013) Principalele rezultate pentru România. Afacerea de familie Un model sustenabil pentru secolul 21. https://www.wall-street.ro/files/164545500.pdf 
[3] Law on small and medium-sized enterprises no. 179 din 21.07.2016. Moldovan Official Journal no.306-313/651 of 16.09 .2016

[4] $\mathrm{PwC}$. Частный и семейный бизнес в России: вызовы и факторы роста сегодня и завтра Обзор результатов исследования в России, $(2014-2015)$ www.pwc.ru/fbs2014

[5] Overview of Family Business Relevant Issues. Austrian Institute for SME Research. Vienna 2008

[6] PwC. Global Family Business Survey (2016/2017) Principalele rezultate pentru România. Afacerile de familie din România Strategia antreprenorială și planificarea succesiunii. www.pwc.ro/pcs

[7] EY. In harmony: family business cohesion and profitability, Initial findings from the global survey of the world's largest family businesses. (2017). https:/coles.kennesaw.edu/familybusiness/docs/eyfamily-business-cohesion-profitability.pdf

[8] G. Gordon. Strategic Thinking in Family, 14th December (2009), DTI Small Business Survey, (2006)

[9] Retrospectiva Întreprinderilor Mici și Mijlocii din Republica Moldova. Chisinau 2017. https://www.odimm.md/ro/e-biblioteca/publicatii/publicatii-utile/item/retrospectiva-imm-2

[10] Activitatea întreprinderilor mici şi mijlocii în Republica Moldova în anul 2017. Chisinau http://statistica.gov.md/newsview.php?l=ro\&idc=168\&id=6061

[11] M. Barrett, K. Moores. New theoretical perspectives on family business entrepreneurial behavior. University of Wollongong Research Online. 2012. http://ro.uow.edu.au/commpapers/2540

[12] EY. Staying power: how do family businesses create lasting success? Global survey of the world's largest family businesses. 2014.

[13] Activitatea întreprinderilor mici şi mijlocii în Republica Moldova în anul 2017. Chisinau. http://statistica.gov.md/newsview.php?1=ro\&idc=168\&id=6061

[14] Family Business Challenges. Maintaining Family Values. Institute of Family Business with UCG. 2014

[15] EY. Staying power: how do family businesses create lasting success. Global survey of the world's largest family businesses. 2014

[16] I. Mandl. Overview of Family Business Relevant Issues - Final Report. 2008. KMU FORSCHUNG AUSTRIA Austrian Institute for SME Research.

[17] PwC Global Family Business Survey 2016/2017 Principalele rezultate pentru România. Afacerile de familie din România Strategia antreprenorială și planificarea succesiunii;

[18] M. Azucena Vicente Molina, Lanette Rutterford. Towards a theory of the family firm: approach to an operational definition and a framework for family business research, http://elib.bsu.by/bitstream/123456789/51683/1/475-490.pdf

[19] Review of the important issues of family business: research, institutions, and studies," November 2009 Summary of the report of the expert Group of the European Commission on family Business. European Family Businesses GEEF

[20] Barometrul afacerilor de familie din România. Studiu EY România, ediția 2017. https://www.impacthub.ro/wp-content/uploads/2019/01/EY_Barometrul-startup-urilor-din-Romania-2017.pdf

[21] Global Family Business Survey 2018 - China report. PWC. https://www.pwccn.com/en/entrepreneurial-and-private-business/2018-family-business-survey.pdf

[22] Lege cu privire la întreprinderile mici şi mijlocii. nr. 179 din 21.07.2016. Monitorul Oficial nr.306-313/651 din 16.09.2016

[23] Proiecte și a fonduri disponibile pentru lansarea și dezvoltarea afacerilor în RM.https://finantare.gov.md/

[24] PwC. Afacerile de familie din România Strategia antreprenorială și planificarea succesiunii. Global Family Business Survey 2016/2017.https://www.pwc.ro/en/publications/fbs/afacerilede-familie-din-romania-editia-2017.pdf

[25] EY Romania. Barometrul afacerilor de familie din Romania, 2017. https://www.slideshare.net/MihaelaEMatei/ey-romania-barometrul-afacerilor-de-familie-din-romania-2017 


\title{
Pharmacology of active principles of vegetable origin included in tinctures
}

\author{
Valentin Nănescu ${ }^{1}$, Daniela Cîrţînă ${ }^{1}$ \\ 1“Constantin Brâncusi” University of Targu-Jiu, Faculty of Medical and Behavioral Sciences, \\ No. 4, Tineretului St., Tg-Jiu, Romania \\ E-mail: danielacirtina@gmail.com
}

\begin{abstract}
This paper highlights the importance of using tinctures and this is only due to a quick and easy assimilation in the body and the pharmacology of the active principles found in plants that are responsible for the action or actions that the tincture will have. The preparation of tinctures is also an essential step, because it is important to be able to benefit to the maximum from these active principles and one month or one year after the preparation of the tincture.
\end{abstract}

Keywords: active principles, tincture, action, effects

\section{Introduction}

Pharmacology is the science that deals with the study of drugs in relation to living organisms and systems, and phytotherapy refers to a therapy that is performed with the help of the cell plant that biosynthesizes the active substances. The notion of phytotherapy started from medicinal teas and extended to everything that means pharmaceutical or medicinal product in the formula of which will enter as such the medicinal plant along with pure active and extractive substances that are obtained from the plant kingdom. There is also a mixed pharmaceutical product in which formula will be found, along with some active substances from plants, and compounds of semisynthesis and synthesis. Medicinal plants in the form of infusions, teas, syrups, decoctions, tablets, ointments, creams, capsules, tinctures are used for therapeutic purposes. Tinctures are phytotherapeutic forms for internal use, they being hydroalcoholic extractive solutions, are those pharmaceutical forms in which the plants will be percolated or macerated in a mixture made from a higher concentration of alcohol and a lower of water. Both percolation and maceration are two methods of cold extraction of active ingredients.

One of the processes that lead to the production of tinctures is represented by maceration which is the process by which therapeutic substances are extracted from chopped plants, it is also a process that can be easily done at home. It can last for 8 or 10 days, with a food alcohol concentration of $45^{\circ} \mathrm{C}$, $60^{\circ} \mathrm{C}$ and $70^{\circ} \mathrm{C}$. The three essential elements of the maceration process are the alcohol concentration, the amount of plant to be extracted and the extraction time. For a good extraction, the preparation must be shaken at least three times a day and stored in tightly closed bottles. Another method is that of percolation, which can be multiple or simple, representing, moreover, a faster method of making tinctures. It is made with the help of the percolator (Fig. 1) which is the extraction device and have the form of a conical trunk cylinder with tap, being made of stainless material, enameled iron or glass, who allows the circulation of alcohol from top to bottom, obtaining in this way drop by drop. A final process for making tinctures would be vibroextraction or turboextraction, which is the fastest process for making tinctures, being performed using special equipment on an industrial scale. 


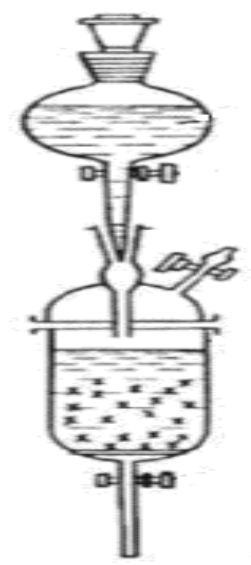

Figure 1 Percolator

The advantages of tinctures are represented by their long shelf life, their simple administration in the form of drops, the fact that their recommendation is aimed at anyone, especially people with hypertension or edema and who are not allowed to consumes a lot of liquids and the fact that the extraction will be complete due to the hydro-alcoholic environment, which only helps the plant product to act completely gently, but also with force, an antagonism found only in natural products. Another great advantage of tinctures, compared to a dragee that can only contain an active ingredient of a certain plant substance, is the effect it has that cannot be compared.

Tinctures contain the active principles of a plant, extracting from the plant principles that are soluble in water and alcohol, and in order to get the most out of these active principles of the plant, it must be harvested at a certain time, the tinctures are obtained from mature plants. The active principles or active substances are those responsible for the therapeutic effect, they are defined as chemically pure medicinal substances that have a pharmacodynamic effect and can be classified according to their physicochemical properties, chemical structures and biological effects (Table 1) [3].

Although a tincture can be obtained at home in a very easy way, it cannot be compared with a tincture obtained in a specialized laboratory because it must be considered what part of the plant must be used, at what temperature the extraction will be performed in order to obtain the maximum of the active principles in the plant, which is the concentration of alcohol used to obtain a maximum effect and how this will be concentrate or dilute in order to maintain the same effectiveness in a few months or years.

Sea buckthorn tincture contains active substances such as essential oils, vitamin B1, B2, B3, B12 and $\mathrm{C}$, thus having antianemic, stomachic, general tonic, antirheumatic, antiseptic properties in the urinary tract, vitaminizing being used in avitaminosis, asthenia, dermal infections, gastrointestinal infections, urticaria, allergic conditions, neuroendocrine diseases, circulatory diseases, liver diseases and in the treatment of weight problems, anorexia, viral hepatitis, growth disorders and diseases of the spinal cord thus helping to restore the body after disease, increase general resistance, strengthening the immune system, vitaminizing the body, protecting cells, protecting tissues and liver cells against oxidative stress. Sea buckthorn tincture is contraindicated in pregnancy and lactation, in children under 12 years, in people allergic to sea buckthorn and people who have been banned from alcohol. It will be administered internally on an empty stomach, 3 or 4 times a day, by diluting a quantity of $5 \mathrm{ml}$ of tincture in $50 \mathrm{ml}$ of tea or water.

Thyme tincture contains as active ingredients tannins, volatile oil, rosemary acid, caffeic acid, bitter substances it is a good antiseptic, antifungal, antitussive, digestive, choleretic, respiratory stimulant, dewormer and nerve tonic, it manages to maintain health, lar of the bronchi and trachea, to 
reduce the risk of bacterial contamination of the digestive and respiratory tract, to reduce the condition of bloating, to increase appetite, to intervene strongly on the kidneys and intestines, helping their functioning in normal parameters.

Table 1. Classification of active principles

\begin{tabular}{|c|c|c|}
\hline Active principles & Characteristics & Examples \\
\hline Alkaloids & $\begin{array}{l}\text { - Nitrogen-containing organic } \\
\text { compounds; } \\
\text { - It has a strong } \\
\text { pharmacodynamic effect; } \\
\text { - It has water-soluble salts; } \\
\text { - Has alkaline reactions. }\end{array}$ & $\begin{array}{l}\text { - Atropine found in Atropa Belladonna, } \\
\text { Datura stramonium; } \\
\text { - Codeine, morphine, papaverine present } \\
\text { in poppy seeds; } \\
\text { - Capsaicin present in the hot artery; } \\
\text { - Colchicine found in toad root; } \\
\text { - Ergotamine, ergotoxin, ergometrine from } \\
\text { rye horn; } \\
\text { - Pilocarpine which is extracted from the } \\
\text { leaves of Pilocarpus microphylus and } \\
\text { jaborandi; } \\
\text { - Ephedrine from Ephedra. }\end{array}$ \\
\hline $\begin{array}{l}\text { Essential oils } \\
\text { (Volatile) }\end{array}$ & $\begin{array}{l}\text { - Volatile, fat-soluble } \\
\text { compounds; } \\
\text { - It has an aromatic smell; } \\
\text { - It has spasmolytic and } \\
\text { antiseptic action. }\end{array}$ & $\begin{array}{l}\text { - Thyme oil; } \\
\text { - Peppermint oil; } \\
\text { - Eucalyptus oil; }\end{array}$ \\
\hline Saponins & $\begin{array}{l}\text { - It has a glycosidic structure; } \\
\text { - It has properties: } \\
\text { - Emulsifiers; } \\
\text { - Surfactants; } \\
\text { - They have an irritating } \\
\text { effect at the local level; } \\
\text {-I produce hemolysis by } \\
\text { intravascular injection. }\end{array}$ & $\begin{array}{l}\text { - Infusion with Primula root that has an } \\
\text { expectorant effect; } \\
\text { - They are also found in Hederae leaves; } \\
\text { Calendulae flowers, in the bark of the } \\
\text { Mimosa tenuiflora tree having a healing } \\
\text { and cyclotrophic effect, due to the } \\
\text { increase of collagen synthesis; } \\
\text { - In licorice root with antiulcer action; } \\
\text {-In chestnut seeds, having vasoprotective } \\
\text { action. }\end{array}$ \\
\hline Glycosides & $\begin{array}{l}\text { It has two components: } \\
-\quad \text { the carbohydrate part } \\
\text { containing several oases; } \\
\text { - the non-carbohydrate part } \\
\text { which is responsible for the } \\
\text { pharmacodynamic effect. }\end{array}$ & $\begin{array}{l}\text { - Cardiotonic glycosides found mainly in } \\
\text { the leaves of some plants that are part of } \\
\text { the Scrophulariaceae family and the } \\
\text { Apocynaceae family; } \\
\text { - Anthracenosides found in the roots, bark } \\
\text { and leaves of Rhamnus frangula. }\end{array}$ \\
\hline $\begin{array}{l}\text { Substances } \\
\text { mucilaginous }\end{array}$ & $\begin{array}{l}\text { - Compounds having a } \\
\text { polysaccharide structure; } \\
\text { - Forms viscous colloidal } \\
\text { solutions together with water; } \\
\text { - Make a protective film on } \\
\text { the surface of the mucosa. }\end{array}$ & - Mallow infusion \\
\hline Tanning substances & $\begin{array}{l}\text { - It has a chemical structure } \\
\text { of condensed polyphenolic } \\
\text { derivatives; } \\
\text { - It has an astringent action. }\end{array}$ & -They are found in blueberry fruits. \\
\hline
\end{tabular}


Artichoke tincture, made from artichoke leaves, is a preparation recommended in angina pectoris, liver failure, cirrhosis, chronic hepatitis, chronic nephritis, atherosclerosis, obesity, enteritis, biliary dyskinesia, hemorrhoids, overwork, intoxication, rheumatism, asthenia acts as a diuretic, choleretic, hepatic antitoxic, antipyretic, hypocholesterolemic, antirheumatic, tonic-bitter, it manages to contribute very well to everything that means an increase in intestinal transit, a maintenance of blood fats and cholesterol in normal concentrations and maintaining the health of the liver by protecting liver cells, stimulating the production and elimination of bile and detoxifying the liver [4]. All these uses are due to the complex therapeutic action that is imprinted by the phytocomplex by the presence of chlorogenic acid, cynarin, cinnaropricrine, cinnaroside, flavones and polyphenolic derivatives.

Echinacea tincture contains cinnarine, chicory acid, pollen derivatives, polyholosides, pyrrolizidine alkaloids, volatile oil with a significant amount of esters, alkamines. It has antibacterial and antiviral effects due to caffeic acid esters, anti-inflammatory due to polyholosides and alkanolamines, healing, immunostimulatory due to alkamines, polyholosides and caffeic acid esters that will stimulate the activity of cells that provide non-specific protection of the body the penetration into the body of pathogens inhibiting hyaluronidase, being recommended in urinary tract infections and in chronic and acute infections of bacterial or viral origin of the respiratory tract. It is administered on an empty stomach, 3 or 4 times a day, $5 \mathrm{ml}$ of tincture which is diluted in $50 \mathrm{ml}$ of tea or water $[5,6]$. It also has some contraindications for patients who have undergone organ transplantation, autoimmune diseases, tuberculosis, multiple sclerosis, collagenosis, leukosis, diabetes, AIDS, in individuals with allergies to echinacea, pregnancy and lactation, children under 12 years, individuals who were not banned from drinking alcohol.

Angelica tincture is indicated in skin diseases such as psoriasis, acne, dermatoses of unknown etiologies, scleroderma, in frequent indigestion, digestive atony, dyspepsia, bulimia, appetite disorders, anorexia, seborrheic skin problems to help it maintaining skin tone and youth, in convalescence, nervous and physical exhaustion, excessive sensitivity to climatic factors, mental confusion, psychosis, neurosis, depression, hysteria administered 3-4 times a day, on an empty stomach, $5 \mathrm{ml}$ of tincture diluted in $50 \mathrm{ml}$ of water $[7,8]$. All these actions and effects are due to the chemical composition containing simple coumarins and furanocoumarins, volatile oil rich in monoterpenic hydrocarbons, flavonic derivatives, sterols, oases, caffeic acid and chlorogenic acid and resins.

Chestnut tincture contains as active ingredients coumarin derivatives, tannins, triterpene saponins and purines with astringent, antiedematous, venotonic, capillary-protective and anti-inflammatory action, leading to its use in chronic venous insufficiency, post-traumatic edema, edema of the lower limbs, thrombophilia, varicose veins, hemorrhoids, muscle pain and cramps, rheumatic joint pain and inflammation by its internal administration in the form of drops, 15 drops diluted in $50 \mathrm{ml}$ of water, 3 times a day or externally diluting $5 \mathrm{ml}$ of tincture in $50 \mathrm{ml}$ of boiled water and then cooled and applied to the affected area in the form of compresses [9].

\section{Conclusions}

To maintain the health of the body, tinctures can be a real godsend, because depending on the plant from which the extraction will be performed, the tinctures can have a wide range of recommendations. They can be easily prepared, can be prepared at home and can be used to treat pain, stress, colds, coughs, to cure skin conditions, contusions, wounds. They can be extremely useful due to the rapid action they have, they are quickly and easily assimilated by the body, the tincture is actually the sap of the plant. It can be a cure for both the psyche and the body, but it can also be used as a preventive measure, managing to block the onset of disease through its prophylactic action. Calming, digestive tinctures or tinctures can be used to eliminate stress, maintain immunity or increase it, depending on the predisposition to a particular disease of each individual. 


\section{References}

[1] Cristea A.N., General pharmacology, Editura Medicala, Bucuresti, 2006.

[2] Duță V., Treatment of diseases through diet, Editura Libris, București, 2006.

[3] Foret R., The alchemy of nature, Editura Paralela 45, București, 2019.

[4] Natea C. N., Nutrition and dietetics, Editura Universității "Lucian Blaga", Sibiu, 2008.

[5] Nica-Badea D., Control of active ingredients in exciting foods, Editura Academica Brâncuși, 2011.

[6] Popescu O., Bojor O. Traditional and modern phytotherapy, Ed. a II-a, Editura Fiat Lux, București, 2001

[7] Vasey C., Translation Alexandra Născuțiu- Detoxification Guide - Simple methods to eliminate toxins from the body, Editura Niculescu, București, 2008

[8] https://www.ncbi.nlm.nih.gov/pmc/articles/PMC3634921/

[9] https://www.who.int/traditional-complementary-integrative-medicine 


\title{
Minority groups in Romania during the communist regime
}

\author{
Andrei Ghimisi ${ }^{1}$ \\ ${ }^{1}$ National University of Political Studies and Public Administration \\ E-mail: ghimisi4567@gmail.com
}

\begin{abstract}
The paper "Minority groups in Romania during the communist regime" aims to tackle the difficulties that the presented groups faced during the communist regime. The challenges that the respective groups faced were different in nature from economic to social inclusion and education. In this paper, relevant and defining methods are presented in order to understand the full length of the problems of the biggest (in number) minority groups and what they had to face in the communist regime
\end{abstract}

Keywords: minorities, public policies, communist regime

\section{Introduction}

Romania, as any other country in the world, faces challenges regarding the integration of minorities inside its society. Nowadays, more and more tools have been created in order to facilitate the integration of minorities from different areas of the world and also to create a proper environment for both the minorities, and the native people of the country to coexist and prosper. Such tools were very poor developed, or even didn't exist during the communist period in Romania.

After World War I, Romania and its population doubled, amounting around 18 million. An interesting aspect is that only two thirds of its people were Romanian of origin, one third being Hungarian, Jewish, German, Bulgarian, South Slavic, Ukrainian and, maybe the most important ethnic group, Roma people. Going for the French model, Romania created a highly centralized state organization, centralized around Bucharest. The challenge of governing a economically and culturally heterogeneous fragmented country was now in the hands of the Romanian elite.

After the Treaty of Trianon peace agreement, around 200.000 Hungarians emigrated back to Hungary. Despite this factor, the majority of inhabitants and elite in major Transylvanian cities were still of German, Jewish and Hungarian origin. The government of Romania began a forced assimilation process, but only until the communist came to power that this "forced assimilation" truly had meaning.

The Second World War was a crucial point for Romania and its development. In the beginning, Bucharest was an ally of Germany until 1944. During this time, the state lost Northern Transylvanian as it was given back to Hungary along with one million Romanian residents. In 1941, Romania regained Bessarabia from its eastern neighbor, the Soviet Union, and managed to bring back the inhabitants, which were mostly Romanian. In 1944, Romania switched sides realizing the imminent defeat of Germany and joined the Allies. This came with both ups and downs, Romania regaining the whole of Transylvania, but losing Bessarabia to the Soviet rule in the process. During the war, the majority of Romanian Jews were killed and the remaining survivors emigrated back to Israel in the late forties.

The communist and their rule didn't put and end to discrimination against Romanian ethnic minorities and moreover for the Hungarians it became far worse. The Hungarian cultural, political and 
religious elites were meant to be intimidated by a number of show trials, but many of those who were persecuted behaved courageously and remained steadfast. The castles, manor houses and lands of the Transylvanian Hungarian aristocrats were confiscated and many more were also deported to labor camps in the Danube Delta.

Going even further, one of the most discriminated and persecuted group of minorities, the Roma people, will suffer many problems at the hands of the communist regime.

\section{Minority groups and their challenges in the first part of the communist regime in Romania (1948-1965).}

The challenges that minority groups faced during the communist regime are numerous and different in nature. The focus is set upon the two main periods of communist Romania: from 1948 to 1965 when Gheroghe Gheorghiu Dej was leader of the state and from 1965 to 1989 when Nicolae Ceausescu ruled over Romania.

In the beginning of the communist regime, Romania's national minorities at the outset of the communist rule were seemingly well served by the Leninist approach. The Constitution provided them equal rights in "all field of economic, political, juridical, social and cultural life" and specifically guaranteed the free use of their native language and the right to education at all levels in their mother tongue.

From the beginning of the communist regime, large numbers of ethnic Romanians joined the party, and their share of total membership rose steadily over the years increasing from 79 percent in 1955 to almost 90 percent in the early 1980s. Even though the regime claimed that minority membership and representation in the Grand National Assembly and in the people's, council were commensurate with their size, minorities were mostly excluded from policy-making bodies on both national and local levels. Even in areas where Hungarian people represented a sizable portion of the population such as Arad, Timis and Maramures, few were found in local PCR bureaus. Going to the national level, the most important and powerful positions in the critical defense, foreign affairs and interior ministries were reserved for ethnic Romanians and minorities were consigned to rubber-stamp institutions.

A special attention was received by the large Hungarian minority with the establishment of the Hungarian Autonomous Region in 1952. Like many other generous provisions regarding nationalities, this concession tuned out to be an empty gesture and masked the true nature of relations between the minorities and the state. The region was never called "home" to more than one quarter of Romania's Hungarian population and it had no more autonomy than other administrative provinces. Even more, after the Hungarian Revolution in 1956, even the autonomy was curtailed. Going further, in 1960 directives from Bucharest aimed to reorganize and rename the province so that its Hungarian nature was even further reduce. The reorganization of the territory, by adding purely Romanian inhabited areas and excluding Hungarian enclaves, managed to increase the Romanian element in the province from 20 to 35 percent and reduced he Hungarian from 77 to 62 percent. The regions were renamed to Mures Autonomous Hungarian Region and thereafter was most often referred to simply as the Mures Region.

It is arguable that the when it comes to education, language and cultural heritage, the communist regime in Romania affected mostly the Hungarians and to lesser extent the Germans. The changes that limited education in their native languages were seen even from the first decade of communist rule. Students could acquire an education in Hungarian-language schools from preschool to university and for the German-language schools, from preschool to high school. But even from the beginning in 1948, some policies were aimed to weaken national minority education. A "reeducation" of faculty in all educational institutions was formed. From that time forward, only teachers that were deemed politically reliable filled out the important teaching positions. At the same time, the nationalization of all private 
and ecclesiastical schools destroyed the traditionally important rule of the church in the German and Hungarian educational systems.

In some communities, schools were merged so that ethnic Romanians constituted the majority of the student body. The regime imposed the teaching of Romanian in all educational institutions in order to 'prevent national isolation'. From 1957, the amalgamation of minority and Romanian schools became the rule rather than the exception. The newly emerged schools were formed of mostly ethnic Romanian directors, whereas Hungarias or Germans filled vice-director or vice-principal positions.

A major blow that was dealt to the Hungarian language education network was the merger of the Romanian Babez University with the Hungarian Bolyai University in Cluj. Because of such a merger, a larger enrollment of ethnic Romanians and a reduced availability of Hungarian language instruction was created. The party dictated what courses would be thought in Hungarian and the more technical courses were taught in Romanian only. It became impossible to study any of the applied sciences in Hungarian, thus restricting career opportunities for the Hungarian minority. The result was a predictable drop in the number of Hungarian undergraduates, from 10.75 percent in 1957 of all undergraduates to only 5.7 percent in 1974.

\section{Minority groups and their challenges in the second part of the communist regime in Romania (1965-1989).}

The year 1965 came with a change in power in the communist regime in Romania. Nicolae Ceausescu is elected as the new leader. In the same year, the Romanian Workers Party presented a new Constitution which proclaimed Romania a socialist unitary state. Thereafter, the country and its multinational character was in most part ignored, and the problem of cohabiting nationalities was officially considered resolved. Three year later, in 1965 the communist regime eliminated the Autonomous Hungarian Region outright.

The regime wanted to maintain the appearance of minority representation at all levels of government, official statistics showing that the part of people from ethnic minority communities employed in government positions were little of number. The reality was even harsher for minorities which had little real power of influence. Speaking at the local level, minority representatives, who were in general Romanianized, were mistrusted by their constituents. Although these spokespersons were in routine hand picked by the PCR, their loyalty for the regime was often suspected. A more accurate reflection of minority representation and participation was the ethnic composition of the party itself.

As Ceausescu rule went further, he started a campaign for de-Sovietization and self-determination in strong connection with a increasing Romanian nationalism in the domestic policy field. Emphasis was especially put on Romanian history, language and culture in order to enhance Ceausescu's popularity among the Romanian majority. In 1976 the PCR presented a nationwide campaign dedicated to the glorification of the Romanian homeland called: 'Hymm to Romania'. In this campaign, all nationalities were expected to join the fete, which placed the German and Hungarian minorities of Transylvania in a grievous predicament. The campaign saw to remove all traces of Hungarian and German territorial identification. In cities that were already Romanianized, artefacts and monuments representing links to the Saxon or Hungarian past were all eliminated, bilingual inscriptions were removed and streets alongside some cities were renamed to emphasize Romanian roots. Thus Cluj, one of Transylvania's most important Hungarian city became Cluj-Napoca.

Other crucial changes that can be seen during Ceausescu's rule that affected the minority groups, in large the people of Hungarian origin, are directed at the education field. In 1973 education laws that were introduced continued the assimilation that had begun earlier with the amalgamation of minority and Romanian schools. The laws emphasized technical studies over humanities in order to keep in touch with the economic program of rapid industrialization. In 1974, only 1.4 percent of the instruction on technical schools was in Hungarian. Also, technical textbooks were rarely translated into minority languages. 
Romanian leaders at that time claimed that the amalgamation of Romanian and minority schools in strong connection with the 1973 educational reforms were necessary for economic and administrative efficiency and were not intended to ensure the assimilation of ethnic minorities. Even though that claimed seemed to be plausible, other actions that diminished the ability of minorities to maintain their ethnic identity were not so readily explained. Over the decades, the gap between the theory and practice in the treatment of minorities widened as the assimilation of national minorities into a "harmonious hole" continued. The state and its discriminatory policies steadily diminished political, linguistic, constitutional and educational rights.

Another interesting factor regarding the status of minority groups in Romania during Nicolae Ceausescu's regime was the fact that even though the goal of the leader was national homogenization and an ethical pure Romania, the regime opposed emigration of ethnic minorities. A campaign was started in the late 1970's that followed two basic tacks. Spokespersons for the ethnic minorities in the workers councils praised the regime and its treatment of minorities and declared their devotion to socialist Romania. In contrast, those who wished to emigrate were presented as weaklings with underdeveloped "patriotic and political consciousness", traitors abandoning their fatherland and the struggle to build socialism.

These attempts to discourage emigration were not entirely left to the media. The official policy of the party allowed emigration only on a individual basis, and only in specific cases such as family reunification. In the years later, the PCR suggested ironically that families could be reunited by immigration in Romania. Obtaining permission to leave the country was a expensive, exhausting and lengthy process. Prospective emigrants were likely to be demoted to positions of lower pay and prestige or be fired from their jobs. They were also publicly evicted from their homes. Other measures in order to discourage the minorities were the rejection of their children to enroll in schools and the denial of medical care and other social benefits.

\section{The Roma population and their challenges during the communist regime in Romania}

The history of the Roma population during the communist regime is even harder to reconstruct than for the years of the Second World War. There were no policies directed directly at the Roma population for a long time in Romania. Even more, at the end of the 1970's and the beginning of the 1980s the authorities did decide to find a solution to the social situation of the Roma and took action in this direction, to certain extent even though the policies were not made public.

After the Transnistrian episode, the Roma people who survived deportation returned to their villages, while other nomads settle on the edges of Bucharest. The General Union of Roma in Romania and its leader Gheorghe Niculescu resumed their activity, without producing any publication. The Union was the disbanded in 1949 by the Communist authorities together with all other organizations that did not fit in the totalitarian system. This comes in contrast with the 1946 electoral campaign, when the Bloc of Democratic Parties, the electoral alliance headed by the communist party, sent our special manifestations to the Roma, addressing them as 'Brothers and Sisters Roma!' [1], This was just an electoral move as for many years the authorities paid no attention to the fate of the Roma

The year 1948 is the moment when the communist regime established itself in Romania and with it the Roma population wiped out from any official documents of political nature. The Roma population were not represented as an ethnic group at the level of the state administration and Party. Also, there were no institutions that could promote their collective interests and to deal specifically with the problems of this minority, within the limits of the totalitarian Communist State. Even in the end of the 1960s when a new form of representations for minorities was introduced, there was no national council of workers of Roma nationality. For almost three decades, until the late 1970s, the communist regime did not pay any attention the fate of the Roma population, as there were no special policies dedicated directly for them. 
The social and the economic transformations that took place in Romania during the communist regime also affected the Roma. The process of industrialization and urbanization, the nationalization of the economy, the transformation of the village as a result of the collectivization of agriculture, the policy of social "'homogenization" the occupational changes that took place, all of these changes could not fail to affect the Roma people.

One transformation that affected alone this population was the sedentarization of the Roma people who still practiced nomadism in one form or another. In the 1960's, the nomadic Roma were settled by the authorities in fixed settlements [2]. The result was, however, not the one that was expected. Even if they were provided with houses, the Roma people continues to live in a tent pitched in the yard, with the house being used as a stable for horses. The number of nomadic and semi-nomadic Roma people was estimated by the authorities in 1977 to be around 65.000 .

In regards to the economic transformation that took place in the communist regime in Romania, it affected the Roma population to very big extent. This transformation resulted in the gradual disappearance of the specific occupations and traditional crafts of the Roma population. In the new social and economic context, Roma people who still practiced their old crafts were forced to take up modern occupations and professions. Different groups of gypsies tried to adapt to these demands in specific wats. For example, there was a new role for the old blacksmiths in construction and heavy industry. In towns, Roma people were able to find work in factories and also street-cleaning jobs became an area in which they held a virtual monopoly. In the last period of the communist regime, even the agricultural co-operatives summoned sometimes the Roma to work, even though they were not members of the respective co-operative.

To a certain extent, some of the traditional occupations of the Roma population nonetheless survived. In areas of the country, the brick that was required was supplied by the ones who were specialized in crafts. The price of the work would be bargained when they would install themselves along with their entire family on the boundary of the respective village. This was a seasonal occupation. They were also presented into rudari, which would manufacture wooden objects, or caldari, which would manufacture cooper goods for the distilling of brandy.

In 1977, an analysis of the situation of the Roma people was carried out by the Central Committee of the Romanian Communist party and it initiated a special program designed to integrate them into society. The program was never made public and researchers alongside historians do not even have access to the archives of the period. Until now, only the report that was compiled in 1983 by the Propaganda Section of the Central Committee of the Romanian Communist Party, in which an assessment of the result achieved until that point, has been published [3].

As a general characterization, the Roma population in Romania during the communist regime went under a significant occupational transformation. Most of them were forced to abandon their occupations that had been for a long time characteristic for them and to find their place in the communist- type economy.

\section{Conclusion}

In conclusion, the minority groups in Romania suffered many transformations during the communist regime in Romania. The German, Hungarian and Roma groups were the most affected by the rise to power of the communist. In regards to the German and Hungarian minorities inside the Transylvanian territory, the communist regime seeked to wipe out almost every existence of their stay in the respective territory.

Not only that, but more important by reshaping the educational field so as the Hungarian schools no longer exist and there would be only mixed schools in which the teaching, especially for the high technical courses, would be only in the Romanian language, the communist regime offered a clear view 
on how they see their heritage protected. Because of these forced measures and others such as the renaming of cities and the merger of universities, the Hungarian minorities were forced to either compel with the situation or leave.

The Roma people were also one of the most important ethnic groups that suffered during the communist regime. The social and economic context presented by the communist regime was, in large terms, hard to adapt by the Roma population.

\section{References}

[1] Merfea, M.,(1991), Tiganii-Integrarea socială a romilor, Ed. Brasa, Braşov

[2] Cherata, C.L.(1992), Istoria ţiganilor (Origine, specific, limbă) Editura Z, Bucuresti

[3] Cartner, H., (1991), Destroying Ethnic Identity, The persecution of Gypsies in Romania, Ed. Human Rights Watch 
